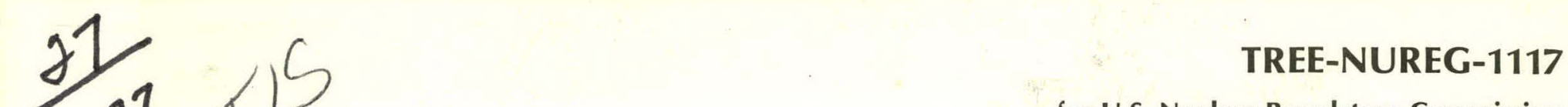

\title{
INVESTIGATION OF ALTERNATE ECC INJECTION CONCEPTS IN THE SEMISCALE MOD-1 SYSTEM
}

\author{
EDWIN A. HARVEGO \\ ANDREW C. PETERSON \\ GUY G. LOOMIS \\ O. MARK HANNER
}

September 1977

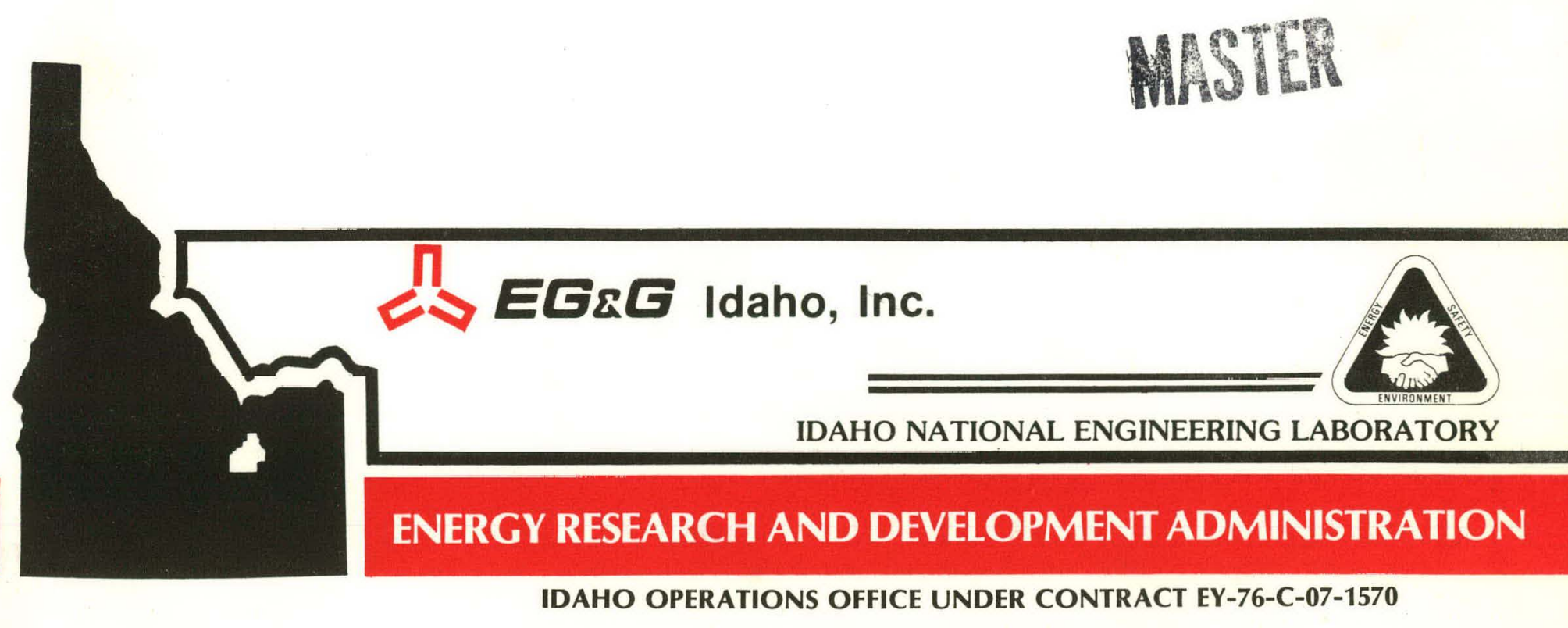




\section{DISCLAIMER}

This report was prepared as an account of work sponsored by an agency of the United States Government. Neither the United States Government nor any agency Thereof, nor any of their employees, makes any warranty, express or implied, or assumes any legal liability or responsibility for the accuracy, completeness, or usefulness of any information, apparatus, product, or process disclosed, or represents that its use would not infringe privately owned rights. Reference herein to any specific commercial product, process, or service by trade name, trademark, manufacturer, or otherwise does not necessarily constitute or imply its endorsement, recommendation, or favoring by the United States Government or any agency thereof. The views and opinions of authors expressed herein do not necessarily state or reflect those of the United States Government or any agency thereof. 


\section{DISCLAIMER}

Portions of this document may be illegible in electronic image products. Images are produced from the best available original document. 
Printed in the United States of America

Available from

National Technical Information Service

U.S. Department of Commerce

5285 Port Royal Road

Springfield, Virginia 22161

Price: Printed Copy $\$ 775$; Microfiche $\$ 3.00$

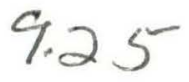

"The NRC will make available data tapes and operational computer codes on research programs dealing with postulated loss-of-coolant accidents in light water reactors. Persons requesting this information must reimburse the NRC contractors for their expenses in preparing copies of the data tapes and the operational computer codes. Requests should be submitted to the Research Applications Branch, Office of Nuclear Regulatory Research, Nuclear Regulatory Commission, Washington, D.C. 20555."

\section{NOTICE}

This report was prepared as an account of work sponsored by the United States Government. Neither the United States nor the Energy Research and Development Administration, nor the Nuclear Regulatory Commission, nor any of their employees, nor any of their contractors, subcontractors, or their employees, makes any warranty, express or implied, or assumes any legal liability or responsibility for the accuracy, completeness or usefulness of any information, apparatus, product or process disclosed, or represents that its use would not infringe privately owned rights. 
TREE-NUREG-1117

\section{INVESTIGATION OF ALTERNATE ECC INJECTION CONCEPTS}

IN THE SEMISCALE MOD-1 SYSTEM

Approved:
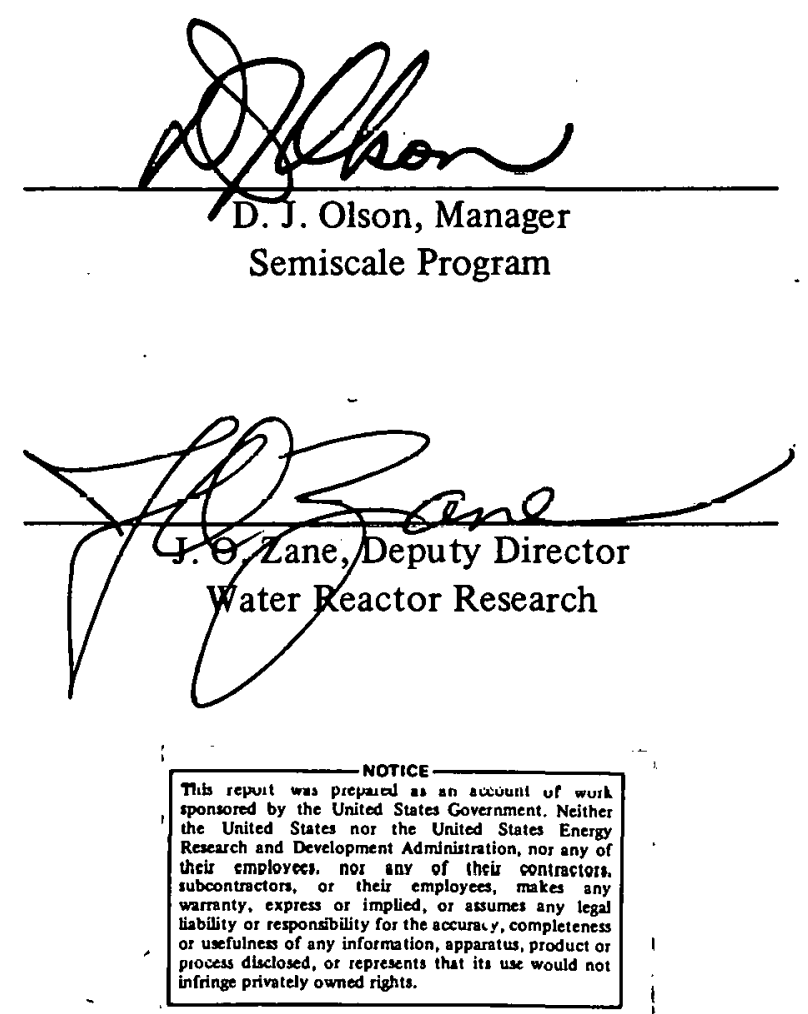


\title{
INVESTIGATION OF ALTERNATE ECC INJECTION CONCEPTS
}

IN THE SEMISCALE MOD-1 SYSTEM

\author{
by
}

Edwin A. Harvego

Andrew C. Peterson

Guy G. Loomis

O. Mark Hanner

EG\&G IDAHO, INC.

September 1977

PREPARED FUK IHE

U.S. NUCLEAR REGULATORY COMMISSION

AND

ENERGY RESEARCH AND DEVELOPMENT ADMINISTRATION

IDAHO OPERATIONS OFFICE

UNDER CONTRACT NO. EY-76-C-07-1570 


\section{ACKNOWLEDGMENTS}

The authors wish to express their thanks to the personnel of the Semiscale Facilities and Test Operation Branch for their efforts in conducting the tests and collecting, verifying, and documenting the data; to the personnel of the Semiscale Data Processing Section for providing data processing support; to P. North and D. J. Hanson for their technical advice and overall contributions to improve the quality of this document; to C. P. Fineman for supplying many of the RELAP4 calculations; to K. A. Dietz for her technical review and editing contributions; and to Elinor Witbeck and Evelyn L. Pierson for their typing and proofreading efforts. 


\begin{abstract}
The potential benefits and relative merits of four alternate emergency core coolant (ECC) injection concepts are investigated in the Semiscale Mod-1 system. The major controlling thermal-hydraulic phenomena associated with the effectiveness of each alternate ECC injection concept are also examined. The principal means used to evaluate the various concepts is a comparative analysis of experimental data for a given concept (from Test Series 5) with data from a baseline cold leg ECC injection test (Test S-04-6), run as part of a prior test series, and with data from other tests in the alternate ECC injection test series. As a result of this investigation conclusions pertaining to the effectiveness of the different concepts in the Semiscale Mod-1 system are reached, and the relative merits of the concepts are identified.
\end{abstract}




\section{SUMMARY}

The potential benefits and relative merits of four alternate emergency core coolant (ECC) injection concepts were investigated in the Semiscale Mod-1 system, in the context of a 200\% double-ended cold leg break, to determine if improvements in cooling effectiveness could be made relative to that provided by cold leg ECC injection. The major controlling thermal-hydraulic phenomena associated with the effectiveness of each of the alternate ECC injection concepts were also identified.

The experimental investigation was performed under the auspices of the Semiscale Mod-1 Program which is conducted by EG\&G Idaho, Inc. as part of the overall U.S. Nuclear Kegulatory Commission (INRC) and Energy Resedrclı and Develupnuent Adninisistration sponsored research and development program to investigate the behavior of the pressurized water reactor (PWR) system during a hypothesized loss-of-coolant accident (LOCA). The Semiscale Mod-1 tests are performed with a nonnuclear experimental system which simulates the principal physical features of a commercial nuclear plant but which is much smaller in volume. Nuclear heating is simulated in the tests by an electrically heated core contained in a pressure vessel. The pressure vessel also includes a downcomer, lower plenum, and upper plenum. The system piping is arranged in a 1-1/2 loop configuration with the intact loop containing an active steam generator and pump, and with the broken loop containing passive simulators for the steam generator and pump.

The first alternate ECC injection concept investigated was that of $\mathrm{ECC}$ injection in the vessel lower plenum. This concept proved to be the most effective injection scheme investigated in the Mod-1 system. Lower plenum injection eliminated the hot wall delay and the ECC bypass caused by countercurrent flow. The concept was effective primarily because it resulted in rapid lower plenum refill causing reflood to start while the system pressure was high (170 psig). The high pressure reflood resulted in effective core cooling accompanied by significant steam generation, which maintained the high system pressure. The conditions that produced effective core cooling were, therefore, self-sustaining and the entire core was quenched by $52 \mathrm{sec}$ after rupture. The concept as used in the Semiscale Mod-1 system had the disadvantage that rupture of the injection line represents a serious $L O C^{-1}$. However, careful design of the ECC piping could eliminate this problem.

The second concept investigated employed ECC accumulator injection into the upper plenum and accumulator and pumped ECC injection into the cold legs. With this concepl, good core cooling effectiveness resulted primarily from upper plenum ECC fluid being swept into the core by negative intact loop and core flows. The negative flows were strongly related to condensation in the downcomer inlet annulus due to the presence of subcooled ECC fluid injected in the cold leg. This cooling mechanism caused the core to quench predominantly from the top downward. The investigation of injection rate as an operating parameter in this concept led to the conclusion that core cooling effectiveness was not strongly related to upper plenum injection rate over the range tested. The absence of a strong relationship between upper plenum accumulator injection rate and core cooling 
effectiveness occurred because, for the vessel injection rates studied, penetration of the core by ECC injected into the upper plenum was largely controlled by the condensation process in the downcomer inlet annulus rather than by a supply mechanism in the upper plenum.

The third alternate ECC concept investigated used cold leg injection, but provided upper plenum venting through a bypass line which led from the broken loop hot side piping to the broken loop cold side piping just outside the vessel. This concept resulted in improved cooling during both the blowdown and reflood portions of the experiment. Good cooling during blowdown occurred because the vent line reduced the negative core flow allowing liquid to be retained in the lower plenum and subsequently delivered to the core. The good core cooling during reflood was due to the hot side venting action which led to reduced cold leg ECC bypass and rapid reflood.

The fourth concept investigated utilized ECC injection into the pump suction leg. The investigation of this concept showed that, with pump suction ECC injection, the core cooling effectiveness depends on a complex relationship between the developed pump head and the condensation potential of a particular ECC injection rate. Within this context, the relationship between pump flow capacity, ECC injection rate, and the geometry of the ' $U$ ' shaped pump suction seal can strongly influence the system behavior. The limited range of testing supported by an analytical study indicated that, because of the complex relation discussed above, successful application of this concept may be limited to a narrow operating range. Consequently, in the absence of a substantial testing and development program with larger scales, it would be difficult to develop any confidence in this concept:

Within the general context of upper plenum injection, a separate and independent study was conducted on upper plenum low pressure injection system (LPIS) injection. Since this injection scheme is used exclusively on two-loop reactors, a larger scaled break area, representative of that for a $200 \%$ cold leg break in a two-loop plant, was used in the investigation of this concept. Therefore, the results from this investigation are not directly comparable with other concepts examined in this series. Nevertheless, some significant observations can be made relative to the system hydraulic behavior and core thermal response with upper plenum LPIS injection. The study showed that upper plenum LPIS injection results in strong multidimensional core cooling and quenching behavior. The relatively small injection rate and the large negative core flows early in the transient resulted in rapid top down cooling and quenching of a sector of the core immediately below the injection location. The top down cooling and quenching of the side of the core opposite the injection location was relatively ineffective as there was no strong driving mechanism to carry fluid into that sector of the core. The results of this experimental investigation are difficult to interpret as they relate to a PWR. With the large core flow area of a PWR and the increased potential for flow channeling, there is the possibility that LPIS fluid could flow through the core and fill the lower plenum, which would contribute to bottom flooding of the majority of the core as opposed to the top downward quenching process observed in the Semiscale tests.

The conclusions reached concerning each of the above described alternate ECC injection concepts relate specifically to the Semiscale Mod-1 system. The one-dimensional 
characteristics of the Mod-1 system, as well as a number of other factors unique to Semiscale, preclude a definitive assessment of the specific benefit in terms of temperature or power for a given concept in a full sized PWR. Nevertheless, these factors appear unlikely to alter the broad picture of the relative merits of the various concepts. 


\section{CONTENTS}

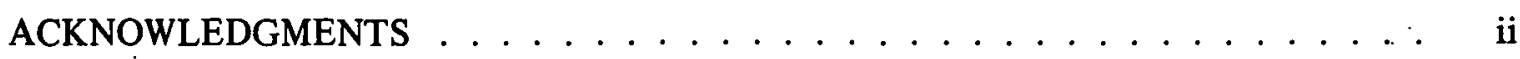

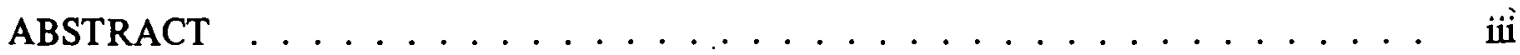

SUMMARY $\ldots \ldots \ldots \ldots \ldots \ldots \ldots \ldots \ldots$

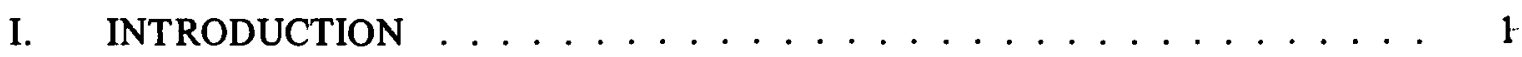

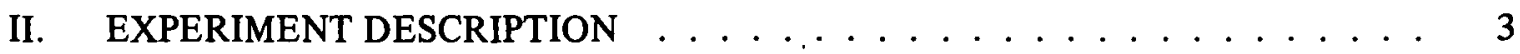

1. SYSTEM HARDWARE DESCRIPTION ............. 3

1.1 ECC Injection Systems and Geometries . . . . . . . . . . . 5

1.2 Semiscale Mod-1 Core .............. 8

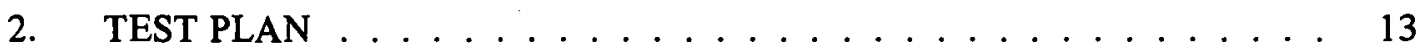

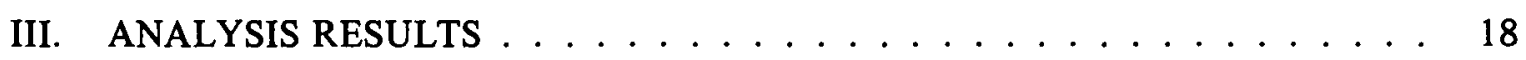

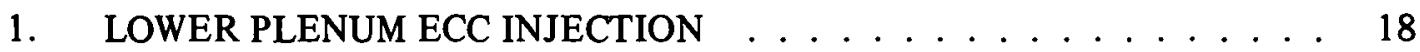

1.1 Core Thermal Response . . . . . . . . . . . . . . . . . . 19

1.2 System Behavior Contributing to Core Thermal Response . . . . 21

1.3 Factors Specific to the Semiscale Mod-1 System that may Influence Results . . . . . . . . . . . . . . . 23

1.4 Assessment of Effectiveness of Lower Plenum Injection in the Semiscale Mod-1 System . . . . . . . . . . . 24

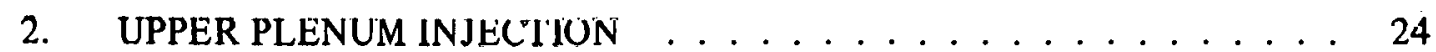

2.1 Upper Plenum Accumulator Injection . . . . . . . . . . . 25

2.2 Upper Plenum LPIS Injection . . . . . . . . . . . . . . . 34

3. COLD LEG INJECTION WITH VENT LINE . . . . . . . . . . . 41

3.1 Core Thermal Response .................. 41

3.2 System Behavior Contributing to Core Thermal Response . . . . . 44

3.3 Factors Specific to the Semiscale Mod-1 System that may Influence Results . . . . . . . . . . . . . . 47

3.4 Assessment of Effectiveness of Vent Line in the

Semiscale Mod-1 System .............. . 48 
4. PUMP SUCTION INJECTION $\ldots \ldots \ldots \ldots \ldots$

4.1 Core Thermal Response ................ 49

4.2 System Behavior Contributing to Core Thermal Response . . . . 50

4.3 Extension of the Investigation of the Pump Suction Injection Concept through RELAP4 Calculations . . . . . . . . 55

4.4 Factors Specific to the Semiscale Mod-1 System that may Influence Results . . . . . . . . . . . . 56

4.5 Assessment of Effectiveness of Pump Suction Injection in the Semiscale Mod-1 System . . . . . . . . . . . 57

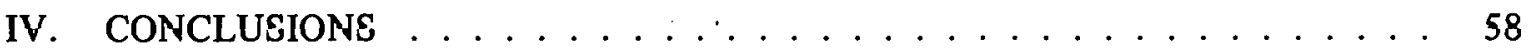

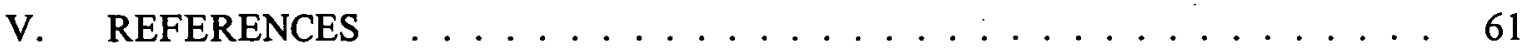

APPENDIX A - LOWER PLENUM ECC INJECTION . . . . . . . . . . . . . 63

1. INTRODUCTION ........................ 65

2. EXPERIMENTAL RESULTS ................. 68

2.1 Core Thermal Response . . . . . . . . . . . . . . . 68

2.2 Major System Factors Resulting in the Observed

Core Thermal Respones $\ldots$. . . . . . . . . . . . . 72

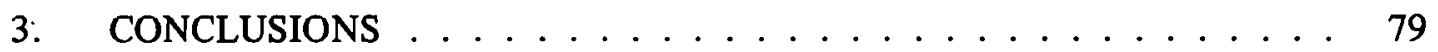

3.1 Cüre Therind Respürise . . . . . . . . . . . . . . . 79

3.2 Core Hydraulic Response . . . . . . . . . . . . . . . . 79

4. REFERENCES ........................ 80

APPENDIX B - UPPER PLENUM ACCUMULATOR INJECTION

ACCOMPANIED BY COLD LEG INJECTION . . . . . . . . . . . . . 81

1. INTRODUCTION ....................... 83

2. CORE THERMAL RESPONSE ............... 87

2.1 Core Quenching Behavior . . . . . . . . . . . . . 87

2.2 Core Heat 'l'ranster ................. 90

3. SYSTEM THERMAL-HYDRAULIC BEHAVIOR CONTRIBUTING

TO CORE THERMAL RESPONSE . . . . . . . . . . . . . . . 92 


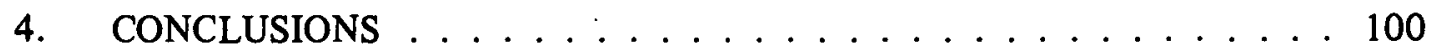

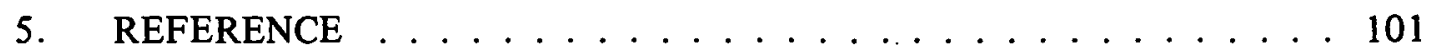

APPENDIX C - LOW PRESSURE INJECTION SYSTEM ECC INJECTION

IN THE UPPER PLENUM WITH OTHER ECC INJECTION IN THE

COLD LEG . . . . . . . . . . . . . . . . . . . 103

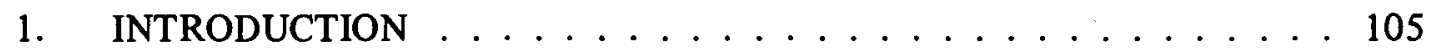

2. EXPERIMENTAL RESULTS $\ldots \ldots \ldots \ldots \ldots \ldots$

2.1 Results from the Semiscale Two-Loop Plant Scaling with Cold Leg ECC Injection . . . . . . . . . . . . . . . 108

2.2 Results from the Semiscale Two-Loop Configuration with Upper Plenum LPIS Injection (Test S-05-7) . . . . . . . . 116

3. CONCLUSIONS ..................... 123

3.1 Conclusions from Two-Loop Plant Scaling with Cold Leg ECC Injection . . . . . . . . . . . . . 123

3.2 Conclusions from Two-Loop Plant Scaling with Upper Plenum LPIS Injection . . . . . . . . . . . . . . . . 124

4. REFERENCES . . . . . . . . . . . . . . . . 124

APPENDIX D - COLD LEG ECC INJECTION WITH A VENT LINE $\ldots \ldots \ldots$

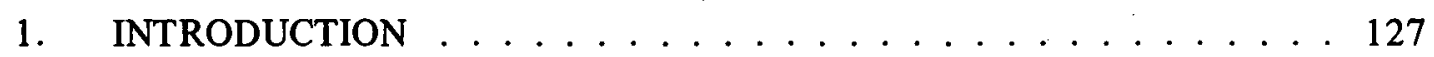

2. EXPERIMENTAL THERMAL-HYDRAULIC RESPONSE $\ldots \ldots \ldots .129$

2.1 Core Thermal Response . . . . . . . . . . . . . . . 130

2.2 Major System Behavior Contributing to the
Core Thermal Response . . . . . . . . . . . . 133

3. RESULTS OF THE ANALYTICAL STUDY . . . . . . . . . 139

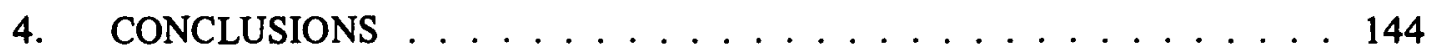

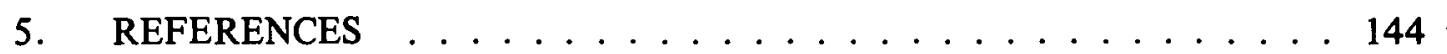

APPENDIX E - PUMP SUCTION LEG ECC INJECTION $\ldots \ldots \ldots \ldots$

1. INTRODUCTION . . . . . . . . . . . . . . . 149 
2. RESULTS OF THE EXPERIMENTAL INVESTIGATION . . . . . . 153

2.1 Influence of Pump Speed Control on the Core Thermal Response . . . . . . . . . . . . . . . 153

2.2 System Thermal-Hydraulic Response with the Pump at $64 \%(\simeq 1530 \mathrm{rpm})$ of the Prerupture Speed . . . . . . . . . 155

2.3 System Thermal-Hydraulic Response with the Pump at $100 \%(2345 \mathrm{rpm})$ of the Prerupture Speed ... . . . . . . . 161

2.4 System Thermal-Hydraulic Response with a Pump Coastdown to a Stop . . . . . . . . . . . . 166

3. RESULTS OF THE ANALYTICAL INVESTIGATIONS . . . . . . . 171.

3.1 Effect of ECC Injection Rate on the System and Core Response . . . . . . . . . . . . . . . . . . . . . . . 171

3.2 Effect of the Pump Characteristics on the System and Core Response . . . . . . . . . . . . . . 177

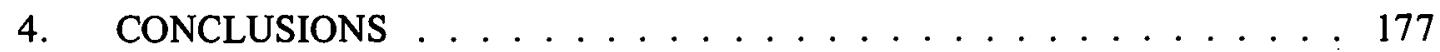

4.1 Effect of Pump Speed on the Core Thermal Response . . . . . . 178

4.2 RELAP4 Analysis of Pump Suction Leg ECC Injection . . . . . . 178

5. REFERENCES ........................ 178

\section{FIGURES}

1. Semiscale Mod-1 system cold leg break configuration - isometric . . . . . . 4

2. ECC injection points and vent line location used in Semiscale

Mod-1 system ........................ 6

3. Semiscale lower plenum injection nozzle configuration . . . . . . . . 6

4. Semiscale upper plenum injection nozzle configuration . . . . . . . . 7

5. Schematic of Semiscale vent line ................. 7

6. Semiscale pump suction injection location $\ldots \ldots \ldots$

7. Semiscale Mod-1 electric heater rod . . . . . . . . . . . . 9

8. Semiscale Mod-1 vessel with core ................ 10 
9. Vessel cross section and core layout ................. 11

10. Semiscale Mod-1 core - plan view with thermocouple locations . . . . . . 12

11. Semiscale Mod-1 heater rod axial power distribution . . . . . . . . . 13

12. Core power control for the alternate ECC injection tests and the cold leg baseline ECC injection test . . . . . . . . . . . . . . . 14

13. Heater rod temperature response demonstrating the rapid quench . of three core elevations in the lower plenum ECC injection test . . . . . . . . 20

14. Rod quench times for lower plenum ECC injection . . . . . . . . . . . . 20

15. Core inlet density for lower plenum ECC injection test - measured at bottom of core barrel . . . . . . . . . . . . . . . 21

16. Density in the broken loop hot leg next to vessel for the lower plenum ECC injection test . . . . . . . . . . . . . . . 23

17. Rod cladding temperature response at the 9-, 29-, and 39-in. elevations for upper plenum ECC injection rate of $8.4 \mathrm{gpm} \ldots 26$

18. Rod cladding temperature response at the 8-, 28-, and 37-in. elevations for upper plenum ECC injection rate of $8.4 \mathrm{gpm} \ldots \ldots 27$

19. Rod quench times for upper plenum ECC injection rate of $16 \mathrm{gpm} \quad \ldots . \ldots 27$

20. Rod quench times for upper plenum ECC injection rate of $8.4 \mathrm{gpm}$ with overlay quench times envelope for injection rate of $16 \mathrm{gpm} \quad \ldots \ldots 28$

21. Comparison of coire inlel volumetric fluws fur cold leg ECC injection and for upper plenum ECC injection (16 gpm)

22. Core inlet flow and downcomer fluid temperature for upper plenum accumulator injection rate of $16 \mathrm{gpm} \ldots \ldots \ldots$

23. Rod cladding temperatuse at four elevations for the upper plenum LPIS injection test . . . . . . . . . . . . . . . . 36

24. Rod quench times for upper plenum LPIS injection . . . . . . . . . . . . . 37

25. Density in intact loop hot leg next to vessel for the upper plenum LPIS injection test . . . . . . . . . . . . . . . . 38 
26. Rod cladding temperature response at 14 -in. elevation for cold leg injection tests with and without upper plenum venting . . . . . . . . . 42

27. Rod cladding temperature response at 29 -in. elevation for cold leg injection tests with and without upper plenum venting . . . . . . . . .

28. Rod cladding temperature response at 33-in. elevation for cold leg injection tests with and without upper plenum venting . . . . . . . . .

2.9. Comparisons of core inlet volumetric flows for cold leg ECC injection tests with and without upper plenum venting . . . . . . . . 45

30. Comparison of core inlet fluid densities for cold leg ECC injection tests with and without upper plenum venting

31. Comparison of calculated downcomer collapsed liquid levels for cold leg ECC injection tests with and without upper plenum venting . . . . . . 46

32. Comparison of calculated core collapsed liquid levels for cold leg ECC injection tests with and without upper plenum venting . . . . . . .

33. Comparison of heater rod temperature response for pump suction ECC injection tests with three pump speed profiles, and for cold leg ECC injection . . . . . . . . . . . . . . .

34. Intact loop pump differential pressure for pump suction ECC injection test with pump coastdown to $64 \%$ of prerupture value

35. Core inlet volumetric flow for pump suction ECC injection test with pump coastdown to $64 \%$ of prerupture value

36. Intact loop hot leg volumetric flow for pump suction ECC injection test with pump coastdown to $64 \%$ of prerupture value . . . . . . . . . . . 52

37. Intact loop pump differential pressure for pump suction ECC injection test with pump specd maintalned at $100 \%$ of pres upture

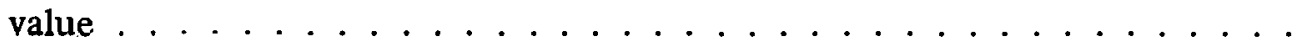

38. Fluid temperature in downcomer inlet annulus for pump suction ECC injection tcst with pump speed maintained at $100 \%$ of prerupture.

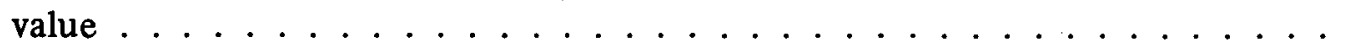


A-1. Semiscale Mod-1 system configuration with lower plenum ECC injection ..................... 66

A-2. Lower plenum ECC injection line schematic . . . . . . . . . . . 66

A-3. Comparison of core heater temperature response with lower plenum and cold leg ECC injection - Tests S-05-1 and S-04-6 . . . . . . . . . . . 69

A-4. Comparison of rod cladding and saturation temperature during lower plenum ECC injection - Test S-05-1 . . . . . . . . . . . . . 69

A-5. Surface heat flux at the core peak power elevation with lower plenum ECC injection - Test S-05-1

A-6. Surface heat flux at the core peak power elevation with cold leg ECC injection - Test S-04-6

A-7. Heat transfer coefficient response at the core peak power elevation during lower plenum ECC injection - Test S-05-1

A-8. Core inlet density response during lower plenum ECC injection - Test S-05-1

A-9. Comparison of the system pressure during lower plenum and cold leg ECC injection - Tests S-05-1 and S-04-6

A-10. Short-term core inlet volumetric flow response during lower plenum

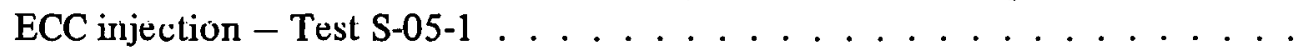

A-11. Short-term response of the fluid temperature at the core inlet with lower plcnum ECC injection - Test S-05-1 75

A-12. Comparison of the downcomer collapsed liquid levels for lower plenum and cold leg ECC injection - Tests S-05-1 and S-04-6

A-13. Comparison of the downcomer and core collapsed liquid levels during lower plenum ECC injection - Test S-05-1

A-14. Density response at the vessel side of rupture during lower plenum ECC injection - Test S-05-1

A-15. Core inlet volumetric flow during lower plenum ECC injection - Test S-05-

A-16. Corc inlet fluid tempcraturc during lower plenum ECC injection - Test S-05-1 
B-1. Semiscale Mod-1 system configuration . . . . . . . . . . . . . 84

B-2. Upper plenum accumulator injection configuration . . . . . . . 85

B-3. Semiscale Mod-1 core heater rod layout . . . . . . . . . . . 86

B-4. Axial distribution of quench times with 8.4-gpm upper plenum injection rate . . . . . . . . . . . . . . 87

B-5. Axial distribution of quench times with 16-gpm upper plenum

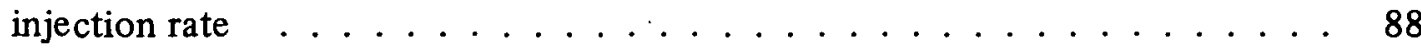

B-6. Comparison of quench times for 8.4-gpm upper plenum injection rate with envelope of quench times for 16-gpm upper plenum injection rate . . . . 89

B-7. Effect of upper plenum injection rate on core quenching . . . . . . . 89

B-8. Heat transfer coefficient at the 9-in. elevation for the 16-gpm upper plenum injection rate . . . . . . . . . . . . . 91

B-9. Heat transfer coefficient at the 29-in. elevation for the 16-gpm upper plenum injection rate . . . . . . . . . . . . . . 91

B-10. Comparison of core inlet volumetric flows for cold leg ECC injection and for upper plenum ECC injection $-16 \mathrm{gpm} \ldots \ldots$. . . . . . . 93 $^{3}$

B-11. Relationship between core flow oscillations and condensation in the vessel inlet annulus - 16-gpm upper plenum injection rate

B-12. Comparison of cold leg broken loop fluid density and the inlet annulus fluid temperature for the 16-gpm upper plenum injection rate . . . . 95

B-13. Coupling between negative core flow and fluid temperature at the top of the core for the 16 -gpm upper plenum injection rate

B-14. Effect of oscillatory core flow on core heat transfer -.7 in. elevulion for the 8.4-ypin upper plenum injoction rate .

B-15. Effect of nitrogen injection on intact loop cold leg fluid density -

8.4-gpm upper plenum injection rate . . . . . . . . . . . .

B-16. Effect of nitrogen injection on cold leg broken loop fluid density - 8.4-gpm upper plenum injection rate

B-17. Effect of nitrog $~ \eta$ injection on core inlet fluid density 16-gpm upper plenum injection rate 
B-18. Effect of nitrogen injection on broken loop hot leg fluid density for the $16 \mathrm{gpm}$ upper plenum injection rate . . . . . . . . . . . . . .

B-19. Effect of nitrogen injection on cladding temperature for the $8.4 \mathrm{gpm}$ upper plenum injection rate -15 -in. elevation . . . . . . . 100

C-1. Semiscale Mod-1 system . . . . . . . . . . . . . . . . 106

C-2. Schematic of upper plenum LPIS injection location . . . . . . . . . . . 108

C-3. Effect of system contiguration on depressurization rate . . . . . . . . . . 109

C-4. Effect of system configuration on broken loop cold leg flow . . . . . . . 110

C-5. Comparison of core inlet volumetric flow rates for two- and four-loop configurations . . . . . . . . . . . . . . . 110

C-6. Comparison of intact loop hot leg volumetric flows for the twoand four-loop configurations

C-7. Effect of system configuration on core DNB behavior - 29-in.

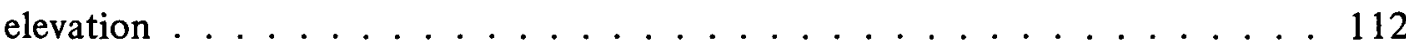

C-8. Effect of system configuration on core DNB behavior - 15-in.

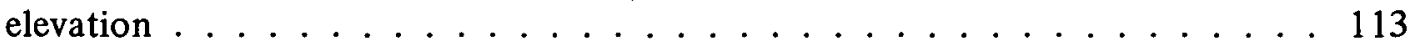

C-9. Effect of intact loop water on core thermal response for the two-loop configuration . . . . . . . . . . . . . 113

C-10. Downcomer collapsed liquid level for the two-loop configuration . . . . . . 114

C-11. Rod cladding temperature at the 14- and 29-in. elevations for the

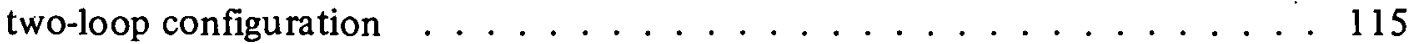

C-12. Axial quenching pattern for two- and four-loop configurations . . . . . 116

C-13. Effect of upper plenum LPIS injection on rod cladding temperature at the 14-in. elevation in the core region below the LPIS injection location

C-14. Effect of upper plenum LPIS injection on rod cladding temperature at the 57-in. elevation in the core region below the LPIS injection location 
C-15. Dependence of local heat transfer coefficient on transverse location in the core in the two-loop configuration with upper plenum LPIS injection . . . . . . . . . . . . . . . . . . . . 119

C-16. Effect of upper plenum LPIS injection on rod cladding temperature at the 21 -in. elevation in the core region opposite the LPIS injection location

C-17. Effect of upper plenum LPIS injection on rod cladding temperature at the 33-in. elevation in the core region opposite the LPIS injection location

C-18. Quench time profile for upper plenum LPIS injection . . . . . . . . . 121

C-19. Intact loop hot leg fluid density for the two-loop configuration with upper plenum LPIS injection . . . . . . . . . . . . . . . 122

C-20. Broken loop hot leg fluid density for the two-loop configuration with upper plenum LPIS injection . . . . . . . . . . . . . . . . . . . . . 122

D-1. Semiscale Mod-1 system configuration for cold leg ECC injection with a vent line

D-2. Short-term rod cladding temperature response at the core peak power elevation with and without a vent line - I'ests S-05-5 and S-04-6.......................... 130

D-3. Comparison of rod cladding temperature responses at the 29-in. elevation with and without a vent line - Tests S-05-5 and $\mathrm{S}-04-6 \ldots \ldots \ldots \ldots \ldots$

D-4. Response of the heat transfer coefficient at the core peak power elevation with vent line - Test S-05-5 . . . . . . . . . . . . 132

D-5. Comparison of rod cladding temperatures at the 9- and 22-in. elevations with and without vent line - Tests S-05-5 and S-04-6

D-6. Comparison of rod cladding temperatures at the initiation of reflood with and without vent line

D-7. Quenching at various elevations as a function of the time after rupture for the test with vent line - Test S-05-5

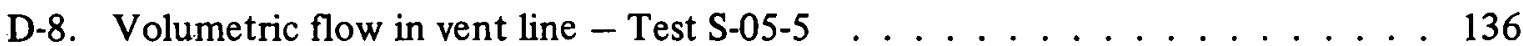


D-9. Short-term core inlet volumetric flow with vent line - Test S-05-5 . . . . 136

D-10. Comparison of core inlet density with and without vent line Tests S-05-5 and S-04-6 . . . . . . . . . . . . . . 137

D-11. Comparison of downcomer collapsed liquid level with and without vent line - Tests S-05-5 and S-04-6.

D-12. RELAP4 model of Semiscale Mod-1 system using cold leg ECC injection with a vent line

D-13. Effect of vent line resistance on the RELAP4 calculated rod surface temperature at rod high power elevation

D-14. Effect of vent line resistance on the RELAP4 calculated surface temperature at $20 \mathrm{sec}$ after rupture at the core high power elevation

D-15. Effect of vent line resistance on the RELAP4 calculated vent line mass flow

D-16. Effect of vent line resistance on the RELAP4 calculated core inlet flow

D-17. Effect of vent line resistance on the RELAP4 calculated upper plenum pressure

E-1. Semiscale Mod-1 system configuration for pump suction leg ECC injection

E-2. Pump speed control profiles investigated during pump suction leg ECC injection

E-3. Comparison of rod cladding temperature response at the 29-in. elevation showing the effect of pump speed

E-4. Density response in the pump suction leg during pump suction leg ECC injection with a pump speed of $64 \%$ of initial speed - Test S-05-2

E-5. Differential pressure response across the pump during pump suction leg ECC injection with a pump speed of $64 \%$ of initial speed - Test S-05-2

E-6. Short-tcrm corc inlct flow during pump suction leg ECC

injection with a pump speed of $64 \%$ of initial speed - Test S-05-2 
E-7. Short-term core inlet density response during pump suction leg ECC injection with a pump speed of $64 \%$ of initial speed Test S-05-2

E-8. Density response in broken loop hot leg during pump suction leg ECC injection with a pump speed of $64 \%$ of initial speed Test S-05-2

E-9. Intact loop hot leg volumetric flow during pump suction leg ECC injection with a pump speed of $64 \%$ of initial speed Test S-05-2

E-10. Comparison of downcomer annulus tluid temperature and saturation temperature during pump suction leg ECC injection with a pump speed of $64 \%$ of initial speed - Test S-05-2

E-11. Comparison of downcomer and core collapsed liquid levels during pump suction leg ECC injection with a pump speed of $64 \%$ of initial speed - Test S-05-2

E-12. Differential pressure response across the pump during pump suction leg ECC injection with a pump speed of $100 \%$ of initial speed - Test S-05-2A . . . . . . . . . . . . . 162

E-13. Density response in the pump suction leg during pump suction leg ECC injection with a pump speed of $100 \%$ of initial speed Test $\mathrm{S}-05-2 \mathrm{~A} \ldots \ldots \ldots \ldots \ldots$

E-14. Core inlet volumetric flow during pump suction leg ECC injection with a pump speed of $100 \%$ of initial speed - Test S-05-2A . . . . . 163

E-15. Volumetric flow in the intact loop hot leg during pump suction leg $\bar{E} \overline{C C}$ injection with a pump speed of $100 \%$ of initial speed Test S-0.5-2A

E-16. Effect of the core inlet volumetric flow on the heat transfer coefficent during pump suction leg ECC injection with a pump speed of $100 \%$ of initial speed - Test S-05-2A

E-17. Comparison of downcomer inlet annulus fluid temperature and saturation temperature during pump suction leg ECC injection with a pump speed of $100 \%$ of initial speed - Test S-05-2A . . . . . . . . 165

E-18. Density response in vessel side of broken loop during pump suction leg ECC injection with a pump speed of $100 \%$ of initial spe ?d Test S-05-2A 
E-19. Comparison of downcomer and core collapsed liquid levels during pump suction leg ECC injection with a pump speed of $100 \%$ of initial speed - Test S-05-2A . . . . . . . . . . . . . 167

E-20. Short-term comparison of rod cladding temperature response at the 26-in. elevation during pump suction leg ECC injection with a pump coastdown to a stop - Test S-05-2B . . . . . . . . . . . . . 168

E-21. Response of the differential pressure across the pump during pump suction leg ECC injection with pump coastdown to a stop Test S-05-2B . . . . . . . . . . . . . . . . . 169

E-22. Core inlet volumetric flow during pump suction leg ECC injection with a pump coastdown to a stop - Test S-05-2B

E-23. Comparison of downcomer and core collapsed liquid levels during pump suction leg ECC injection with a pump coastdown to a stop Test S-05-2B ....................... . . 170

E-24. RELAP4 model of Semiscale Mod-1 system using pump suction leg ECC injection ......................... 172

E-25. Comparison of measured (Test S-05-2A) and calculated (RELAP4) rod cladding temperature responses at the core peak power elevation . . . . . 173

E-26. Pump suction leg fluid density response calculated by RELAP4 during pump suction leg ECC injection with a pump speed of $100 \%$ of

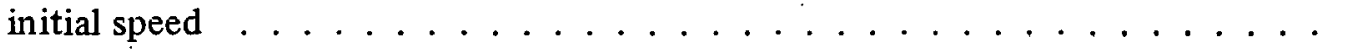

E-27. Effect of accumulator flow rate on the surface temperature response at the core peak power elevations calculated by RELAP4 during pump suction leg ECC injection with a pump speed of $100 \%$ of initial speed . . . . . .

E-28. Effect of accumulator flow rate on the core inlet mass flowrate calculated by RELAP4 during pump suction leg ECC injection with a pump speed of $100 \%$ of initial speed

E-29. Effect of accumulator flow rate on the fluid temperature entering the downcomer calculated by RELAP4 during pump suction leg ECC injection with a pump speed of $100 \%$ of initial specd

E-30. Effect of accumulator flow rate on the differential pressure acrosss the purnp calculated by RELAP4 during pump suction leg ECC injection with a pump speed of $100 \%$ of initial speed $\ldots \ldots 176$ 
E-31. Effect of pump model on the rod cladding surface temperature calculated by RELAP4 during pump suction leg ECC injection with a pump speed of $100 \%$ of initial speed

\section{TABLES}

I. Test and Prerupture Conditions for Alternate ECC Injection

Test Series ....................... 16

A-I. Test Conditions for Lower Plenum ECC Injection . . . . . . . . . . . . . 67

C-I. Modifications to the Semiscale Four-Loop Configuration to Achieve a Two-Loop Configuration . . . . . . . . . . . . . 107

D-I. Test Conditions for Cold Leg Injection with Vent Line . . . . . . . . . . . 129

E-I. Test Conditions for Pump Suction Injection Tests . . . . . . . . . . . 151 


\title{
INVESTIGATION OF ALTERNATE ECC INJECTION CONCEPTS
}

\author{
IN THE SEMISCALE MOD-1 SYSTEM
}

\section{INTRODUCTION}

In the unlikely event of a loss-of-coolant accident (LOCA) in a pressurized water reactor (PWR) various emergency core coolant (ECC) injection systems are activated in order to remove decay heat from the core so that the consequences of such an accident are minimal. The injection location commonly employed in American made PWRs is in the cold leg between the pump discharge and the vessel inlet annulus. Coolant injected at this location must penetrate the downcomer and fill the lower plenum before it can become effective in removing energy from the core. Even after the coolant initially enters the core, complex thermal-hydraulic interactions can impede its further progress into the core and reduce its cooling effectiveness. In view of these limitations, the investigation of other possible injection locations appears worthwhile to determine whether improvements can be made. Considerable international effort has been expended in the analysis of alternate ECC injection concepts, but heretofore no single investigation has combined an overview analysis of the effectiveness of several concepts in a single system. The major objectives of the present work are:

(1) To investigate the potential benefits and relative merits of various alternate ECC injection concepts in a single system, particularly those concepts proposed by vendors and those under consideration for the Loss-of-Fluid Test (LOFT) Program [1]

(2) To examine the major controlling thermal-hydraulic phenomena associated with the effectiveness of the various alternate ECC injection concepts.

The investigation undertaken to accomplish these objectives was performed in the Semiscale Mod-1 Program. This program, conducted by EG\&G Idaho, Inc. is part of the overall U.S. Nuclear Regulatory Commission (NRC) and Energy Research and Development Administration sponsored research and development program to investigate the behavior of the pressurized water reactor system during a hypothesized LOCA. The Semiscale Mod-1 Program is a major contributor of experimental data that provide a means of evaluating the adequacy of overall system analytical models as well as models of the individual system components.

The experimental investigation of various alternate ECC injection concepts was conducted in the Semiscale Mod-1 system which simulates the principal physical features of a nuclear plant, but which is much smaller in volume. Nuclear heating is simulated by a core composed of an array of electrically heated rods. The core is contained in a pressure vessel 
which also includes a downcomer, a lower plenum, and an upper plenum. The system piping is arranged in a 1-1/2 loop configuration with the intact loop containing an active steam generator and pump, and the broken loop containing passive simulators for the steam generator and pump.

In the work presented herein, four major alternate ECC injection concepts were investigated in the context of a $200 \%$ double-ended cold leg break. The first concept was that of ECC injection in the vessel lower plenum. This concept had the potential for eliminating any delays associated with ECC penetration of the downcomer and, therefore, provided the possibility of effective core cooling very early in the transient. The second concept employed combined ECC injection into both the upper plenum and the cold legs. This concept offered the possibility that the added upper plenum injection would provide additional coolant to the core, and possibly act as a condensation sink in the upper plenumn to reduce steam binding effects associated with bottom reflooding. The third alternate ECC concept used cold leg injection but provided upper plenum venting through a bypass line which led from the broken loop hot side piping to the broken loop cold side piping just outside the vessel. The vent line offered the advantage of improved steam flow out of the upper plenum region, thereby increasing the rate of core cooling by reducing the resistance to bottom flooding. The fourth and final concept utilized ECC injection in to the pump suction leg. In this case, the pump could provide a driving force to aid delivery of ECC to the core, and the ECC injection could reduce steam binding by condensing high velocity steam before it reached the largest potential hydraulic resistance in the system, the pump.

The results of the alternate ECC injection tests performed in the Semiscale Mod-1 system cannot be applied directly to a PWR due to the large difference in physical scale and the scaling compromises present in the Mod-1 system. However, the results can be used meaningfully in evaluating the overall effectiveness and relative merits of each alternate ECC injection concept investigated.

The overall effectiveness and relative merits of each of the alternate ECC injection concepts under investigation are discussed in the main text of this report, along with the major causal phenomena and, where possible, parametric trends within a given concept. The Appendixes contain detailed discussions of each concept, the observed causal phenomena, and related system secondary behavior.

Section II of this report presents a description of the Semiscale Mod-1 system and the various ECC injection configurations used to represent the alternate ECC injection concepts under investigation. It also includes a test plan by which the various concepts were evaluated. Section III discusses the analysis results as they relate to the relative effectiveness of the various concepts, and Section IV presents the major conclusions drawn from the analysis. 


\section{EXPERIMENT DESCRIPTION}

The Semiscale Mod-1 system was used for the experimental investigation of various alternate ECC injection concepts including lower plenum injection, simultaneous upper plenum and cold leg injection, cold leg injection with upper plenum venting, and pump suction leg injection. The investigation was conducted by means of a series of integral blowdown-reflood tests in which the initial conditions were maintained essentially the same but the ECC injection parameters were varied, or system modifications were made, to represent the various injection concepts. In each case a $200 \%$ double-ended cold leg break was employed. With some of the concepts additional tests were conducted to allow the variation of an appropriate ECC system parameter, such as injection rate.

This section presents a description of the system hardware and a plan of the tests conducted for the series of tests used to investigate alternate ECC concepts. Since the major objective of the investigation was to evaluate the relative effectiveness of various alternate ECC injection concepts in the Semiscale Mod-1 system, the system description contains a complete discussion of the ECC injection locations and geometries in addition to a general description of the major system characteristics. Correspondingly, the test plan provides details on the operation of the given concepts, including such factors as accumulator set points, fluid volumes, and injection rates.

\section{SYSTEM HARDWARE DESCRIPTION}

The Semiscale Mod-1 test apparatus, shown in Figure 1, is a high pressure system consisting of a pressure vessel with simulated reactor internals (downcomer, lower plenum, electrically heated core region, and upper plenum); and intact loop which is a volume scaled model of three loops of a commercial four-loop PWR with a tube and shell heat exchanger, active circulating pump, and pressurizer; a broken loop with rupture diaphragm assemblies, simulated steam generator, and simulated pump; a pressure suppression system with a 91.7- $\mathrm{ft}^{3}$ suppression tank and header; and simulated ECC injection systems with accumulators and injection pumps which can be arranged to inject at different locations to allow the investigation of the various alternate ECC injection concepts. The system water volume is approximately $7.8 \mathrm{ft}^{3}$ which represents a volume scaling of approximately $1 / 1500$ relative to a PWR. Detailed descriptions of the system components, including volumes and flow resistances, are contained in Reference 2.

Measurements taken in the Semiscale system include volumetric flow rates, material temperatures, fluid temperatures, pressure drops, pressures, and fluid densities. Thermocouples were used for the material and fluid temperatures. The differential pressure drop measurements were made with calibrated differential pressure transducers. The volumetric flow rates were obtained with full flow turbine flowmeters, and the fluid densities were obtained with vertical and horizontal oriented single-beam gamma densitometers and dual 


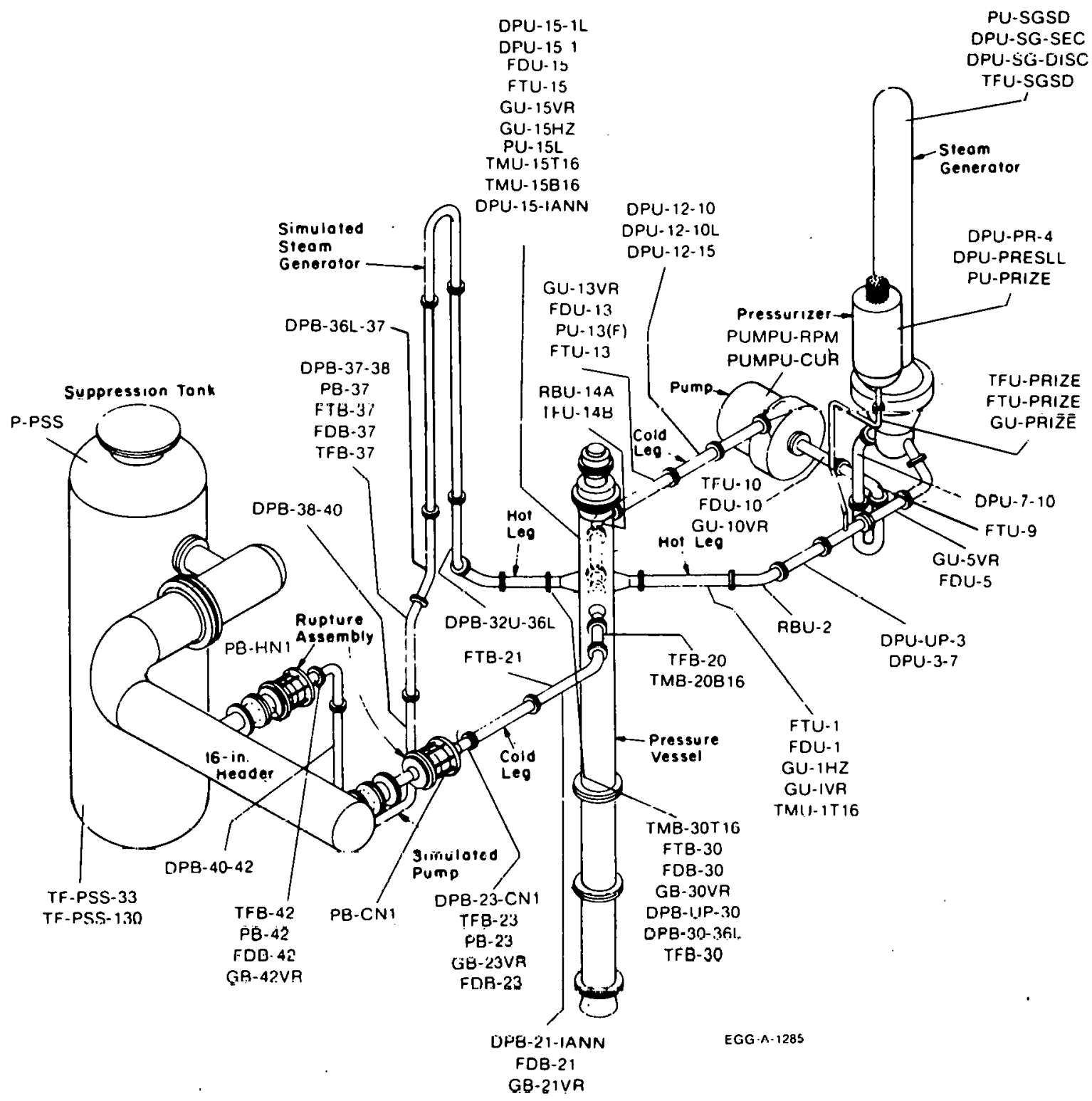

Fig. 1 Semiscale Mod-1 system cold leg break configuration - isometric.

beam gamma densitometers. Core measurements taken included heater rod cladding temperatures, core voltage, power, current, fluid temperature, inlet flow, and inlet density. The total expected error in each type of measurement is identified in Relierence 2.

In the context of the experimental investigation of the effectiveness of alternate ECC injection concepts, both the Semiscale Mod-1 ECC injection systems and the electrically heated core are of special importance. The ECC injection systems are important becausc it is through the use of these systems that the various alternate ECC injection concepts were represented in the Mod-1 system. The electrically heated core is important because the core thermal response is the major variable by which the effectiveness of an alternate ECC 
injection concept was assessed. Furthermore, details of the core, such as the existence of unpowered rods, have the potential for influencing the core thermal response. The following section briefly describes the Semiscale Mod-1 ECC injection systems and then outlines the ways in which these systems were used to represent the various alternate ECC injection concepts, giving details of the various injection geometries. The subsequent section describes the Semiscale Mod-1 core simulation.

\subsection{ECC Injection Systems and Geometries}

The ECC injection system includes three types of injection subsystems: the compressed nitrogen-water accumulator subsystem, and the low pressure injection and high pressure injection pump subsystems. The ECC system injection locations were systematically changed among the tests to provide lower plenum injection, simultaneous upper plenum and cold leg injection, cold leg injection with a vent line, and pump suction leg injection. The system and vessel injection locations are shown in Figure 2 along with the vent line connection points between the broken loop hot and cold legs. The following paragraphs present details of the various injection geometries for the different concepts investigated.

In the investigation of lower plenum ECC injection, all the employed ECC systems injected into the lower plenum through a nozzle located $1.72 \mathrm{in}$. below the bottom of the core barrel. The schematic drawing in Figure 3 shows the injection location and the geometric characteristics of the nozzle. To mitigate the potential for ECC to inject directly into the core, the nozzle design was such that when the nozzle was mounted in the horizontal position, it injected ECC downward toward the bottom of the lower plenum.

The upper plenum ECC injection investigation involved two different injection concepts. In the first, ECC from the vessel accumulator was injected into the upper plenum simultaneously with intact and broken loop cold leg ECC injection. In the second concept, ECC was again injected into the intact and broken loop cold legs, but in this case ECC from the LPIS was pumped into the upper plenum. The upper plenum injection nozzle location and geomelry were identical for both concepts investigated. Figure 4 shows the upper plenum ECC injection nozzle location relative to the core heater rods as well as the axial and azimuthal locations on the vessel. The ECC injection location was $13.5 \mathrm{in}$. above the cold leg centerline and the nozzle was mounted horizontally so that the ECC impinged directly on the upper plenum heater rod extensions.

In the investigation of cold leg injection with upper plenum venting, a vent line between the broken loop hot and cold legs was utilized. Figure 5 is a schematic showing the location of the Semiscale vent line. Although this configuration is not intended to simulate a PWR with upper plenum venting, the vent line resistance $\left(R^{\prime}\right)$ was core area scaled to give an equivalent resistance approximating that of a PWR vent system. In addition to a control valve in the line to set the desired effective vent line resistance, a check valve was also included to prevent flow from the broken loop cold leg to the broken loop hot leg under pretest operating conditions when the pressure in the inlet annulus exceeded the pressure in the upper plenum. 


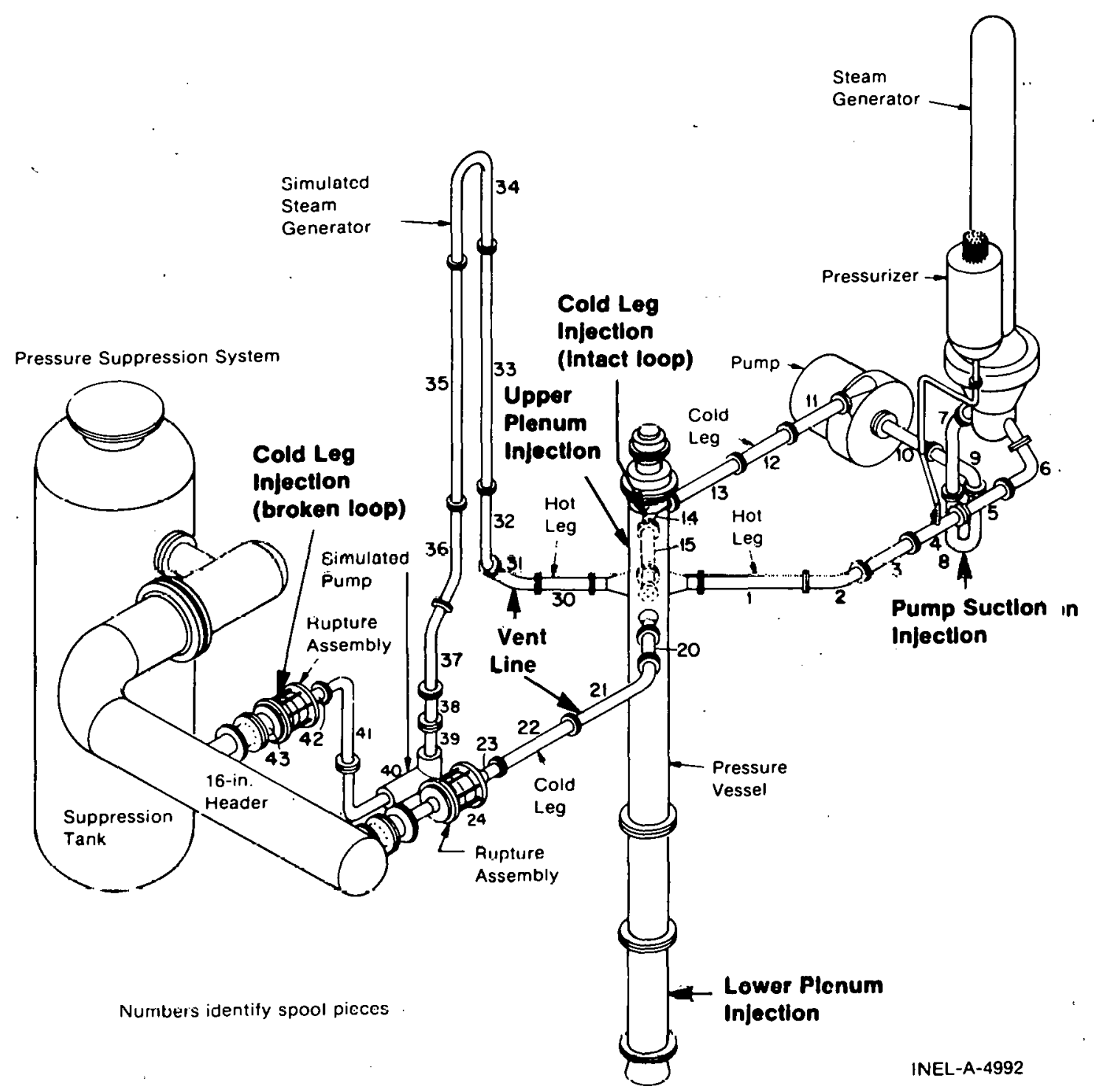

Fig. 2 ECC injection points and vent line location used in Semiscale Mod-1 system.

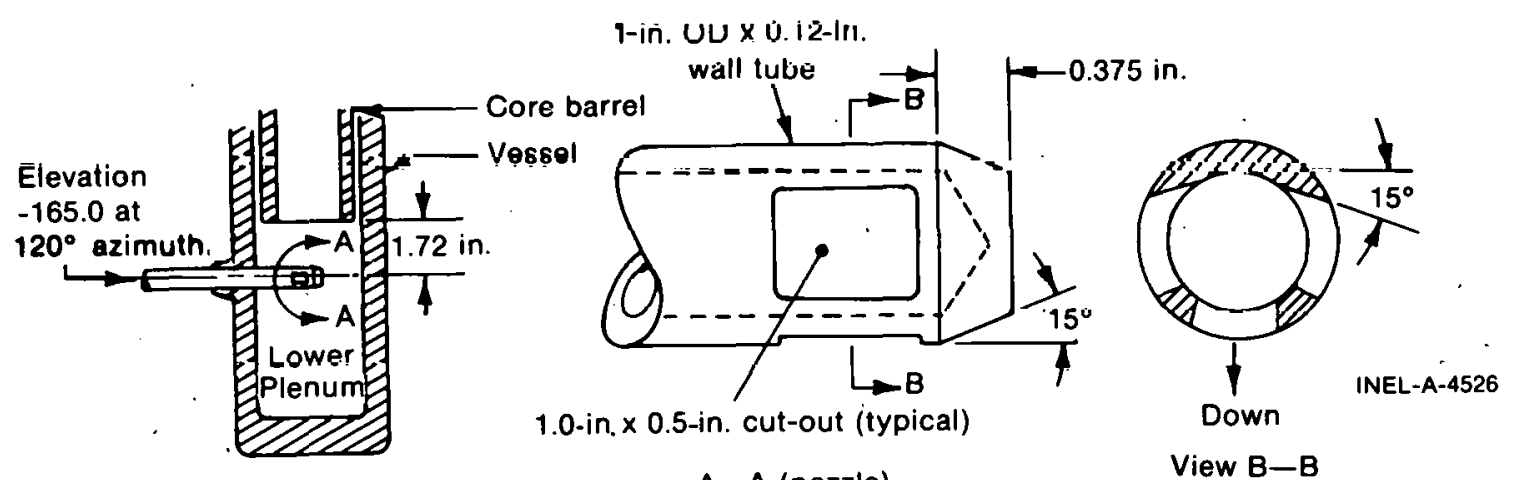

Fig. 3 Semiscale lower plenum injection nozzle configuration. 


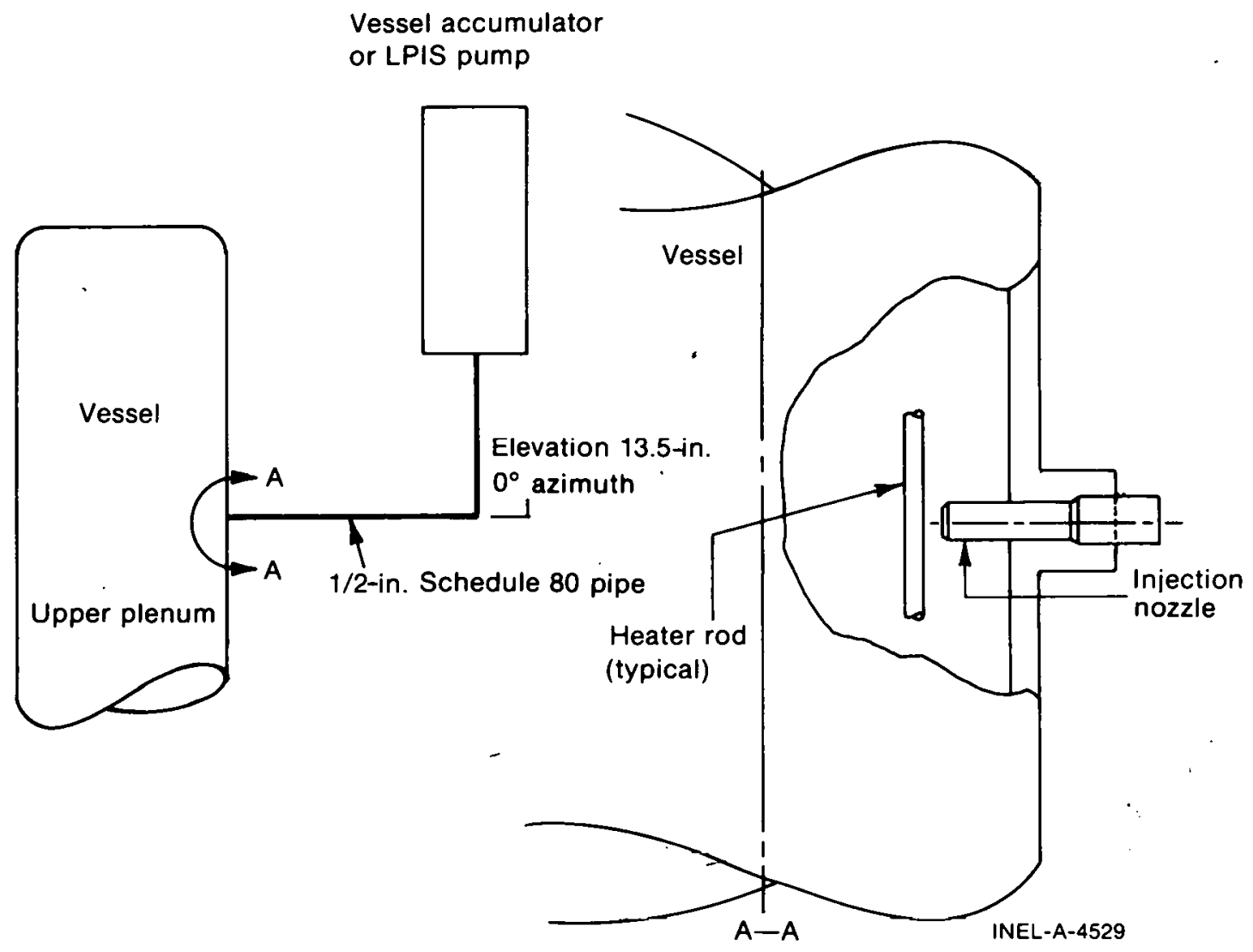

Fig. 4 Semiscale upper plenum injection nozzle configuration.

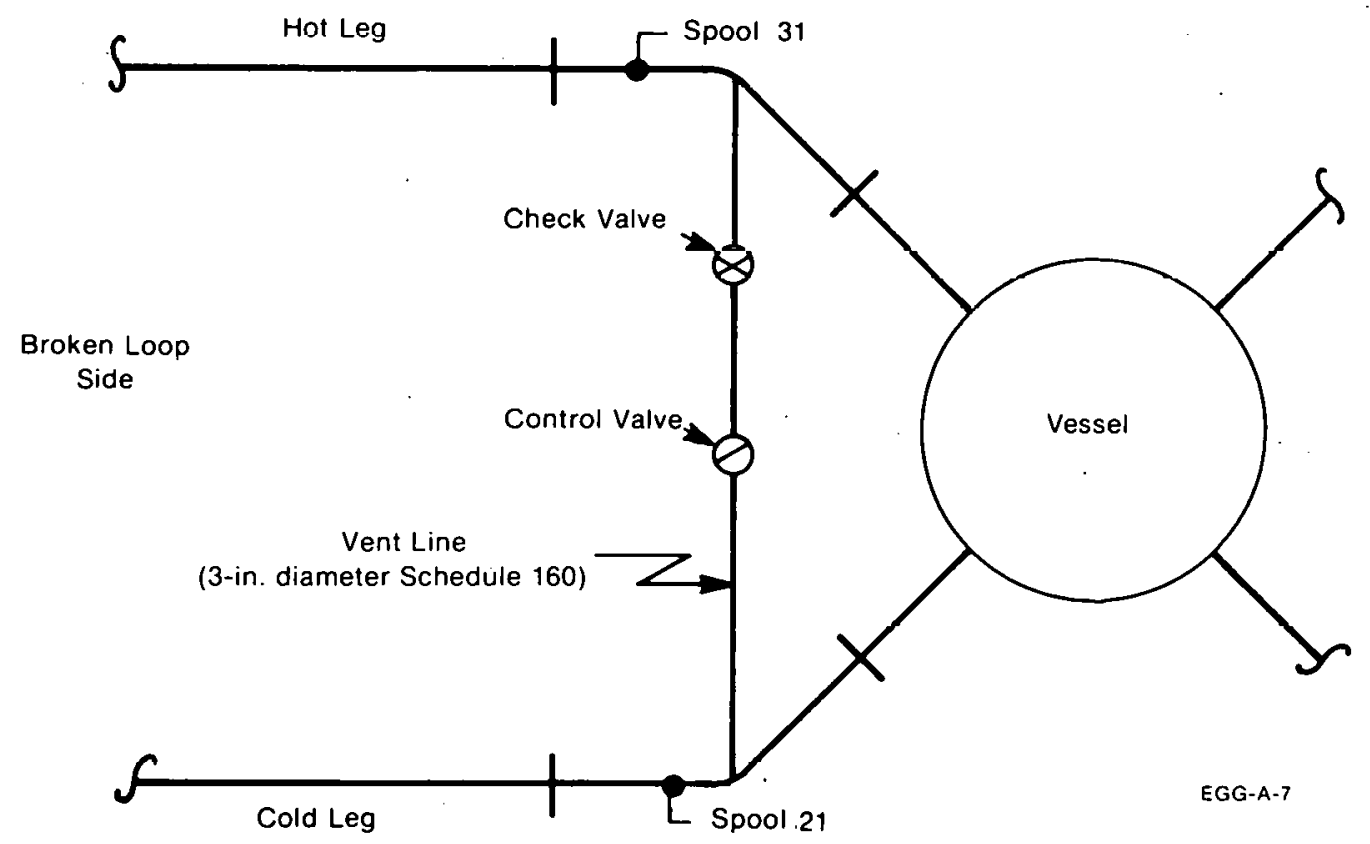

Fig. 5 Schematic of Semiscale vent line. 
For the investigation of pump suction leg ECC injection, ECC was injected into the intact loop pump suction leg at the location shown in Figure 6. In one of the experimental investigations all ECC systems injected into the pump suction leg location. However, in two subsequent investigations the LPIS was moved to the intact loop cold leg injection location to assess the effect of the LPIS injection location on the overall effectiveness of this concept. In each of the experimental investigations, ECC was not injected into the broken loop pump suction but instead injected into the cold leg injection location downstream of the simulated pump discharge. The decision not to inject into the broken loop pump suction was based on the fact that the broken loop pump simulator would behave differently than an active pump and, therefore, would produce hydraulic behavior atypical of that expected to occur in a PWR.

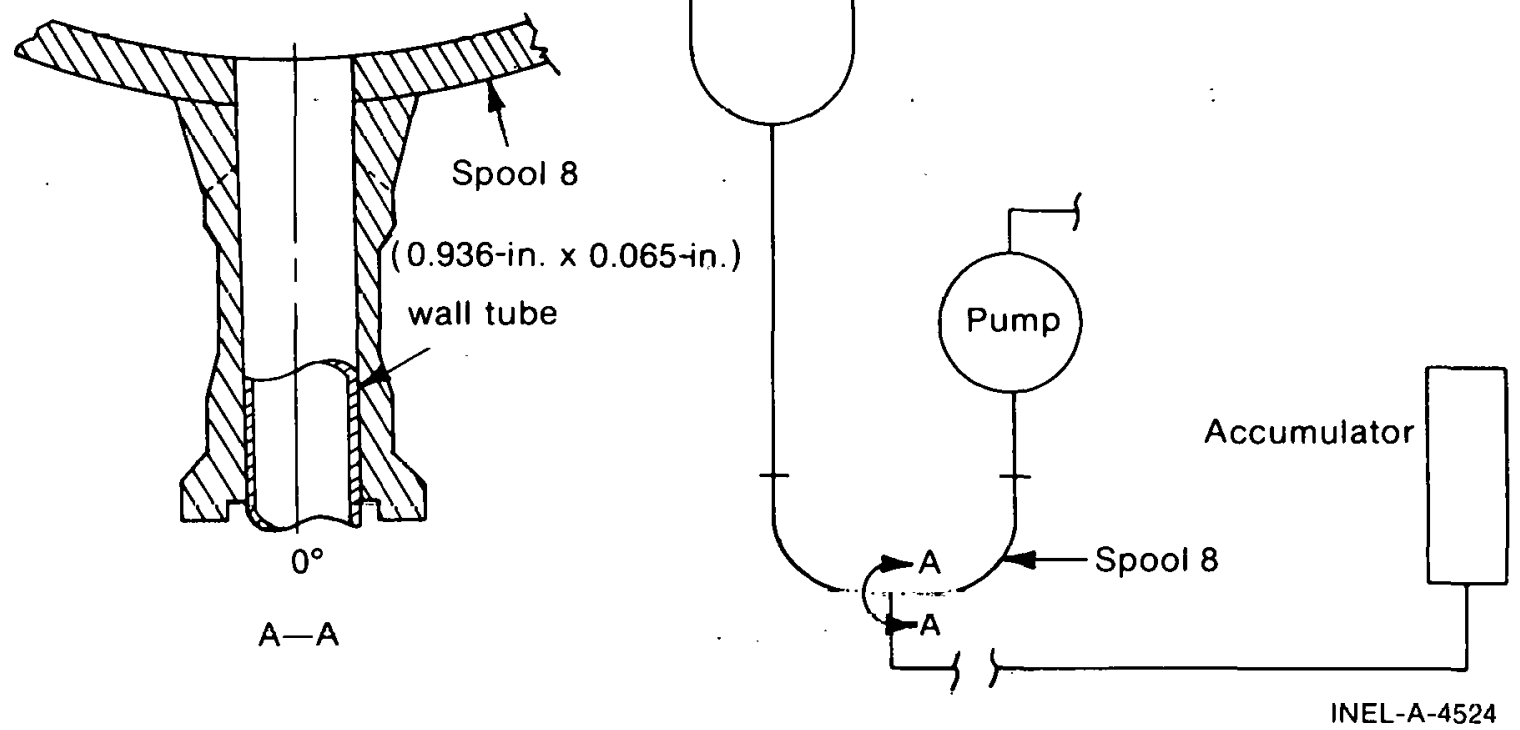

Fig. 6 Semiscale pump suction injection location.

\subsection{Semiscale Mod-1 Core}

The core simulator in the Semiscale system consists of 40 electrically heated rods of typical PWR fuel rod diameter (0.422 in.) and axial power peaking (1.58). Figure 7 shows the Semiscale heater rod internals, and a detailed description of the general construction of the rod is contained in Reference 2. The overall length of the rod is about 207 in., and the bottom of the 5.5 -ft electrically heated core is about $143 \mathrm{in}$. below the vessel cold leg centerline as shown in Figure 8. The rods extend from the bottom of the heated core to the upper plenum and pass out through the vessel upper head.

The 40 heater rods are positioned and held in the core with 10 grid spacers which maintain the heaters on a typical PWR pitch ( 0.563 in.). Figure 9 shows a plan view of the 


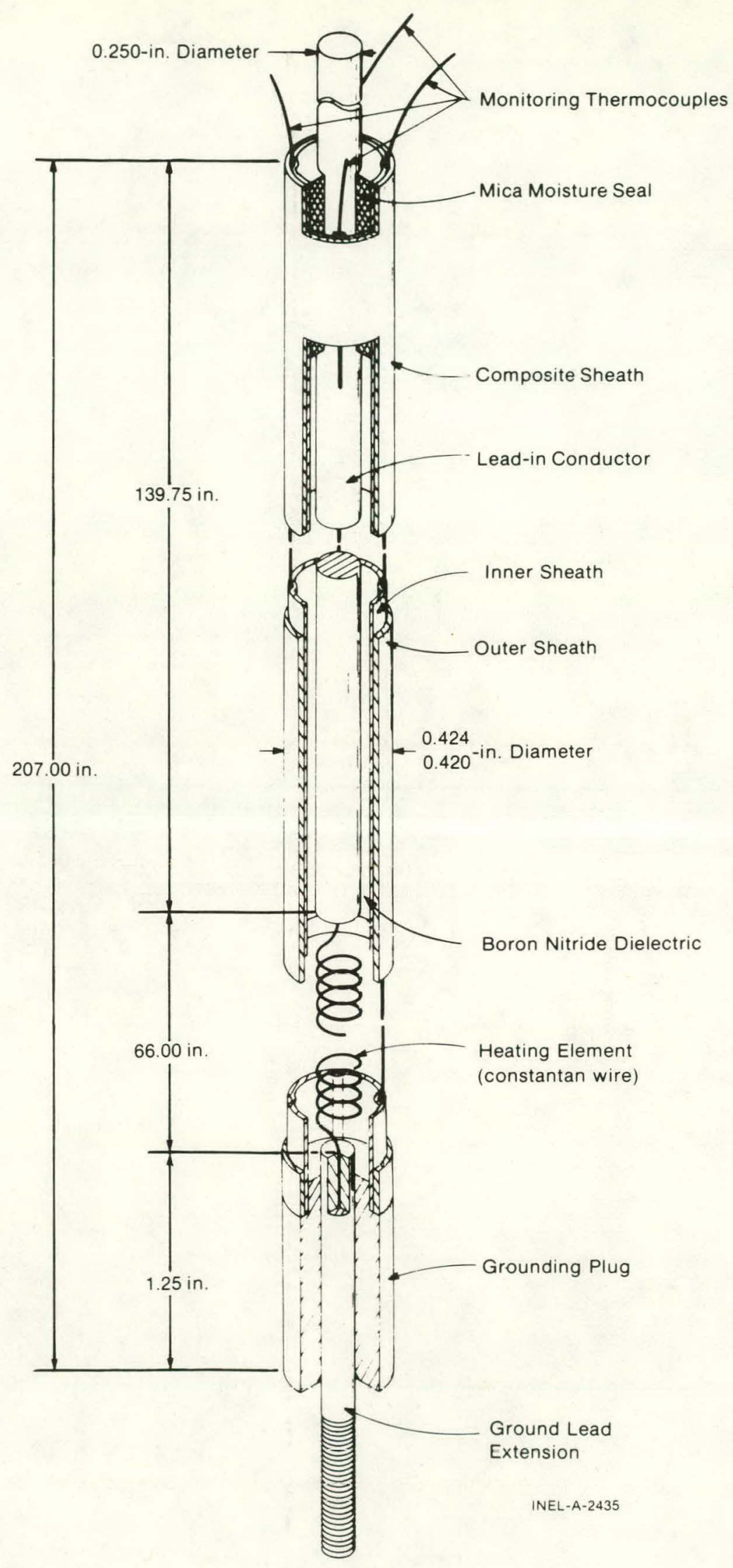

Fig. 7 Semiscale Mod-1 electric heater rod. 


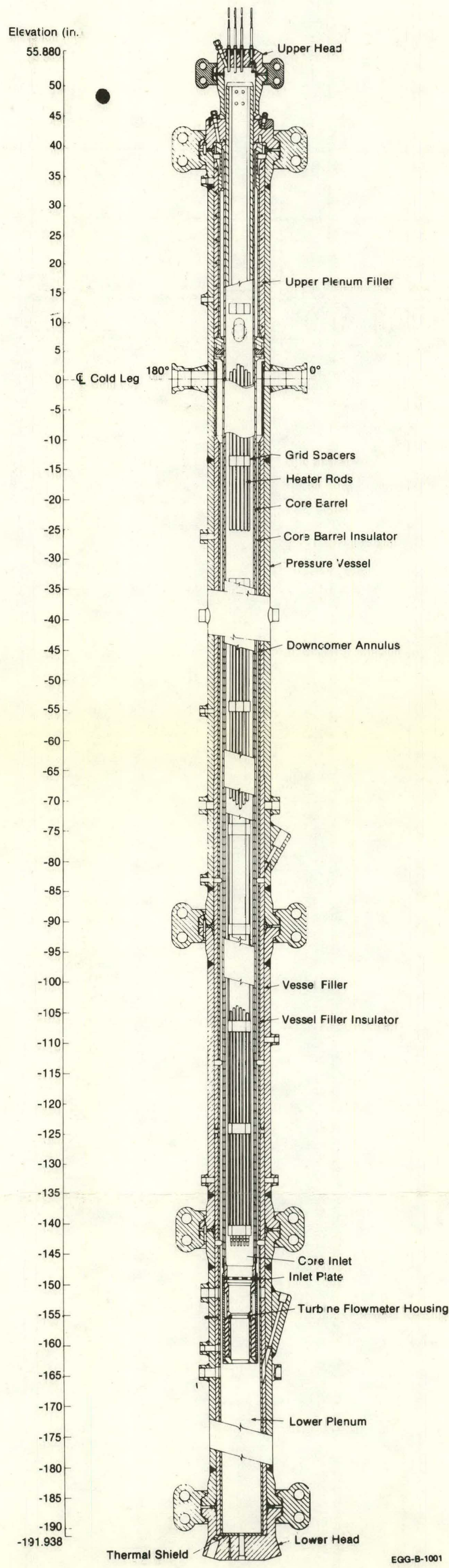




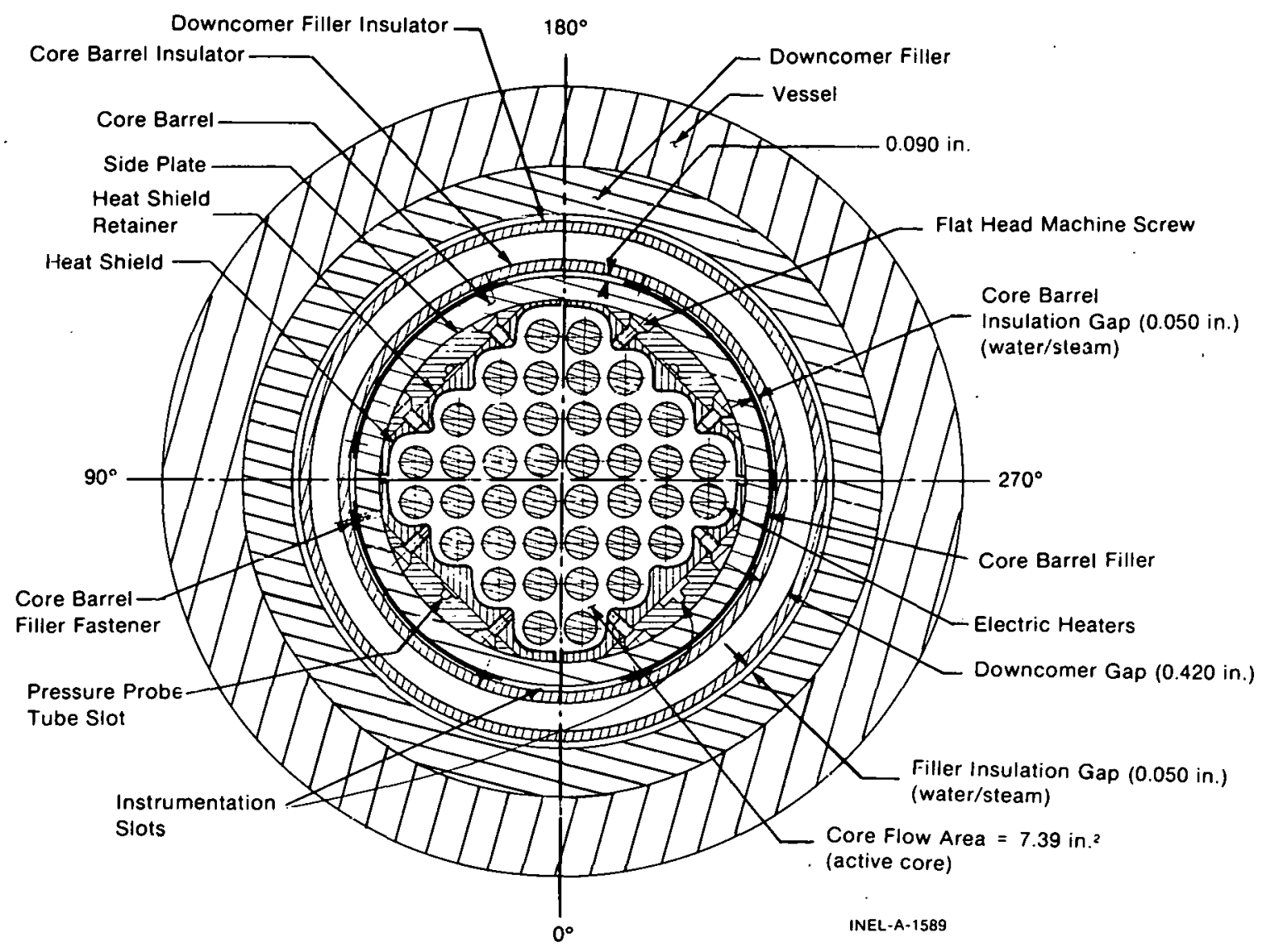

Fig. 9 Vessel cross section and core layout.

Semiscale vessel and core simulator assembly, and Figure 10 illustrates the heater rod matrix and cladding thermocouple locations. The heater rods are located within the matrix by reference to the row of letters across the top and the column of numbers down the side of the matrix. Similarly, the thermocouples are identified by the rod they are on and by their elevation above the bottom of the heated length of the core. The thermocouple on Rod D5 at the 29-in. elevation is thus referred to as TH-D5-29; where TH means a core heater cladding tcmperature, D5 refers to the rod upon which the thermocouple is located, and 29 gives the thermocouple elevation in inches above the core bottom. (The arrows in Figure 10 indicate thermocouple azimuthal locations.) A heat shield assembly, composed of 0.018-in. thick stainless steel, surrounds the rod matrix and reduces the core flow area to 7.39 in. ${ }^{2}$.

In the 40-rod core heater bundlc unly 36 rods were powered. Four rods were unpowercd to make the core bundle more representative of a PWR fuel assembly with control rod thimbles and instrument tubes. Three of the center heater rods were operated at a $5 \%$ higher peak power density than the remaining 33 powered rods to also simulate the radial power profile near a control rod thimble in a PWR fuel assembly. The normalized axial power profile for the rods is illustrated in Figure 11. The low power heater rods had a peak power density of $11.5 \mathrm{~kW} / \mathrm{ft}$ and the three center rods at $5 \%$ higher initial power had a peak power density of about $12.1 \mathrm{~kW} / \mathrm{ft}$. A sufficient factor of safety was built into the rods to allow for the implementation of a flat radial power profile in the core simulator if desired. 

A
B
C
D
E
F
G
H

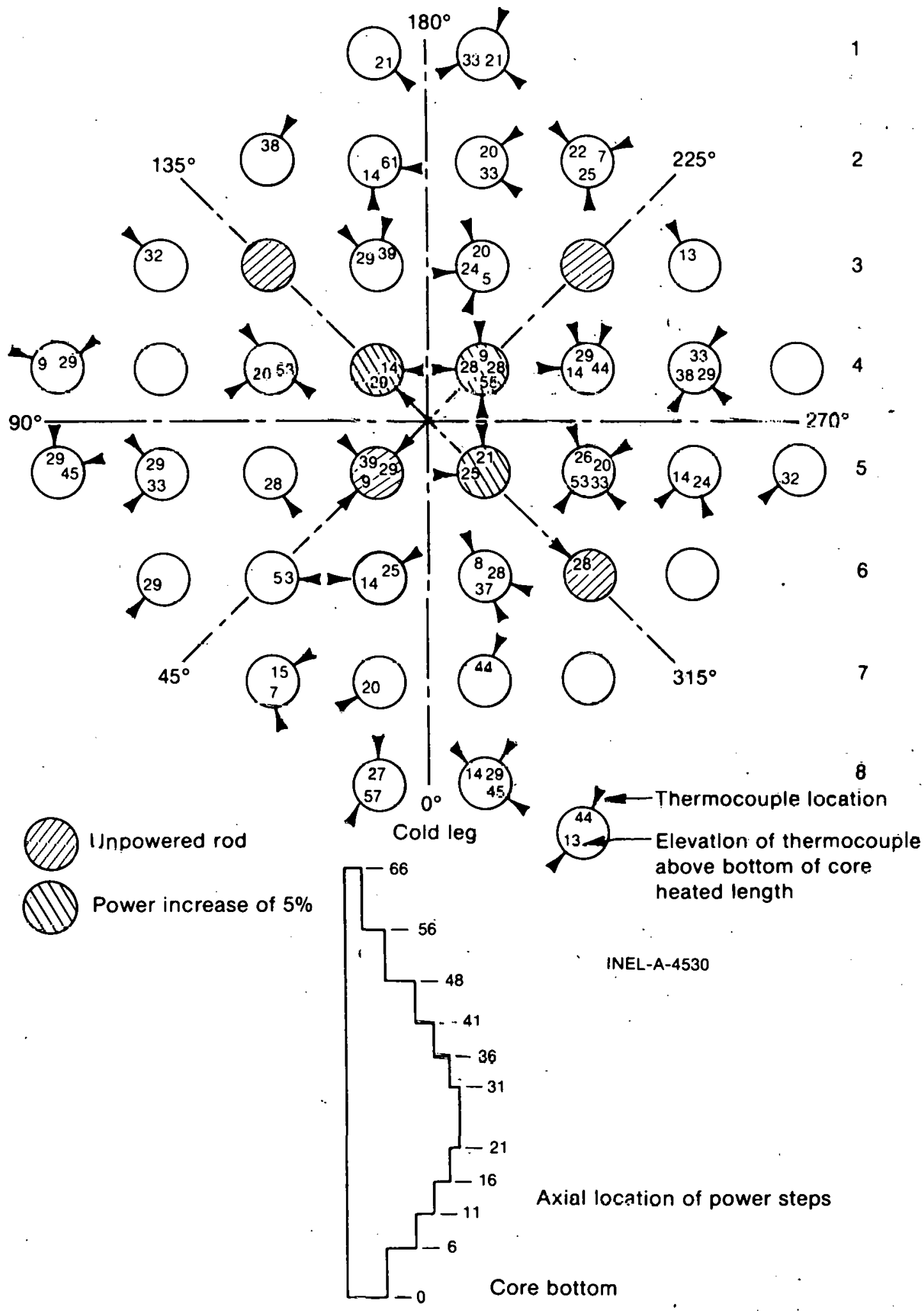

Fig. 10 Semiscale Mod-1 core - plan view with thermocouple locations. 


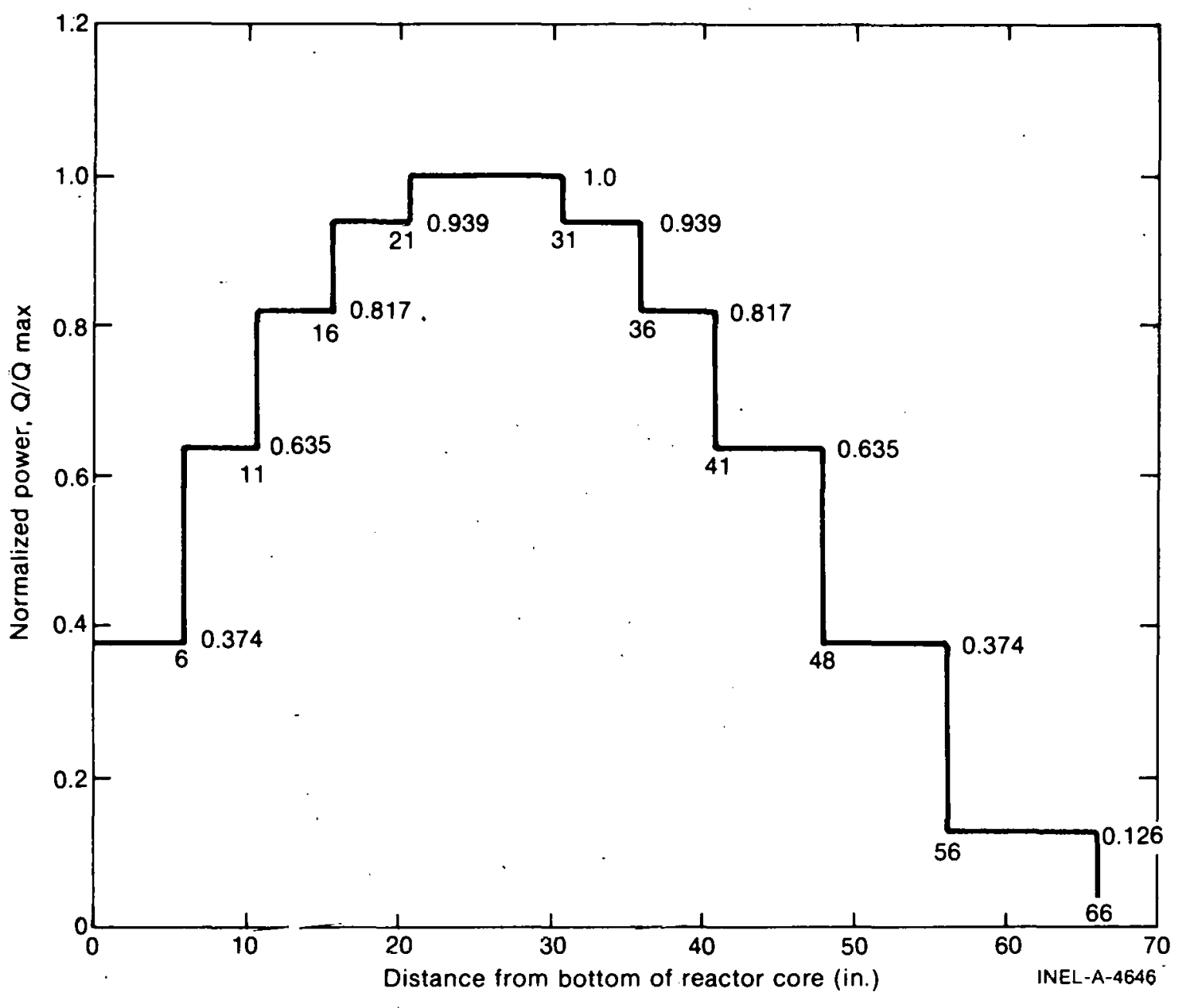

Fig. 11 Semiscalc Mod-1 heater rod axial power distribution.

\section{TEST PLAN}

The principal objective of the test series was to obtain data on the different ECC injection schemes from which a comparative analysis could be made to determine the relative merits of the different injection concepts. Each test investigated a particular concept which utilized different combinations of F.CC injection locations and rates. Each of the tests, utilizing an alternate ECC injection concept, was set up with essentially the same prerupture conditions as in an appropriate cold leg injection baseline test (either Test S-04-6 of Test Series $4^{[3]}$ or Test S-05-6 of the present test group). The transient core power control was also maintained constant among the alternate ECC injection tests and the baseline tests, and is shown in Figure 12. The electrical power control for the first $20 \mathrm{sec}$ following rupture was defined to allow simulation of the thermal response of a muclear rod with the electrical rods, and was determined by analytically matching the surface heat flux calculated for a nuclear rod, assuming that both rods were subjected to the same transient 


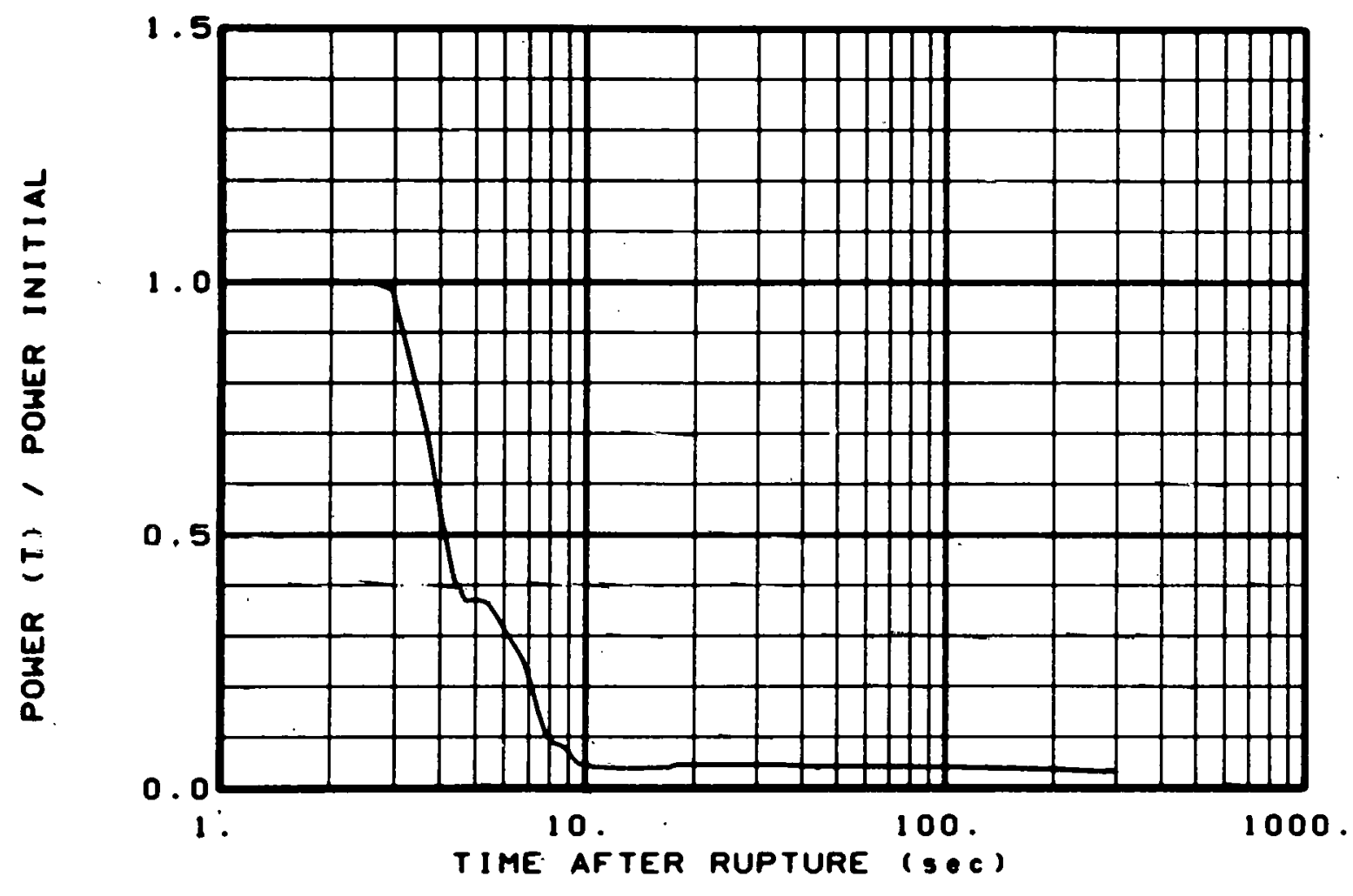

Fig. 12 Core power control for the alternate ECC injection tests and the cold leg baseline ECC injection test.

boundary conditions (obtained from test data). A detailed description of the technique used to determine the core power control is contained in Reference 4. The core power decay curve aftc1 $20 \mathrm{sec}$ is based on the Amcrican Nuclear Society (ANS) standard power decay curve ${ }^{[5]}$. With both the initial conditions and the core power control being held cssentially constant among tests, direct comparisons could bc made with only the F.C. injection concept as a variahle.

One test was conducted to investigate the concept of lower plenum injection. For this test (Test S-U5-1) ${ }^{[6]}$, all the ECC injection systems including the HPIS, accumulator, and LPIS injected directly into the Semiscale lower plenum. The ECC volumes and flow rates for this test were nearly the same as for the baseline cold leg injection test except for the accumulator volume, which was reduced by an amount to account for the elimination of the Semiscale hot wall delay. This hot wall delay, which is discussed in detail in Reference 7, is caused by heat transfer from the downcomer walls which generate steam, increase the downcomer fluid quality, and consequently the velocity of negative flow up the downcomer during the initial blowdown period. With cold leg ECC injection, the complex interaction between ECC and the blowdown fluids together with the steam generated at the downcomer walls, prevents ECC fluid from immediately entering the downcomer and results in bypass of ECC out the cold leg break, thereby delaying the delivery of water to the lower plenum. By reducing the amount of ECC injected into the lower plenum by an amount equal to that expected to be bypassed out the cold leg break during the baseline test, a direct comparison of the lower plenum injection and cold leg injection concepts was possible, since equivalent 
amounts of ECC were available for cooling the core. When the vessel accumulator water was completely discharged in the lower plenum injection test, the nitrogen in the accumulators was allowed to flow for about $27 \mathrm{sec}$ as in the baseline cold leg injection test. The test and prerupture conditions for the lower plenum injection test and for the other tests in this series are given in Table I.

Tests $S-05-3^{[8]}$ and S-05-4[9] were used to evaluate a second concept in which accumulator injection into the upper plenum was combined with ECC injection into the. intact and broken loop cold legs. In both tests, injection into the cold legs was initiated at the nominal set points for the ECC systems (Table I), and injection into the upper plenum was delayed until a system pressure of about 300 psi was reached to provide for injection well in to the reflood period. For the first test utilizing upper plenum accumulator injection, the vessel accumulator water volume was scaled from a PWR cold leg accumulator water volume according to the stored thermal energy content in the metal mass of the upper plenum relative to that for a PWR. An injection rate of approximately $16 \mathrm{gpm}$ was selected for this test to ensure very little net steam generation during the cooldown of the upper plenum structures. In the second upper plenum accumulator injection test the vessel accumulator water volume. was the same as that injected into the lower plenum during the previously discussed lower plenum injection test. The vessel injection rate in the second test was reduced relative to that of the first test to evaluate the effects of differences in injection rate on core thermal response and overall system behavior, and to maintain about the same total injection period. In both tests in which accumulator ECC was injected into the upper plenum, injection was terminated prior to the depletion of the accumulator water. Therefore, nitrogen from the accumulators did not inject into the Semiscale upper plenum region.

To investigate LPIS injection into the upper plenum combined with accumulator injection into the cold legs, two tests were conducted. The two tests were necessary because upper plenum LPIS injection is normally associated with two-loop PWRs. Since a $200 \%$ double-ended cold leg break in one loop of a two-loop PWR represents a larger break area than a similar break in one loop of a four-loop PWR, the scaled Semiscale break areas for this concept are larger than the corresponding break areas scaled from a four-loop PWR. The two tests were, therefore, required to separate the effects of the larger break area from the effects of LPIS injection into the upper plenum. The first test, Test S-05-6 ${ }^{[10]}$, employed accumulator and LPIS injection into the cold legs and provided baseline data for the two-loop representation. The injection locations for this test were identical to those used in the baseline test for the four-loop Semiscale representation; however modifications were made to the Mod-1 system to more closely represent a two-loop PWR. These modifications included additional hydraulic resistance in the intact loop, increased break flow area, and changes in ECC injection rates and volumes. The second test, designated Test S-05-7[10], differed from the first only in that in tact and broken loop LPIS was eliminated and instead the LPIS injection was into the upper plenum. This change in a single test parameter made possible an evaluation of the influence of upper plenum LPIS injection through comparative analysis.

Test S-05-5[11], investigated a concept which combined cold leg ECi' injection with venting of the upper plenum through the use of a vent line between the broken loop hot and 
TABLE I

TEST AND PRERUPTURE CONDITIONS FOR ALTERNATE ECC INJECTION TEST SERIES

Core power $(\mathrm{MW})^{[\mathrm{a}]}$

Intact loop cold leg fluid temperature $\left({ }^{\circ} \mathrm{F}\right)^{[\mathrm{a}]}$

Hot leg to cold leg temperature differential $\left({ }^{\circ} \mathrm{F}\right)^{[\mathrm{a}]}$

Steam generator feedwater temperature $\left({ }^{\circ} \mathrm{F}\right)^{[\mathrm{a}]}$

Steam generator liquid level (in.) ${ }^{[a, b]}$

Pressurizer pressure (psia) ${ }^{[a]}$

Pressurizer liquid volume $\left(\mathrm{ft}^{3}\right)^{[\mathrm{a}, \mathrm{c}]}$

Core flow rate $(\mathrm{gpm})^{[\mathrm{a}]}$

Pressure suppression system pressure $(p s i a)^{[a]}$

Intact/broken loop accumulator injection location

Liquid volume $\left(\mathrm{ft}^{3}\right)$
Injection rate $(\mathrm{gpm})[\mathrm{d}]$
Actuation pressure $(\mathrm{psia})$

Intact/broken loop LPIS injection location

Injection rate $(\mathrm{gpm})$
Actuation pressure $(\mathrm{psia})$

Intact/broken loop HPIS injection location

Injection rate $(\mathrm{gpm})^{[\mathrm{d}]}$

Actuation pressure (psia)

Vessel accumulator injection location

Liquid volume $\left(\mathrm{ft}^{3}\right)$
Injection rate $(\mathrm{gpm})$

Actuation. pressure (psia)

Prior to rupture.

Above bottom of tube sheet.

Based on average fluid density of $37.41 \mathrm{bm} / \mathrm{ft}^{3}$.

Average attained during test.
Set-point based on elapsed time after rupture $(25 \mathrm{sec})$.

147

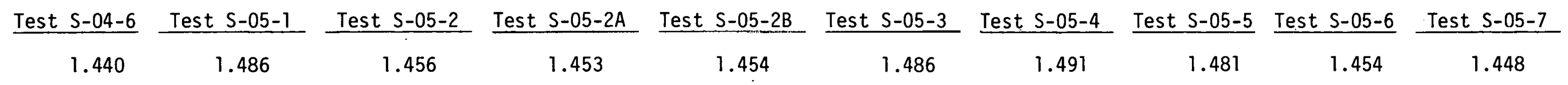

$\begin{array}{rcr}1.440 & 1.486 & \\ 543 & 544 & 5 \\ 67 & 65 & \\ 440 & 440 & 440 \\ 116 & 116 & 116 \\ 2252 & 2263 & 2263 \\ 0.58 & 0.61 & \end{array}$

543

$65 . \quad 68$

$440 \quad 437$

$116 \quad 115$

437

2263

35

149

35

$0.54-0.66$

146

35

$\begin{array}{ccccc}\text { Cold leg/ } & \begin{array}{c}\text { Lower plenum/ } \\ \text { not used }\end{array} & \begin{array}{c}\text { Pump suction/ } \\ \text { Spool 4pol 42 }\end{array} & \begin{array}{c}\text { Pump suction/ } \\ \text { Spool 42 }\end{array} & \begin{array}{c}\text { Pump suction/ } \\ \text { Spool } 42\end{array}\end{array}$

$1.454 \quad 1.486$

542

68

545

543

68

435

445

115

2272

440

111

118
2266

2263

0.67

0.61

0.54

537

550

551

72

59

58

445

117

400

106

400

2263

2263

109

$144 \quad 151$

144

$2.83 / 0.4$
$23.0 / 7.8$
$595 / 600$

$\begin{array}{rr}2.9 / 1.0 & 2.6 / 1.1 \\ 18.8 / 8.0 & 24.0 / 8.0 \\ 597 / 600 & 597 / 602\end{array}$

609

$597 / 600$

$597 / 602$

$2.9 / 0.9$

$25.9 / 0.9$
$596 / 600$

Cold leg/

Spool 42

Spool 42

$4.7 / 1.17$
$160 / 170$

$$
4.7
$$

$4.7 / 1.16$
$170 / 130$

Not used

Not used/
not used

Not used/
not used

not used Spool 42

$\begin{array}{ccc}1.3 / 0.6 & 0.5 & 0.6 / 0.6 \\ 1800 / 1800 & 1800 & 1800 / 1800\end{array}$

Not used Not used Not used

Not used

Not used
35

35

Cold leg/
Spool 42

$2.7 / 0.2$
$23.0 / 7.5$

$23.0 / 7.5$
$594 / 600$

r.nld leg/

Spool 42

$2.7 / 1.0$
$20.5 / 9.8$

$20.5 / 9.8$
$597 / 597$

conit leg/

Spoul 42

$4.7 / 1.17$
$165 / 140$

$4.7 / 1.15$
$160 / 110$

Cold leg/ Cold leg/

Cold leg/
Spool 42

$0,9 / 0,8$

$1.0 / 0.7$

$1800 / 1800$

Upper plenum Upper plenum

$\begin{array}{cc}2.6 & 4.4 \\ 8.4 & 16.0 \\ 300 & 308\end{array}$


cold legs. Although this vent line was core area scaled from a PWR to give an equivalent resistance approximating a PWR vent system, the Semiscale vent location between the broken loop hot and cold legs differed from that of a typical PWR with venting between the upper plenum and downcomer inlet annulus. In addition to a control valve to set the desired flow resistance, the vent line also included a check valve which permitted flow from the broken loop hot leg to the broken loop cold leg to develop when the pressure in the upper plenum region exceeded that in the downcomer annulus, but which prevented flow in the opposite direction. In Test S-05-5 the cold leg ECC injection was nearly identical to that used in the baseline test, allowing a direct assessment of the effect of the vent line on system behavior and core thermal response.

Finally, three tests were conducted to investigate the effectiveness of ECC injection into the pump suction leg, with pump speed being the major parameter varied between the tests. Two of the tests (Tests S-05-2A and S-05-2B) ${ }^{[12]}$ were bounding cases designed to evaluate the concept effectiveness at the extreme of expected pump speed profiles. The first limiting case (Test S-05-2A) was that of the pump running at essentially the prerupture speed throughout the transient, whereas the second limiting case (Test S-05-2B), simulated loss of pump power at the time of rupture, followed by pump coastdown to a stop. The coastdown pump speed profile of the second case was similar to the calculated coastdown of a PWR pump with pump suction injection. The third pump speed profile investigated (Test S-05-2) ${ }^{[13]}$, was a pump coastdown to $64 \%$ of the initial prerupture pump speed. This pump speed profile was the same as that used with other injection concepts and, therefore, provided a means for direct comparison where required. Whereas the pump speed profile was varied among the tests, the ECC injection rates and volumes remained constant at about the same values used in the investigation of cold leg injection alone (Table I). The only significant change in the injection parameters among the three pump suction ECC injection tests was the LPIS injection location which, as discussed in the previous section, was at the pump suction leg in the investigation of one of the pump speed profiles (Test S-05-2), and at the intact loop cold leg in the remaining two investigations (Tests S-05-2A and S-05-2B). This change in the LPIS injection scheme, while maintaining accumulator ECC injection into the pump suction, permitted an assessment of the effect of the LPIS injection location on the overall effectiveness of this concept, but did not influence the early system behavior or the evaluation of pump behavior on system response and core cooling effectiveness. 


\section{ANALYSIS RESULTS}

The following sections present an evaluation of each of the four alternate ECC injection concepts investigated in the Semiscale Mod-l system. This evaluation was accomplished primarily through comparative analysis of experimental results from application of each alternate ECC injection concept with results acquired for the baseline cold leg injection concept. In addition to the comparative analyses, which in some cases involved the use of data from more than one test for a given ECC injection concept, analytical studies were also conducted using the RELAP4 ${ }^{[14]}$ and FLOOD4 ${ }^{[15]}$ computer codes. The analytical studies were made to extend the usefulness of the experimental investigations by identifying parametric trends in the test data, and where possible, by predicting the effect of changes in important system variables on major system thermal and hydraulic behavior. As a result of the testing and analysis of the different ECC injection concepts, the major system phenomena as well as the potential benefits associated with each concept have been identified. In addition, the relative merits of each concept have been defined and an ordering of the concepts in terms of their relative effectiveness in the Semiscale test facility has been-established. However, since several factors unique to Semiscale may have influenced the results, conclusions reached relate specifically to the Semiscale Mod-1 system and, therefore, care should be exercised in applying these results to a full sized PWR.

The following sections discuss the overall core cooling effectiveness, the major controlling system phenomena which contributed to this core cooling, and the relative merits and overall effectiveness of (a) lower plenum ECC injection, (b) combined upper plenum ECC injection, which includes both accumulator and LPIS upper plenum ECC injection concepts, (c) cold leg ECC injection with broken loop hot leg venting, and (d) pump suction injection.

\section{LOWER PLENUM ECC INJECTION}

Evaluation of the lower plenum ECC injection concept was accomplished through a comparative analysis of experimental results obtained with lower plenum injection relative to those obtained with cold leg ECC injection. For the lower plenum ECC injection concept, ECC injection rates and volumes were nearly identical to those used for the cold leg ECC injection concept except for the accumulator injection volume, which was reduced by an amount to account for the elimination of the Semiscale hot wall delay. In this way the effect of ECC injection location could be isolated because the injection location was effectively the single variable between the two experimental investigations.

The concept of lower plenum injection offered a means for more direct delivery of ECC to the core and is less affected by complex system interactions than are the other injection concepts investigated. Specifically, the core cooling effectiveness of the lower plenum injection concept is less influenced by hydraulic behavior and system response related to 
downcomer and loop piping phenomena because of the closeness of the injection point to the bottom of the core. Therefore, lower plenum injection could result in early delivery of ECC to the core because the delay in ECC penetration of the downcomer caused by countercurrent flow and downcomer hot wall effects was eliminated. The combination of these factors provided the possibility of very early refill of the lower plenum and the initiation of early core reflood which could result in effective cooling of the core.

Despite the potential for good core cooling with lower plenum injection, the possibility also existed that adverse system behavior could result in periods of ineffective core cooling. Specifically, the existence of relatively high reverse core flows during the early injection period could result in sweepout of ECC from the lower plenum during the lower plenum filling process, resulting in poor initial core cooling. Also, when nitrogen injection in to the lower plenum was initiated (after the vessel accumulator was exhausted), mass depletion of the lower plenum and downcomer could occur. Either of these events could result in poor core cooling and high heater rod temperatures.

Each of the described potential advantages and disadvantages were addressed in the analysis and evaluation of this ECC injection concept. The following sections discuss the core thermal response which occurred in the lower plenum injection test and the system behavior which contributed to the core thermal response characteristics.

\subsection{Core Thermal Response}

Injection of ECC into the lower plenum region of the Semiscale test system resulted in an early and rapid quenching of the entire core. The temperature traces in Figure 13 show the rapid quenching which occurred on a single rod at three elevations of the core and are typical of others throughout the core. With lower plenum injection the entire Semiscale core was quenched by $52 \mathrm{sec}$ after rupture. The rod cladding temperatures decreased to below the system saturation temperature indicating most of the core was filled with subcooled liquid immediately after the core quenching process was completed. In contrast to the rapid core quenching that occurred with lower plenum injection, the core hot spot with cold leg injection only did not quench until $242 \mathrm{sec}$ after rupture, and one measurement location above the core hot spot had not quenched by 300 sec after rupture.

The early and effective core cooling with lower plenum injection appeared to be caused by substantial amounts of liquid which were entrained in the positive core flow. The existence of entrained liquid in the core flow is indicated in Figure 14 by the early quenching of many locations in the upper core regions prior to the quenching of the core hot spot.(21- to 31-in. elevations). Furthermore, at about $25 \mathrm{sec}$ after rupture, heat transfer coefficients calculated from thermocouple measurements at the 29-in. elevation were oscillatory in nature, and peak values in excess of $20 \mathrm{Btu} / \mathrm{hr}-\mathrm{ft}^{2}{ }^{\circ}{ }^{\circ} \mathrm{F}$ corresponded to periods of positive core flow. The peak magnitudes of the calculated heat transfer coefficients, which corresponded to the positive core flow periods, are indicative of dispersed flow heat transfer at the 29 -in. core elevation, supporting the conclusion that substantial entrainment occurred. Appendix A discusses the details of these heat transfer calculations which were performed as part of the analysis of the lower plenum injection concept. 


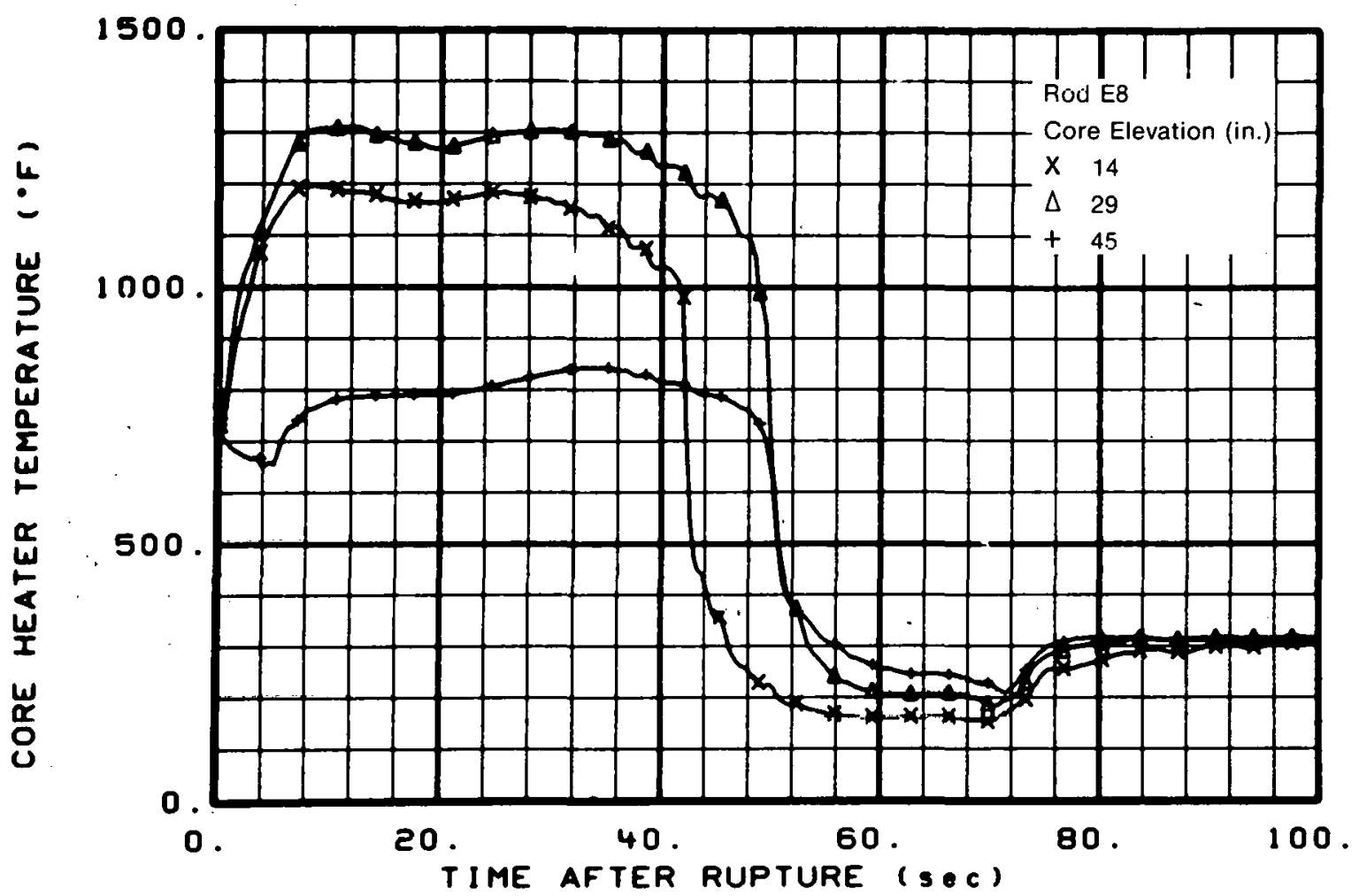

Fig. 13 Heater rod temperature response demonstrating the rapid quench of three core elevations in the lower plenum ECC injection test.

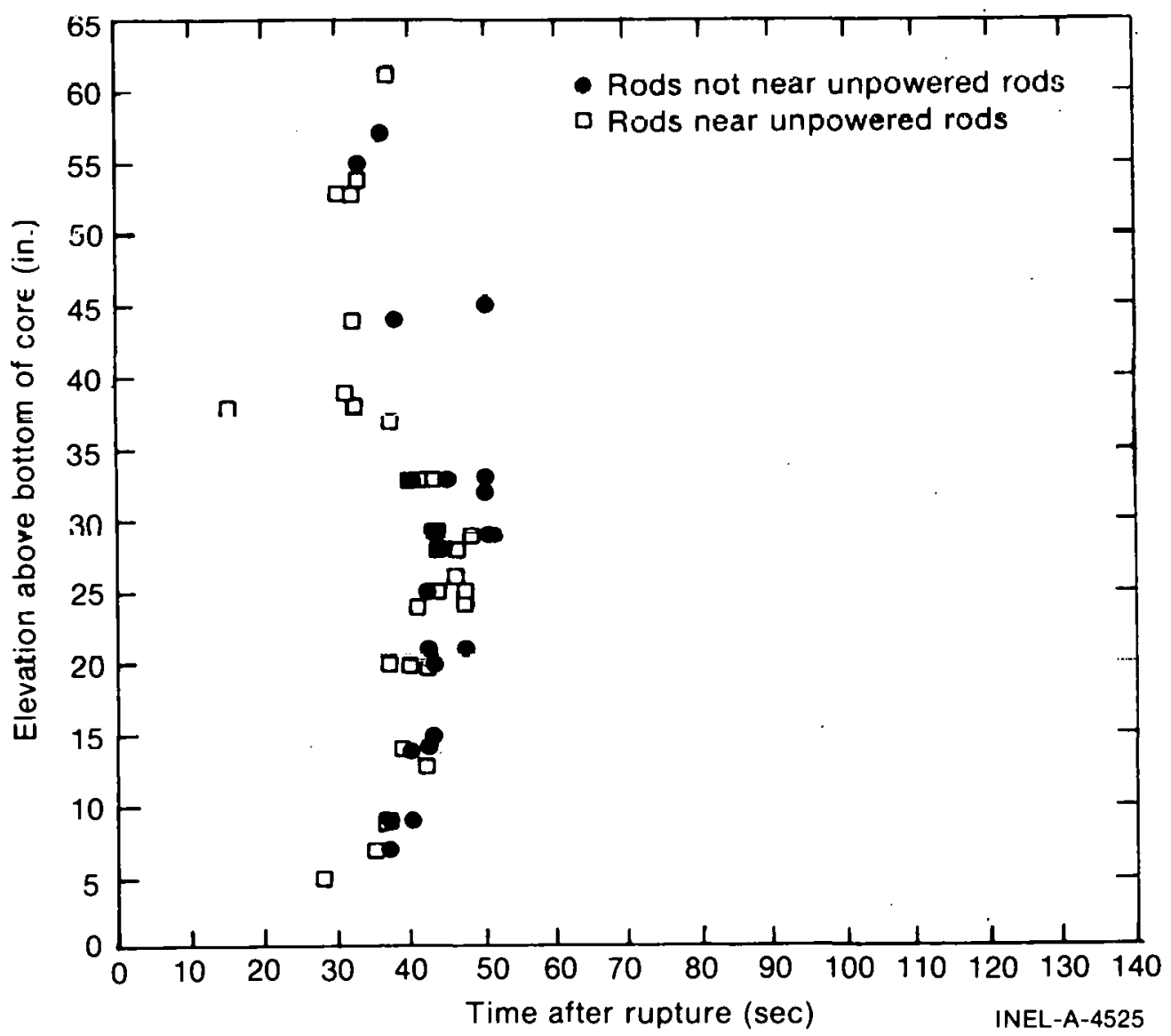

Fig. 14 Rod quench times for lower plenum ECC injection. 
The core thermal response did not appear to be substantially affected by the flow of nitrogen in the lower plenum following accumulator exhaustion. The core had entirely quenched prior to nitrogen injection into the vessel at about $70 \mathrm{sec}$ after rupture, and the increase of about $100^{\circ} \mathrm{F}$ in the rod cladding temperature, at about the time nitrogen flow in to the vessel started (Figure 13), appears to correspond to an observed increase in system pressure. However, the core remained quenched and no dryout at any of the core elevations was observed during this period.

\subsection{System Behavior Contributing to Core Thermal Response}

The very good core cooling effectiveness which was obtained with lower plenum injection is directly related to the early filling of the lower plenum to a level above the bottom of the core barrel, which provided the source for the liquid entrainment discussed in the previous section. This early filling of the lower plenum is apparent from the core inlet density measurement shown in Figure 15. This figure shows that the core inlet was covered with water by $23 \mathrm{sec}$ after rupture and remained covered during the accumulator injection period. The early filling of the lower plenum had a secondary effect in that it altered the initial core hydraulic behavior somewhat and resulted in a small increase in core temperatures prior to reflood (discussed in Appendix A). However, the observed differences in heater rod temperature response (relative to the baseline cold leg injection results) did not influence the overall cooling effectiveness of the lower plenum injection concept.

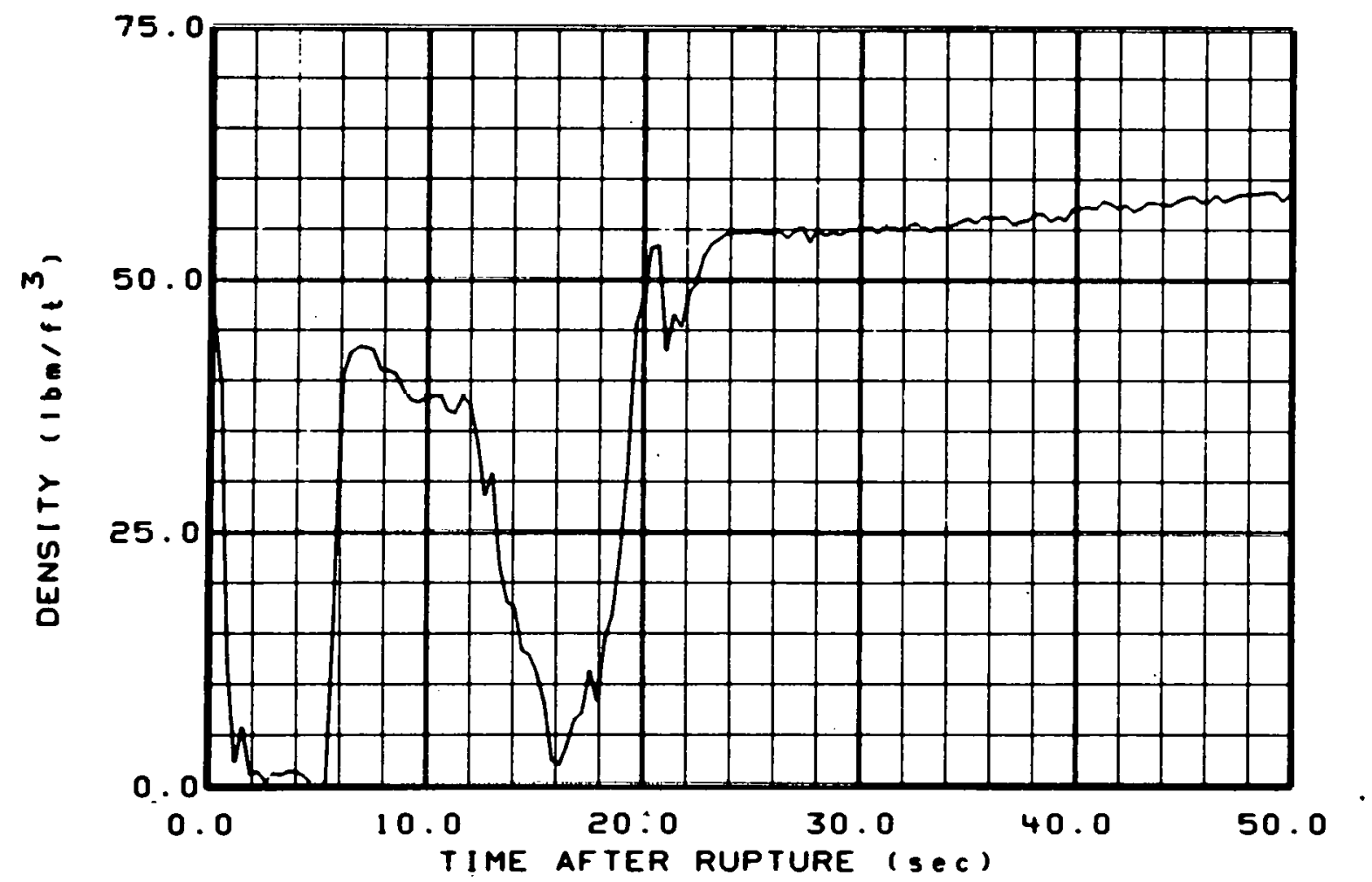

Fig. 15 Core inlet density for lower plenum ECC injection test - measured at bottom of core barrel. 
The early refill and subsequent early initiation of reflood occurred because the use of lower plenum injection eliminated the usual countercurrent flow delay experienced with cold leg injection, and also eliminated the Semiscale hot wall delay. Without the hot wall and countercurrent flow delays, filling of the lower plenum to the bottom of the core barrel and the subsequent initiation of core reflood occurred about $23 \mathrm{sec}$ after rupture compared with $60 \mathrm{sec}$ after rupture for cold leg injection.

The early initiation of core reflood allowed the reflood process to start when the system pressure was relatively high (200 psi compared with 35 psi for cold leg injection), which affected the reflooding process in two ways. First, the higher steam density associated with the higher steam pressure allowed a rapid reflood of the core with a smaller downcomer head because the increased fluid density at the higher pressure resulted in a smaller volume of steam being generated in the core. With a smaller volume of steam to be removed from the core, less downcomer head was required to drive the reflood process. With a given injection rate and less mass storage in the downcomer more coolant was available to the core.

The second way in which the higher system pressure affected the core reflood process was that it resulted in improved core heat transfer. As noted in other reflood tests ${ }^{[16]}$, reflood at higher pressures has been shown to result in increased heat transfer rates relative to those at lower pressures because of changes in the fluid properties. Also, as noted in the previous discussion of core thermal response, the higher core heat transfer was aided by entrainment of liquid from the lower plenum and carryover through the core. This carryover of ECC through the core is indicated by the increased broken loop hot leg density shown in Figure 16 which occurred between 45 and $70 \mathrm{sec}$ after rupture.

The rapid reflood of the core at a high system pressure contributed to the very effective core cooling and also resulted in a sufficient rate of steam production which tended to maintain the high system pressure. Therefore, the high pressure reflood and core quenching process prior to nitrogen injection tended to be self-sustaining.

The flow of nitrogen into the lower plenum following accumulator exhaustion caused significant mass depletion in both the downcomer and the core but did not have a major effect on the core thermal response in the Semiscale Mod-1 system. Nitrogen injection began about $70 \mathrm{sec}$ after rupture and lasted for approximately $24 \mathrm{sec}$. The nitrogen flow forced water up the downcomer and predominantly out of the broken loop cold leg resulting in the loss of a substantial fraction of the water initially in the downcomer and lower plenum. Very little if any of the nitrogen appeared to enter the core, but the downcomer mass depletion induced a reduction in the core liquid level. Because of the mass reduction in the core the subcooled fluid conditions existing before nitrogen injection were not maintained (Figure 13). Although enough liquid remained in the core to prevent dryout, and high temperatures did not result, the fluid in the core did become heated to saturation. The first five seconds of nitrogen injection were also accompanied by a rise in system pressure, probably caused by the pressurizing effects of the nitrogen and by steam generation on hot surfaces in the upper plenum. However, the instrumentation in the upper plenum region was insufficient to determine whether nitrogen pressurization or steam generation was the major contributor to the increase in system pressure. 


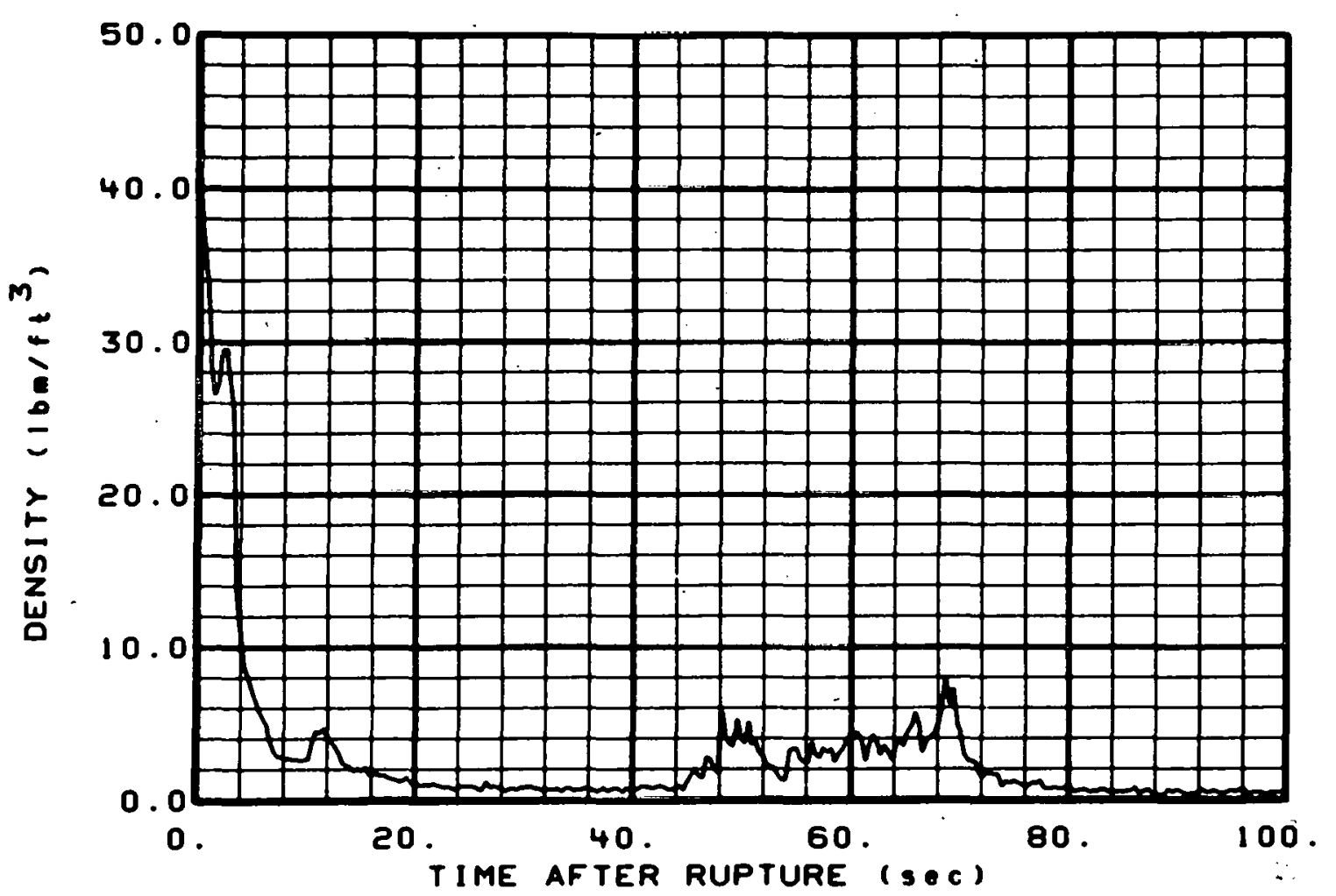

Fig. 16 Density in the broken loop hot leg next to vessel for the lower plenum ECC injection test.

Although lower plenum injection proved to be very effective in cooling the Semiscale core, several factors were noted which are unique to Semiscale which may influence the apparent merits of lower plenum injection relative to that of cold leg injection. These factors are discussed in the following section.

\subsection{Factors Specific to the Semiscale Mod-1 System that may Influence Results}

Among the factors which are unique to the Semiscale Mod-1 system and which could influence the effectiveness of the lower plenum injection concept are the core length and the system break size. Both of these factors must be taken into account in the interpretation of the Semiscale results with respect to a full scale PWR.

The Semiscale Mod-1 system has a 5.5-ft core compared with the $12-\mathrm{ft}$ core of a ty pical full sized PWR. A FLOOD4 calculation for a 12-ft core using lower plenum injection (discussed in Appendix A) shows that quenching would not be complete before the initiation of nitrogen injection. Therefore, when mass depletion occurs in the longer core, following the initiation of nitrogen flow into the vessel, dryout of the core and high fuel rod temperatures could be expected to result.

The system break size contributed to the maintenance of a high system pressure during reflood which in turn contributed in some degree to the good core cooling effectiveness. The break size was volume scaled to a PWR to yield the proper blowdown 
behavior. However, during reflood, core area scaling would be more appropriate and in Semiscale would result in a larger break area. Therefore, the smaller break area used in the test contributed to the maintenance of a high system pressure which contributed to the good heat transfer and effectiveness of the lower plenum ECC concept.

\subsection{Assessment of Effectiveness of Lower Plenum Injection in the Semiscale Mod-1 System}

Injection of ECC into the lower plenum region of the Semiscale Mod-1 system proved to be the most effective of any of the alternate ECC injection concepts investigated. The effectiveness of this concept appeared to rely on relatively simple mechanisms that were independent of complex system interactions which affected other ECC injection concepts. However, the significant benefits of early and effective core cooling with this concept may have been somewhat exaggerated by the direct comparison with cold leg injection in the Semiscale Mod-1 system.

The factors unique to Semiscale which may have exaggerated the effectiveness of lower plenum ECC injection compared with cold leg ECC injection, were (a) the Semiscale hot wall delay, (b) the break area scaling, and (c) the short core length. The hot wall delay increased the difference in reflood time between cold leg and lower plenum injection. The volume scaled break contributed to the high system pressure and, therefore, to good core cooling. Finally, the short core allowed complete quenching of the heater rods before nitrogen injection in to the lower plenum was initiated.

Despite these factors which may have exaggerated its effectiveness, lower plenum ECC injection still appears to be very effective based on the very good core cooling which was attained. However, this concept may require care in practical application to a PWR because rupture of the injection line itself could represent a serious LOCA.

\section{UPPER PLENUM INJECTION}

Two different ECC injection approaches were investigated in the study of the overall effectiveness of the upper plenum ECC injection concept. The first approach investigated, employed upper plenum accumulator injection combined with cold leg ECC injection. The second approach investigated, utilized the LPIS to inject ECC into the upper plenum and the accumulators to inject ECC into both the intact and broken loop cold legs. Although the latter concept could be applicable to a four-loop PWR, it has generally been associated with two-loop plants.

Two essentially independent investigations were performed. The effectiveness of upper plenum accumulator injection coupled with cold leg ECC injection was investigated experimentally with the Semiscale Mod-1 system in the standard four-loop configuration. The effectiveness of this concept was then evaluated by comparative analysis relative to the 
baseline four-loop investigation with cold leg ECC injection alone. The results from the investigation of upper plenum accumulator injection were directly comparable with those of the other alternate ECC concepts because they also uttlized the Semiscale Mod-1 system in the four-loop test configuration.

The effectiveness of upper plenum LPIS injection combined with cold leg ECC injection was investigated with the Semiscale Mod-1 system modified to represent a two-loop plant configuration. For this configuration, differences in experimental results relative to other investigations were not entirely the result of variations in ECC injection parameters, but were also related to the break scaling and flow resistance distribution necessary to represent the two-loop application of the concept. To assess the effect of the two-loop plant scaling on system behavior required an additional experimental investigation in which data from the Semiscale Mod-1 system in the two-loop configuration with cold leg ECC injection only was evaluated by a comparative analysis with results from the baseline four-loop test with cold leg injection. In this way, system response differences due to the experimental break size and flow resistance distribution could be assessed. The effects of the upper plenum LPIS injection on system behavior and core thermal response were evaluated separately by a comparative analysis with results from a subsequent test in which the only variable changed was the LPIS injection location which was moved from the intact loop cold leg to the upper plenum region.

The following sections present the results of the investigation of the concept employing upper plenum accumulator ECC injection. The results of upper plenum LPIS injection are then presented, and evaluated with respect to the effect of both the break size and the injection location on the observed Semiscale system behavior.

\subsection{Upper Plenum Accumulator Injection}

The major operating parameter varied in the study of accumulator ECC injection into the upper plenum combined with ECC injection into the intact and broken loop cold legs was the upper plenum injection rate. Two different injection rates were used in the investigation. The first injection rate was selected to limit steam generation caused by the cooldown of the upper plenum structures during the initial injection period. For this case the volume of ECC injected into the upper plenum from the accumulator was scaled according to the stored thermal energy of the metal structures in the Semiscale upper plenum relative to that estimated for a full sized PWR. This scaling approach resulted in an average ECC injection rate into the upper plenum of approximately $16 \mathrm{gpm}$ for a period of about $120 \mathrm{sec}$.

The second injection rate was specified so that over about the same injection period the total volume of ECC injected in to the upper plenum would essentially equal the volume of ECC injected into the vessel during the investigation of lower plenum injection. This approach provided a means for direct comparison of the effectiveness of the upper plenum and lower plenum ECC injection concepts. The specification of the injection time and total injected volume for the second upper plenum accumulator injection test resulted in an injection rate of about $8.4 \mathrm{gpm}$, which is approximately half the previous upper plenum accumulator injection rate. 
The following sections discuss both the effect of upper plenum accumulator injection rate on the core thermal response, and the major system behavior which led to this response. The emphasis is placed on identifying and examining behavior specifically related to the injection concept and on the significance of the change in injection rate.

2.1.1 Core Thermal Response. The major effects of accumulator ECC injection into the upper plenum region of the Semiscale Mod-1 system were the early and predominantly top down core cooling and quenching process which occurred, and the distinctly different thermal behavior in the upper and lower portions of the core. The top down quenching process is evident in the overlay of temperatures at the 9-, 29-, and 39-in. elevations for heater Rod A4 shown in Figure 17, and in the overlay of temperatures at the 8-, 28-, and 37-in. elevations for heater Rod E6 shown in Figure 18, for an injection rate of $8.4 \mathrm{gpm}$. Both figures show that the quenching of the rods starts at the upper elevations and progresses to the lower elevations. The top down quenching process is also shown in the quench time plots in Figures 19 and 20 for accumulator injection rates of $16 \mathrm{gpm}$ and $8.4 \mathrm{gpm}$, respectively. However, although the plots show that the quenching process was predominantly top down, in both cases, the thermal response in the upper and lower portions of the core were very different.

The cooling of the upper portions of the core was rapid and exhibited a strong top down characteristic which was relatively independent of upper plenum injection rate for the two injection rates investigated. The effectiveness of the cooling of the upper regions of the core is indicated by the relatively early quench times and the steep slope of the plotted

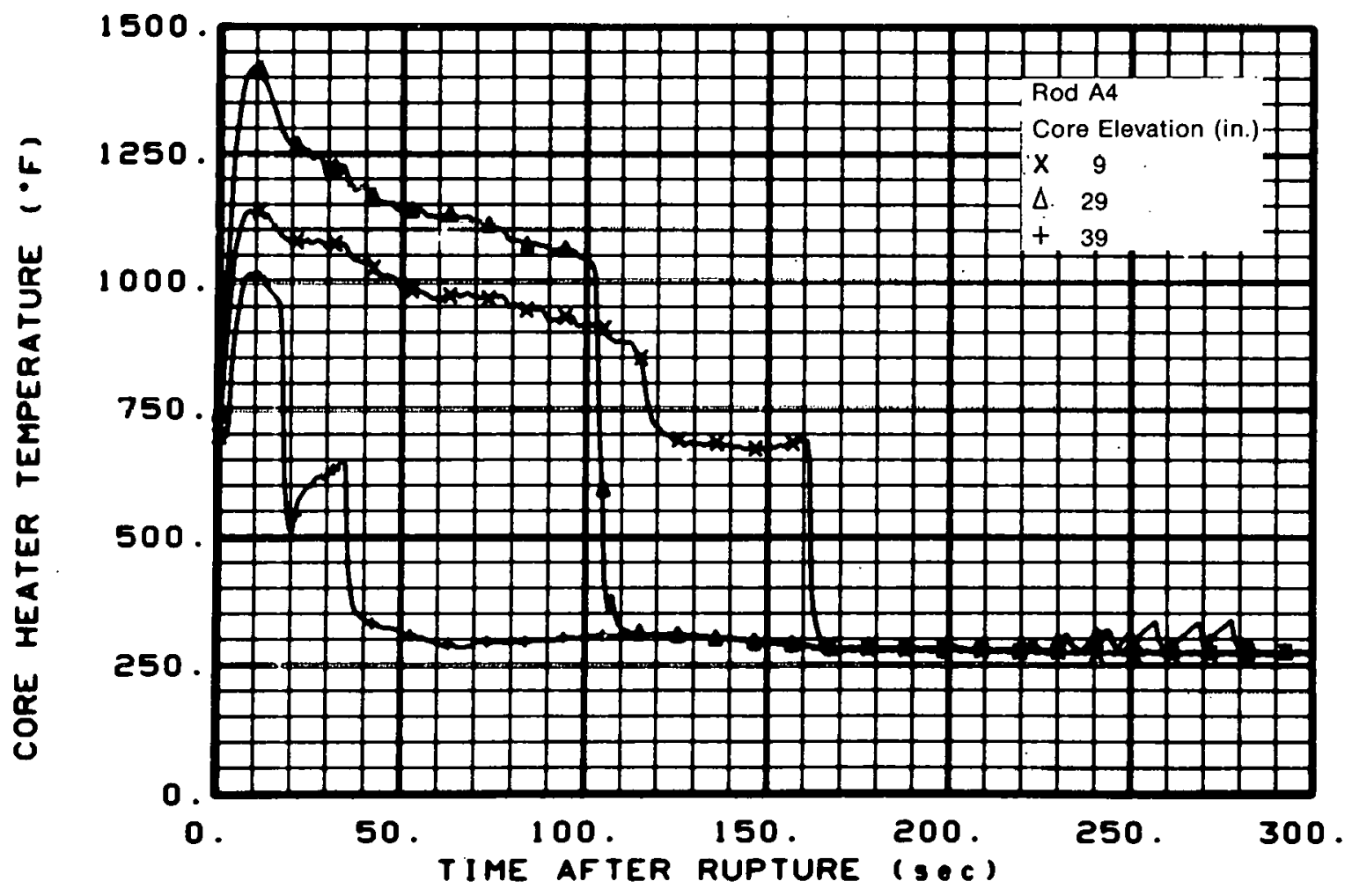

Fig. 17 Rod cladcing temperature response at the 9-, 29-, and 39-in. elevations for $u_{1}$ jer plenum ECC injection rate of $8.4 \mathrm{gpm}$. 


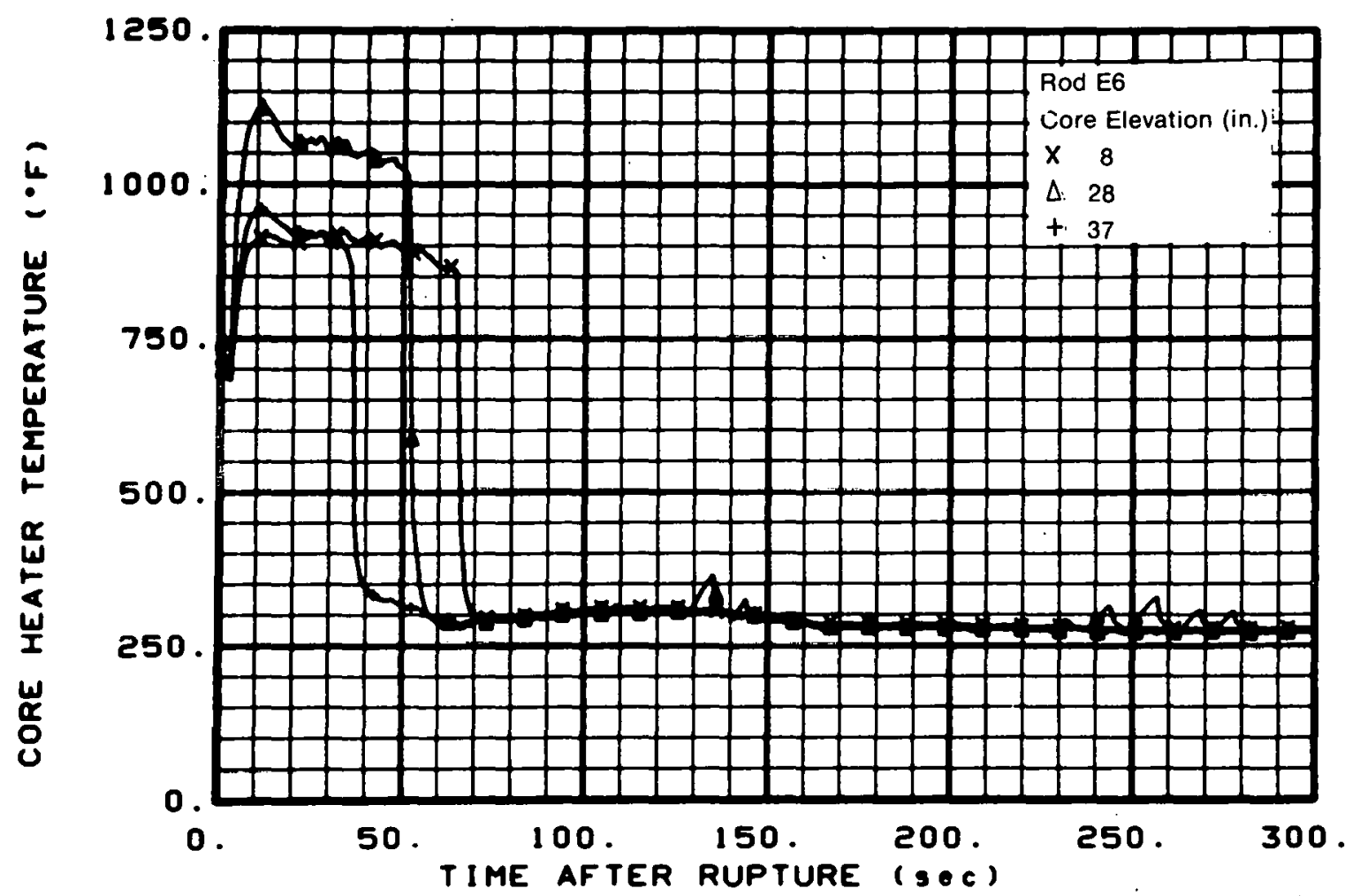

Fig. 18 Rod cladding temperature response at the 8-, 28-, and 37-in. elevations for upper plenum ECC injection rate of $8.4 \mathrm{gpm}$.

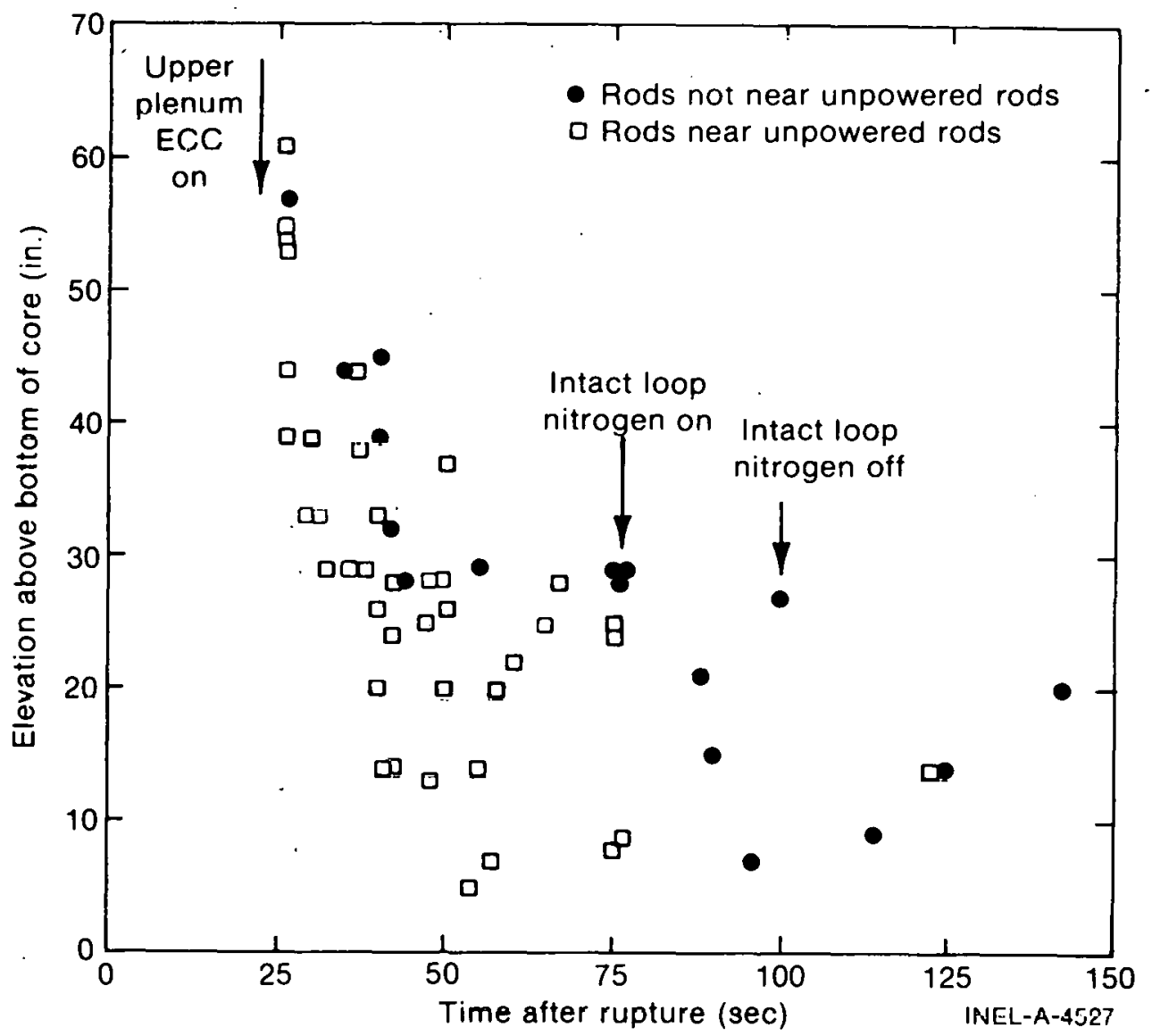

Fig. 19 Rod quench times for upper plenum ECC injection rate of $16 \mathrm{gpm}$. 


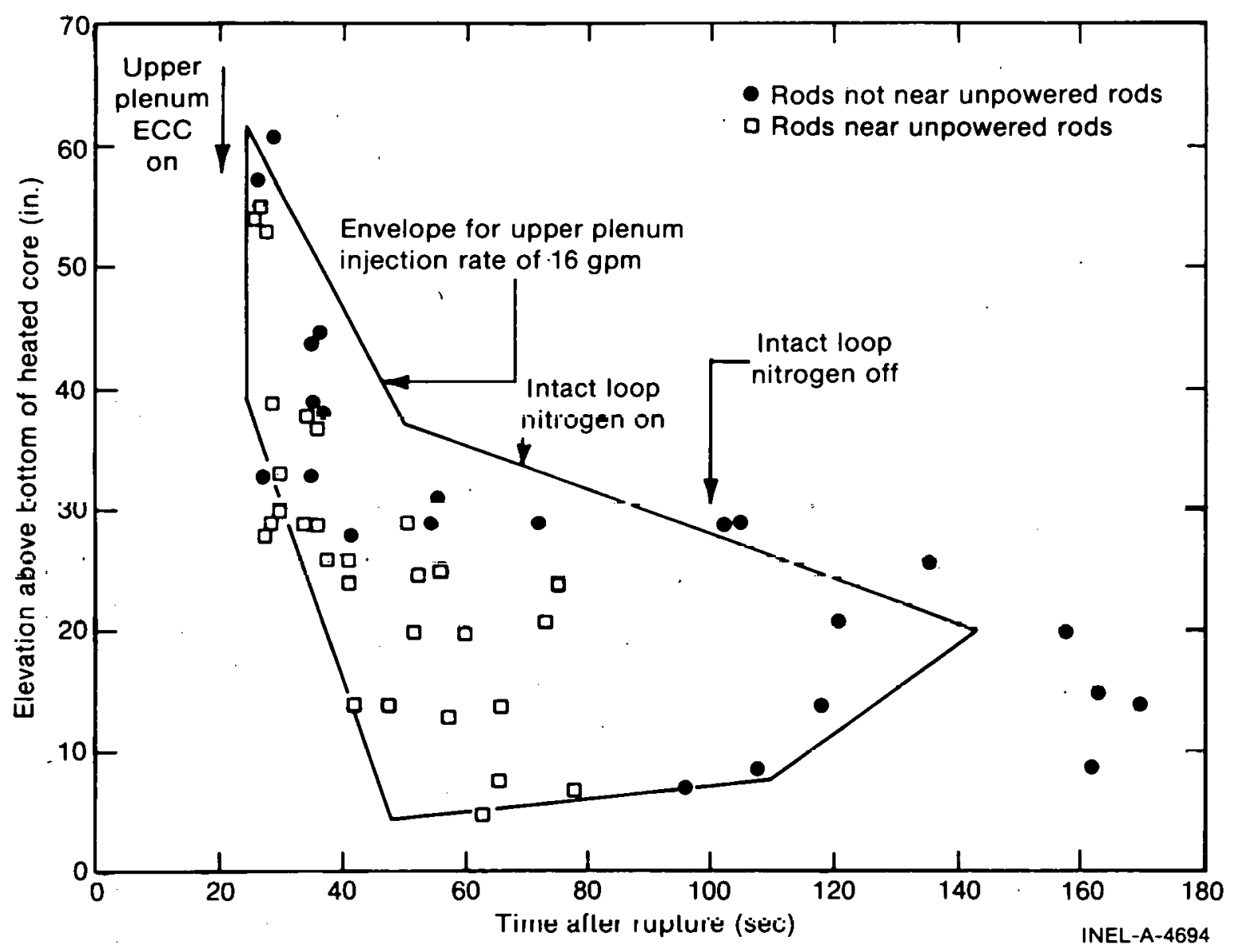

Fig. 20 Rod quench times for upper plenum ECC injection rate of $8.4 \mathrm{gpm}$ with overlay quench times envelope for injection rate of $16 \mathrm{grm}$.

quench points above the 29 -in. elevation. Evidence that the quench front appeared to progress from the top of the core to the 29-in. elevation independent of injection rate can be seen in Figure 20 which shows that the majority of quenches above the 29 -in. elevation for the smaller vessel accumulator injection rate fall within the envelope of quench times for the higher injection rate.

The progression of the quench front down through the upper portions of the core also appeared to be relatively uniform. No tendency was observed for preferential channeling of flow in regions of the core containing unheated rods which had been observed with cold leg injection alone. The one-dimensional flow characteristics in the higher elevations of the core (above the 29-in. elevation) with upper plenum accumulator injection are apparent from an examination of Figures 19 and 20, where rods near unpowered rods exhibited no particular preference for earlier quenching when compared with those rods not near unpowered rods.

The heater rod thermal response of the lower portion of the core (below the core hot spot elevation) differed from that in the upper portion both in the degree to which the top down cooling characteristic was in evidence and in the rate of the quenching process. The plotted quench times in Figures 19 and 20 show that much more scatter in the quench data 
occurred below the 29-in. elevation, and the strong top down quenching observed in the upper core elevations was not as apparent below the 29-in. core elevation.

The marked reduction in the slope of the average quench times below the 29-in. core elevation is indicative of the reduced cooling and the slower quench rate which occurred in the lower core elevations. The slower quenching process in the lower portions of the core (relative to that in the higher core elevations), particularly with the smaller upper plenum ECC injection rate, is significant because the axial power profile was skewed towards the bottom of the core with the peak power density occurring between the 21- and 31-in. elevations. Therefore, ineffective cooling of the lower elevations of the core could result in higher maximum core temperatures despite the good core cooling provided the upper portions of the core. However, these high temperatures did not occur within the range of upper plenum injection rates investigated because in each case the quantity of ECC fluid delivered to the core was sufficient to provide effective cooling even at the lower core elevations. As a result, the concept with upper plenum accumulator injection was able to provide better cooling in the lower portions of the core than was achieved with cold leg ECC injection alone.

Another way in which the behavior in the lower core regions differed from that in the upper regions was that an increased tendency was observed for earlier quenching of rods adjacent to unpowered rods in the lower portion-of the core. This preferential quenching of rods near unpowered rods is shown in Figures 19 and 20 by the consistently shorter observed quench times for rods near unpowered rods compared with the quench times of rods not near unpowered rods. As a specific example of the preferential quenching, comparison of the relative quench times between Rod A4 (Figure 17), which is not near an unpowered rod, and Rod E6 (Figure 18) which is adjacent to an unpowered rod, shows that Rod E6 quenched sooner at elevations below the core hot spot than did Rod A4, indicating preferential quenching of those rods near unpowered rods at the lower core elevations.

Finally, below the core hot spot elevation the quenching process did appear to be somewhat sensitive to the upper plenum accumulator injection rate. The overlay of quench times for the smaller upper plenum injection rate with the envelope of the quench times for the larger injection rate (Figure 20) shows that with the lower injection rate, quenching of the lower portions of the core was slower. This slower quenching is believed to be because less ECC fluid was available at the lower core elevations for the lower injection rate, which resulted in delayed quenching of the hotter rods (not near unpowered rods). Therefore, the preferential flow of ECC fluid down regions of the core containing unpowered rods appears more pronounced in the lower core elevations with the smaller upper plenum accumulator injection rate. A more detailed description of the core quench phenomena observed at the lower core elevations is contained in the discussion of upper plenum accumulator injection in Appendix B.

Overall, the distinctly different thermal response of the upper and lower portions of the core indicates that different controlling phenomena were in effect during different periods in the transient. The following section examines the system behavior which is 
related to the observed differences in the core thermal behavior, and by this process identifies the major controlling phenomena which determine the effectiveness of the upper plenum accumulator injection concept.

2.1.2 System Behavior Contributing to Core Thermal Response. The analysis of the system thermal-hydraulic phenomena indicated that the effective core cooling, demonstrated by the core thermal response, was actually the result of three periods of distinctly different core flow behavior. The first period lasted from the time of rupture to about 6 sec after the start of upper plenum ECC injection, and the associated phenomena contributed strongly to the rapid and uniform quenching of the upper core elevations. The second period followed and lasted until the start of cold leg nitrogen injection. The major system thermal-hydraulic phenomena during this period controlled the cooling and quenching of much of the core hot spot region (29-in. core elevation). The final period continued during and after cold leg nitrogen injection and covered lie quenclimig of the remaining lower portions of the core. The major system thermal-hydraulic phenomena occurring during each of these periods are discussed in llte fulluwing paragraphs, and are related to the core thermal response.

During the first core flow period, the rapid and uniform cooling and quenching of the upper core elevations resulted from upper plenum ECC being swept directly into the core by established negative intact loop and core tlows. These flows developed prior to any ECC injection and were nearly identical to the initial core flow observed in previous experimental investigations. Intact loop cold leg accumulator injection, initiated between 17 and $19 \mathrm{sec}$ after rupture, occurred before the start of upper plenum injection and subcooled water from the intact loop accumulator entered the cold leg and inlet annulus. This subcooled water provided a condensation sink for the already established negative core steam flow. Therefore, when ECC injection into the upper plenum started about $22 \mathrm{sec}$ after rupture the negative intact loop and core flows, apparently aided by condensation in the downcomer inlet annulus, swept upper plenum ECC into the core, and resulted in the observed fast and uniform quenching of the upper portions of the core. During this initial core flow period, little evidence existed that significant initial steam generation caused by the cooldown of upper plenum structures occurred in either of the upper plenum accumulator injection tests. Therefore, the effect of the upper plenum structures on overall system behavior and core thermal response appears to be minimal for the injection rates investigated in the Semiscale tests.

During the second core flow period, the continued effectiveness of the upper plenum injection was dependent on a complex oscillatory process which developed as a result of phenomena associated with steam generation in the core and condensation in the downcomer inlet annulus. The penetration of the core by ECC injected into the upper plenum resulted in large volumes of steam being generated within the core which in turn caused large negative flows to develop out the core inlet and up the downcomer. The large negative core flow which developed for the case of an upper plenum ECC injection rate of $16 \mathrm{gpm}$ is shown relative to that for the case with cold leg injection only in Figure 21. With upper plenum ECC injection, the large negative flows out the bottom of the core and up the downcomer caused significant bypass of the intact loop ECC out of the broken loop cold leg , and delayed penetration of the cold leg ECC to the lower plenum. 


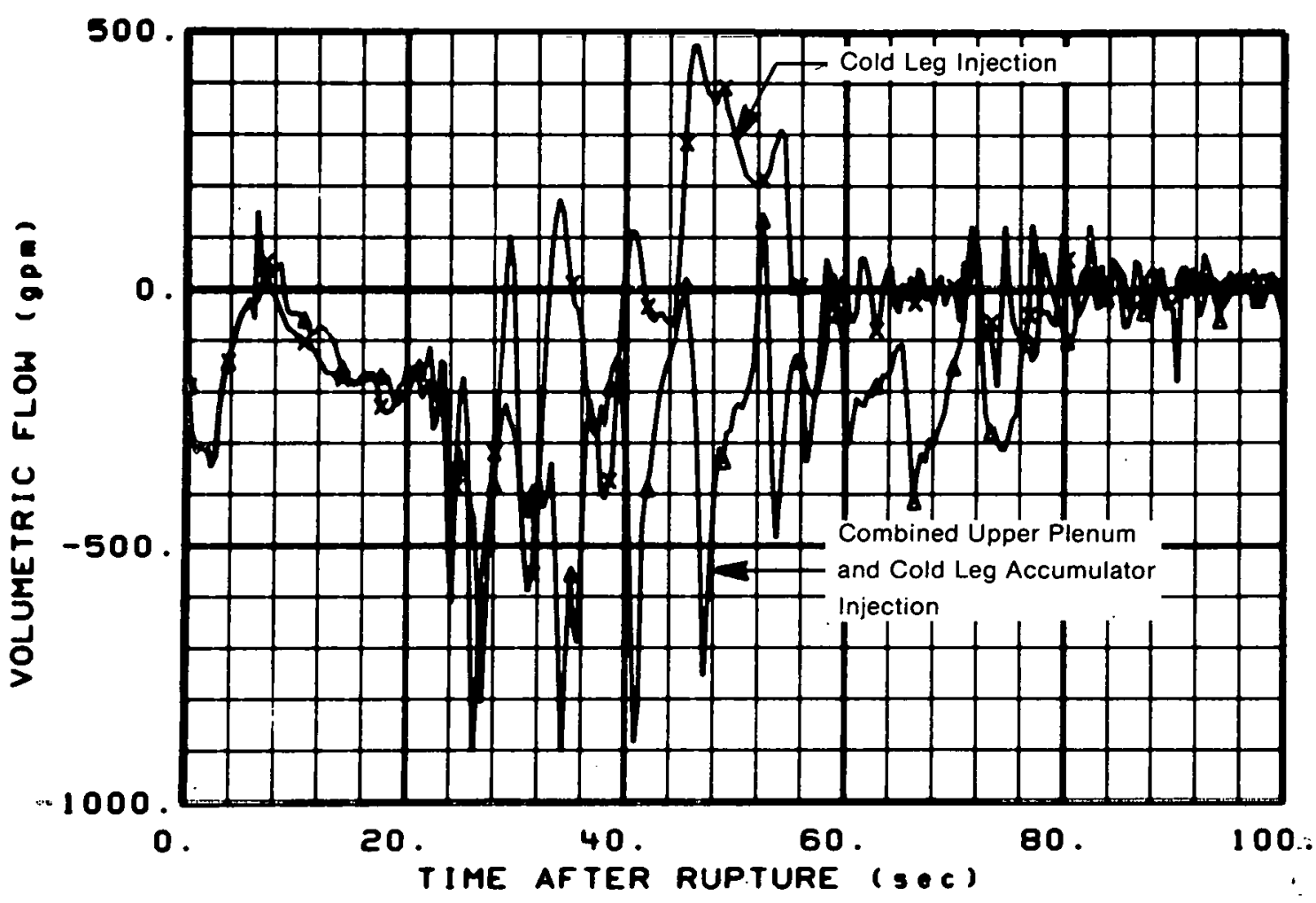

Fig. 21 Comparison of core inlet volumetric flows for cold leg ECC injection and for upper plenum ECC injection (16 gpm).

The mechanism underlying the strong negative core flow which caused bypass and the penetration delay during this period is related to the condensation process which occurred in the downcomer inlet annulus. The process was initiated when subcooled water from the intact loop accumulator entered the downcomer inlet annulus causing condensation of steam in the annulus and inducing a surge of steam flow down through the core and up the downcomer. The relation between the negative surges in steam. flow and the subcooled water in the inlet annulus is demonstrated in Figure 22 by the negative steam flow surges which correspond to periods when subcooled water existed in the inlet annulus. The strong negative flow surges held up ECC water in the inlet annulus causing substantial bypass. However, these condensation induced flow surges up the downcomer could not be sustained because a saturated layer of fluid between the subcooled water and the steam apparently developed in the confined area of the downcomer. This saturated layer of fluid stopped the condensation process, and the continued, but lower negative steam flow, forced the collected liquid out the top of the downcomer. This liquid then bypassed out the cold leg break, the broken loop cold leg being essentially voided of water by the steam flow as indicated by periods of decreased density in the broken loop cold leg which correspond to the periods of reduced negative core flow at the core inlet. After the saturated fluid plug was removed by the negative core flow, subcooled water reentered the inlet annulus, and the condensation process was repeated, causing oscillating core and bypass flows which continued until the intact loop accumulator water was exhausted. 


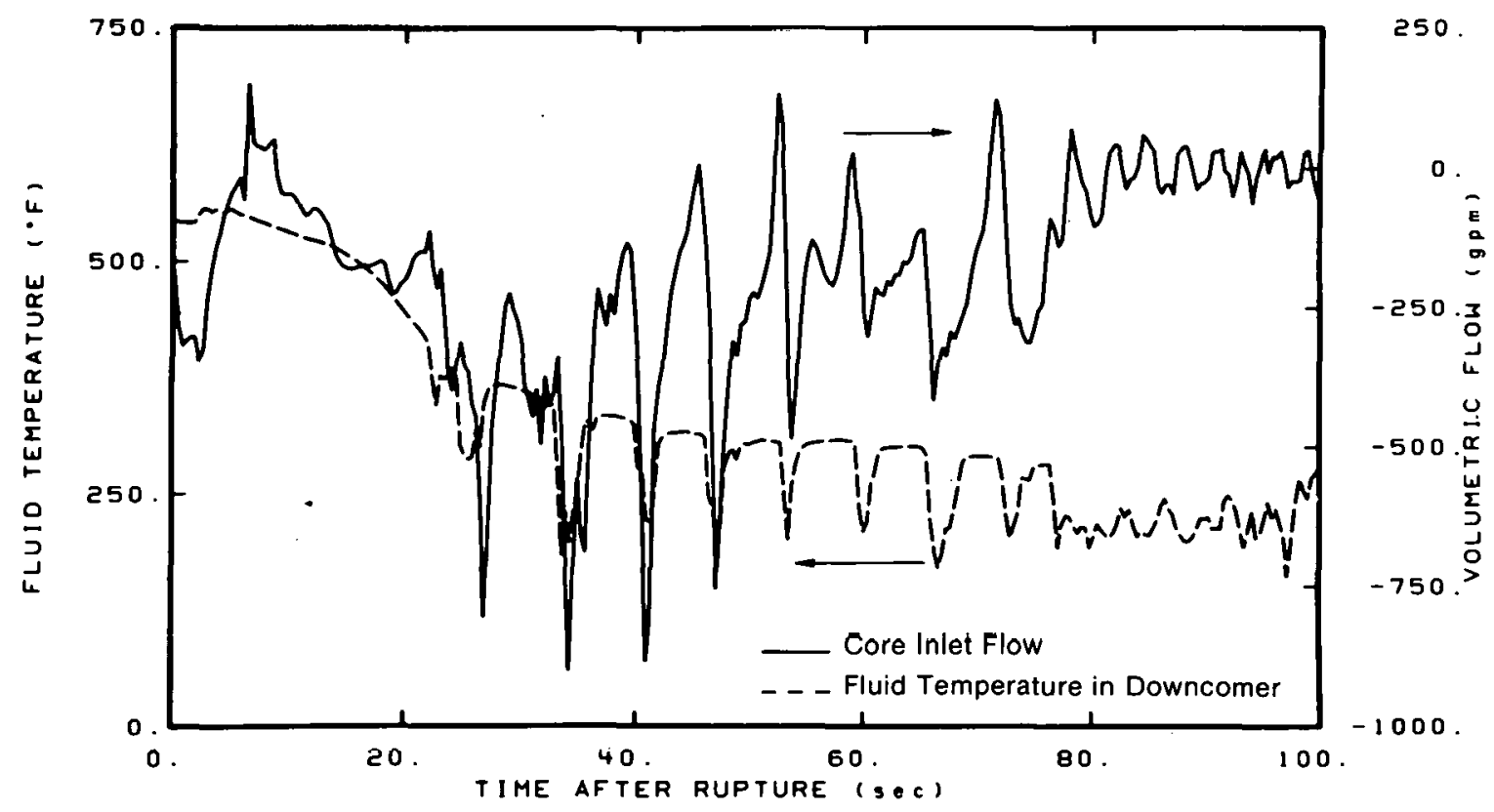

Fig. 22 Core inlet flow and downcomer fluid temperature for upper plenum accumulator injection rate of $16 \mathrm{gpm}$.

The condensation process described in the preceding paragraph strongly influenced the effectiveness of the upper plenum ECC injection through the induced negative surges in core flow. The flow surges allowed continued upper plenum ECC penetration into the core and resulted in periods of increased core heat transfer. It was by this means that much of the central region of the core (core hot spot) was cooled and ultimately quenched. A more detailed description of the core heat transfer phenomena which occurred during the negative surges in core flow is contained in Appendix B of this report. Calculations of core heat transfer coetticients, also presented in Appendix B, suggest that substantial entrained liyuid in the negative core flow surges significantly contributed to the core cooling effectiveness of the upper plenum accumulator injection concept.

The oscillatory nature of the condensation induced core flow also caused substantial bypass of ECC injected in to the upper plenum out the hot leg side of the break. The periods in which upper plenum ECC penetrated the core were followed by periods of significant steam generation. As a result, some holdup of ECC occurred in the upper plenum accompanied by bypass out the broken loop hot leg side of the break. This bypass of fluid, indicated by the relatively high densities measured in the broken loop hot leg next to the vessel, occurred for both the high and low accumulator injection rates. However, a more substantial quantity of ECC bypassed the core for the larger injection rate (16 gpm) than for the lower injection rate $(8.4 \mathrm{gpm})$. Therefore, the full effect of the difference in upper plenum injection rates was not felt by the core, and as a result, the core cooling effectiveness for the two injection rates was very similar.

The final period of distinctly different core flow behavior occurred after the termination of cold leg accumulator water injection, when nitrogen flow from the 
accumulator in to the intact loop cleared the subcooled water from the cold leg and downcomer inlet annulus. Without the supply of subcooled fluid delivered by the intact loop accumulator, the large negative surges in core flow induced by condensation of steam in the inlet annulus did not persist and without the aid of the large negative surges in core flow, penetration of the core by the upper plenum ECC was not as effective. The reduced penetration of the core by ECC resulted in less effective core cooling and the slower, more scattered quenching which is observed to occur after $75 \mathrm{sec}$ in Figure 19 and after $68 \mathrm{sec}$ in Figure 20. This scattered quenching of the lower core elevations during and after the nitrogen injection period may have been caused in part by ECC from the upper plenum flowing down cold channels of the core, filling the lower plenum, and initiating bottom reflood. Evidence that this bottom flooding mechanism does occur late in the transient is provided by the increase in the measured density at the core inlet, which indicates the presence of substantial liquid at the core inlet following the initiation of nitrogen injection.

The sequential occurrence of the three different thermal-hydraulic behaviors caused the different thermal response in the upper and lower portions of the core. The early delivery of ECC to the core followed by condensation induced oscillating core flow surges resulted in good core cooling and early quenching of the upper portions of the core which was relatively independent of injection rate. The elimination of the condensation front in the downcomer inlet annulus, caused by the injection of nitrogen into the intact loop cold leg, resulted in a reduction in the negative core flow and a slower, more scattered quenching of the lower core regions.

Overall, upper plenum accumulator injection was effective in cooling the Semiscale core. However, some of the observed system and core thermal characteristics which resulted in the effective cooling may have been in part due to factors specific to the Mod-1 system. These factors are discussed in the following section.

2.1.3 Factors Specific to the Semiscale Mod-1 System that may Influence Results. Several geometric factors in the Semiscale Mod-1 system could have significantly influenced the thermal-hydraulic behavior associated with upper plenum accumulator injection. Among the most important of these factors are the core length and core cross-sectional area, which determined the core flow resistance, and the relatively massive upper plenum structures which contributed to the total stored energy of the Mod-1 system and could have influenced the availability of water for cooling the core.

The difference in core length between Semiscale and a full sized PWR is significant in that for both Semiscale upper plenum accumulator injection rates, the last quenches were observed to occur at about the same time as upper plenum injection was terminated. Since the Semiscale core is only about half the length of the typical 12-ft core, quenching of the longer length would probably not be completed before upper plenum injection would be terminated. In this event, substantially higher temperatures could occur in the lower portions of the core.

In addition to the core length consideration, the Semiscale core area which was scaled to LOFT is larger than the equivalent area scaled to a PWR. As a result, the core flow 
resistance in Semiscale is considerably lower than might be expected in a PWR. Therefore, the magnitude of the large negative core flows observed in the Semiscale test facility might not be reproduced in a PWR, and a slower top to bottom quench than observed in the Semiscale experiments might occur. The combination of the longer core and the increased core flow resistance in a full sized PWR would, therefore, be expected to result in less effective core cooling, particularly at the lower core elevations.

Another geometry consideration unique to Semiscale which might be expected to affect the overall results is the energy storage in the Semiscale upper plenum region. Although the initial steam generation caused by cooling of the upper plenum structures seems to be relatively small and, therefore, did not appear to affect the overall system behavior significantly, the limited available upper plenum instrumentation makes the total effect of the more massive Semiscale upper plenum structures difficult to assess.

A final factor which might have affected overall system behavior and core thermal response in the Semiscale experimental investigations is again related to the flow area of the Semiscale vessel relative to a PWR. In a full sized PWR, with the much larger core flow areas, preferential channeling of the fluid down cold regions of the core (or possibly around the outer periphery of the core) might result in significant filling of the lower plenum by the vessel accumulator injection and could result in signficantly different core quenching behavior than was observed in Semiscale.

2.1.4 Assessment of Effectiveness of Upper Plenum Accumulator Injection and Cold Leg Injection in the Semiscale Mod-1 System. Overall, simultaneous upper plenum accumulator and cold leg ECC injection proved very effective in the Semiscale Mod- 1 system. This injection concept resulted in significantly better core cooling and earlier core quenching than was observed with cold leg injection alone. A disadvantage of this particular concept in Semiscale, however, lies in the fact that the top down cooling caused the.lower elevations of the core to be the last to quench. Since the axial power profile had the peak power density skewed toward the bottom of the core, the concept resulted in the least effective cooling being applied to the maximum power region. Nevertheless the cooling of the high power region was still significantly better than that obtained with cold leg injection.

Finally, the test results for the upper plenum injection concept were significantly influenced by the relationship between steam generated in the core and condensation in the downcomer inlet annulus. Therefore, apparently the results could be strongly influenced by the timing of the respective upper plenum and intact loop accumulator injections. If upper plenum injection was delayed until reflood was started the concept might have worked with bottom flooding and condensation in the upper plenum. Either way, the concept appears potentially effective.

\subsection{Upper Plenum LPIS Injection}

In the experimental investigation of upper plenum LPIS injection, modifications to the Semiscale Mod-1 cystem which were made to provide the best possible representation of 
a two-loop PWR system, also produced signficant changes in the system thermal-hydraulic response. The modifications included changes in the Semiscale Mod-1 scaled break area, intact loop hydraulic resistances, and ECC volumes and injection rates. Since these modifications caused differences in system behavior which influenced the overall effectiveness of the injection concept being investigated, they were made the subject of a separate experimental analysis.

The analysis of the two-loop scaling effects was accomplished through an experimental study which incorporated the previously described modifications into the Semiscale Mod-1 system but utilized ECC injection into the cold legs only. This configuration provided a basis for a direct comparison of two-loop and four-loop scaling effects on the overall Semiscale Mod-1 system behavior.

The independent experimental analysis of the two-loop scaling effects also provided a means for direct evaluation of the upper plenum LPIS injection concept. This evaluation was accomplished by utilizing the Semiscale Mod-1 system in the modified two-loop configuration described previously, but injecting ECC from the LPIS into the upper plenum rather than into the cold legs. In this manner the effects of upper plenum LPIS injection could be isolated.

The following sections concentrate on the core thermal response and system behavior caused primarily by the injection of ECC from the LPIS into the upper plenum. The core thermal response and system behavior attributable to the two-loop scaling effects are not dealt with extensively in the main body of this report, and the reader is referred to the discussion of the upper plenum LPIS injection concept in Appendix C, where the results of the two-loop scaling investigation are discussed in detail.

2.2.1 Core Thermal Response. The core thermal response with upper plenum LPIS injection was significantly affected by both the injection location and the two-loop scaling. To be consistent with licensing assumptions applicable to this concept, upper plenum LPIS injection was initiated about $25 \mathrm{sec}$ after rupture. The system changes associated with the two-loop representation, particularly the break size, caused two major changes in the thermal reponse during the first $25 \mathrm{sec}$ of the transient. These predominantly break-induced changes are significant in that they influence the thermal conditions in the core at the start of upper plenum LPIS injection.

The first break-induced difference in the core thermal response during the initial portion of the blowdown was a complete absence of early and sustained DNB. This absence of early and sustained DNB is in contrast to the response with the four-loop scaled break area which exhibited both early and delayed DNB as a function of axial and radial locations within the core. An initial period of good core cooling, combined with the generally delayed DNB, resulted in early turnover in rod temperatures and in lower peak blowdown temperatures with the two-loop representation.

The second break-induced difference in core thermal, response was a period of good core cooling between 10 and $14 \mathrm{sec}$ after rupture which resulted in a rapid drop in heater 
rod temperatures throughout the core. The relatively good core cooling associated with this rapid drop in temperature was caused by water from the intact loop hot leg which entered the upper plenum and was swept through the core by the large negative core flows. This same period of good core cooling was observed for cold leg ECC injection with the Semiscale Mod-1 system in the standard four-loop configuration but was limited to the upper elevations of the core above the 35 -in. elevation.

After the period of effective core cooling from 10 to $14 \mathrm{sec}$ after rupture, a period of ineffective core cooling followed in which the heater rods experienced significant temperature increase until LPIS injection was initiated about $25 \mathrm{sec}$ after rupture.

The most significant aspect of the core thermal response which relates directly to the upper plenum LPIS injection location is a multidimensional top down cooling and quenching process which was strongly dependent on the core location relative to the LPIS injection point. When LPIS injection in to the upper plenum was initiated, there followed an early top down quench of rods in a section of the core immediately beluw the LPIS injection point. This top down quenching can be seen in Figure 23, which shows the upper elevations of RodF5 quenching first and the rod quench pattern progressing steadily downward. The quenches shown in Figure 23 occur from 38 to $68 \mathrm{sec}$ after rupture. In contrast to the good core cooling which occurred in the sector of the core immediately below the LPIS injection point, the initial cooling of the sector on the opposite side of the core was ineffective. The differing thermal behaviors of the core sectors below and opposite the LPIS injection location and the relatively sharp geometric segregation of the behaviors are evident in the axial quenching pattern shown in Figure 24 . The initially effective cooling

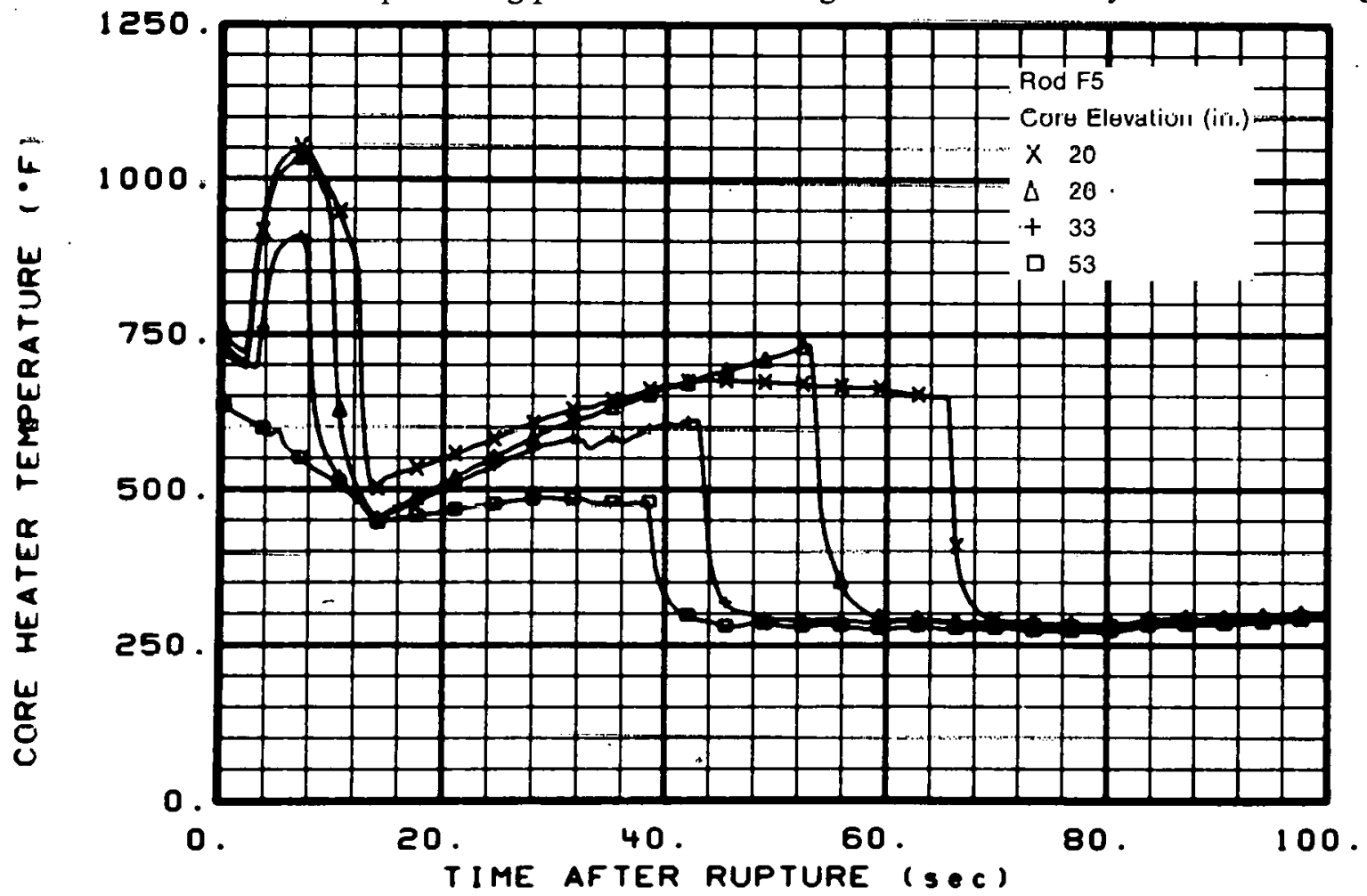

Fig. 23 Rod cladding temperature at four elevations for the upper plenum LPIS injection test. 


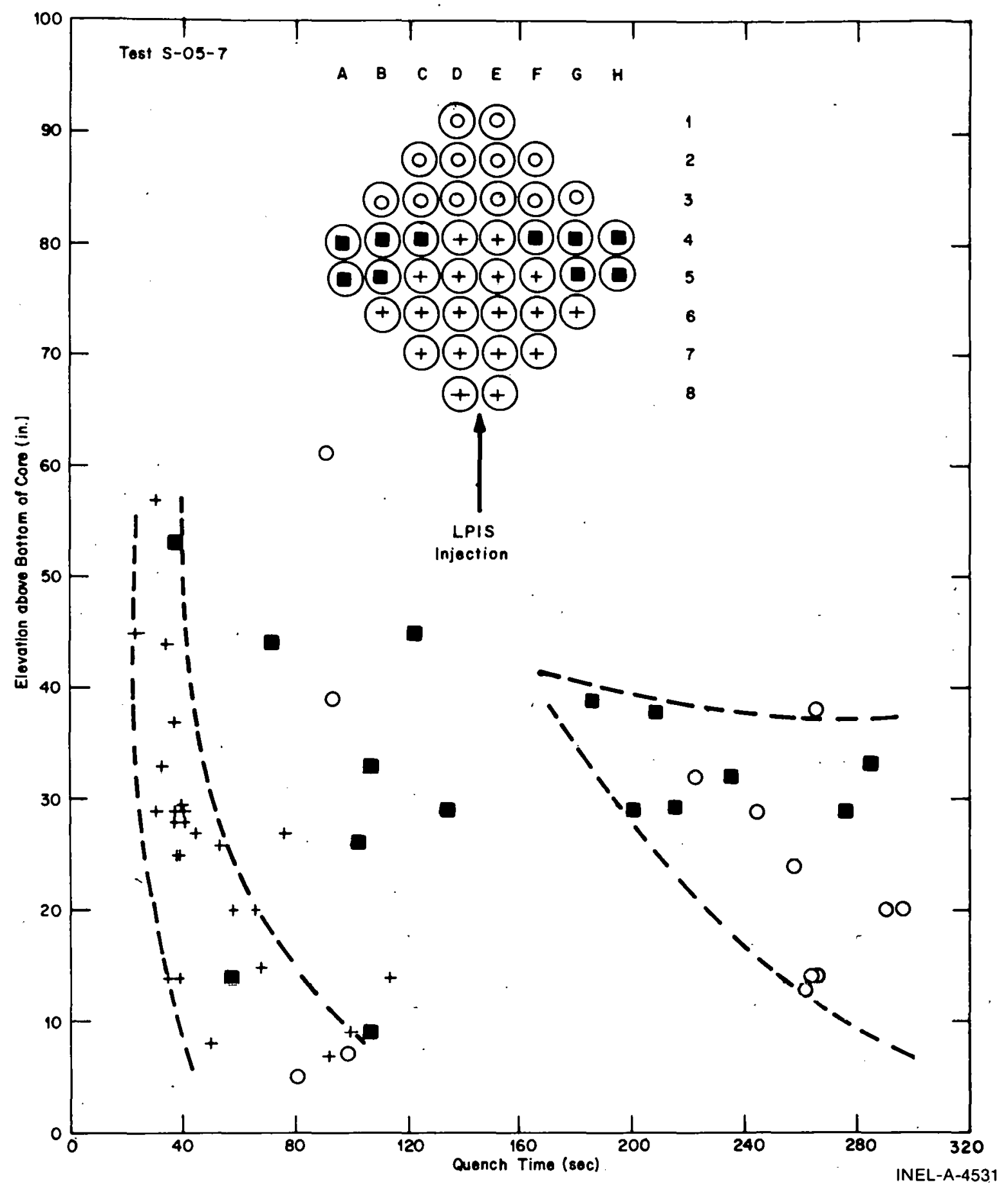

Fig. 24 Rod quench times for upper plenum LPIS injection.

which resulted in nearly complete quenching of the core sector below the LPIS injection point by $80 \mathrm{sec}$ after rupture was followed by a period of sporadic core quenching between 80 and $170 \mathrm{sec}$ after rupture. After this period of sporadic quenches, the sector of the core opposite the injection location experienced a slow and scattered top down quenching which started about $170 \mathrm{sec}$ after rupture. 
The unique core thermal behavior observed with upper plenum LPIS injection is very closely related to overall system thermal-hydraulic phenomena observed during this investigation. The following section discusses the system behavior and hydraulic mechanisms which contributed to the core thermal response and overall effectiveness of the upper plenum LPIS injection concept.

2.2.2 System Behavior Contributing to Core Thermal Response. The early initial core thermal behavior which resulted in delayed DNB and early turnover in peak blowdown temperatures is break related and is not a function of the ECC Injection concept. Large negative intact loop hot leg and core flows developed soon after rupture due to the larger break used in the two-loop Semiscale representation. The larger break resulted in proportionately lower resistance to flow down the core and out the cold leg side of the break relative to that in the hot leg side of the broken loop, therefore causing more negative flow through the core and downcomer. (Detailed descriptions of the broken loop characteristics which caused the large negative intact loop and core flows are contained in Appendix C.) The large negative flows provided the cooling required to delay the occurrence of DNB and produce the early turnover in peak blowdown temperatures.

The large negative intact loop hot leg and core flows, caused by the larger break size, also resulted in the good core cooling between 10 and $14 \mathrm{sec}$ after rupture. The flows apparently carried intact loop hot leg water into the core which produced the good core cooling. The pressurizer appears to have been a significant contribution to this intact loop hot leg liquid. Figure 25 shows that the intact loop hot leg fluid density increased about

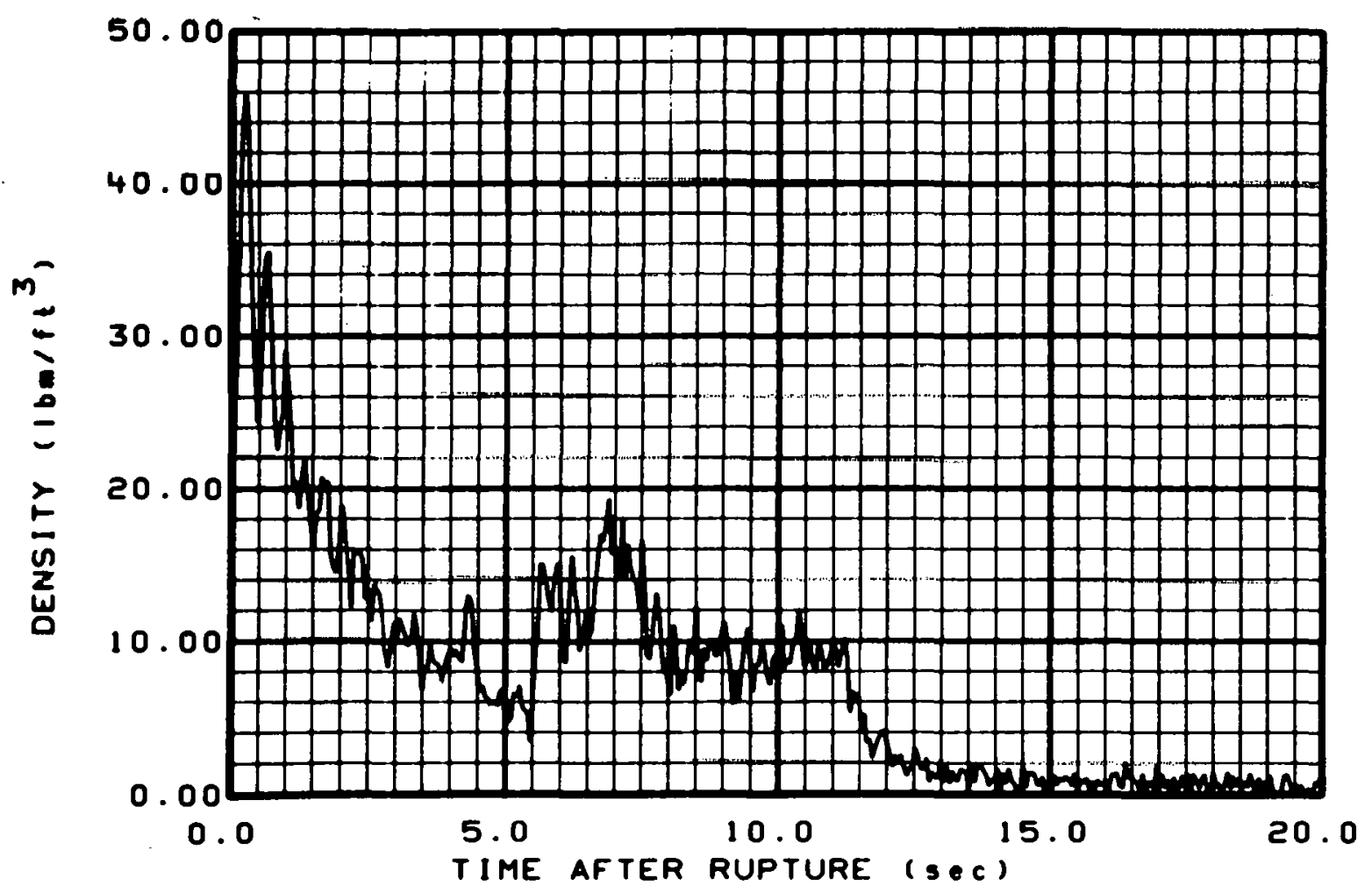

Fig. 25 Density in intact loop hot leg next to vessel for the upper plenum LPIS injection test. 
$4 \mathrm{sec}$ after rupture when the flow reversed and began to pass into the upper plenum region. The density then dropped to a relatively low value at about $14 \mathrm{sec}$, when the pressurizer emptied of water. Although the close correspondence between the intact loop hot leg density and the emptying of the pressurizer suggests the pressurizer contributed significantly to the intact loop water; some of the liquid may also have come from water which accumulated in the steam generator during the initial $4 \mathrm{sec}$ of positive intact loop hot leg flow; this liquid was carried into the upper plenum region during the period of negative intact loop hot leg flow. A more complete discussion of the system hydraulics which contributed to the core cooling phenomena which occurred between 10 and $14 \mathrm{sec}$ after rupture is contained in Appendix C.

Overall, the early thermal-hydraulic behavior accompanying the upper plenum LPIS injection concept is considerably different than that accompanying the other concepts investigated due to its particular application to a two-loop configuration with the larger scaled break. As a result, the system conditions at the start of ECC injection differ from those obtained with the other concepts, making a direct comparison of results inappropriate. However, certain major phenomena relating to the effectiveness of upper plenum LPIS injection are of interest.

In general terms, the major phenomena relating to the effectiveness of the upper plenum LPIS injection concept are similar to those occurring with upper plenum accumulator injection. Negative intact loop and core flows, coupled with the potential for condensation in the downcomer inlet annulus, again play a significant role. When LPIS injection into the upper plenum was initiated, the already established negative core flow swept the ECC fluid in to the core. However, the relatively low LPIS injection rate and the relatively large volumetric core flow resulted in preferential channeling of the ECC fluid into the sector of the core immediately below the upper plenum injection point. This preferential flow caused the multidimensional core cooling phenomenon discussed in the previous section, and resulted in the sharply distinct division between the core quenching regions. Condensation in the downcomer inlet annulus was very significant because it was a major driving mechanism in the maintenance of the negative core flow. As a result, quenching was rapid in the core sector immediately below the upper plenum injection location so long as the intact loop cold leg ECC injection provided the condensation sink. This condition applied until exhaustion of the intact loop accumulator at $80 \mathrm{sec}$ after rupture and produced the early quenching pattern shown in Figure 24.

Termination of the cold leg ECC injection at about $80 \mathrm{sec}$ after rupture removed the condensation driving mechanism, resulting in reduced core cooling effectiveness. After the intact loop accumulator water was exhausted, a surge of nitrogen forced downcomer liquid into the core and removed the condensation potential, causing termination of the large negative core and intact loop flows. Without the aid of the large negative core flows, the upper plenum fluid penetration of the core was significantly reduced, as indicated by the reduced activity in core quenching between 80 and $170 \mathrm{sec}$ after rupture (Figure 24). During this period, a significant amount of LPIS fluid was bypassed out the intact and broken loop hot legs. 
The cooling and ultimate quenching of the sector of the core opposite the upper plenum injection point took place in the absence of condensacion induced negative core flow and relied upon less effective mechanisms. After nitrogen injection terminated, significant ECC bypass continued, but some ECC penetration of the core occurred. The fluid supply to the core was sufficient to keep the quenched sector of core from drying out, and also contributed to some filling of the lower plenum. The ineffective cooling of that sector of the core which had not quenched continued until the rods had cooled sufficiently to allow increased ECC penetration at about $170 \mathrm{sec}$. This increased penetration of the core resulted in the slower scattered top down quenching of the remainder of the core as shown in Figure 24.

2.2.3 Factors Specific to the Semiscale Mod-1 System that may Influence Results. Many of the factors which affected upper plenum accumulator injection are also important in the interpretation of the Semiscale test results for upper plenum LPIS injection. This section discusses the effects of core length, core hydraulic resistance, two-loop volume scaling, stored energy in the structures of the upper plenum, and the two-dimensional aspects of the observed core cooling on overall core thermal response and system behavior. Although other factors may have affected system behavior, these factors appear to have the greatest potential for affecting system response and influencing the interpretation of overall experimental results.

The length of the heated Semiscale core could be a significant factor influencing the initial cooling and subsequent quenching process with upper plenum LPIS injection. Quenching of the core sector opposite the point of upper plenum injection occurred late and at a slow rate. Possibly in a longer 12-ft core the lower portions of the core opposite the injection location would experience delayed quenches and higher temperatures than were observed in the Semiscale investigation.

The relatively small Semiscale core resistance, compared to that in a full sized PWR, could have contributed to the large negative core flow which developed. This large negative core flow was a significant factor in the observed multidimensional core cooling behavior, and without it the preferential channeling of fluid through the core and the sharply distinct quenching patterns probably would not have been as apparent.

Since the Semiscale intact loop volumes were scaled to the LOFT facility, the total volume of the intact loop is approximately a factor of two larger than the equivalent volume scaled to a two-loop PWR. 'Ihe increased intact loop volume could potentially contribute to the large sustained negative core flows which developed, and would have much the same affect on core thermal response and quench behavior as the small core resistance discussed previously.

The much larger stored energy of the Semiscale upper plenum region may have affected overall core temperatures and quench times and contributed in part to the approximate 10-sec delay between the start of upper plenum injection and the first quenches in the upper core elevations. Overall, however, stored energy did not appear to influence the system behavior unduly. 
Finally, the multidimensional core cooling that occurred in the essentially onedimensional Semiscale test facility makes the extrapolation of results to a full sized PWR difficult. However, the preferential channeling of ECC fluid in the relatively confined area of the Semiscale core indicates that flow channeling may be an important factor in the long term cooling of a full sized two-loop PWR.

2.2.4 Assessment of Effectiveness of Upper Plenum LPIS Injection and Cold Leg Injection in the Semiscale Mod-1 System. Upper plenum LPIS injection proved to be effective in quenching a particular sector of the Semiscale core immediately below the injection point. The injection rate used was sufficient to allow steam generation, which contributed to the countercurrent steam flow early in the transient but was not sufficient for early quench of the entire core. Therefore, a significant portion of the Semiscale core experienced ineffective cooling.

Since considerable ECC penetration occurred directly under the point of LPIS injection, channeling of ECC fluid through the core, caused by increased injection rates or continued injection (beyond the $300 \mathrm{sec}$ of the test) may allow LPIS fluid to penetrate to the lower plenum and contribute to filling of the core from the bottom. This bottom filling would represent a different core cooling mechanism and may influence the effectiveness of the upper plenum LPIS injection concept.

\section{COLD LEG INJECTION WITH VENT LINE}

The effectiveness of an ECC system employing cold leg injection with a vent line between the broken loop hot and cold legs was examined through a comparative analysis of experimental results for cold leg injection with and without broken loop hot leg venting. During reflood, the vent line provides the potential for an increase in the core reflooding rate by reducing the resistance to steam flow out of the upper plenum region, thereby reducing the adverse pressure differential between the upper plenum region and the downcomer inlet annulus which can exist during this period. The vent line concept is unique, however, in that it also has the potential for altering core hydraulic behavior during the blowdown and refill periods by providing a low-resistance parallel flow path to the cold leg break during the negative core flow period. Therefore, the total effect of the combined blowdown, refill, and reflood system behavior and core thermal response was of interest in the evaluation of this concept.

The core thermal response and overall system behavior for the experimental investigation of cold leg ECC injection with broken loop hot leg venting are discussed in the following two sections.

\subsection{Core Thermal Response}

The use of a vent line affected the Semiscale Mod-1 core thermal response both immediately after rupture and during core reflood. During the initial blowdown period, the 
vent line apparently altered the core flow characteristics, and as a result no delayed DNB took place in the core whereas delayed DNB had occurred on rods adjacent to unpowered rods in the absence of the vent line. Because of this difference in DNB behavior, many rod locations reached higher peak blowdown temperatures with the vent line concept than with just the cold leg injection concept without the vent line. However, since the maximum blowdown temperature without the vent line occurred at a location with an early and stable DNB, the maximum blowdown temperature in the core remained essentially unchanged $\left(1450^{\circ} \mathrm{F}\right.$ with the vent line, compared with $1475^{\circ} \mathrm{F}$ without the vent line).

Following the initial period in which substantial differences in DNB behavior were observed, the vent line caused a second significant difference in the core thermal response in that relatively good core cooling occurred in the vent line test from approximately 3 to $19 \mathrm{sec}$ after rupture. This good cooling resulted in an earlier turnover of, and a rapid drop in, heater rod temperatures compared with the temperatures observed in the baseline cold leg injection test without the vent line. The temperature traces in Figures 26, 27, and 28, compare heater rod temperature responses for the cold leg injection tests both with and without the vent line. The figures show, for the 14-, 29-, and 33-in. elevations, that the higher peak temperatures achieved with the vent line occurred from 4 to $6 \mathrm{sec}$ before the corresponding peaks in the baseline test, and also demonstrate the rapid temperature reductions associated with the period of good core cooling from 3 to 19 sec after rupture. This good core cooling is significant since as indicated in Figures 26, 27, and 28, many rod temperatures were lower at the start of reflood than those measured without the vent line.

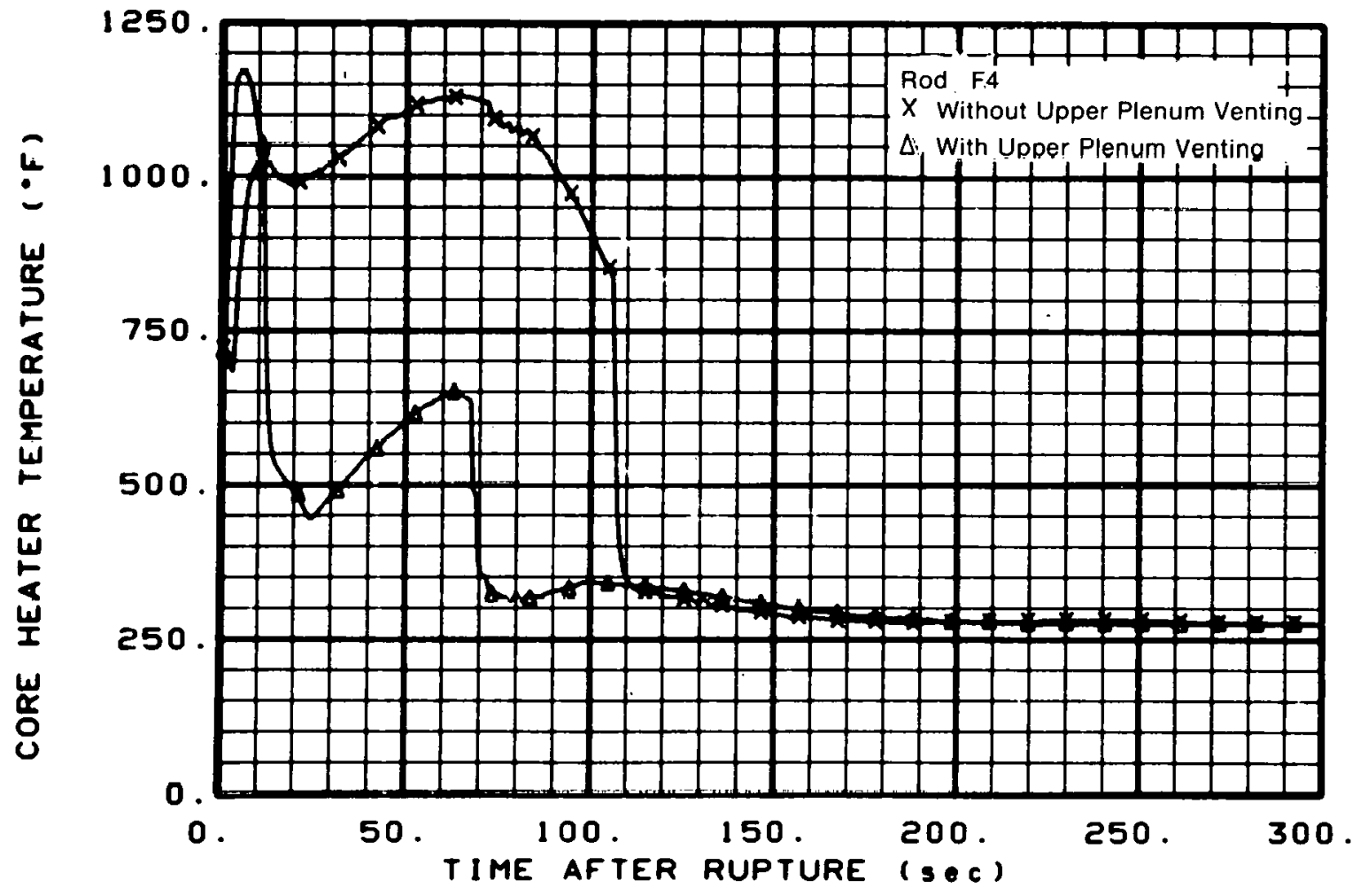

Fig. 26 Rod cladding temperature response at 14 -in. elevation for cold leg injection tests with and without upper plenum venting. 


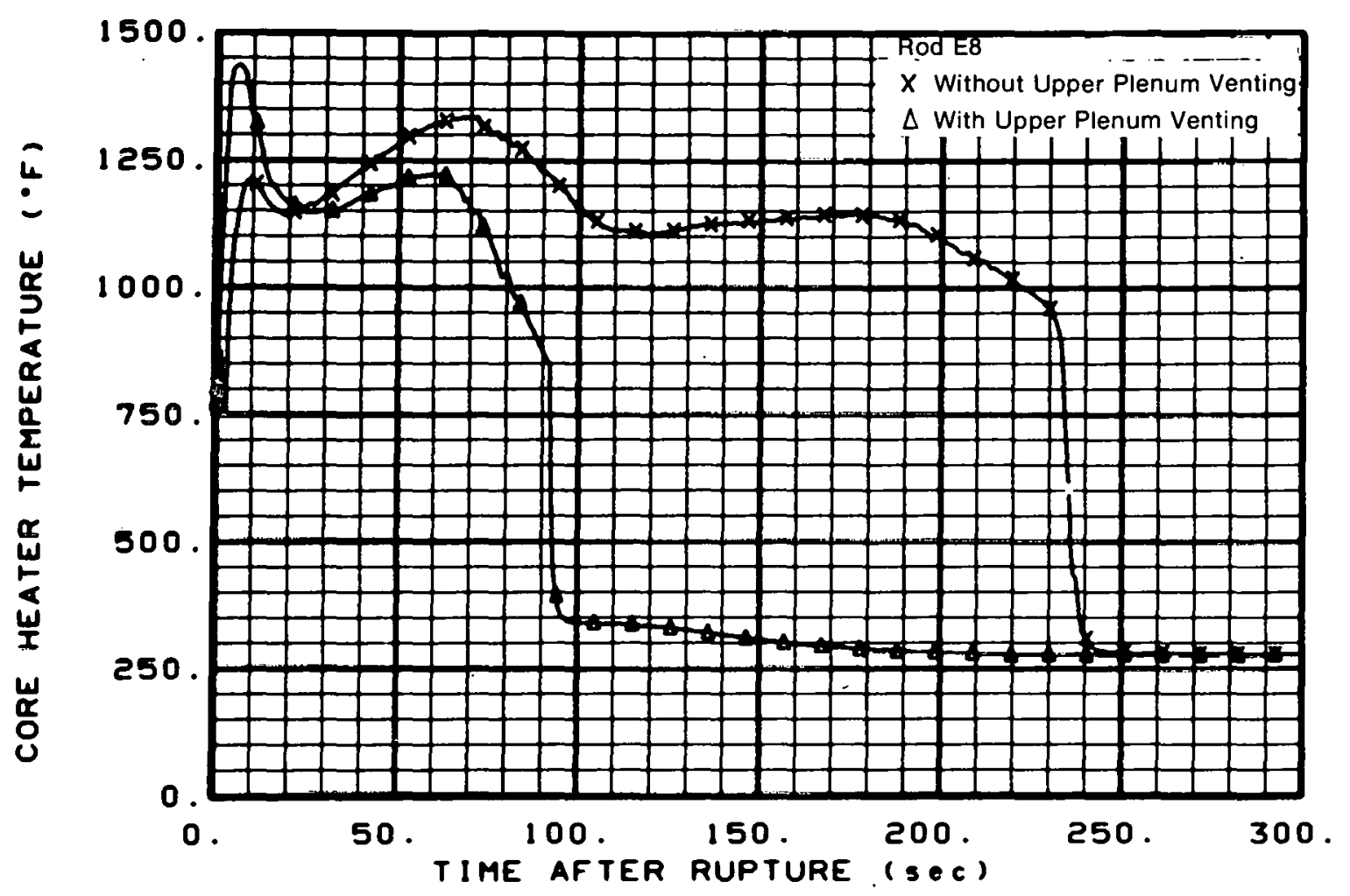

Fig. 27 Rod cladding temperature response at 29 -in. elevation for cold leg injection tests with and without upper plenum venting.

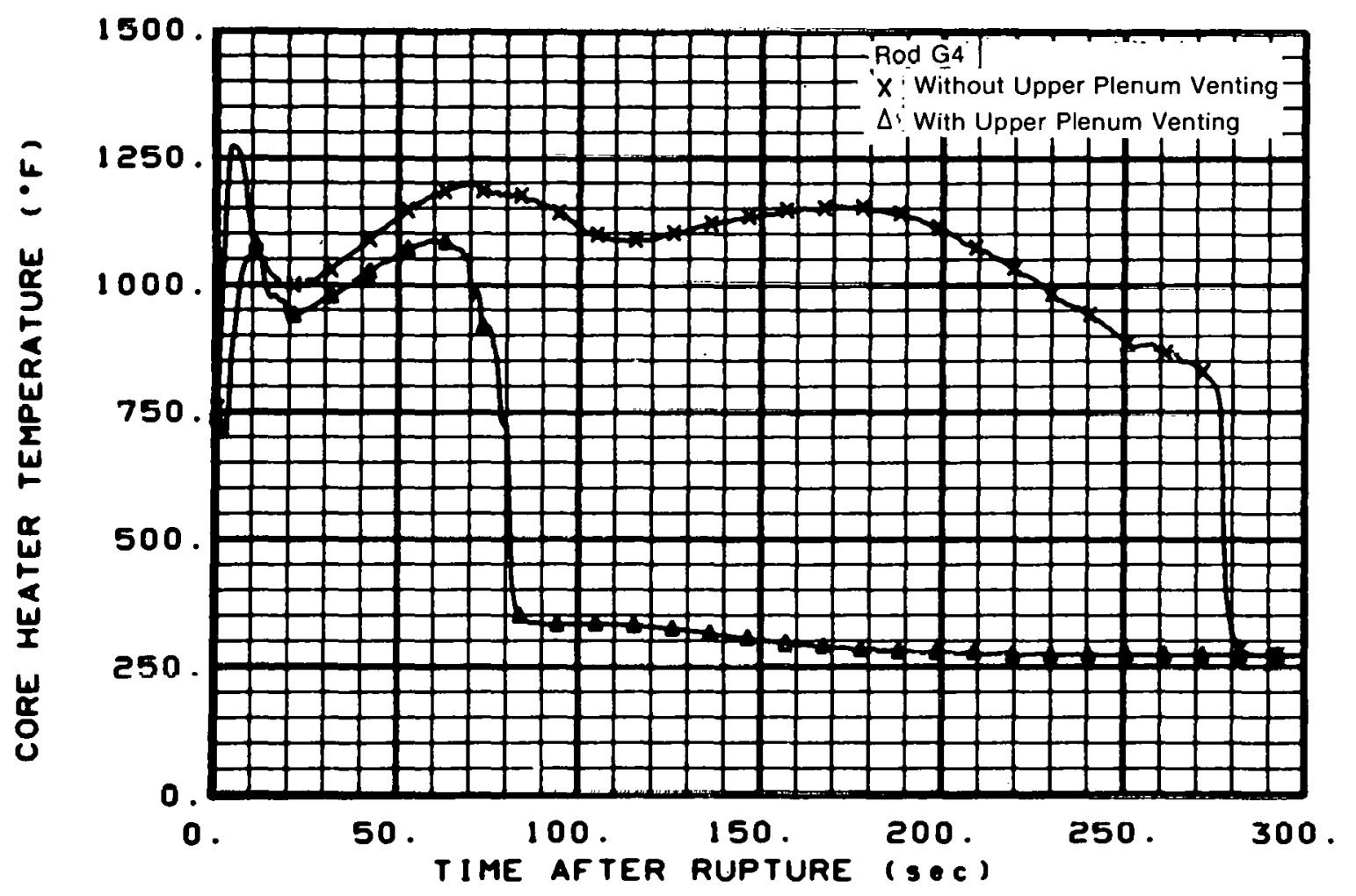

Fig. 28 Rod cladding temperature response at 33-in. elevation for cold leg injection tests with and without upper plenum venting. 
During the reflood period, the vent line appeared to function as expected, allowing increased steam flow out of the upper plenum which resulted in a more rapid reflood of the core. As a result, earlier quenching of all elevations of the core occurred with the vent line concept (Figures 26, 27, and 28). The last recorded quench at the core hot spot occurred $93 \mathrm{sec}$ after rupture with the vent line. By comparison, the last measured core hot spot temperature quenched $242 \mathrm{sec}$ after rupture in the cold leg injection test without the vent line.

With the vent line, the overall core thermal response was affected little by nitrogen injection into the intact loop cold leg after the accumulator water was exhausted. Most of the core quenched before nitrogen injection was terminated, and remained quenched for the remainder of the transient.

Overall, despite higher peak blowdown temperatures at some core locations, the cold leg ECC injection with upper plenum venting provided effective core cooling. The improved core cooling early in the blowdown period which caused an early turnuver in peak temperatures was significant in that it resulted in more energy being removed from the core before the start of reflood (relative to the cold leg injection case without the vent line). The rapid reflood of the core caused earlier quenching compared with cold leg injection alone, and the entire core remained quenched throughout the remainder of the transient. The system behavior which caused the effective core cooling with the vent line concept is discussed in the next section.

\subsection{System Behavior Contributing to Core Thermal Response}

The use of the vent line in the Semiscale Mod-1 system caused major changes in the system hydraulic response during blowdown which resulted in the early core thermal behavior described in the previous section. Flow was initiated through the vent line immediately after rupture, reducing the resistance to flow out of the upper plenum region and strongly influencing the core hydraulics. Figure 29 shows that the magnitude and duration of the initial reverse core flow was much less for cold leg injection with the vent line than for cold leg injection without the vent line. The lower reverse flow at the core inlet with the vent line apparently affected fluid conditions within the core, which in turn caused the predominance of early DNBs discussed previously.

The reduced magnitude and duration of the initial reverse core flow that occurred because of flow through the vent line also played a significant role in establishing the good core cooling that occurred from 3 to $19 \mathrm{sec}$ after rupture. The reduced magnitude and relatively short duration of the initial negative core flow apparently did not allow the lower plenum to be emptied of water. As a result, liquid which remained in the lower plenum was entrained and carried into the core when the core inlet flow became positive approximately $3 \mathrm{sec}$ after rupture (Figure 29). Evidence of this entrainment process is provided by the increase and then the gradual drop in the fluid density at the core inlet from $3 \mathrm{sec}$ after rupture as shown in Figure 30. The measured density for the cold leg injection test without the vent line is shown for comparison. The positive flow of relatively high density fluid at the core inlet resulted in the good core cooling during this portion of the blowdown period. 


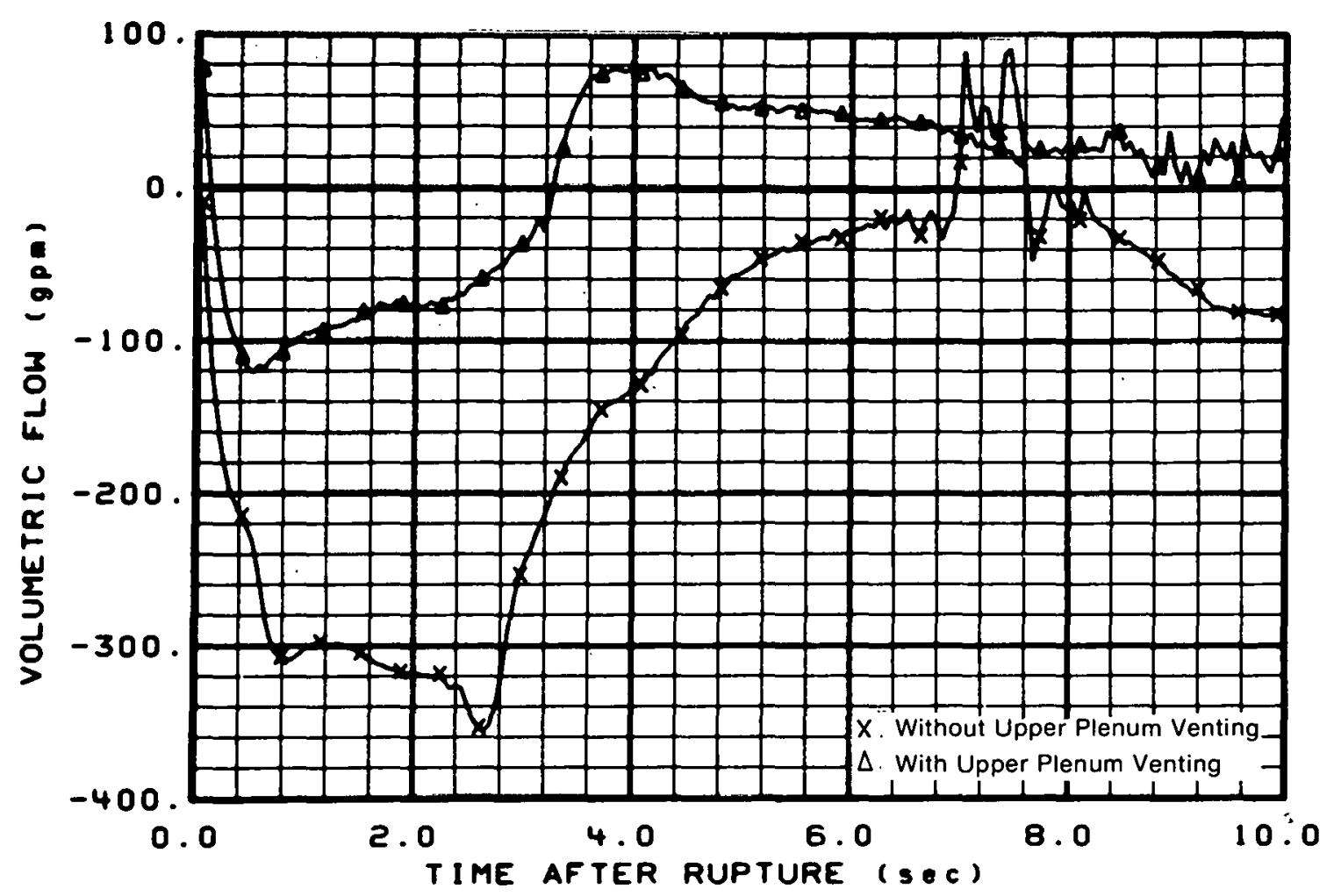

Fig. 29 Comparisons of core inlet volumetric flows for cold leg ECC injection tests with and without upper plenum venting.

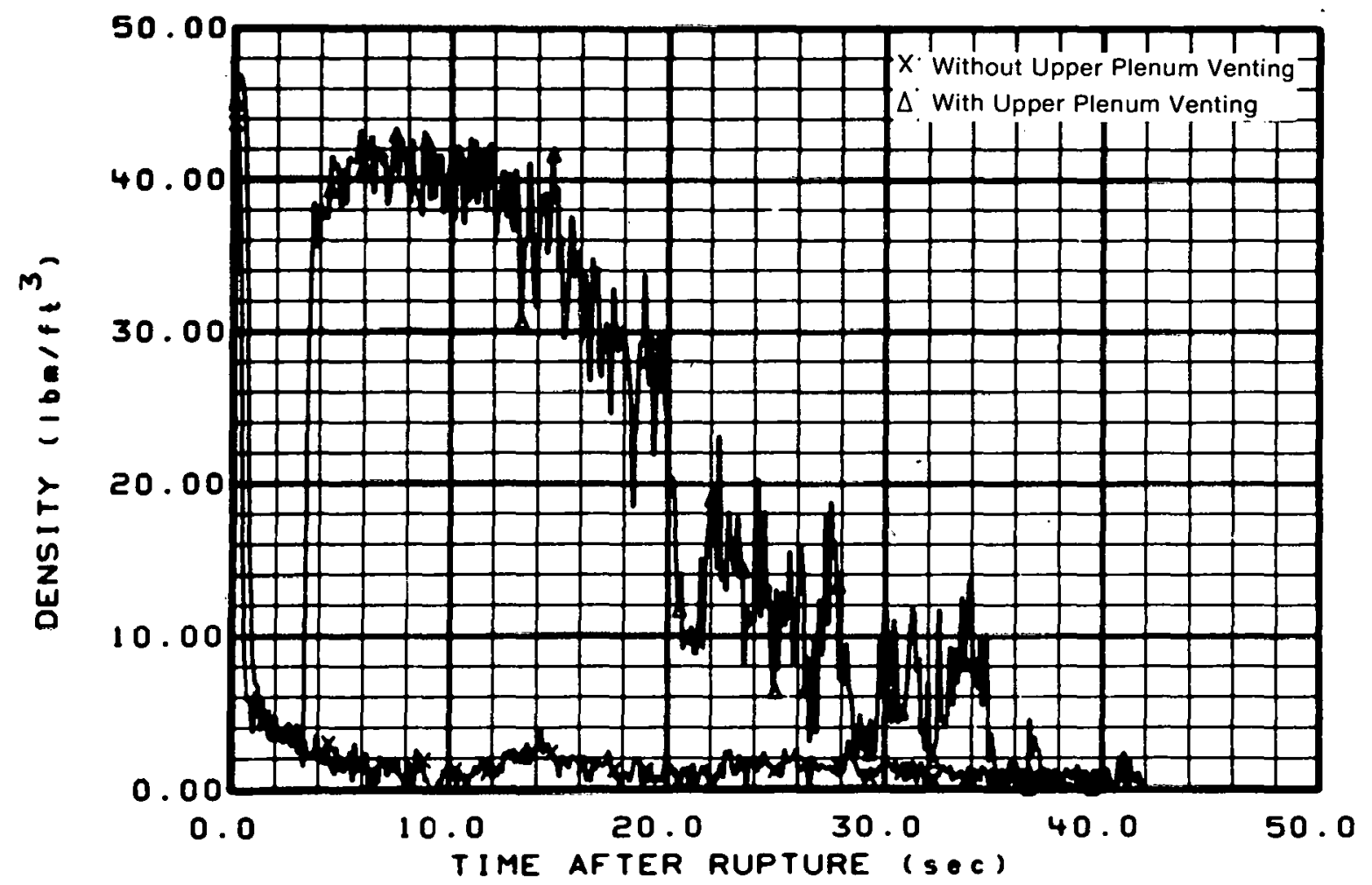

Fig. 30 Comparison of core inlet fluid densities for cold leg ECC injection tests with and without upper plenum venting. 
The vent line had very little effect on the delayed delivery of ECC to the lower plenum associated with downcomer countercurrent flow and hot walls. Core and downcomer collapsed liquid levels, which are an indication of mass storage, were calculated from the pressure drops between pressure taps above and below the core and downcomer. The calculated liquid levels, shown in Figures 31 and 32 , indicate almost identical downcomer and core behavior prior to the initiation of reflood both with and without the vent line. In addition, reflood started at about the same time, approximately $60 \mathrm{sec}$ after rupture, in each case. Both of these facts indicate that the vent line did not affect the early penetration of the downcomer by ECC fluid.

Once reflood was initiated, flow through the vent line caused the hydraulic resistance to flow out of the upper plenum region to be reduced. The reduced resistance to steam flow virtually eliminated the tendency for the steam generated in the core to uncover the core inlet and allowed more rapid coolant penetration of the core with a given downcomer head. Figure 31 shows that the downcomer collapsed liquid level was essentially uninfluenced by the vent line whereas a much more rapid increase in the core collapsed liquid level during reflood was observed with the vent line than without it (Figure 32). The core collapsed liquid level increased at about $4 \mathrm{in} . / \mathrm{sec}$ with the vent line, indicating a very high reflood rate.

The downcomer and core hydraulic behavior did not appear to be substantially influenced by the presence of the vent line during or after the nitrogen injection period. Intact loop and broken loop cold leg density measurements indicate that when nitrogen

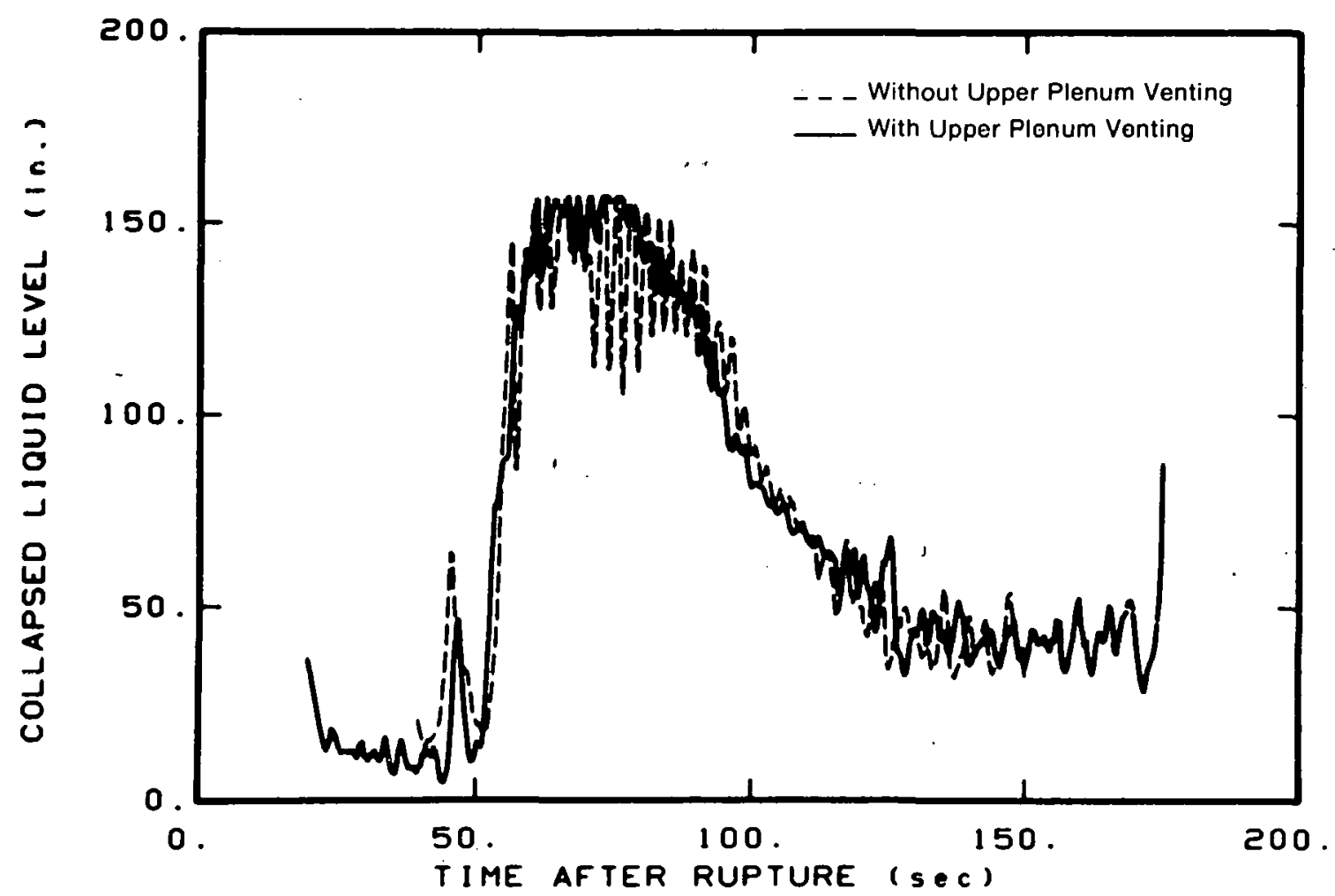

Fig. 31 Comparison of calculated downcomer collapsed liquid levels for cold leg ECC injection tests with and without upper plenum venting. 


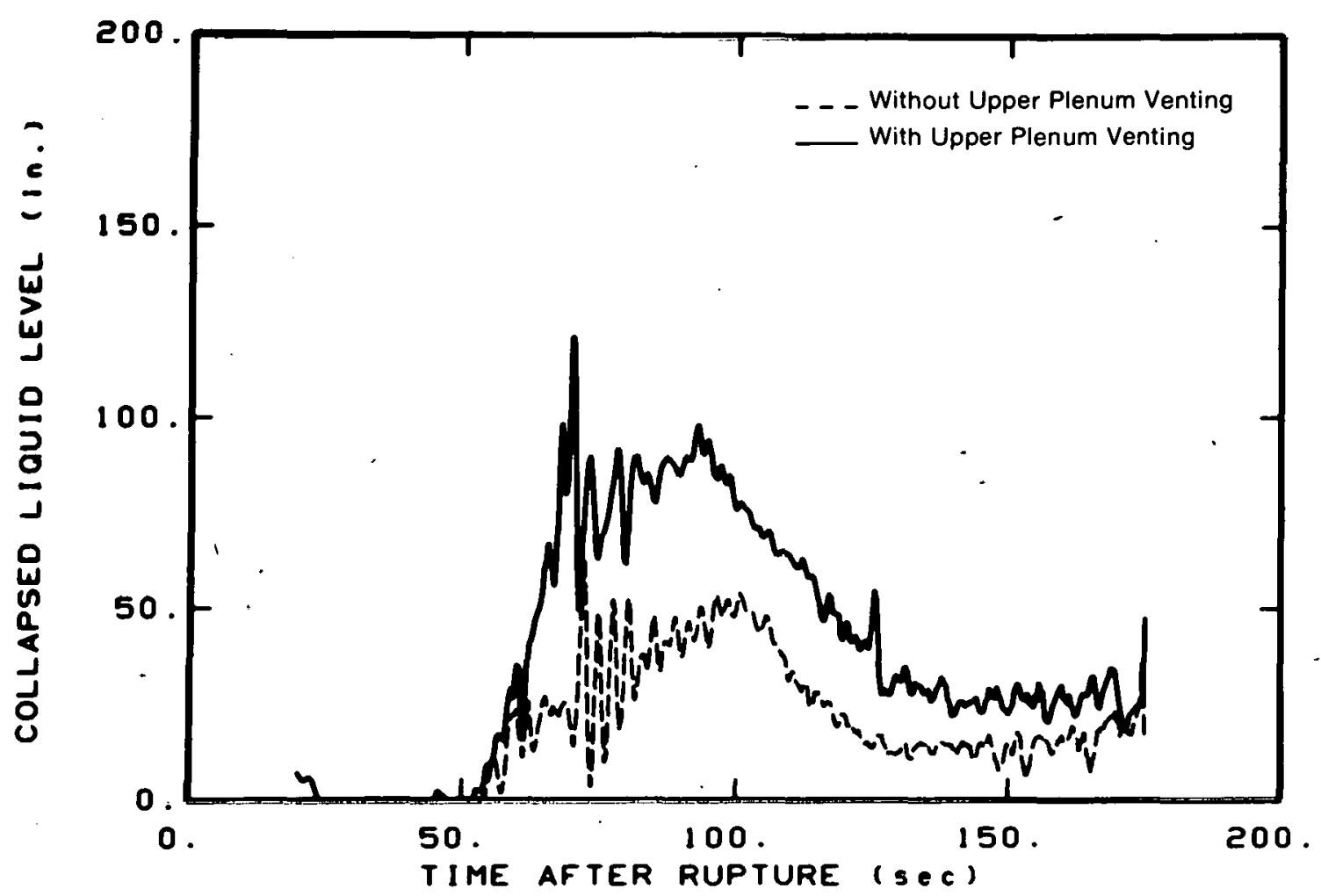

Fig. 32 Comparison of calculated core collapsed liquid levels for cold leg ECC injection tests with and without upper plenum venting.

began to flow from the accumulator, the cold legs were substantially cleared of water. At the same time, the collapsed liquid level in the downcomer began to decrease and continued to decrease throughout the nitrogen injection period. Substantially similar downcomer behavior was also observed in the cold leg injection test without the vent line. After nitrogen injection terminated, the mass depletion in the core and downcomer was very similar both with and without the vent line. The effects of the mass depletion on the rod temperatures differed, however, because the bulk of the core had quenched before significant depletion took place in the vent line test. As a result, no dryout of rods occurred in the upper portions of the core in the presence of the vent line, whereas dryout did occur on some rods without it.

\subsection{Factors Specific to the Semiscale Mod-1 System that may Influence Results}

Many of the Semiscale Mod-1 geometric factors which influenced the results of the previously discussed experimental investigations would also influence the results of the evaluation of cold leg ECC injection with venting between the broken loop hot and cold legs. However, the single most important consideration in this investigation appears to be the geometry and hydraulic behavior of the vent line itself. Therefore, the following discussion deals specifically with the differences between the Semiscale vent line and the vent system in a full sized PWR which may influence the interpretation of the experimental results. 
Although the Semiscale Mod-1 vent line hydraulic resistance $\left(R^{\prime}\right)$ was core area scaled from a PWR to give an equivalent resistance approximating that of a PWR vent system, the vent line location and geometry were not typical of the potential vent path between a PWR upper plenum and inlet annulus. Specifically, the added flow path between the broken loop hot and cold legs in the Semiscale system could result in differences in the magnitude and direction of broken loop flows which are not representative of a PWR with venting between the upper plenum and inlet annulus. For example, venting into the single broken loop cold leg during blowdown could result in a different effective cold leg resistance than would occur due to venting into the inlet annulus. Also, the condensation of steam from the upper plenum in the inlet annulus (which might be expected to occur in a PWR) may occur at a different rate with the broken loop vent line configuration used in the Semiscale test facility. Although each of these differences between the Semiscale and PWR vent systems may produce differences in core thermal response and system hydraulic behavior, they are not expected to detract from the overall effectiveness of the concept.

Analytical studies using the RELAP4 code indicate that the core thermal response is relatively insensitive to the vent line resistance when the resistance is varied over a limited range around the value used in the Semiscale test. The calculations, which are discussed in more detail in Appendix D, show that changing the vent line resistance to a value representative of that which would be obtained if scaling of the resistance were based on the ratio of system volumes would result in only a relatively small change in peak blowdown temperatures. Therefore, although other factors such as vent line location and geometry may affect the phenomena observed during blowdown in the Semiscale vent line concept it is unlikely that system behavior would be affected significantly if system volume scaling rather than core area scaling of the vent line resistance to a PWR had been used.

\subsection{Assessment of Effectiveness of Vent Line in the Semiscale Mod-1 System}

Overall effectiveness, based on the core cooling, was judged to be good when cold leg injection and venting of the upper plenum region were combined. Despite somewhat higher blowdown peak temperatures at some locations, this concept allowed a rapid core reflood and earlier core quenching relative to cold leg injection alone. On this basis the vent line appears to warrant further investigation as an alternate ECC concept.

\section{PUMP SUCTION INJECTION}

The effectiveness of ECC injection into the pump suction leg was investigated in the Semiscalc Mod-1 system with pump speed being the major operating parameter. The investigation of pump speed histories included two extreme operating conditions. The first was that of a pump running at essentially the prerupture speed throughout the transient, whereas the second involved a simulated loss of power at the time of rupture, followed by coastdown to a stop. The coastdown pump speed profile of the second condition was similar to the calculated coastdown of a PWR pump with pump suction injection. A third pump 
speed history was also used which involved the use of a pump coastdown to $64 \%$ of the initial pump speed. This pump speed profile was the same as that used with the other injection concepts investigated so that direct comparisons could be made where required. The ECC injection rate remained nominally constant at about $23 \mathrm{gpm}$.

The following two sections discuss the core thermal response which occurred for tests conducted at the three different pump speeds, and the system behavior that contributed to the observed differences in core thermal response. An extension of the concept of pump suction injection through a series of RELAP4 calculations is then discussed, and the last two sections discuss factors which are specific to the Semiscale Mod-1 system and the overall assessment of the effectiveness of this concept.

\subsection{Core Thermal Response}

The core thermal response in the investigation of pump suction injection was significantly influenced by the selected pump speed profile. The variability of core cooling with pump speed history is demonstrated in Figure 33 which is an overlay of temperature response plots obtained from a measurement at the core hot spot (29-in. elevation) for the tests with the three different pump speed profiles. The temperature response resulting from cold leg injection with a pump coastdown to $64 \%$ of its initial prerupture speed, is also. shown for comparison. The following paragraphs discuss the core thermal response for the different pump speed profiles in the order of decreasing final pump speed.

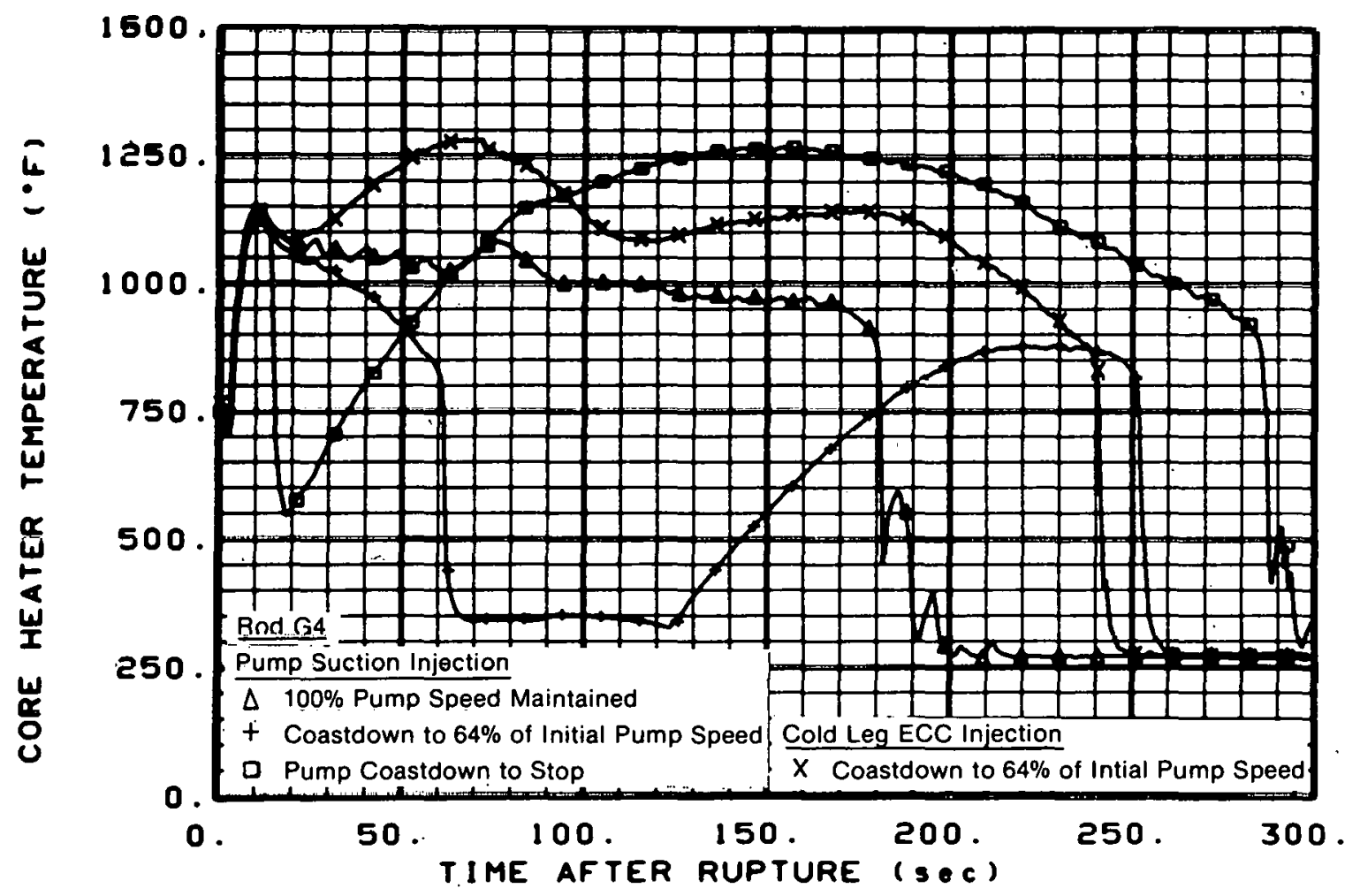

Fig. 33 Comparison of heater rod temperature response for pump suction ECC injection tests with three pump speed profiles, and for cold leg ECC injection. 
For the case in which the pump speed was maintained at $100 \%$ of initial speed $(2345 \mathrm{rpm})$ throughout the test, fairly good core cooling was obtained. Overall, the core cooling for this case of pump suction injection was better than that for cold leg injection and generally slightly shorter quench times were observed. This general behavior was observed for the 29-in. (peak temperature) elevation (Figure 33) although the last recorded quench at this elevation occurred at $250 \mathrm{sec}$ after rupture whereas in the baseline cold leg injection test it occurred at $242 \mathrm{sec}$ after rupture. For this case of pump suction injection the entire core was quenched by $280 \mathrm{sec}$ after rupture whereas with cold leg injection one core location above the 29 -in. elevation did not quench by $300 \mathrm{sec}$ after rupture. In general, the core cooling was effective but not as much so as for some of the other alternate ECC concepts investigated.

For the case in which the pump coasted down to $64 \%$ of the initial speed very good initial core cooling was observed. Rod quenching occurred very early in the transient and this pump speed provided the most effective core cooling with the given ECC injection rate. In this case the last recorded quench at the core hot spot occurred by 75 sec after rupture. A second core hcatup occurred in this case which was due to the particular LPIS location used in the test. The significance of this second heatup is limited however, since high temperatures did not develop.

Overall, the test in which the pump coasted down to a stop gave the least effective cooling of the three pump speed histories investigated. For this case, significant differences developed early in the blowdown relative to the other tests with pump suction injection. Before ECC injection was initiated (at about $18 \mathrm{sec}$ after rupture) early effective cooling of the core down to the 26 -in. elevation was observed. This effective cooling is shown in the appropriate temperature trace in Figure 33 which indicates a rapid drop in temperature occurred prior to $18 \mathrm{sec}$ after rupture. The good cooling did not occur on all rods above the 26-in. elevation, however, and was significant only in that it occurred at locations down to the 26-in. elevation. (In the baseline cold leg injection test, this same effective cooling of the upper portions of the core was also apparent, but with cold leg injection the cooling of heater rods occurred only down to the 32 -in. core elevation.) The period of effective core cooling was followed by a period of ineffective cooling in which the core temperatures increased. Eventually, marginal coollng was established with slow bottom-up quenching of the core. The temperature response curves in Figure 33 show that pump suction injection with a.coastdown to zero pump speed provided less effective cooling than was observed with cold leg injection.

Despite the observed variability in thermal response, the pump suction injection concept is capable of providing good core cooling. However, to assess this concept adequately the causes of the differences in cooling effectiveness must be understood.

\subsection{System Behavior Contributing to Core Thermal Response}

With pump suction injection, a complex relation exists between the system hydraulic behavior and the core thermal response with each given pump speed profile, and the complexity is further compounded by variations in that profile. In the following discussion 
the system behavior is first related to the core thermal response for the case in which the pump speed coasted down to $64 \%$ of its prerupture value. This case produced very good core cooling and the discussion concentrates on the responsible mechanisms. The subsequent discussions then deal with the other two cases in which the pump speed was respectively held at $100 \%$ of the prerupture value and allowed to coast to a stop. The major thrust of the latter discussions is to evaluate the causes of the wide variability in thermal response that occurred as a result of the differences in the pump speed profiles.

For the case in which the pump coasted down to $64 \%$ of its prerupture speed, the pump differential pressure that developed following ECC injection played a major role in the good core cooling. After an initial seven-sec delay, during which the pump suction leg was filling with water, the ECC injection provided high density fluid at the pump inlet, causing the pump to develop a positive differential pressure as shown in Figure 34. Even when oscillations developed in the pump differential pressure the oscillatory minima continued to be positive. (The pump differential pressure oscillations are related to the filling and emptying of the ' $U$ ' shaped pump suction leg and are discussed in detail in Appendix E.) The continued substantial and positive pump differential pressure resulted in the establishment and continuation of large positive flows in both the core and intact loop.

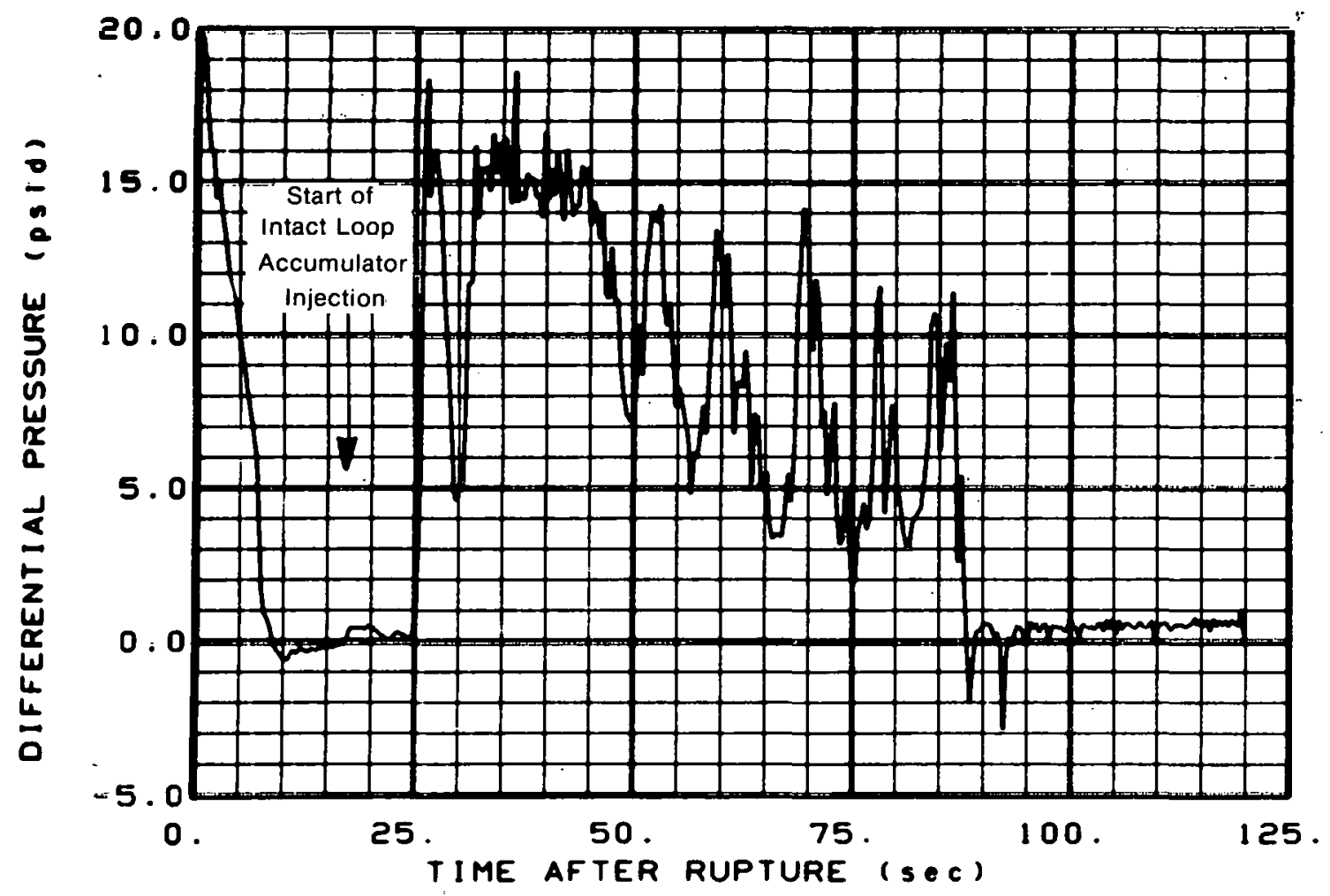

Fig. 34 Intact loop pump differential pressure for pump suction ECC injection test with pump coastdown to $64 \%$ of prerupture value.

The large positive core flow; indicated by the core inlet fluid volumetric flow (obtained from the turbine flowmeter), shown in Figure 35, contributed directly to the core cooling by supplying relatively low quality coolant to the core inlet, whereas the strongly positive intact loop flow, indicated by the hot leg flow measurement (Figure 36), influenced 


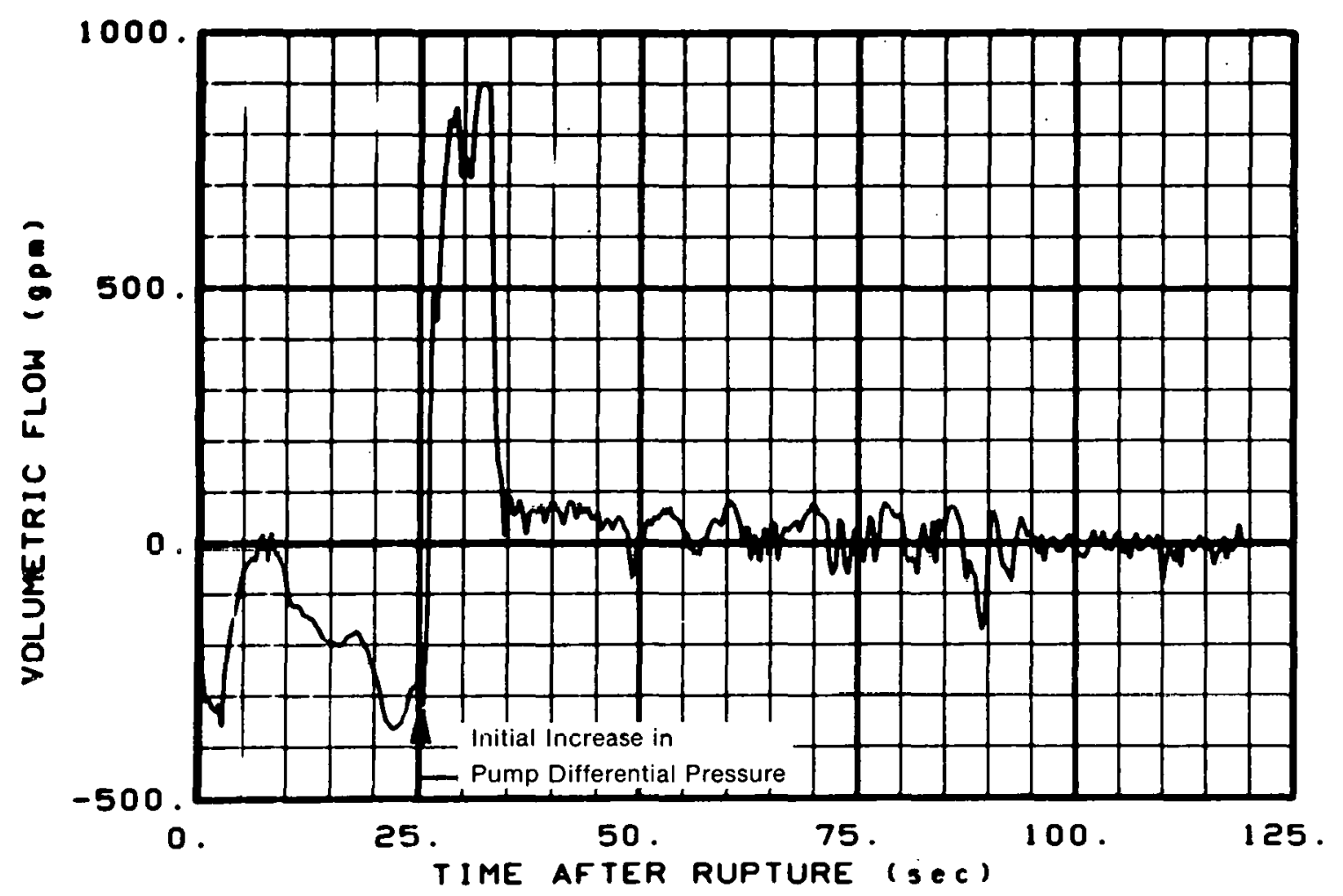

Fig. 35 Core inlet volumetric flow for pump suction ECC injection test with pump coastdown to $64 \%$ of prerupture value.

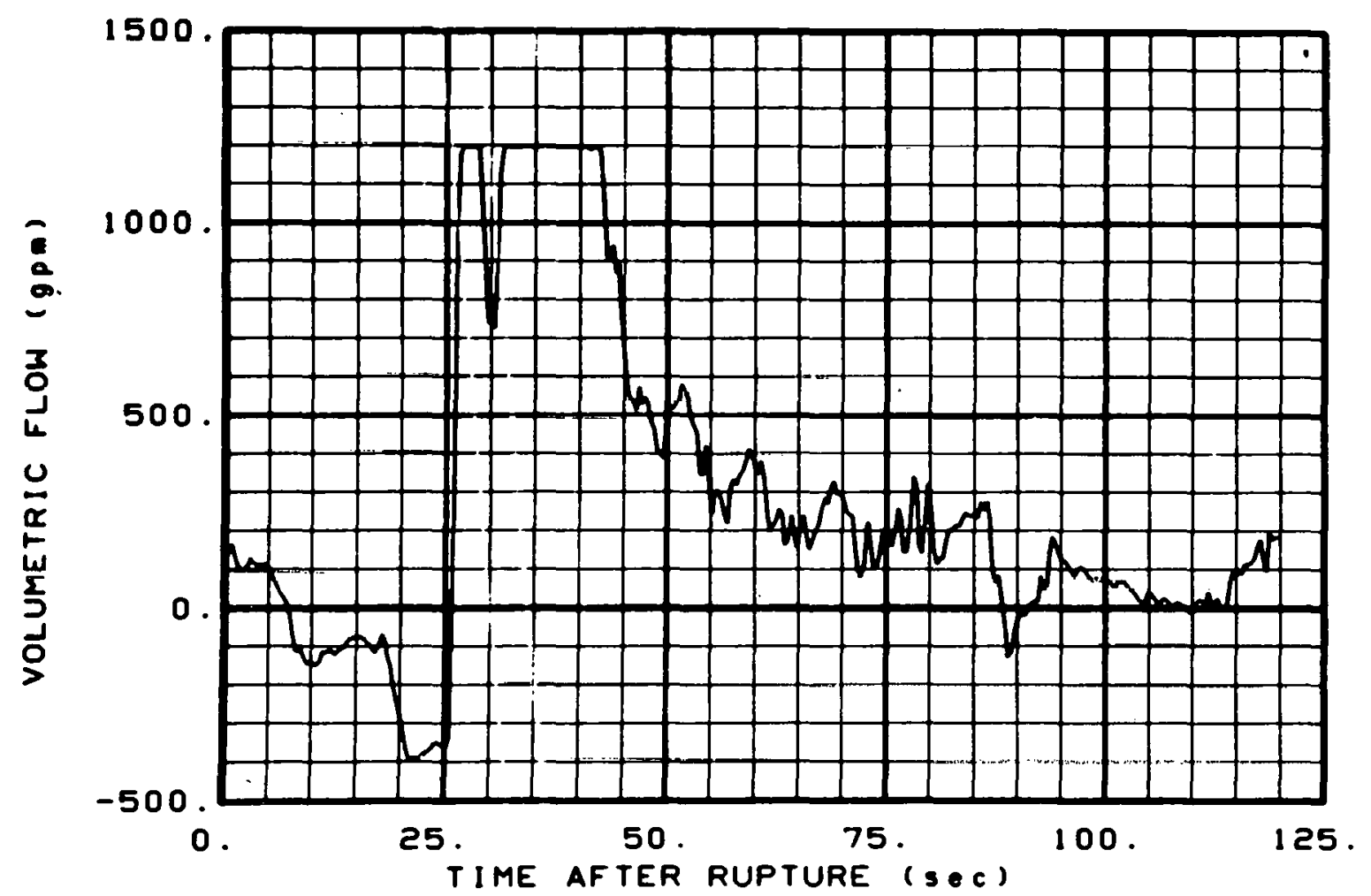

Fig. 36 Intact loop hot leg volumetric flow for pump suction ECC injection test with pump coastdown to $64 \%$ of prerupture value. 
the core thermal behavior in a more subtle fashion. The positive intact loop flow developed because of condensation of intact loop steam by the subcooled ECC fluid injected into the pump suction leg. As a result of this condensation process in the pump suction leg, the pump delivered saturated fluid to the downcomer inlet annulus for a significant period. Since the saturated fluid could not provide a condensation sink in the inlet annulus, the strong negative core and downcomer flows that generally occur as a result of the condensation process did not develop. As a result, holdup and bypass of ECC fluid out of the cold leg break were minimized and positive core flow was maintained even during the period of pump differential pressure oscillations. Therefore, the combination of the sustained positive pump differential pressure and the delivery of saturated fluid to the downcomer were the major factors resulting in the good core cooling for this case.

For the case in which the pump speed was maintained at $100 \%$ of the prerupture value the reduced core cooling effectiveness, relative to that of the previous case, was again related to the pump differential pressure history. The increased pump speed resulted in the early development of large differential pressure oscillations during which the differential pressure degraded to zero for short periods as shown in Figure 37. Because no period of sustained positive pump differential pressure occurred, the positive core flow and intact loop circulation were not established as strongly as in the case with $64 \%$ pump speed. In fact, periods of reverse core and intact loop flow developed during the lower differential pressure portions of the pump oscillations. The lack of sustained positive core flow and intact loop circulation resulted in reduced core cooling particularly during the periods when the core inlet flow was reversed.

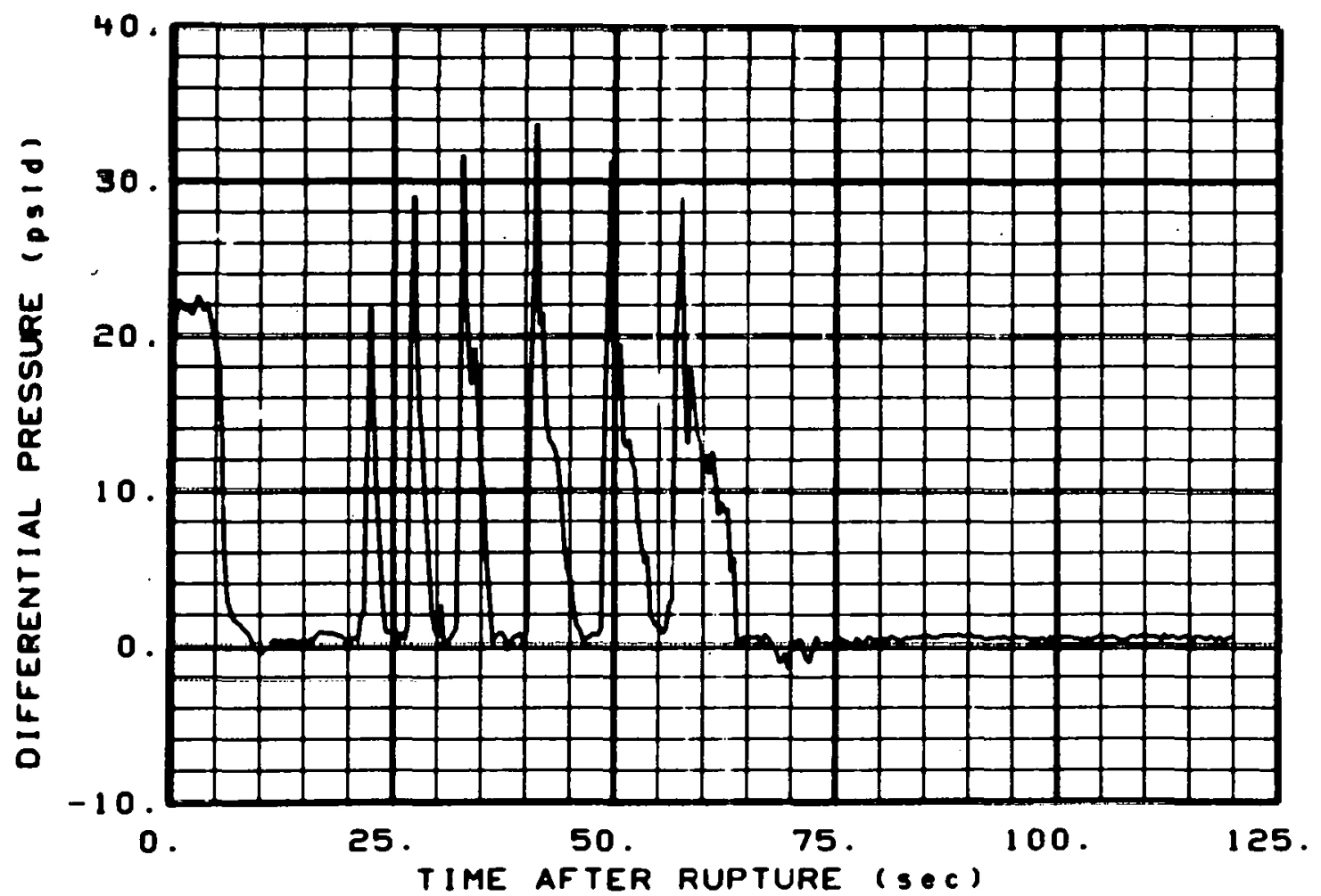

Fig. 37 Intact loop pump differential pressure for pump suction ECC injection test with pump speed maintained at $100 \%$ of prerupture value. 
The absence of a significant and sustained intact loop circulation further affected the core thermal response because condensation at the pump suction was not sufficient to cause the injected ECC fluid to reach saturated conditions prior to reaching the vessel inlet annulus. The delivery of subcooled fluid to the inlet annulus, reflected in Figure 38, caused steam to be condensed in the downcomer which induced a negative surge in the core and downcomer flows when the pump differential pressure degraded to zero. The negative flow surge in turn prevented significant ECC penetration of the downcomer, resulting in substantial ECC bypass. The continued pump oscillations allowed this bypass to occur repeatedly which resulted in a reduction in core cooling effectiveness.

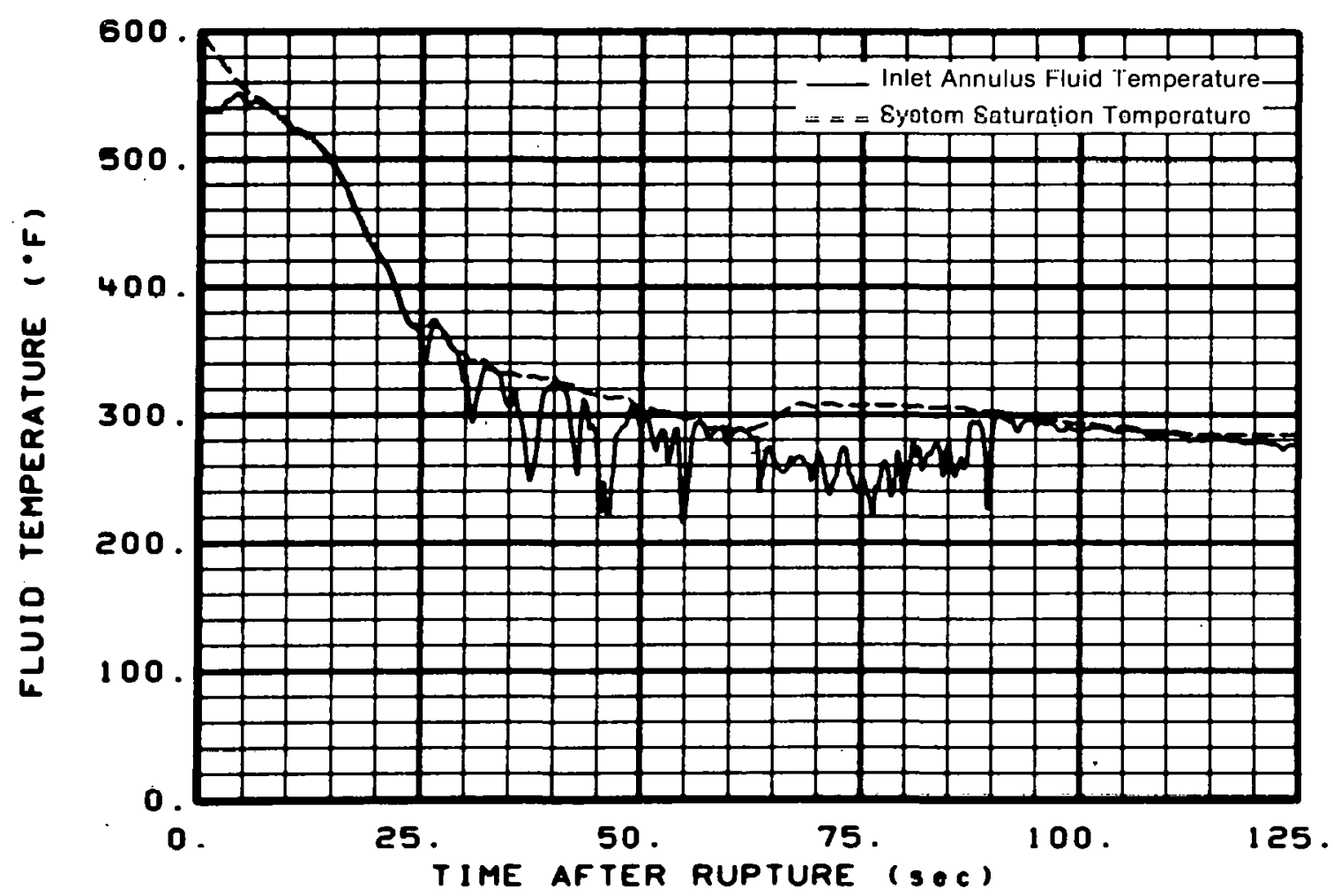

Fig. 38 Fluid temperature in downcomer inlet annulus for pump suction ECC injection test with pump speed maintained at $100 \%$ of prerupture value.

For the case in which the pump coasted down to a stop, the pump influenced the core thermal behavior not only during the ECC injection period, but also during the initial blowdown. Because of its coastdown characteristics, the pump acted as a hydraulic resistance to positive in tact loop flow during part of the initial blowdown period. As a result of the added resistance of the pump the total resistance to positive intact loop flow increased. The increased intact loop hydraulic resistance caused an increase in the reverse flow from the intact loop hot leg into the upper plenum and core. As a result, intact loop hot leg liquid, either from the steam generator or the pressurizer, penetrated into the core causing the early quenching down to the 26 -in. elevation rather than the 32 -in. elevation (in the baseline cold leg injection test) as discussed in Section III-4.1. This difference in behavior represents a second order effect in this particular case but indicates the potential for significantly changed blowdown behavior if a more rapid coas 'down were to occur. 
After intact loop ECC injection was initiated, at about $17 \mathrm{sec}$ after rupture, the small differential pressure developed by the decelerating pump led to poor core cooling. The differential pressure did not undergo oscillations because the reduced pump speed did not allow the suction leg to be depleted of liquid but the pump coastdown caused the already small differential pressure to decay rapidly. Significant positive intact loop circulation did not develop and the pump delivered subcooled water to the downcomer inlet annulus. The resulting condensation of steam in the downcomer contributed to the development of negative core and downcomer flows which prevented further penetration of the downcomer by ECC fluid and resulted in the ineffective core cooling.

\subsection{Extension of the Investigation of the Pump Suction Injection Concept Through RELAP4 Calculations}

The investigation of the pump suction injection concept was extended by using the RELAP4 code to examine the effects of ECC injection rate as an operating parameter. As noted earlier, the experimental investigation used the pump speed profile as an operating parameter and the injection rate was held constant. To provide further information on the pump suction injection concept, calculations were performed with the pump speed held constant at $100 \%$ of the prerupture value but with four different ECC injection rates. The first calculation used the experimental injection rate, about $23 \mathrm{gpm}$, to allow direct comparison between the calculated and the experimental results. On the basis of this comparison three further calculations were conducted employing higher injection rates of 46,74 , and $101 \mathrm{gpm}$.

The calculation that was performed with the same injection rate as the experiment, allowed confidence to be developed in the calculation of the hydraulic phenomena that were demonstrated, by the experiments, to be important to the core thermal response. The code calculated the large pump differential pressure oscillations very accurately and showed that the pump delivered subcooled water to the downcomer inlet annulus. The calculation also exhibited core flow oscillations with negative flow periods resulting in significant ECC bypass. Overall, the correlation between the calculations and the experimental data was close with regard to those conditions which resulted in the reduced core cooling in the experiment. This close agreement between calculations and experimental data led to the conclusion that additional calculations were warranted. Therefore, further calculations were , conducted to determine whether the hydraulic phenomena, leading to the good core cooling in the experiment in which the pump was maintained at $64 \%$ of its prerupture speed, were unique or whether they could be reproduced with $100 \%$ pump speed and a different injection rate.

The calculations showed that if the injection rate was increased to $46 \mathrm{gpm}$, the hydraulic conditions leading to good core cooling could be produced with the pump speed maintained at its prerupture value. With this injection rate the pump differential pressure again underwent oscillations but did not degrade to zero. Intact loop circulation was established and the calculation indicated that saturated fluid would be delivered to the downcomer inlet annulus. The experiments led to the consensus that these conditions would result in effective core cooling. 
The calculations with the higher injection rates demonstrated that increasing the injection rate did not necessarily provide good core cooling with the pump suction injection concept. The calculations with injection rates of $74 \mathrm{gpm}$ and $101 \mathrm{gpm}$ showed that the pump differential pressure did not undergo significant oscillation or degradation. As a result, strong intact loop circulation was established. Despite the steam circulation, however, the increased ECC injection rates resulted in subcooled liquid being delivered to the downcomer inlet annulus. As a result, countercurrent flows developed due to the condensation of steam in the downcomer. The countercurrent flows caused substantial bypass of the ECC fluid which would result in reduced core cooling effectiveness.

The calculations, together with the experimental results, demonstrate that very specific pump speed and injection rate conditions are required to provide good core cooling with the pump suction injection concept. Positive pump differential pressure must be maintained to provide positive core and intact loop flows. The relationship between the intact loop circulation and the ECC injection rate must be such as to provide saturated fluid to the downcomer inlet annulus. 'These conditions can be achicied with more than one pump speed and injection rate combination although there is no indication that a broad operating range can be achieved.

\subsection{Factors Specific to the Semiscale Mod-1 System that may Influence Results}

In the evaluation of the pump suction injection concept the Semiscale pump coastdown operating point characteristics could not be exactly matched to those for a full sized PWR. In addition, differences in the downcomer geometry and scaled intact loop volumes existed between the Semiscale facility and a PWR. The combination of these differences in pump performance characteristics and system geometry resulted in core thermal response and system hydraulic behavior in Semiscale which may not be entirely representative of that in a full sized PWR.

On the basis of experimental results and on calculation models, the combination of pump speed and pump suction injection rate appear to be of prime importance in determining the overall effectiveness of this concept in the Semiscale Mod-1 system. If these two variables are such that the combination results in a sustained positive pump differential pressure, and if sufficient intact loop condensation occurs so that the pump delivers saturated fluid to the downcomer inlet annulus, then the Semiscale results indicate that effective core cooling will result. However, if the combination of the pump speed and injection rate do not produce a sustained positive pump head and delivery of saturated fluid to the downcomer, then ineffective cooling results. In a full sized PWR with a larger downcomer flow area, the delivery of saturated fluid to the downcomer inlet annulus may not be necessary to provide good core cooling. Without the Semiscale hot wall and countercurrent flow delays subcooled water could possibly be delivered to the downcomer without large bypass of ECC out the cold leg break being experiericed. Under these conditions the effects of condensation phenomena on the pump suction ECC injection rate required for effective core cooling would not be as influential. Therefore, good core cooling over a broader range of operating conditions could be possible. 
The experimental evaluation of the pump suction ECC injection concept was performed by injecting ECC into the Semiscale intact loop pump suction leg only. This injection scheme differs from that which would occur in a full sized PWR, in that in a hypothesized LOCA, ECC would also inject into the broken loop pump suction. The decision not to inject into the broken loop pump suction was based on the fact that the broken loop did not contain an active pump, only a pump simulator. Since the broken loop pump simulator could not be expected to behave like an active pump with pump suction injection and because the intact loop pump behavior was expected to be more of a factor in influencing the overall system behavior with this concept, pump suction injection into the broken loop was not used.

\subsection{Assessment of Effectiveness of Pump Suction Injection in the Semiscale Mod-1 $\underline{\text { System }}$}

The concept of pump suction injection can result in very effective cooling, but the effectiveness of this method depends on a complex relationship between the developed pump differential pressure and the condensation potential of the particular ECC injection rate. To be effective, correct matching of the pump characteristics, injection rate, and pump suction geometry is required. The intact loop circulation developed must be capable of allowing the ECC fluid to condense enough flow to produce saturated fluid on the delivery side of the pump. Although this concépt can be effective, the effectiveness clearly depends on complex phenomena. In the absence of large scale testing, it would be difficult to develop confidence in this concept because no indication exists from the present investigation that the required system thermal-hydraulic conditions can be achieved over an extended range of pump speed and injection rate. 


\section{CONCLUSIONS}

The investigation of alternate ECC injection methods included the experimental and analytical evaluation of four distinctly different injection concepts. Each of the concepts investigated was evaluated on the basis of overall core cooling effectiveness and the effectiveness was compared with that achieved through use of cold leg ECC injection and through use of other alternate injection concepts. An important factor influencing core cooling effectiveness during the experimental investigation of several of these concepts was the condensation of steam by injected ECC. The following paragraphs present conclusions pertaining to the effectiveness of the various ECC injection concepts investigated, and address the subject of condensation and its effect on the experimenlal results.

The injection of ECC fluid into the lower plenum proved to be the most effective concept investigated in the Semiscale Mod-1 system. Lower plenum ECC injection was clearly more effective than cold leg injection in the Semiscale Mod-1 system although the Semiscale downcomer hot wall and countercurrent flow delays tend to exaggerate its superiority. Lower plenum injection eliminated the hot wall delay and the ECC bypass caused by countercurrent flow. The concept was effective primarily because it resulted in rapid lower plenum refill causing reflood to start while the system pressure was high $(170 \mathrm{psig})$. The high pressure reflood resulted in effective core cooling accompanied by significant steam generation, which maintained the high system pressure. The conditions that produced effective core cooling were, therefore, self-sustaining and the entire core was quenched by $53 \mathrm{sec}$ after rupture. The concept as used in the Semiscale Mod-1 system had the disadvantage that the rupture of the injection line itself represents a serious LOCA. However, careful design of the ECC piping could eliminate this problem.

Simultaneous accumulator injection into the upper plenum and into the cold legs was an effective ECC injection concept, as was the concept of cold leg injection with a vent line between the broken loop hot and cold legs. The cooling rates and quench times achieved with these concepts overlapped considerably and no basis exists for rating either concept significantly better than the other. In the Semiscale Mod-1 system both of the concepts provided cooling rates and quench times superior to those obtained with cold leg injection alone.

With combined upper plenum and cold leg accumulator injection the good core cooling effectiveness was primarily the result of upper plenum ECC fluid being swept into the core by negative intact loop and core flows. The negative flows were strongly related to condensation in the downcomer inlet annulus due to the presence of subcooled ECC fluid injected into the cold leg. This cooling mechanism caused the core to quench predominantly from the top down, which could represent a disadvantage with strongly bottom skewed axial power profiles. The investigation of upper plenum accumulator injection rate as an operating parameter led to the conclusion that core cooling effectiveness was not strongly related to upper plenum injection rate over the range of injection rates tested. The absence of a strong relationship between upper plenum accumulator injection rate and core cooling 
effectiveness occurred because, for the vessel injection rates used, penetration of the core by ECC injected into the upper plenum was largely controlled by the condensation process in the downcomer inlet annulus rather than by a supply mechanism in the upper plenum.

With cold leg injection and a vent line between the broken loop hot and cold legs the core cooling effectiveness was found to be related to improved cooling during both the blowdown and reflood portions of the experiment. Good core cooling during blowdown occurred because the vent line reduced the negative core flow thereby allowing liquid to be retained in the lower plenum and subsequently to be delivered to the core. The good core copoling during reflood was due to the venting action on the hot side of the core, which led to reduced cold leg ECC bypass and rapid reflood.

Overall, the conclusion was reached that both the simultaneous upper plenum and cold leg accumulator injection concept and the cold leg injection concept with the vent line were worthy of further investigation as alternate ECC injection concepts.

The investigation of the pump suction injection concept showed that, although the concept was capable of providing very good core cooling, the results were extremely variable and that some operating conditions resulted in less effective core cooling than that provided by any of the other alternate ECC concepts examined. Under some operating conditions the pump suction injection concept provided less effective core cooling than did the baseline cold leg injection concept. The investigation showed that, for the pump suction injection concept, the core cooling effectiveness depends on a complex relationship between the developed pump head and the condensation potential of a particular ECC injection rate. Within this context, the relationship between pump flow capacity, ECC injection rate and the' geometry of the ' $U$ ' shaped pump suction seal can strongly influence the system behavior. The investigation provided no indication that the pump suction injection concept could produce effective core cooling over an appreciable range of operating conditions. Consequently, without a more extensive testing program, to place any confidence in this concept would be unjustified.

Within the general context of upper plenum injection, a separate and independent study was conducted on upper plenum LPIS injection. Since this injection scheme is used exclusively on two-loop reactors, a larger scaled break area, representative of that for a $200 \%$ cold leg break in a two-loop plant, was used in the investigation of this concept. Therefore, a direct comparison of the results from this concept with those of the other concepts examined is not possible. Nevertheless, some significant observations can be made relating to the system hydraulic behavior and core thermal response with this injection concept. The study showed that upper plenum LPIS injection results in strong multidimensional core cooling and quenching behavior. The relatively small injection rate and the large negative core flows early in the transient, resulted in rapid top down cooling and quenching of that sector of the core immediately below the injection location. The top down cooling and quenching of the side of the core opposite the injection location was relatively ineffective as no strong driving mechanism was available to carry fluid into that sector of the core. The results of this experimental investigation are difficult to interpret as 
they relate to a PWR. With the large core flow area of a PWR and the increased potential for flow channeling, the possibility exists that LPIS fluid could flow through the core and fill the lower plenum, which would contribute to bottom flooding of the bulk of the core as opposed to the top down quenching process observed in the Semiscale tests.

The evaluation of experimental results from the various concepts investigated, demonstrated convincingly that condensation of steam caused by the injection of subcooled ECC fluid was very influential with regard to the core cooling effectiveness of several ECC injection concepts. The condensation process could be beneficial or detrimental to core cooling depending on the details of the specific injection concept employed. Condensation in the downcomer inlet annulus can induce strong countercurrent flows which inhibit ECC injected into the cold leg from penetrating the downcomer and thus results in significant bypass. This condensation process, and its affect on ECC penetration of the downcomer was demonstrated in the investigation of pump suction infection, in which llie best cuie cuuling was achieved when conditions were such that saturated fluid was delivered to the downcomer inlet annulus, eliminating the condensation process. Conversely, for upper plenum ECC injection, the negative core flows induced by condensation in the downcomer inlet annulus provided a strong mechanism for carrying upper plenum $\mathrm{ECC}$ fluid into the core, thereby providing effective core cooling. These observations lead to the conclusion that the difference between injecting saturated ECC fluid or subcooled ECC fluid at a given location within a given ECC concept is important to obtaining optimum core cooling.

The conclusions reached concerning each of the alternale ECC injection concepts investigated relate specifically to the Semiscale Mod-1 system. The one-dimensional characteristics of the Semiscale Mod-1 sytem as well as a. number of other factors unique to Semiscale preclude a definitive assessment of the specific benefit in terms of temperature or power for a given concept in a full size PWR. Nevertheless, these factors appear unlikely to alter the broad picture of the relative merits of the various concepts. 


\section{REFERENCES}

1. Quarterly Technical Report on Water Reactor Safety Programs Sponsored by the Nuclear Regulatory Commission's Division of Reactor Safety Research, January - March 1975, ANCR-1254 (September 1975) pp 29-60.

2. E. M. Feldman and D. J. Olson, Semiscale Mod-i Program and System Description for the Blowdown Heat Transfer Tests (Series 2), ANCR-1230 (August 1975).

3. H. S. Crapo, B. L. Collins, K. E. Sackett, Experiment Data Report for Semiscale Mod-1 Tests S-04-5 and S-04-6 (Baseline ECC Tests), TREE-NUREG-1045 (January 1977).

4. T. K. Larson, Core Thermal Response During Semiscale Mod-1 Blowdown Heat Transfer Tests, ANCR-NUREG-1285 (June 1976).

5. Proposed ANS Standard, Decay Energy Release Following Shutdown of Uranium-Fuel Thermal Reactors, ANS-51 (October 1971).

6. E. M. Feldman, M. L. Patton, Jr., K. E. Sackett, Experiment Data Report for Semiscale Mod-1 Test S-05-1 (Alternate ECC Injection Test), TREE-NUREG-1050 (February 1977).

7. D. J. Hanson et al, ECC Performance in the Semiscale Geometry, ANCR-1161 (June 1974).

8. - E. M. Feldman, M. L. Patton, Jr., K. E. Sackett, Experiment Data Report for Semiscale Mod-1 Test S-05-3 (Alternate ECC Injection Test), TREE-NUREG-1052 (March 1977).

9. B. L. Collins and E. M. Feldman, Experiment Data Report for Semiscale Mod-1 Test S-05-4 (Alternate ECC Injection Test), TREE-NUREG-1053 (March 1977).

10. E. M. Feldman and K. E. Sackett, Experiment Data Report for Semiscale Mod-1 Tests S-05-6 and S-05-7 (Alternate ECC Injection Tests), TREE-NUREG-1055 (June 1977).

11. B. L. Collins, M. L. Patton, Jr., K. E. Sackett, Experiment Data Report for Semiscale Mod-1 Test S-05-5 (Alternate ECC Injection Test), TREE-NUREG-1054 (April 1977).

12. M. L. Patton, Jr., B. L. Collins, K. E. Sackett, Experiment Data Report for Semiscale Mod-1 Tests S-05-2A and S-05-2B (Alternate ECC Injection Tests), TREE-NUREG-1057 (April 1977). 
13. E. M. Feldman, B. L. Collins, K. E. Sackett, Experiment Data Report for Semiscale Mod-1 Test S-05-2 (Alternate ECC Injection Test), TREE-NUREG-1051 (February 1977).

14. K. V. Moore and W. H. Rettig, RELAP4-A Computer Program for Transient Thermal-Hydraulic Analysis, ANCR-1 127, Rev. 1 (March 1975).

15. R. L. Benedetti et al, Potential Influence of Three Dimensional Effects of PWR LOCA Behavior, TREE-NUREG-1031 (February 1977).

16. A. C. Peterson, G. G. Loomis, L. L. Chen, Thermal and Hydraulic Response of the Semiscale Mod-1 Core During Forced Feed Reflood Tests, TREE-NUREG-1001 (October 1976). 
APPENDIX A

LOWER PLENUM ECC INJECTION 


\section{THIS PAGE \\ WAS INTENTIONALLY \\ LEFT BLANK}




\section{APPENDIX A \\ LOWER PLENUM ECC INJECTION}

\section{INTRODUCTION}

The potential benefits of using emergency core cooling (ECC) injection concepts other than only cold leg ECC injection were investigated in the Semiscale Mod-1 system. The concept of ECC injection into the lower plenum was included in this investigation. This concept had the potential for eliminating any delays associated with ECC penetration of the downcomer and, therefore, provided the possibility of effective core cooling very early in the transient. The core cooling effectiveness of lower plenum ECC injection and the major system response that resulted in the observed core cooling were both analyzed. The interpretation of the experimental results provided an assessment of the overall effects of using lower plenum ECC injection.

The Semiscale Mod-1 system configuration shown in Figure A-1 was used for investigation of lower plenum injection. The system consisted of a pressure vessel with simulated reactor internals; an intact loop with a steam generator, pump, and pressurizer; and a broken loop with a simulated steam generator, simulated pump, and two rupture assemblies. The simulated steam generator and pump contained orifices to provide the appropriate hydraulic resistance. The intact loop accumulator and the systems for pumped injection were connected to the lower plenum. Figure A-2 shows the details of the injection location and geometry. The initial conditions and ECC flow rates are tabulated in Table A-I. Additional details of the system configuration and instrumentation are documented in Reference A-1.

The experimental conditions for the lower plenum injection test (Test S-05-1) were held essentially the same as those for a baseline cold leg injection test (Test S-04-6) ${ }^{[A-2]}$ to allow comparative analysis between the two injection concepts. In the Semiscale Mod-1 system the hot downcomer walls cause a delay in the penetration of the downcomer by ECC injected in the cold leg due to flashing of the coolant. To compensate for this delay the cold leg injection accumulator water volume was larger than that used with lower plenum injection (by about $0.5 \mathrm{ft}^{3}$ ).

Section 2 of this appendix contains an assessment of the effects on the core thermal response of injecting ECC. in the lower plenum and discusses the effectiveness of the core cooling relative to that achieved with cold leg ECC injection. The major system response that results in the observed core thermal response is also discussed in this section. The significant conclusions from this investigation are presented in Section 3. 


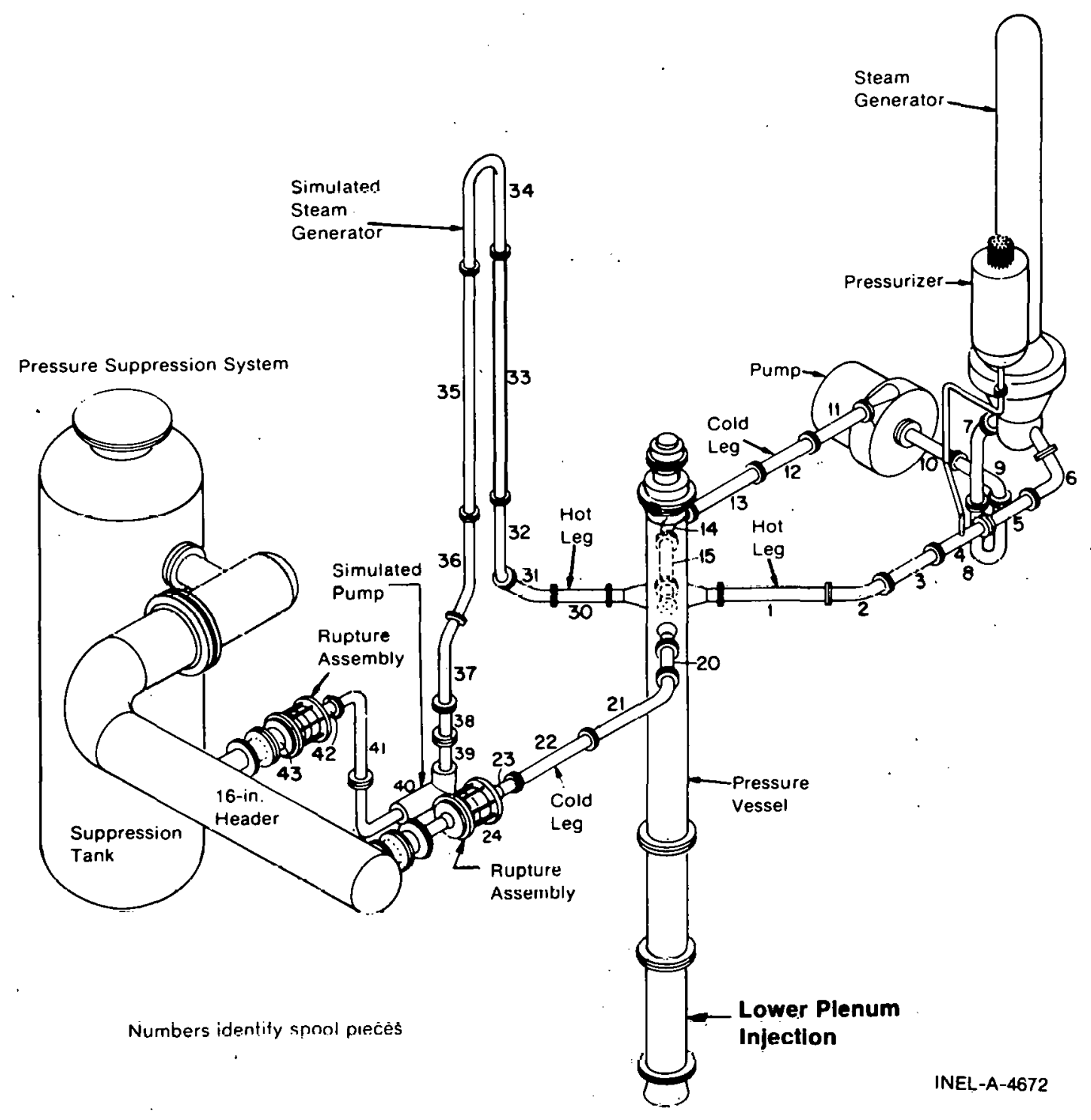

Fig. A-1. Semiscale Mod-1 sy stem configuration with lower plenum ECC injection. , !

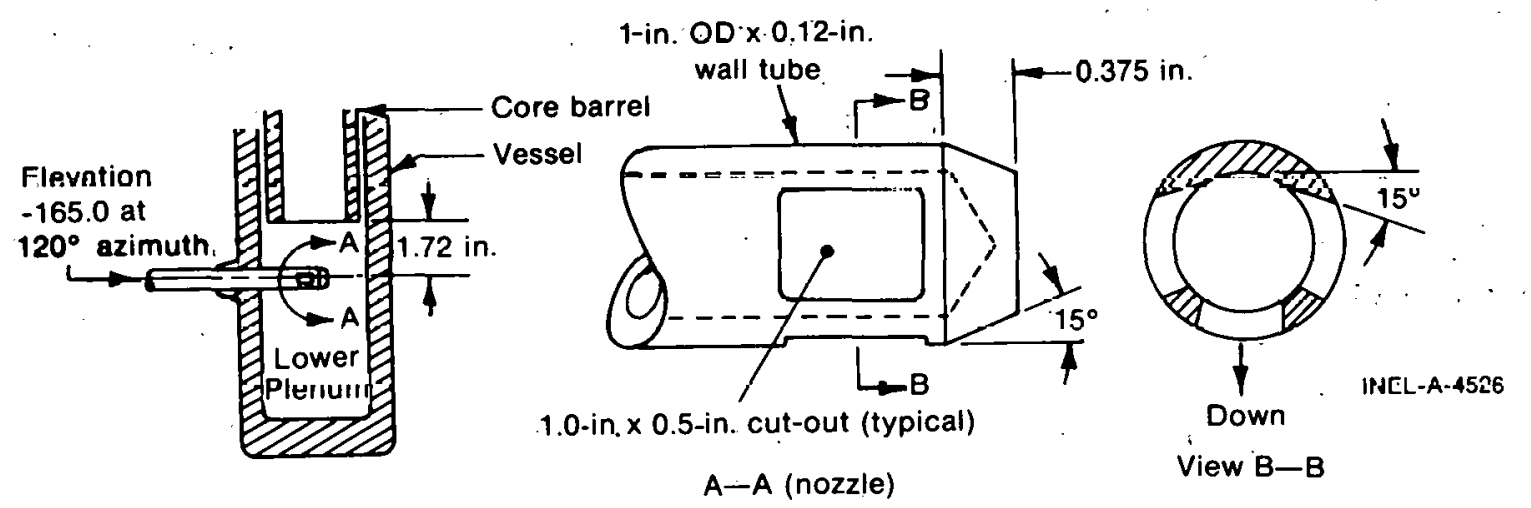

Fig. A-2 Lower plenum ECC injection line schematic. 


\begin{tabular}{|c|c|}
\hline & Test S-05-1 \\
\hline Core power $(M W)^{[a]}$. & 1.486 \\
\hline Intact loop cold leg fluid temperature $\left({ }^{\circ} \mathrm{F}\right)^{[\mathrm{a}]}$ & 544 \\
\hline Hot leg to cold leg temperature differential $\left({ }^{\circ} \mathrm{F}\right)^{[\mathrm{a}]}$ & 65 \\
\hline Steam generator feedwater temperature $\left({ }^{\circ} \mathrm{F}\right)^{[\mathrm{a}]}$ & 440 \\
\hline Steam generator liquid level (in.) ${ }^{[a, b]}$ & 116 \\
\hline Pressurizer pressure (psia) ${ }^{[a]}$ & 2263 \\
\hline Pressurizer liquid volume $\left(f t^{3}\right)^{[a, c]}$ & 0.61 \\
\hline Core flow rate $(\mathrm{gpm})^{[\mathrm{a}]}$ & 149 \\
\hline Pressure suppression system pressure $(p s i a)^{[a]}$ & 35 \\
\hline Intact/broken loop accumulator injection location & $\begin{array}{l}\text { Lower plenum/ } \\
\text { not used }\end{array}$ \\
\hline $\begin{array}{l}\text { Liquid volume }\left(\mathrm{ft}^{3}\right) \\
\text { Injection rate }(\mathrm{gpm}) \\
\text { Actuation pressure (psia) }\end{array}$ & $\begin{array}{l}2.3 \\
20.6 \\
609\end{array}$ \\
\hline Intact/broken loop LPIS injection location & $\begin{array}{l}\text { Lower plenum/ } \\
\text { not used. }\end{array}$ \\
\hline $\begin{array}{l}\text { Injection rate }(g p m) \\
\text { Actuation pressure (psia) }\end{array}$ & $200^{4.7}$ \\
\hline Intact/broken loop HPIS injection location & $\begin{array}{l}\text { Lower plenum/ } \\
\text { not used }\end{array}$ \\
\hline $\begin{array}{l}\text { Injection rate }(\mathrm{gpm}){ }^{[\mathrm{d}]} \\
\text { Actuation pressure }(\mathrm{psia})\end{array}$ & 1800 \\
\hline $\begin{array}{l}\text { Vessel accumulator injection location } \\
\text { Liquid volume }\left(\mathrm{ft}^{3}\right) \\
\text { Injection rate (gpm) }[\mathrm{d}] \\
\text { Actuation pressure (psia) }\end{array}$ & Not used \\
\hline $\begin{array}{l}\text { [a] Prior to rupture. } \\
\text { [b] Above bottom of tube sheet. } \\
\text { [c] Based on average fluid density of } 37.4 \mathrm{lbm} / \mathrm{ft}^{3} \text {. } \\
\text { [d] Average attained during test. }\end{array}$ & \\
\hline
\end{tabular}




\section{EXPERIMENTAL RESULTS}

The results of an experimental investigation with ECC injection in the lower plenum have been evaluated to determine whether improved core cooling can be achieved with this ECC injection concept. The results obtained with lower plenum ECC injection were compared with results obtained with cold leg ECC injection to evaluate the relative merits of lower plenum ECC injection. The core thermal response is discussed in the first section. The major system factors influencing the observed core thermal response are presented in the second section.

The discussion of core thermal response in the following section is limited to phenomena that are direclly related to injection of ECC in the lower plenum. The response during the early period, before ECC injection, was essentially the same as that repurted for the Semiscale blowdown heat transfer test series $[A-3]$. During this early period, unpowered rods in the Semiscale Mod-1 core affect the core response, primarily through their influcnce on the departure from nucleate boiling (DNB) behavior. The DNB behavior was very similar in the lower plenum injection test to that in the baseline cold leg injection test $[\mathrm{A}-4]$.

\subsection{Core Thermal Response}

Injection of ECC into the lower plenum resulted in an early initiation of reflood, generally effective core cooling, and a rapid quench of the core. An indication of the processes occurring is obtained by evaluating the heater rod temperature responsc. The rod cladding temperature responses at lle core ligh power elevation (29 in. ahove the bottom of the core heated length) and the 33-in. elevation during both lower plenum ECC and cold leg ECC injection are compared in Figure A-3. As shown in Flgure A-3, lower plcnum ECC injection caused a somewhal different rod cladding temperature response from that obtained for cold leg ECC injectlon during the initial depiessurization. At about 20 ses after rupture, the rod cladding temperatures started to increase at a more rapid rate with lower plenum injection than they do with cold leg injection. The more rapid temperature increase continued throughout the core until reflood was initiated at $2330 \mathrm{c}$ after rupture. Following the initiation of reflood more effective cooling occurred, progressing to successively higher rnte elevations, until finally a more rapid quench of the core occurred for lower plenum ECC injection than for cold leg ECC injection. The entire core was quenched by alvuit $52 \mathrm{sec}$ after rupture for the test with lower plenum ECC injection. The rod cladding temperntures decreased to helow the system saturation temperature, indicating that most of the core was filled with subcooled liquid. Comparison of the rod cladding temperature on an unpowered rod with the system saturation temperature in Figure A-4 shows that the coolant at the core high power elevation was subcooled by about $180^{\circ} \mathrm{F}$ at $70 \mathrm{sec}$ after rupture. 


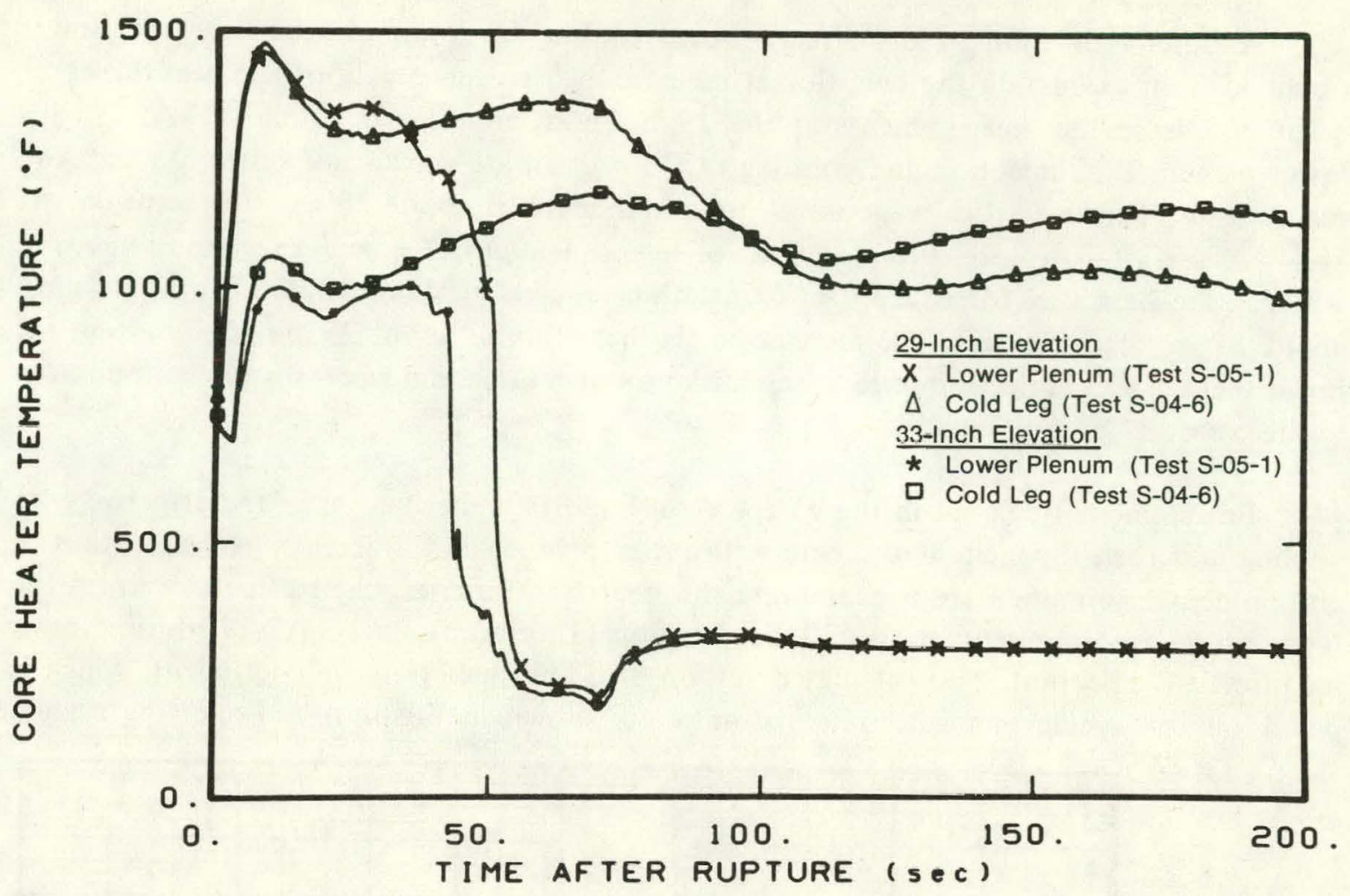

Fig. A-3 Comparison of core heater temperature response with lower plenum and cold leg ECC injection - Tests S-05-1 and S-04-6.

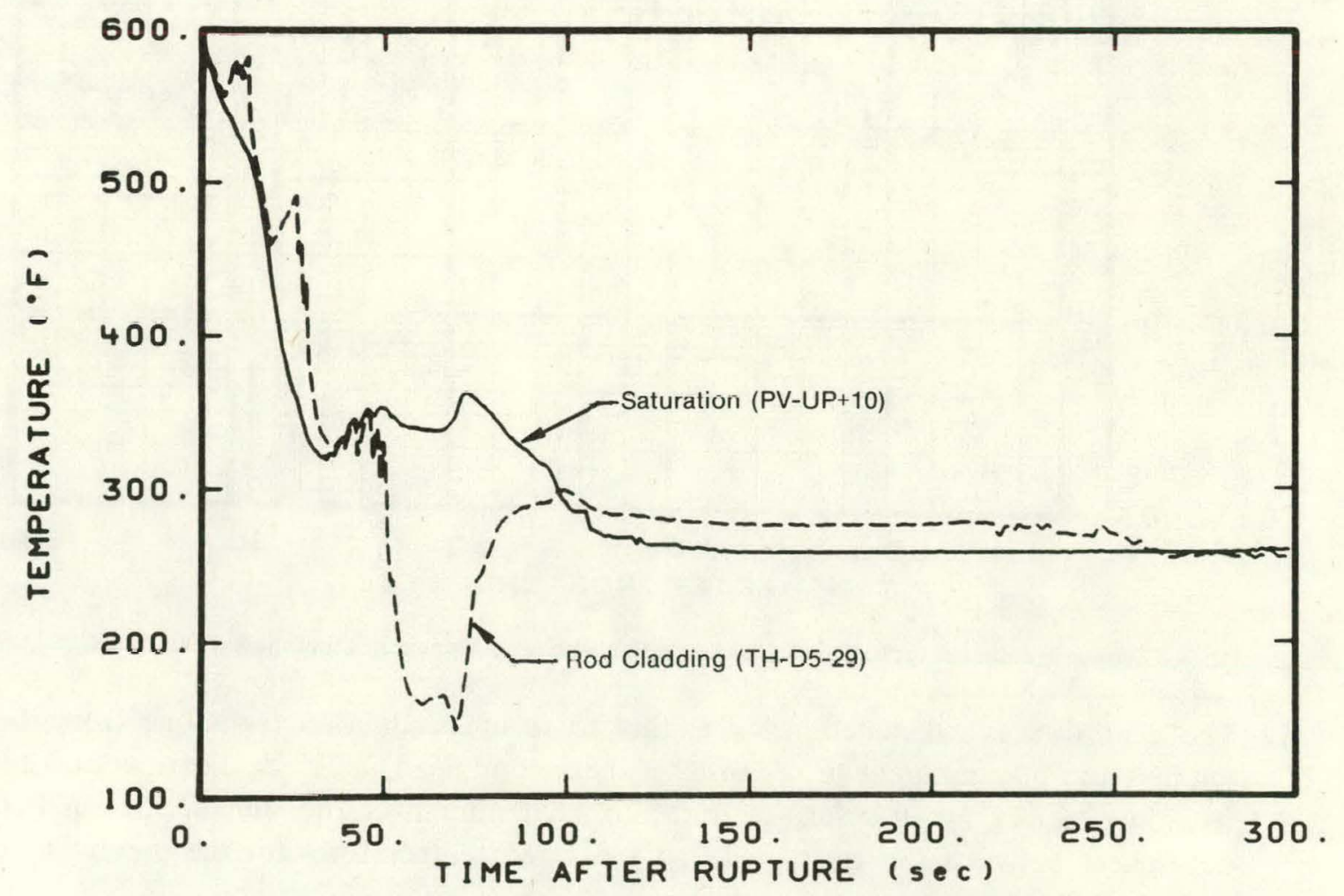

Fig. A-4 Comparison of rod cladding and saturation temperature during lower plenum ECC injection - Test S-05-1. 
Another indication of the effective core cooling for lower plenum ECC injection is obtained from examining the heat flux at the core high power elevation. The heat fluxes ${ }^{[a]}$ calculated from the measurements at the 29-in. elevation (Thermocouple TH-A5-29) for lower plenum ECC injection and cold leg ECC injection are shown in Figures A-5 and A-6, respectively. The heat flux response is quite similar until about $25 \mathrm{sec}$ after rupture. At about $25 \mathrm{sec}$ after rupture, the heat flux for lower plenum ECC injection starts to increase, whereas the heat flux for cold leg ECC injection remains at about $10,000 \mathrm{Btu} / \mathrm{hr}^{-\mathrm{ft}^{2}}$ until about $55 \mathrm{sec}$ after rupture. The increase in the heat flux at about $25 \mathrm{sec}$ after rupture for lower plenum ECC injection reflects the initiation of reflood and water droplet entrainment in the core.

Entrainment of liquid in the core was an important mechanism in the effective core cooling and early quench of the core with lower plenum EC' injection. An indication of entrainment is obtained from examining the heat transfer coefficient calculated from the temperature measurement at the 29-in. elevation (Thermocouple TH-A5-29) during lower plenum $E C^{-1}$ injection. The calculated response of the heat transter coefticient, which is based on the system saturation temperature, is shown in Figurc A-7. Following system

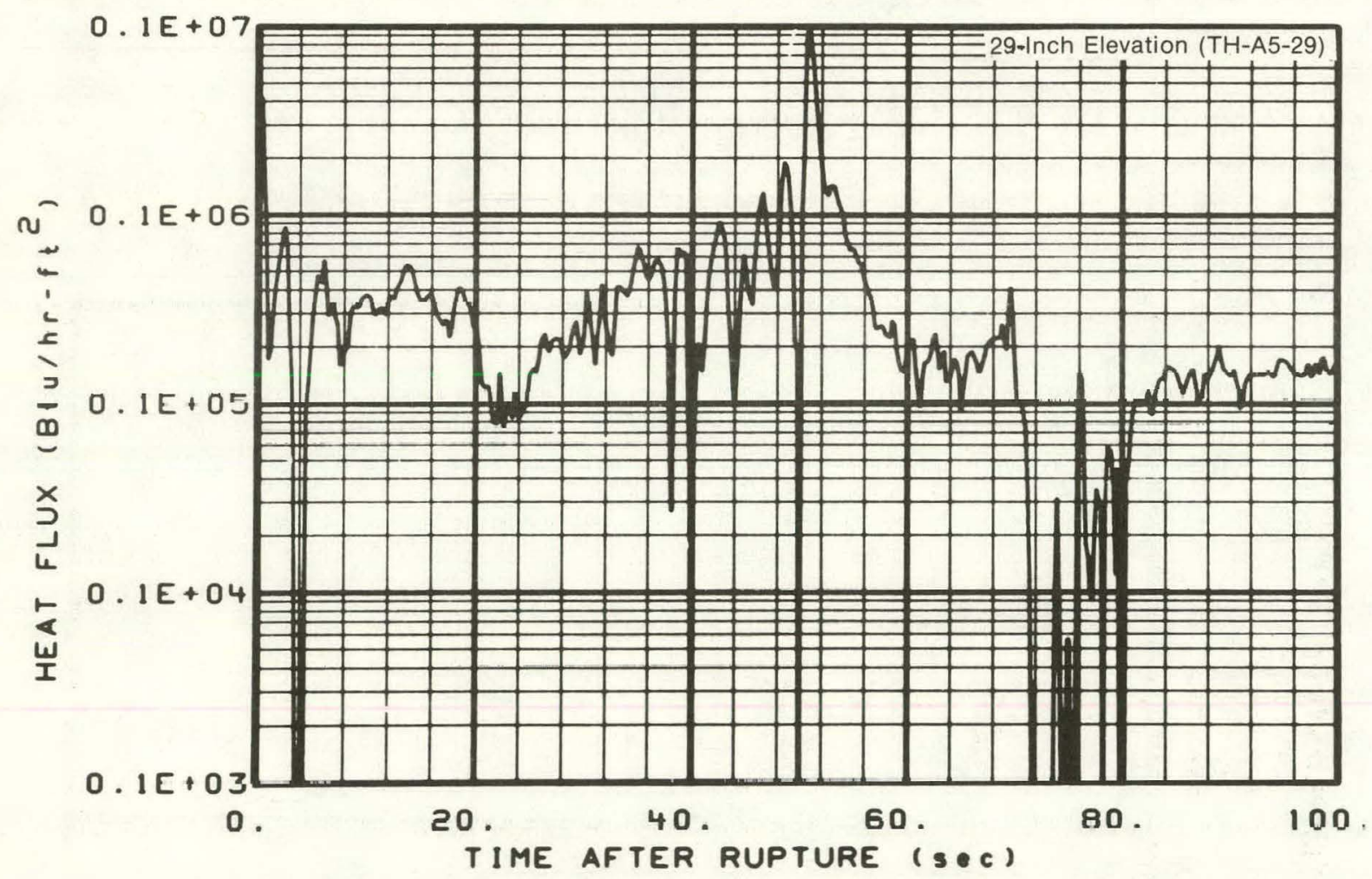

Fig. A-5 Surface heat flux at the core peak power elevation with lower plenum ECC injection - Test S-05-1.

[a] The heat flux is calculated using an inverse heat conduction technique from the temperature measurement provided by a thermocouple. The inverse heat conduction technique solves for the surface heat flux that minimizes the sum of the squared differences between the calculated and measured temperatures for the present time step and a few future time steps. 


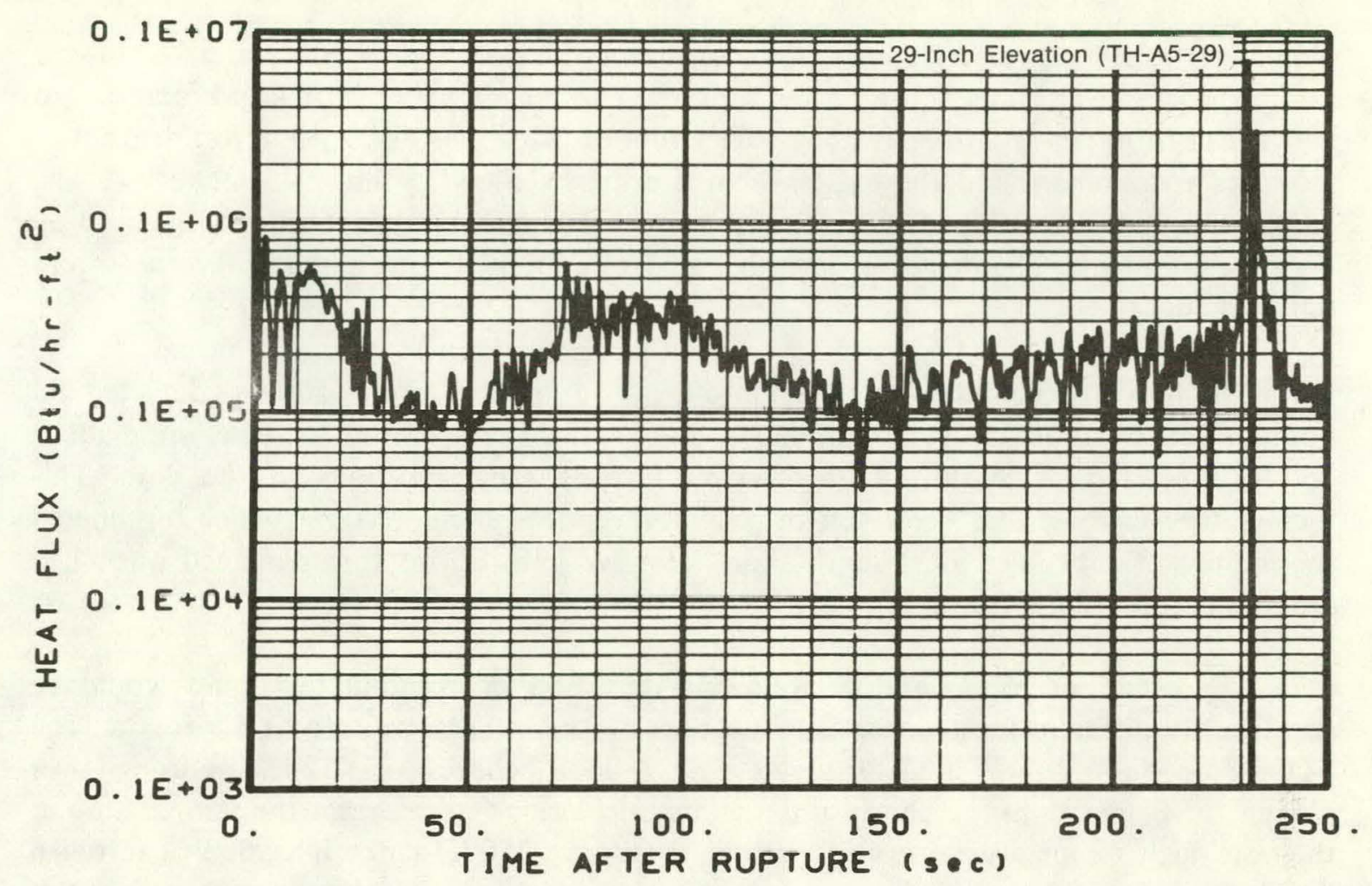

Fig. A-6 Surface heat flux at the core peak power elevation with cold leg ECC injection - Test S-04-6.

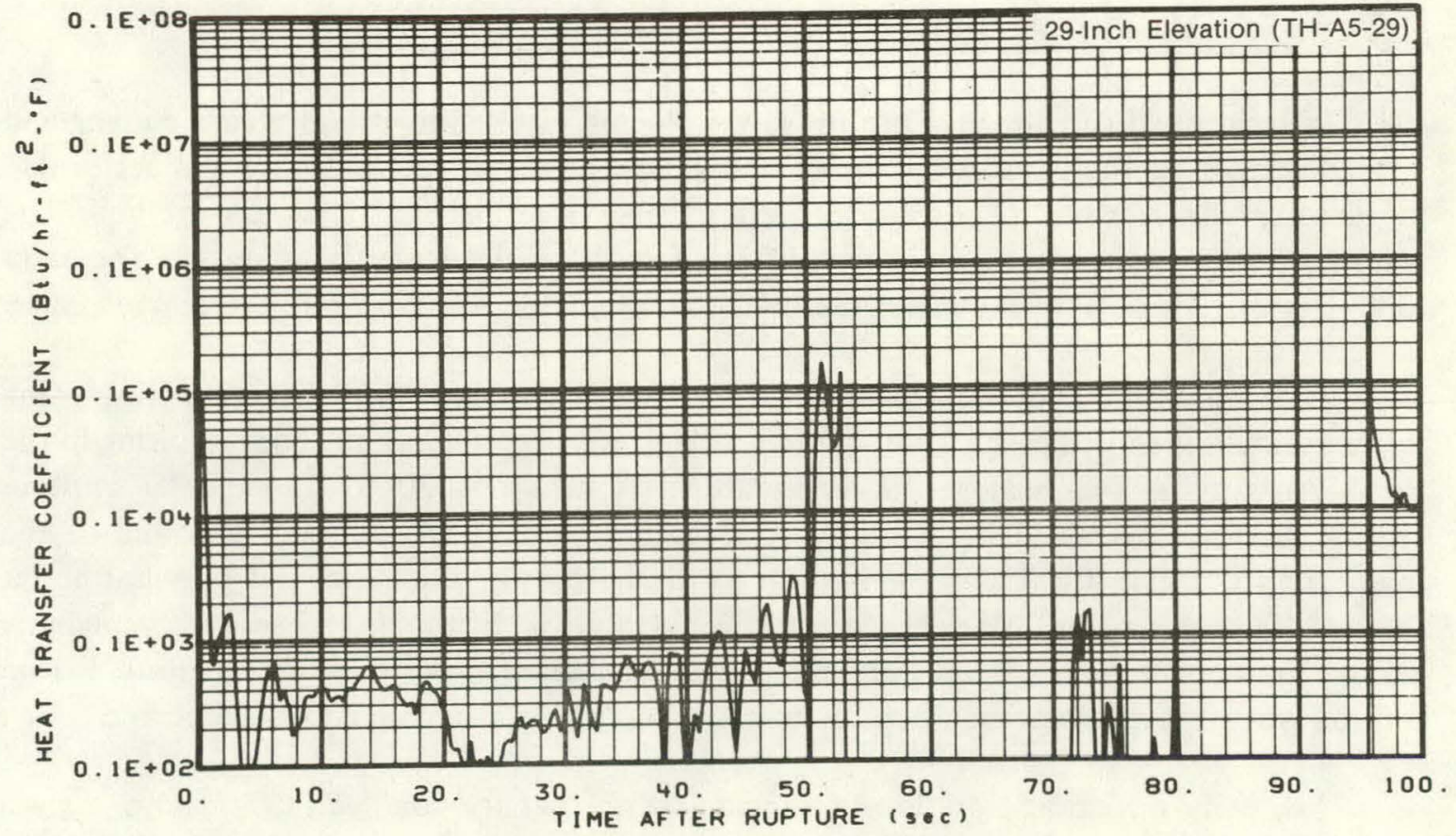

Fig. A-7 Heat transfer coefficient response at the core peak power elevation during lower plenum ECC injection - Test S-05-1. 
blowdown and depressurization, the heat transfer coefficient decreases to about $10 \mathrm{Btu} / \mathrm{hr}-\mathrm{ft}^{2}{ }^{2} \mathrm{~F}$ at about $22 \mathrm{sec}$ after rupture. The heat tran $\mathrm{fer}$ coefficient increases to above $20 \mathrm{Btu} / \mathrm{hr}-\mathrm{ft}^{2}{ }^{\circ} \mathrm{F}$ at about $25 \mathrm{sec}$ after rupture which, as discussed in Reference A-5, indicates entrainment and the existence of a dispersed flow at the 29-in. elevation. The oscillations in the heat transfer coefficient, shown in Figure A-7, are strongly influenced by the core inlet flow. The decreases in heat transfer coefficient correspond to reverse (top to bottom) core flow.

The flow of accumulator nitrogen into the lower plenum when water was depleted did not significantly affect the core thermal response. A slight temperature increase, up to about $150^{\circ} \mathrm{F}$, occurred at about $70 \mathrm{sec}$ after rupture at some locations in the core. This temperature increase was the result of general reversal in the core flow, which terminated the supply of subcooled ECC to the core. However, the entire core remained quenched during the following nitrogen injection.

The effect of nitrogen flow following depletion of accumulator liquid would be significantly different for a longer (12 ft) core than for the Semiscale Mod-1 5.5-ft core. The FLOOD4 code ${ }^{[\mathrm{A}-6]}$ was used to calculate the reflood behavior of a 12-ft core using lower plenum ECC injection ${ }^{[a]}$. The results of this calculation indicate that the temperature at the core high temperature elevation would be about $1350^{\circ} \mathrm{F}$ at the initiation of nitrogen flow. Therefore, the rod cladding temperatures would be expected to increase above this value during nitrogen injection if core flow conditions occurred for a 12 -ft core similar to the results for the 5.5-ft Semiscale Mod-1 system.

\subsection{Major System Factors Resulting in the Observed Core Thermal Response}

Injection of ECC directly into the lower plenum resulted in effective core cooling and a rapid quench of the core. A detailed investigation of the system behavior was performed to identify the reasons for the overall effectiveness of this ECC injection method. The results of this investigation indicate that rapid refill of the lower plenum and the early initiation of reflood were the major factors in obtaining the observed core thermal response.

The rapid filling of the lower plenum changed the core flow direction during the depressurization and caused a short period of ineffective cooling in the core resulting in the rapid increase in the heater rod temperatures from about 20 to $23 \mathrm{sec}$ after rupture (Figure A-3), as discussed in Section 2.1. This change in flow direction was due to the injected ECC filling the lower plenum up to the bottom of the flow inlet sleeve at about $20 \mathrm{sec}$ after rupture and blocking the negative core flow. In the next $3 \mathrm{sec}$, the remaining about 23 in. of the core inlet were filled with coolant. During this 3 -sec period, before reflood was initiated, the core flow rate was low and ineffective core cooling occurred.

The early initiation of reflood (compared with that for cold leg ECC injection) was a major factor in the overall effectiveness of lower plenum ECC injection. The countercurrent

[a] Version FL4B7HVP. 
flow phenomena and hot wall delay associated with cold leg ECC injection in the Semiscale Mod-1 system were eliminated with lower plenum ECC injection. The elimination of the countercurrent flow phenomena and hot wall delay resulted in a rapid filling of the lower plenum and reflood initiation occurring at about $23 \mathrm{sec}$ after rupture, which was about $21 \mathrm{sec}$ earlier than for cold leg ECC injection. The rapid increase in the core inlet density shown in Figure A-8 indicates the initiation of reflood.

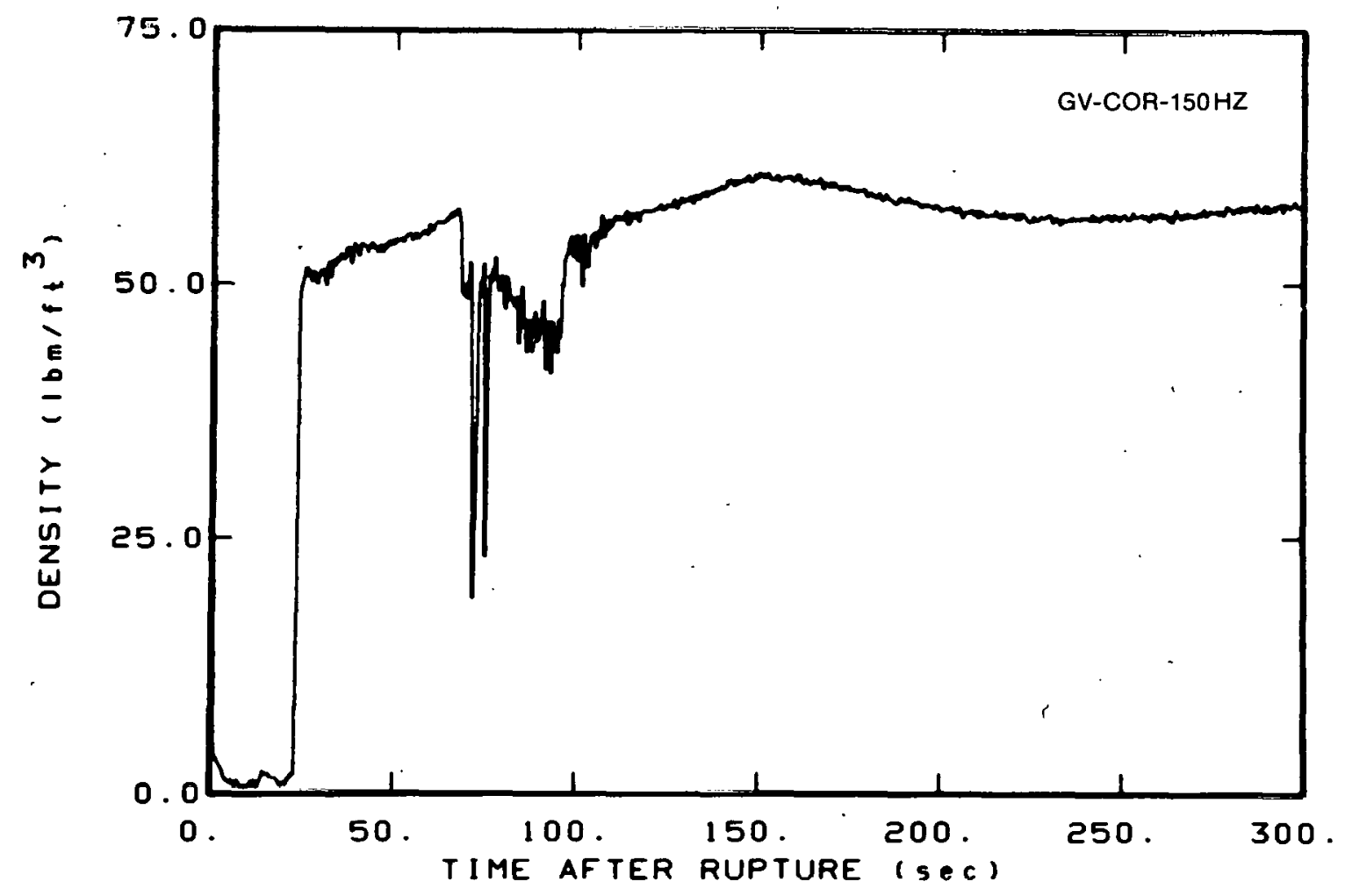

Fig. A-8 Core inlet density response during lower plenum ECC injection - Test S-05-1.

The early initiation of reflood with lower plenum ECC injection caused reflood to occur at a higher system pressure which resulted in improved core cooling relative to cold leg injection. The rapid refill of the lower plenum resulted in the core reflooding at a 70- to 80-psia higher system pressure with lower plenum ECC injection as shown in Figure A-9. Reference A-5 discussed the more effective cooling that occurs during reflood at a higher system pressure due to changes in the physical properties of the steam and the liquid entrainment mechanisms. The liquid was entrained by the rapid steam generation above the quench front as the coolant interacted with the hot core surfaces. The higher system pressure resulted in a higher steam generation rate which fed back to maintain a high system pressure prior to accumulator nitrogen injection.

Another factor which could have contributed to the maintenance of a high system pressure was the existence of choked flow in the cold leg break nozzle, although whether choked flow developed at the nozzle or not is not known with certainty. The choked flowrate was calculated using measured temperatures, pressures, and fluid densities with the homogeneous equilibrium model. I'his calculation indicated that choked flow did exist 


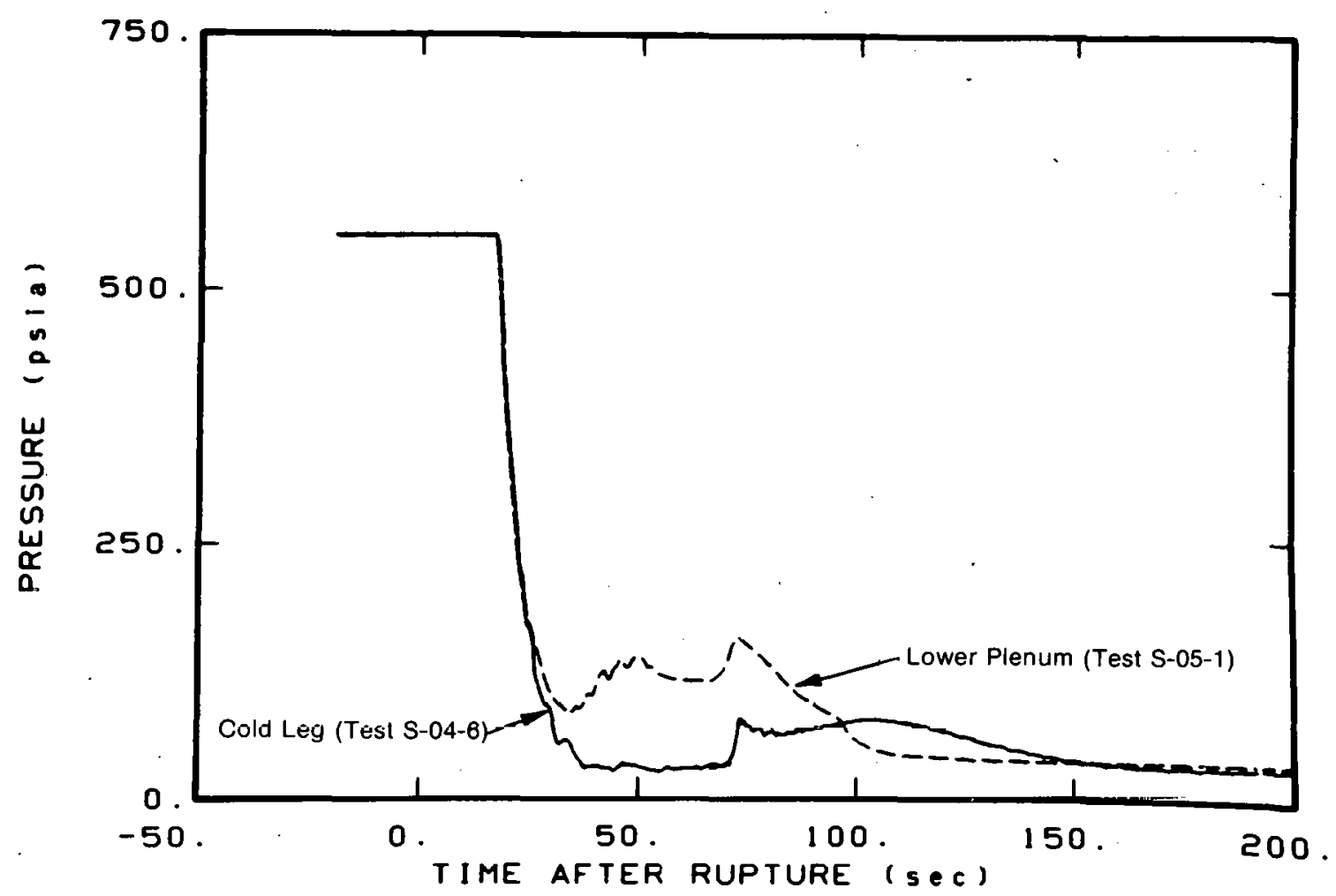

Fig. A-9 Comparison of the system pressure during lower plenum and cold leg ECC injection - Tests S-05-1 and S-04-6.

during the reflood phase of the test, but uncertainty exists because the measured properties used in the calculation were obtained near the lower limits of the measurement ranges and are, therefore, subject to considerable instrument error.

An evaluation of the lower plenum fluid conditions indicates sweepout of the fluid in the lower plenum was not increased by the injection of subcooled coolant into the lower plenum. The rapid filling of the lower plenum using lower plenum injection resulted in the reverse core flow, associated with the system depressurization, being terminated and positive core flow occurring at $23 \mathrm{sec}$ after rupture as illustrated in Figure A-10. Examination of Figure A-10 also shows that some large negative oscillations in the core inlet flow occurred after about $25 \mathrm{sec}$ after rupture. However, the density at the core inlet, shown in Figure A-8, indicates that the inlet of the core remained full of water. Therefore, the oscillations in the core inlet flow do not indicate reverse steam flow out the core and up the downcomer but indicate oscillations in the water level in the core due to steam generation in the core. The temperature measurement of the fluid at the core inlet shown in Figure A-11 indicates spikes of subcooled fluid at the core inlet. This subcooled fluid would condense any reverse steam flow out the core and assures sweepout of the lower plenum by reverse steam flow would not occur.

The downcomer and core fluid behavior was investigated to evaluate the hydraulic interaction between the fluids in these regions for lower plenum ECC injection. The downcomer collapsed liquid levels, calculated from the differential pressure measurement 


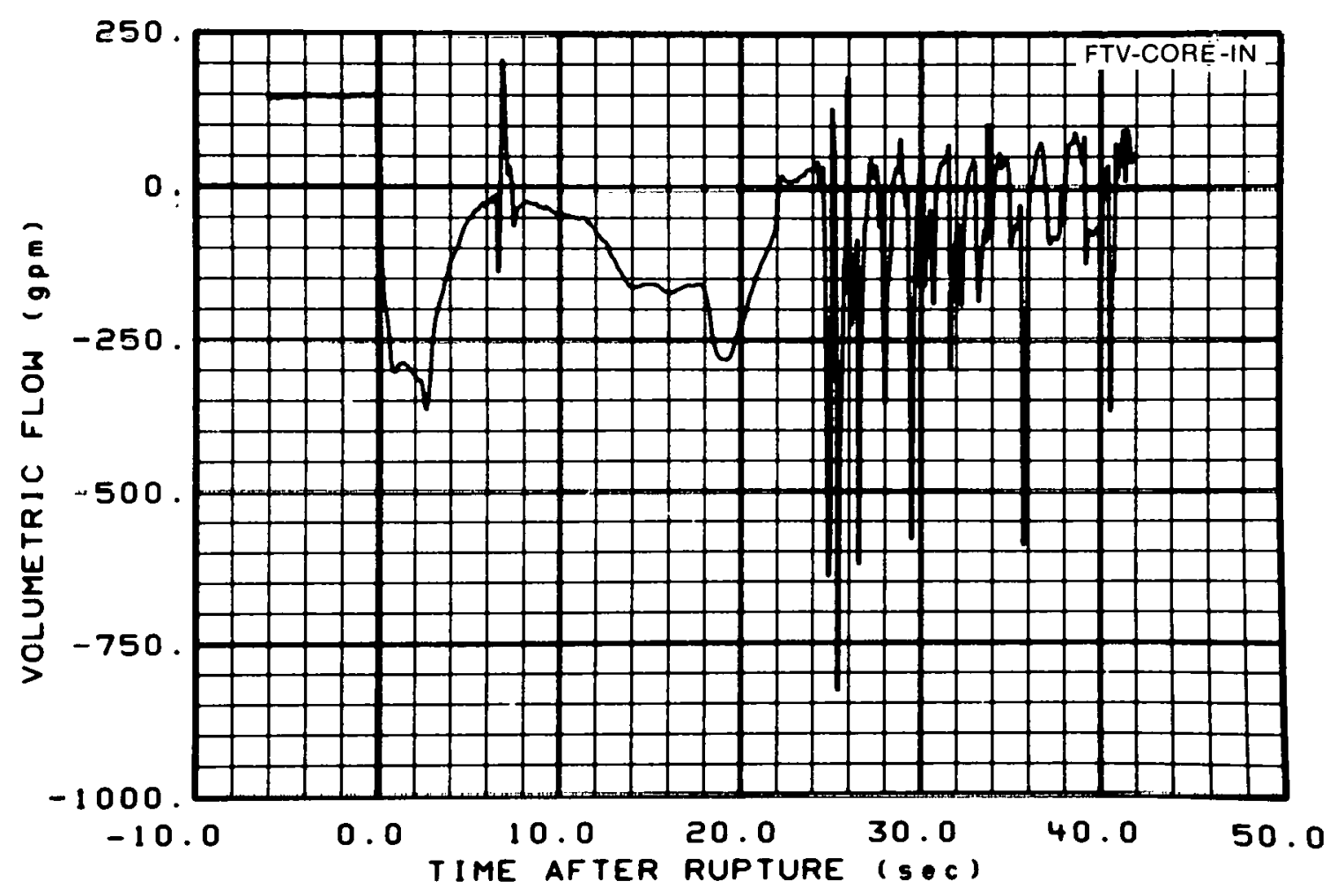

Fig. A-10 Short-term core inlet volumetric flow response during lower plenum ECC injection - Test S-05-1.

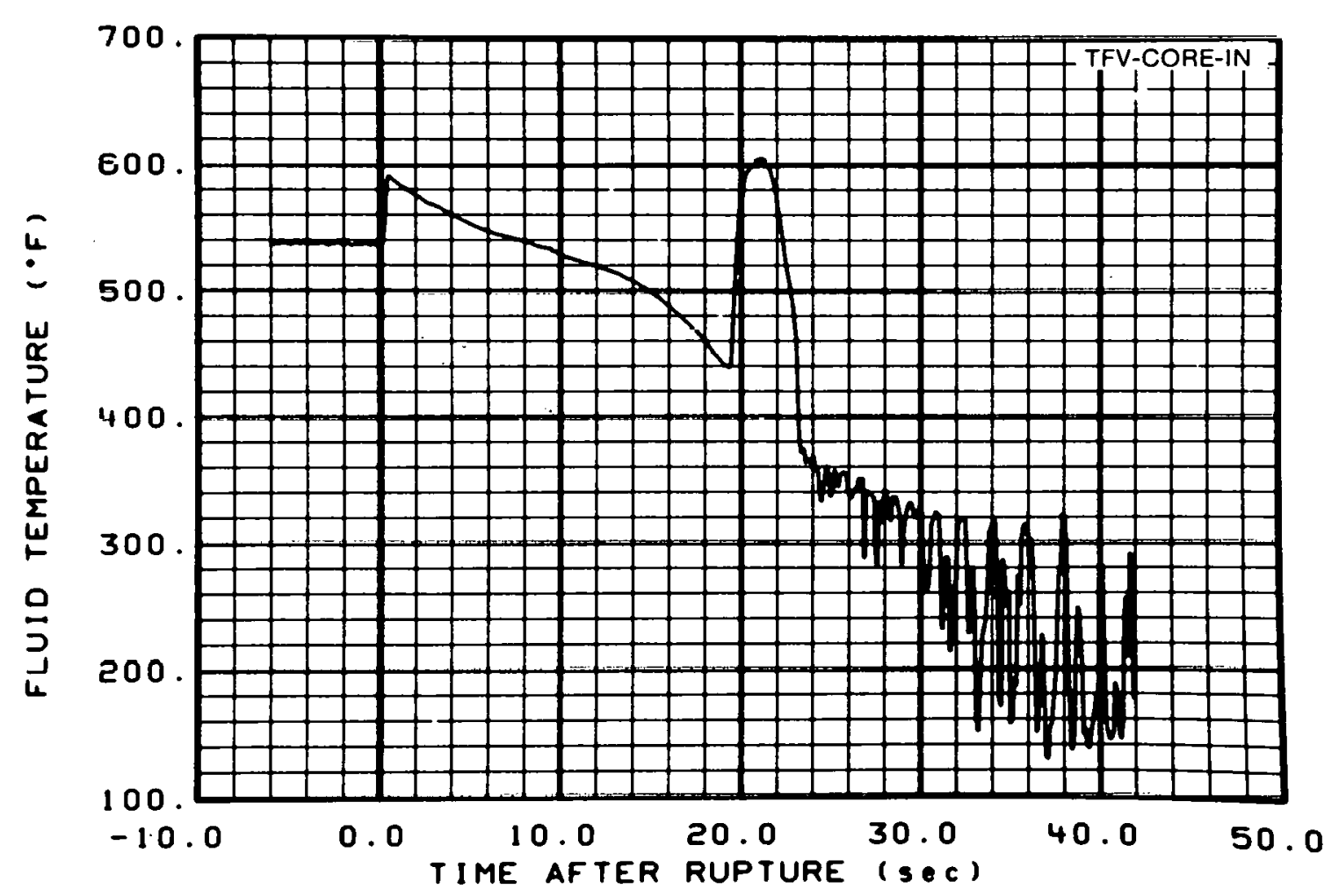

Fig. A-11 Short-term response of the fluid temperature at the core inlet with lower plenum ECC injection - Test S-05-1. 
DPV-9-166, for lower plenum ECC injection and cold leg ECC injection are compared in Figure A-12. As shown, the downcomer was essentially filled by about $35 \mathrm{sec}$ after rupture for lower plenum ECC injection, whereas, about $60 \mathrm{sec}$ were required to fill the downcomer for cold leg ECC injection. The oscillations in the downcomer level were of much smaller magnitude for lower plenum ECC injection than cold leg ECC injection during reflood. The smaller oscillations indicate that less hydraulic interaction occurred between the downcomer and the core for lower plenum ECC injection than cold leg ECC injection. One reason for the lesser interaction was that the entire core was apparently covered with liquid. The downcomer and core collapsed liquid levels are compared in Figure A-13 and show that the downcomer and core are both full of liquid up to 9-in. below the cold leg at about $65 \mathrm{sec}$ after rupture. This filling of the core with water was also indicated by the subcooled temperatures measured by the core heater rod thermocouples as discussed in Section 2.1.

The injection of accumulator nitrogen has several significant effects on the system response; however, since the core was quenched before nitrogen injection was initiated, no adverse thermal effects occurred in the core. The injection of accumulator nitrogen at about $67 \mathrm{sec}$ after rupture resulted in an initial increase in the system pressure, as shown in Figure A-9, and a decrease in the downcomer collapsed liquid level. The pressure increase caused by the nitrogen resulted from two effects: from the factor of about three increase in the volumetric flow from the accumulator during nitrogen flow and from the increased steam generation. The decrease in the downcomer collapsed liquid level was due to the nitrogen sweeping coolant out the vessel side of the break. The increase in the density on the vessel side of the broken loop shown in Figure A-14 indicates that increased flow

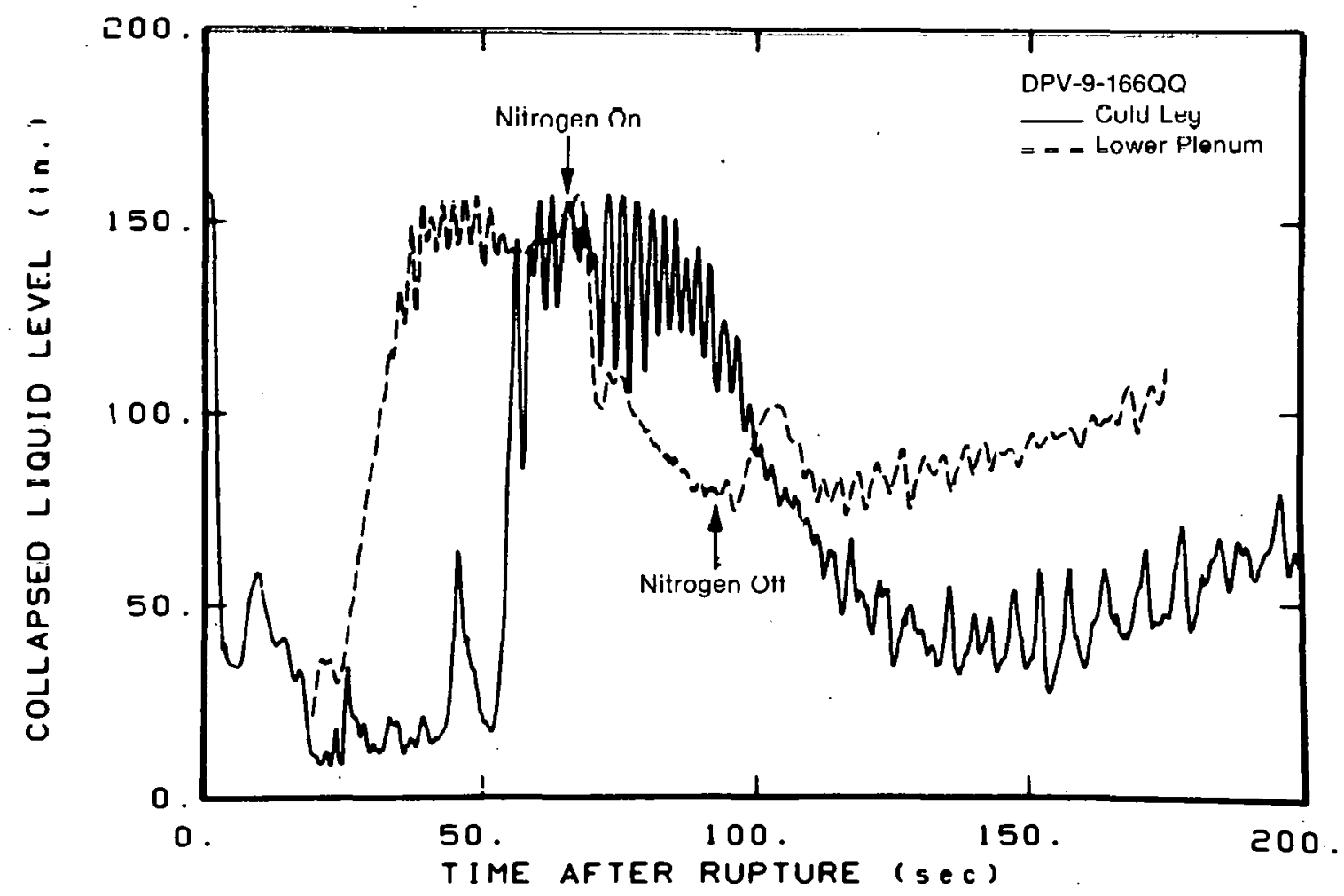

Fig. A-12 Comparison of the downcomer collapsed liquid levels for lower plenum and cold leg ECC injection - Tests S-05-1 and S-04-6. 


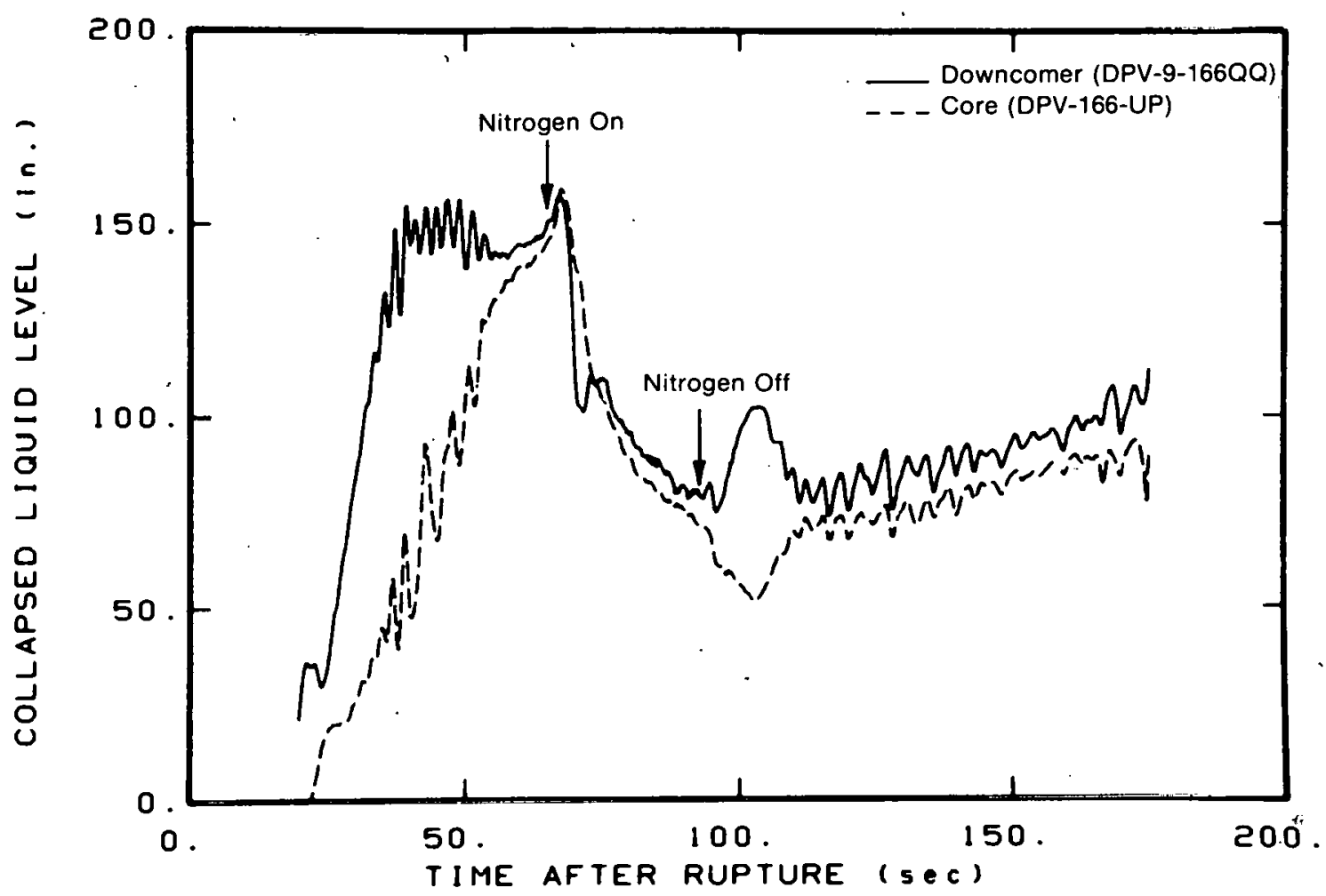

Fig. A-13 Comparison of the downcomer and core collapsed liquid levels during lower plenum ECC injection - Test S-05-1.

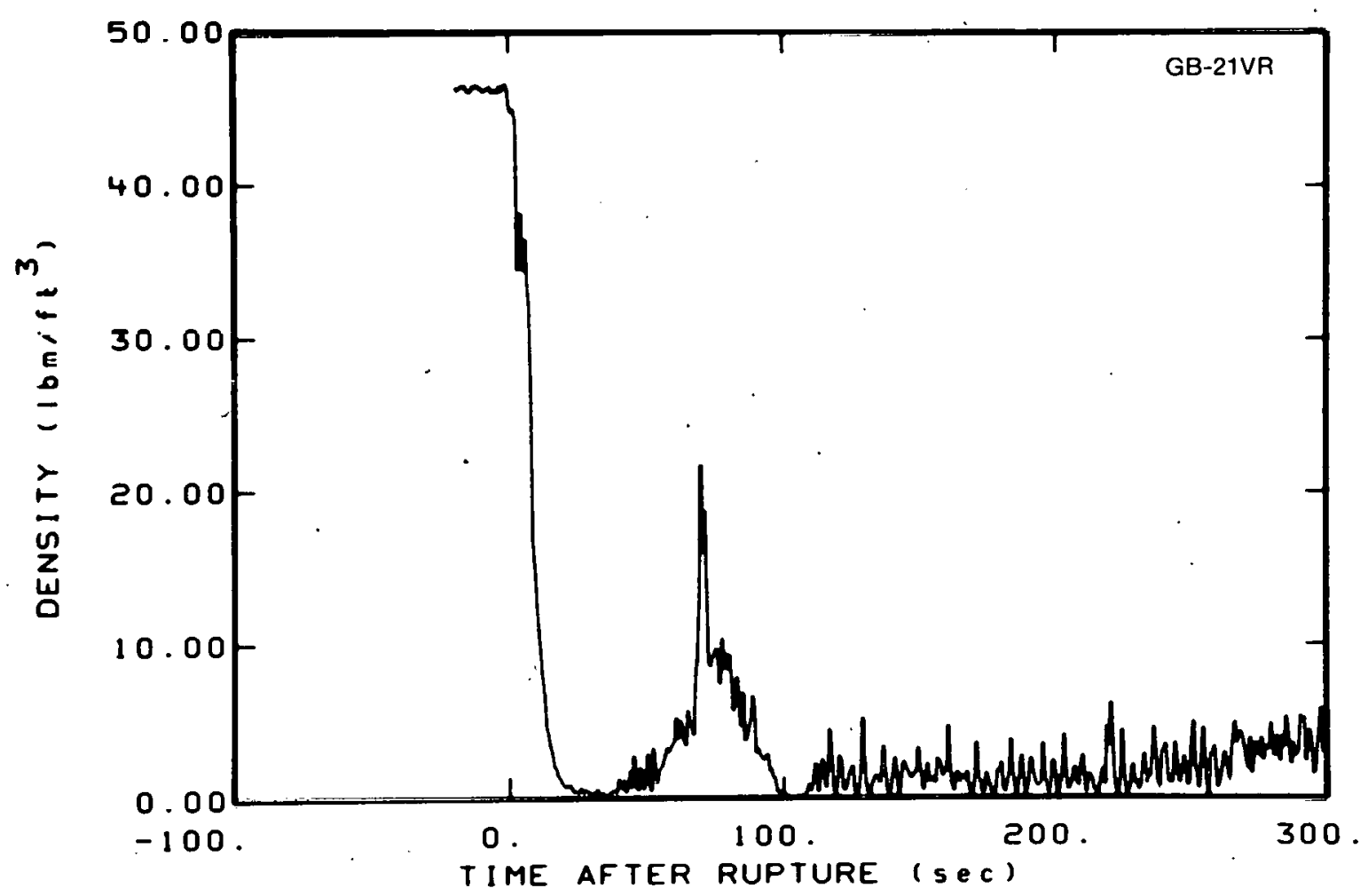

Fig. A-14 Density response at the vessel side of rupture during lower plenum ECC injection - Test S-05-1. 
bypassed out the break. The core inlet flow was negative about $4 \mathrm{sec}$ after the initiation of nitrogen injection (about $69 \mathrm{sec}$ after rupture) as shown in Figure A-15, whereas the core inlet density measurement indicates the core inlet was covered with water until about $69 \mathrm{sec}$ after rupture. These measurements show that nitrogen did not flow into the core.

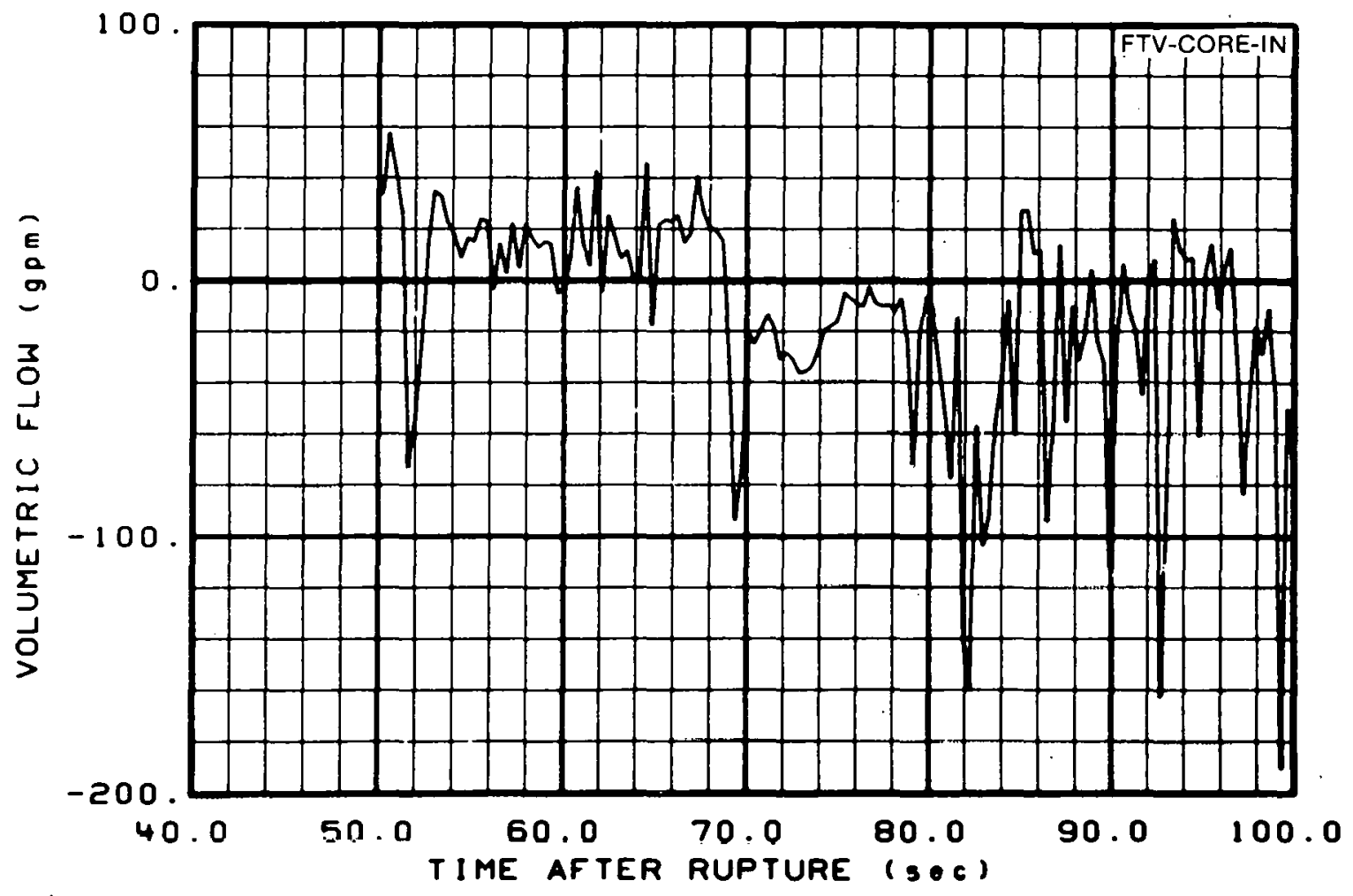

Fig. A-15 Core inlet volumetric flow during lower plenum $\mathrm{ECC}$ injection - Test 5-05-1.

The reverse core flow that occurred during nitrogen injection had a significant effect on the observed core thermal response. This reverse core flow resulted in coolant that had previously passed up through the core, being returned down the core and heated a second time. As a result, hotter fluid existed in the core and the temperature of the rod cladding rose by about $130^{\circ} \mathrm{F}$ as. shown in Figure A-3. Higure A-16 shows that the average temperature of the fluid entering the lower plenum increased by about $100^{\circ} \mathrm{F}$ due to the hot fluid from the core entering the lower plenum. The reverse core flow also exposed surfaces in the upper sections of the core which increased the steam generation rate. 


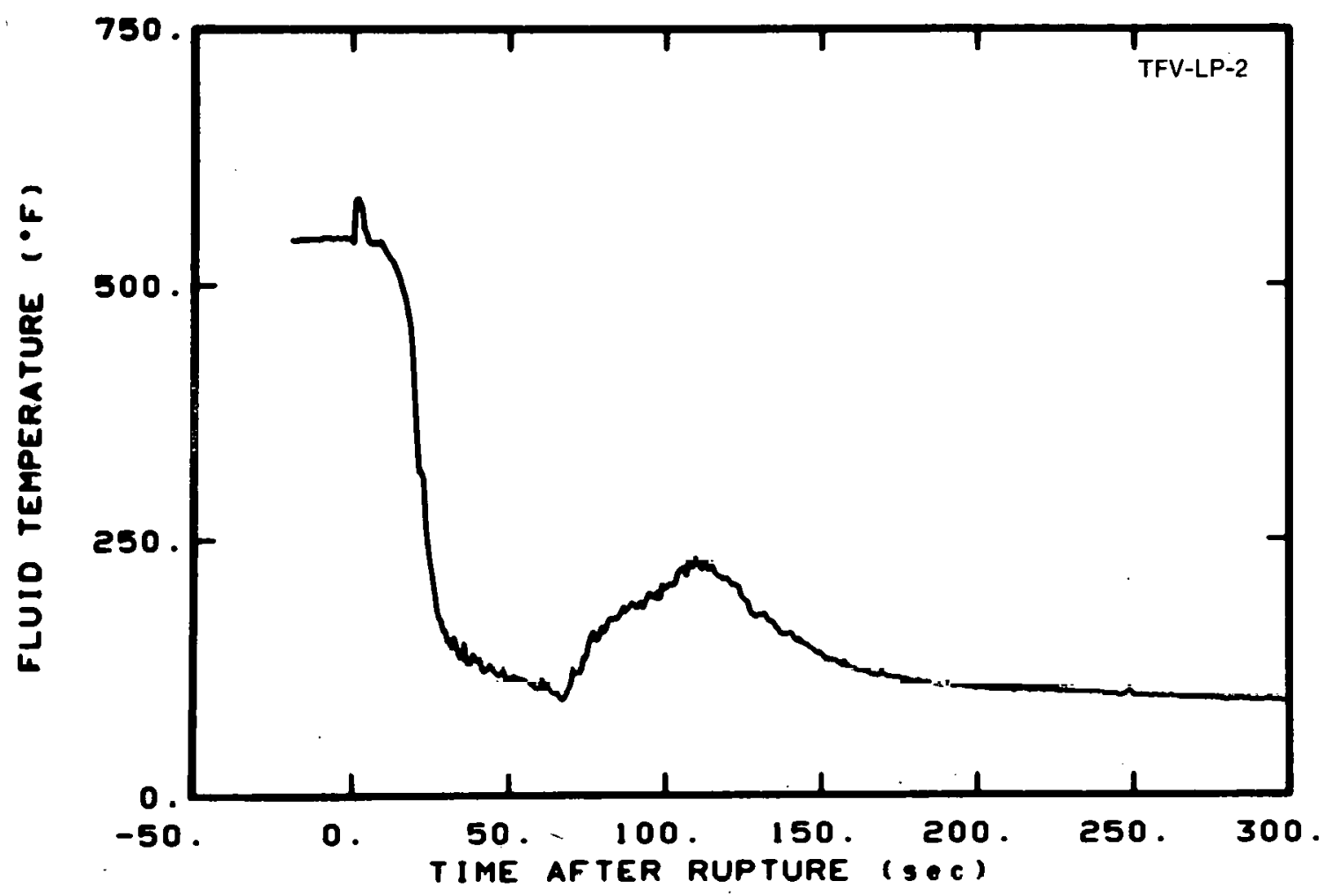

Fig. A-16 Core inlet fluid temperature during lower plenum ECC injection - Test S-05-1.

\section{CONCLUSIONS}

The thermal-hydraulic response of the Semiscale Mod-1 core during lower plenum ECC injection has been investigated. The results of this analysis have led to an increased understanding of the phenomena associated with ECC injection into the lower plenum. The results have also been valuable in evaluating the potential benefits to core cooling of using lower plenum ECC injection in place of cold leg ECC injection.

\subsection{Core Thermal Response}

'The use of lower plenum injection resulted in effective heat transfer and a rapid quench of the core. The cntirc corc was quenched about 52300 after ruplure. The rud cladding temperatures increased about $150^{\circ} \mathrm{F}$ during nitrogen injection due to reverse core now.

\subsection{Corc Hydraulic Responsc}

The effective heat transfer resulted from a rapid refill of the lower plenum and the initiation of reflood at a relatively high system pressure. The rapid filling of the lower plenum with subcooled liquid up to the core inlet eliminated the potential of sweepout of the lower plenum by reverse core flow. 


\section{REFERENCES}

A-1. E. M. Feldman, M. L. Patton, Jr., K. E. Sackett, Experiment Data Report for Semiscale Mod-1 Test S-05-1 (Alternate ECC Injection Test), TREE-NUREG-1050 (February 1977).

A-2: H. S. Crapo, B. L. Collins, K. E. Sackett, Experiment Data Report for Semiscale Mod-1 Tests S-04-5 and S-04-6 (Baseline ECC Tests), TREE-NUREG-1045 (January 1977).

A-3. T. K. Larson, Core Thermal Response During Semiscale Mod-1 Blowdown Heat Transfer Tests, ANCR-NUREG-1285 (June 1976).

A-4. J. M. Cozzuol, Thermal-Hydraulic Analysis of Semiscale Mod-1 Integral Blowdown-Reflood Tests (Baseline ECC Test Series), TREE-NUREG-1077 (March 1977).

A-5. 'A. C. Peterson, G. G. Loomis, L. L. Chen, Thermal and Hydraulic Response of the Semiscale Mod-1 Core During Forced Feed Reflood Tests, TREE-NUREG-1001 (October 1976).

A-6. R. L. Benedetti et al, Potential Influence of Three Dimensional Effects on a PWR LOCA Behavior, TREE-NUREG-1031 (February 1977). 
APPENDIX B

UPPER PLENUM ACCUMULATOR INJECTION ACCOMP.ANIED BY COLD LEG INJECTION 
THIS PAGE

\section{WAS INTENTIONALLY \\ LEFT BLANK}




\section{APPENDIX B \\ UPPER PLENUM ACCUMULATOR INJECTION}

ACCOMPANIED BY COLD LEG INJECTION

\section{INTRODUCTION}

The potential benefits of using emergency core cooling (ECC) injection concepts other than cold leg ECC injection alone following a $200 \%$ double-ended cold leg break were investigated in the Semiscale Mod-1 system. The concept of accumulator injection into the vessel upper plenum, combined with accumulator injection and high and low pressure pumped injection in the cold legs, was included in this investigation. This concept offered the possiblity that the added upper plenum injection would provide additional coolant to the core, and possibly, act as a condensation sink in the upper plenum to reduce steam binding effects associated with bottom reflooding. Two different upper plenum injection rates were used to determine the effects of varying this operational parameter: an 8.4-gpm injection rate (Test S-05-3) and a 16-gpm injection rate (Test S-05-4), both in conjunction with essentially the same cold leg injection rate (about $23 \mathrm{gpm}$ ). The effectiveness of the combined upper plenum accumulator injection and cold leg injection concept was evaluated by comparative analysis with results obtained using cold leg intact loop accumulator injection alone (Test S-04-6) ${ }^{[B-1]}$.

The Semiscale Mod-1 system configuration that was utilized in the investigation of the upper plenum accumulator injection concept is shown in Figure B-1. The system consisted of a pressure vessel with simulated reactor internals; an intact loop with a steam generator, pump and pressurizer; and a broken loop with a simulated steam generator, simulated pump and two rupture assemblies. The simulated steam generator and pump contained orifices to provide the appropriate hydraulic resistance. Details of the upper plenum accumulator ECC injection system are shown in Figure B-2. The upper plenum accumulator injection was initiated when the system pressure reached 300 psia. The cold leg intact loop accumulator injection was initiated when the system pressure reached 600 psia. At the depletion of cold leg intact loop accumulator injection, nitrogen from the accumulator tank was allowed to flow into the Semiscale Mod-1 system; however, no nitrogen was allowed to flow into the vessel upper plenum from the upper plenum injection system. The Semiscale Mod-1 core utilized to investigate the upper plenum injection concept included 36 heated rods and four unheated rods to represent guide tubes and instrument thimbles present in a four-loop pressurized water reactor. Figure B-3 shows the Semiscale Mod-1 core heater rod layout.

The core thermal response is important in evaluating the effectiveness of the upper plenum injection concept and is discussed in Section 2 of this appendix. The system thermal-hydraulic behavior responsible for the core thermal response is discussed in Section 3 and the conclusions regarding the effectiveness of the upper plenum injection concept are presented in Section 4. 


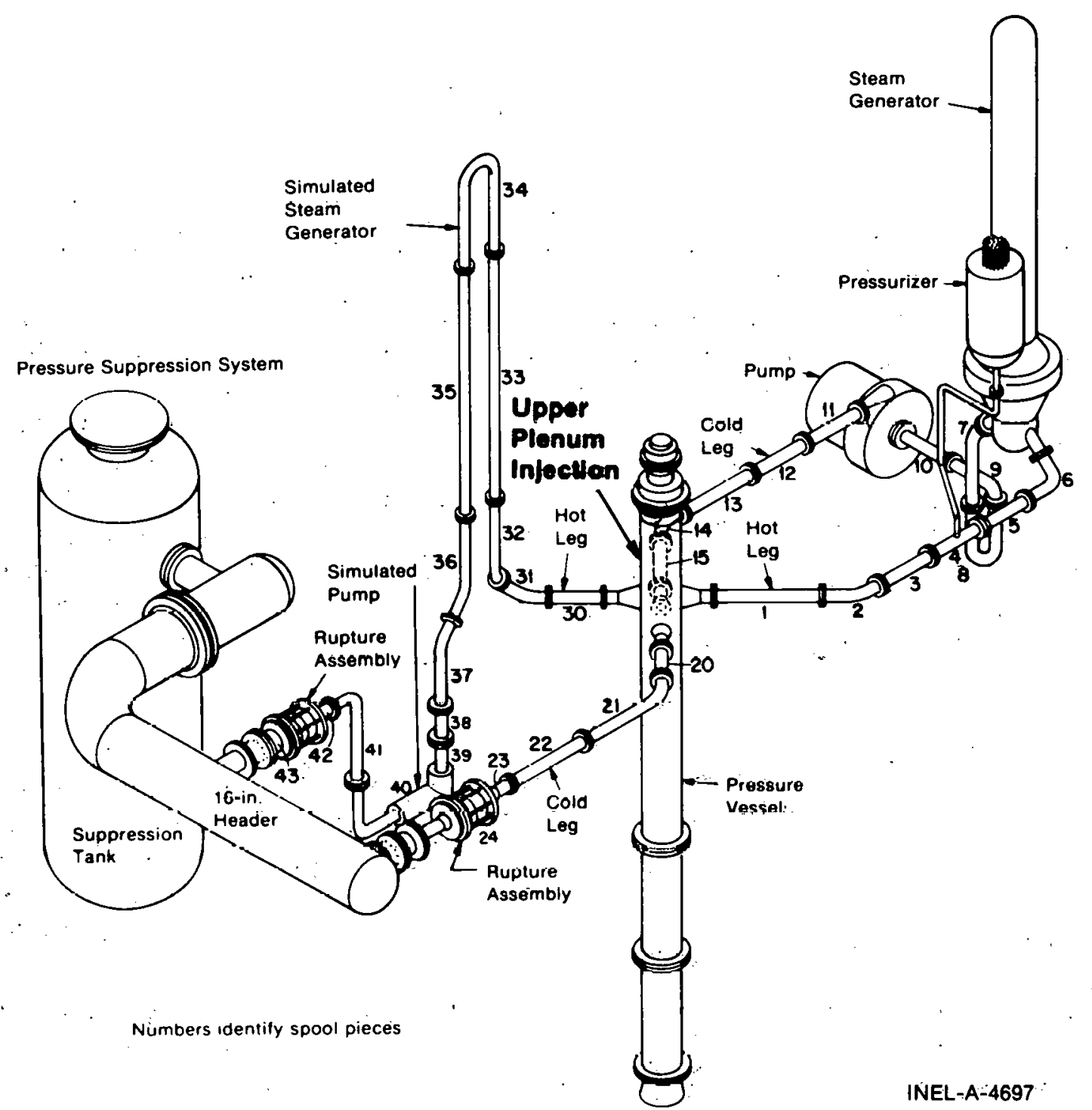

lig. B I Somiscalo Mod-1 systesu coulfigutial init: 


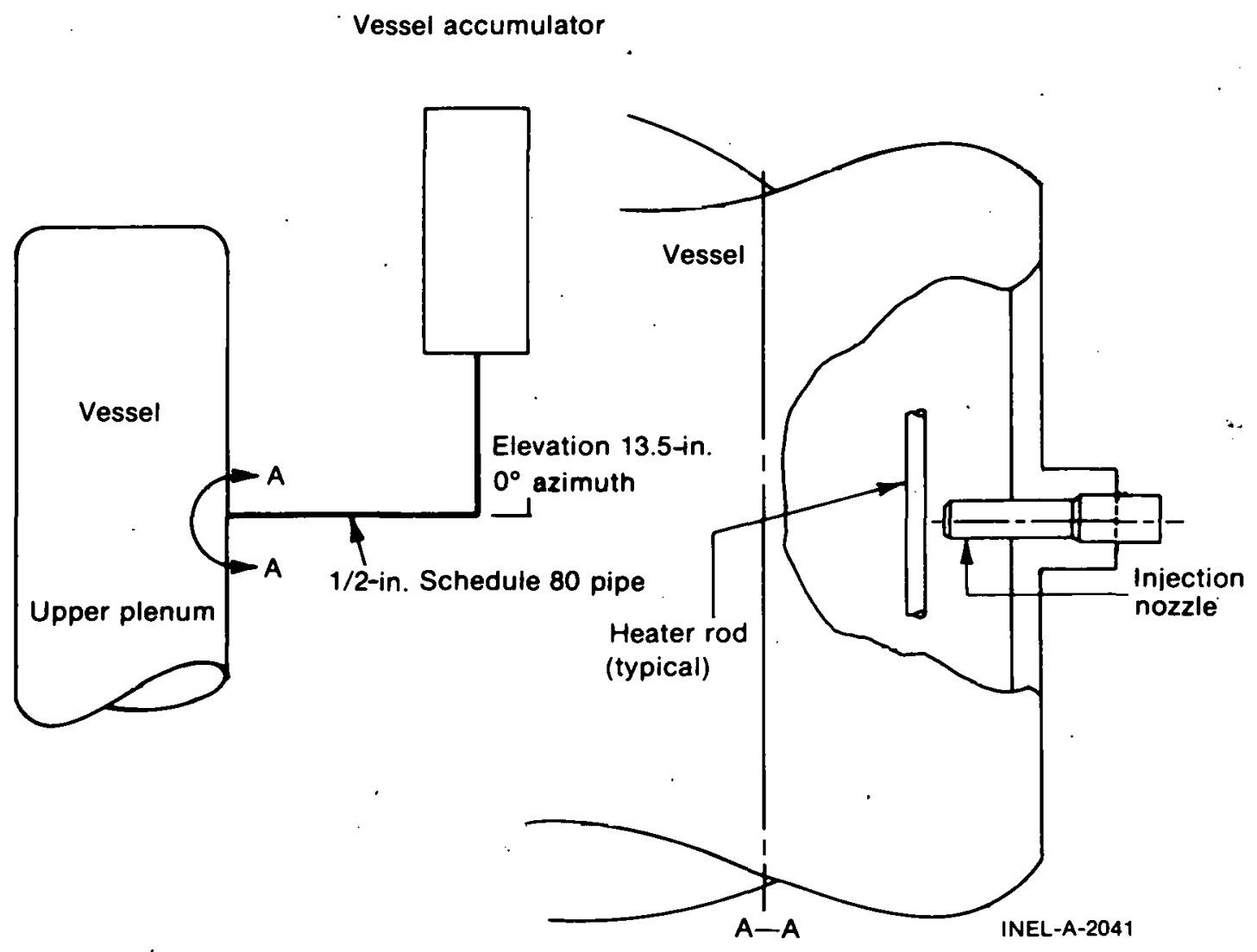

Fig. B-2 Upper plenum accumulator injection configuration. 
$\begin{array}{lllllllll}A & B & C & D & E & F & G & H\end{array}$

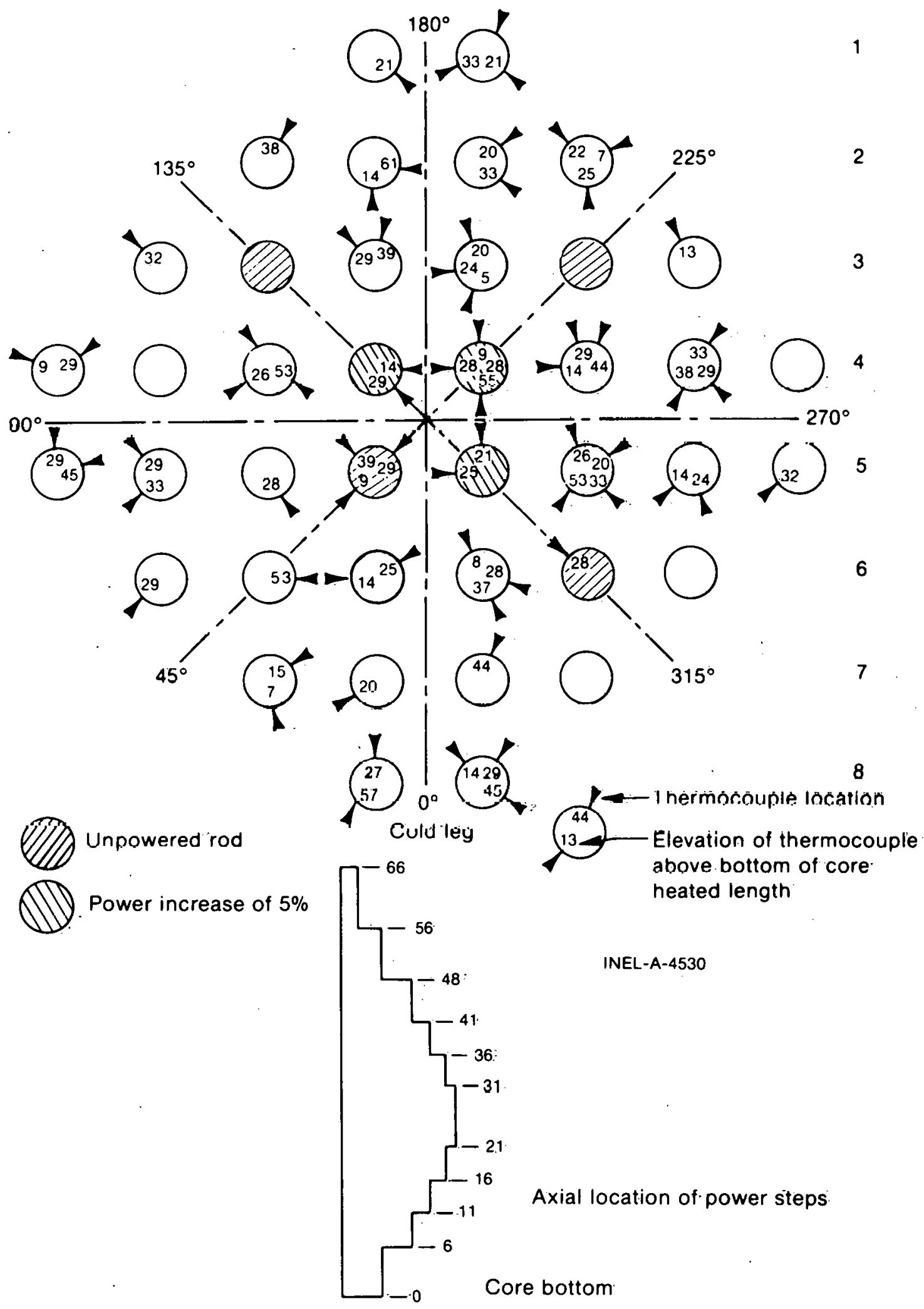

Fig. B-3 Semiscale Mod-1 core heater rod layout. 


\section{CORE THERMAL RESPONSE}

Understanding the core thermal response is of prime importance in evaluating the effectiveness of the upper plenum ECC injection concept. The core thermal behavior is most significantly affected by the upper plenum ECC injection concept during reflood; therefore, the core thermal response discussion is limited to the reflood period. The following section presents an evaluation of the quenching behavior, and the subsequent section discusses the core heat transfer processes.

\subsection{Core Quenching Behavior}

An understanding of the reflood phenomena occurring during upper plenum injection can be gained by examining the rod quench behavior. The quench behavior for the two upper plenum injection rates was examined to determine the general direction of quench front progression, the effect of the upper plenum injection rate, and the influence of unpowered rods on the quench of adjacent rods.

An evaluation of the quench time for each measurement location indicates that a general top down quench front progression occurred with both upper plenum injection rates, but that different quench behaviors occurred in the upper and lower portions of the core. The overall top down quenching behavior is evident in Figures B-4 and B-5 which show

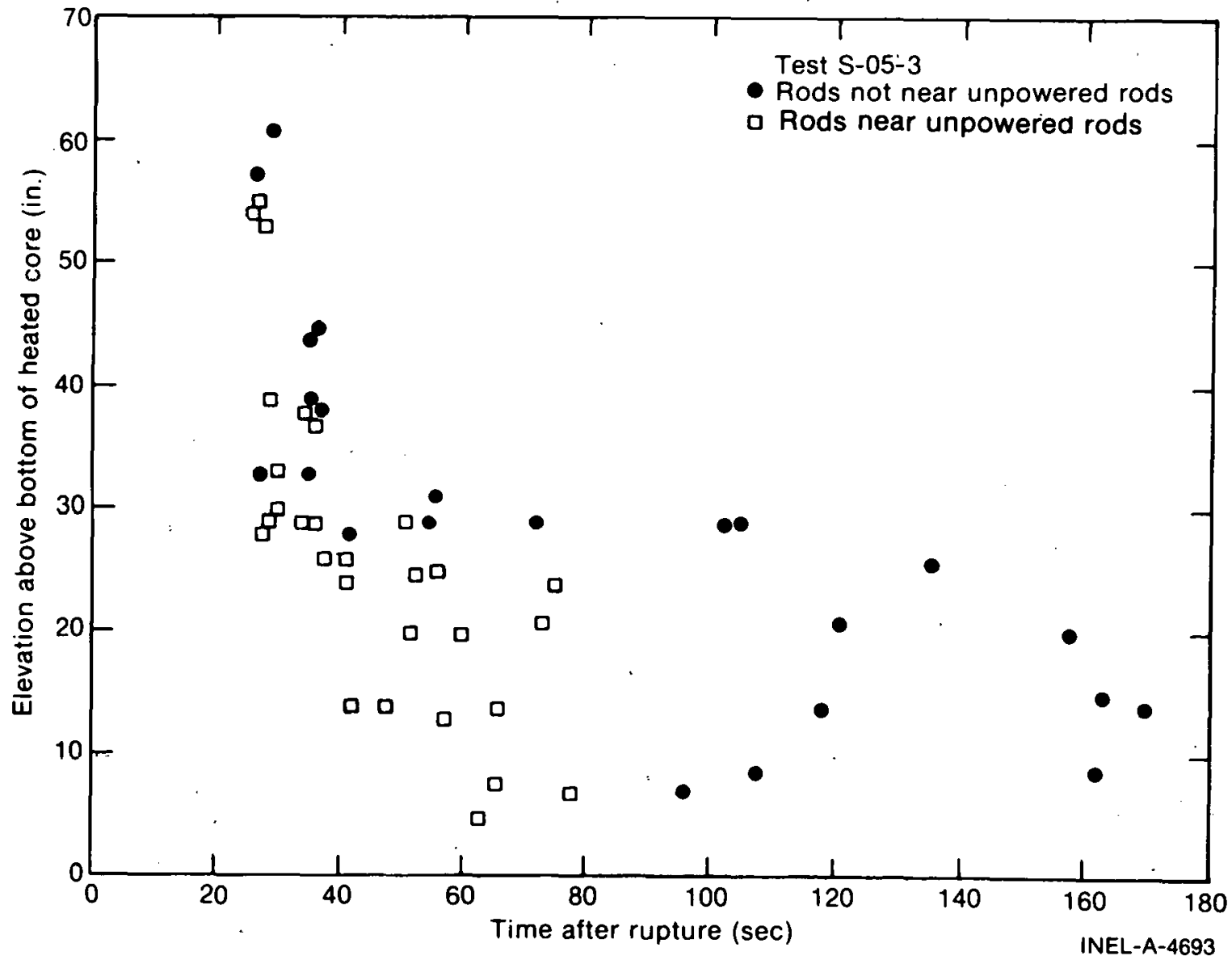

Fig. B-4 Axial distribution of quench times with 8.4-gpm upper plenum injection rate. 


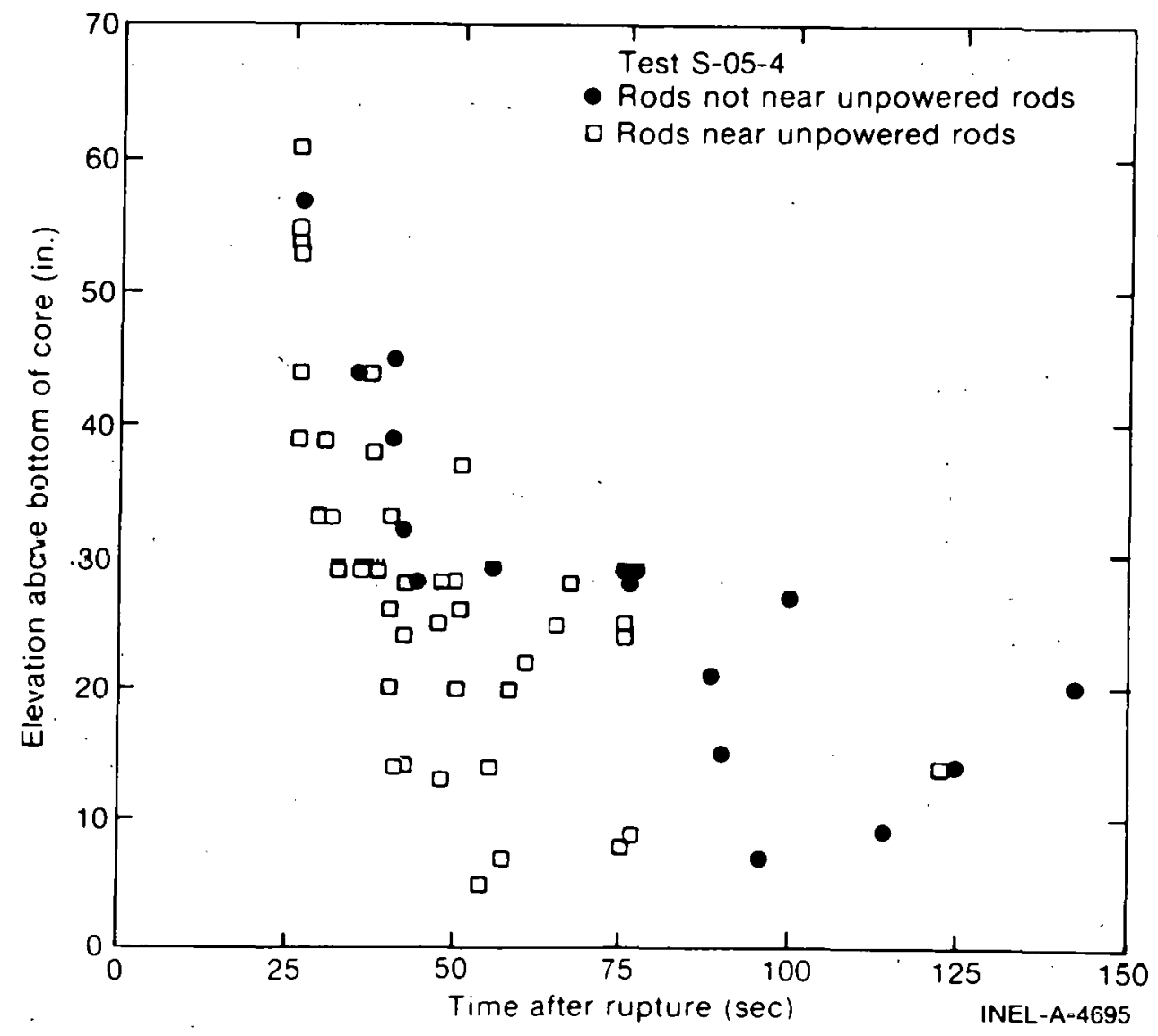

Fig. B-5 Axial distribution of quench times with 16-gpm upper plenum injection rate.

core elevation versus quench time for the 8.4 and $16-\mathrm{gpm}$ upper plenum injection rates, respectively. The results in both figures indicate a much more rapid and uniform quenching of the upper half of the core compared with the lower half. The difference in quenching behavior between the upper and lower portions of the core was attributed partly to the bottom skewed power profile used in the tests but the major cause lies in the system flow phenomena, to be discussed in Section 3.

The overall effect of the rate of injection into the upper plenum on the core quench behavior may be determined by direct comparison of the results from the two upper plenum injection tests. Two forms of comparison are shown in Figures B-6 and B-7. Figure B-6 shows the envelope of the quench times frum the test with the high upper plenum injection rate superimposed on the plot of quench times from the test with the lower injection rate, allowing a comparison of the earliest and latest quenches at any given core elevation. Figure B-7 shows the ratio of the quench times at various locations for the two upper plenum injection rates, providing a direct comparison between the quench times at individual locations. Ratios greater than 1.0 indicate earlier quenching with the higher upper plenum injection rate. In both figures, differences are apparent in the upper and lower portions of the core with regard to the effect of the upper plenum injection rate on the quenching behavior. In the upper 25 in. of the core the quench time envelope from the high 


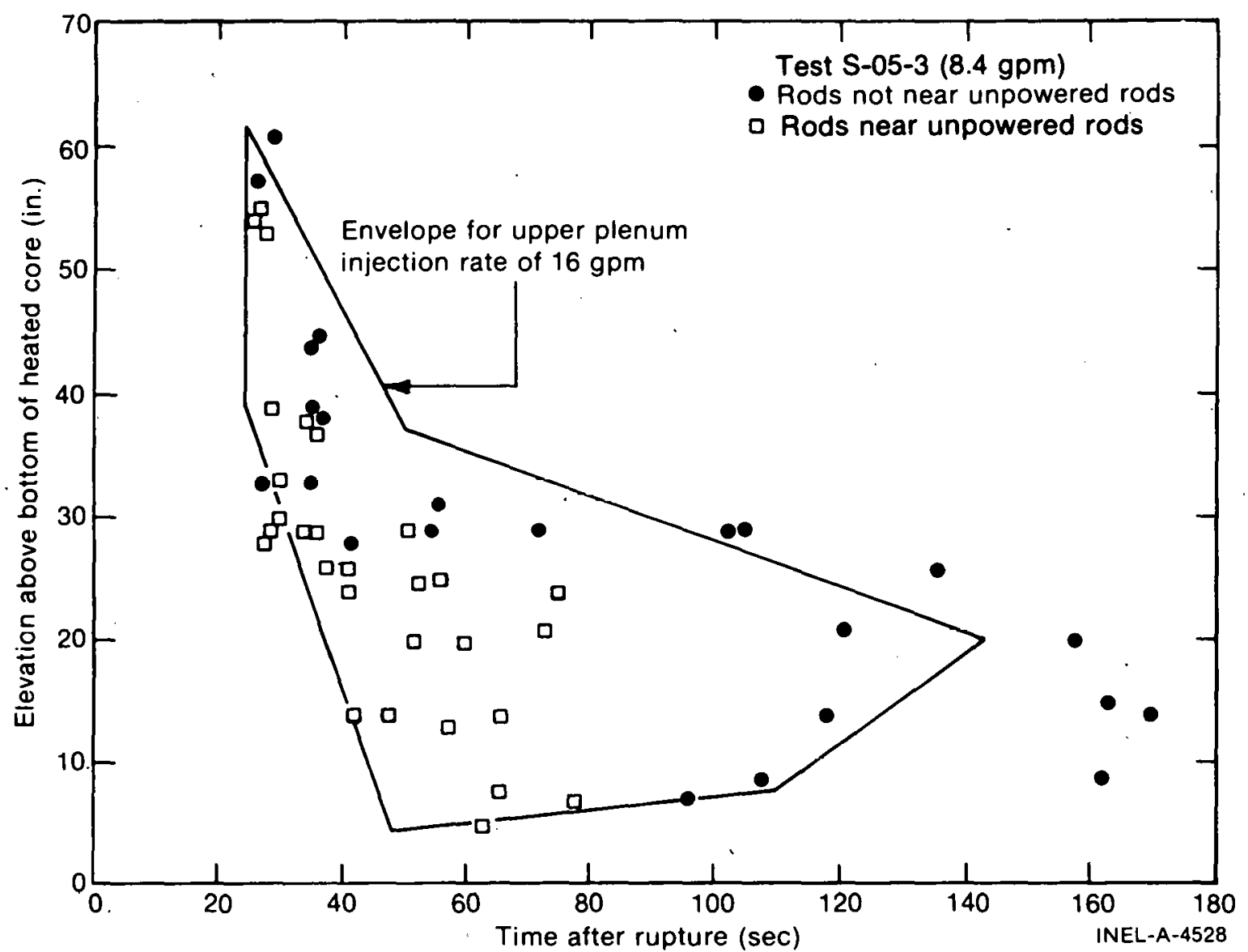

Fig. B-6 Comparison of quench times for 8.4-gpm upper plenum injection rate with envelope of quench times for 16-gpm upper plenum injection rate.

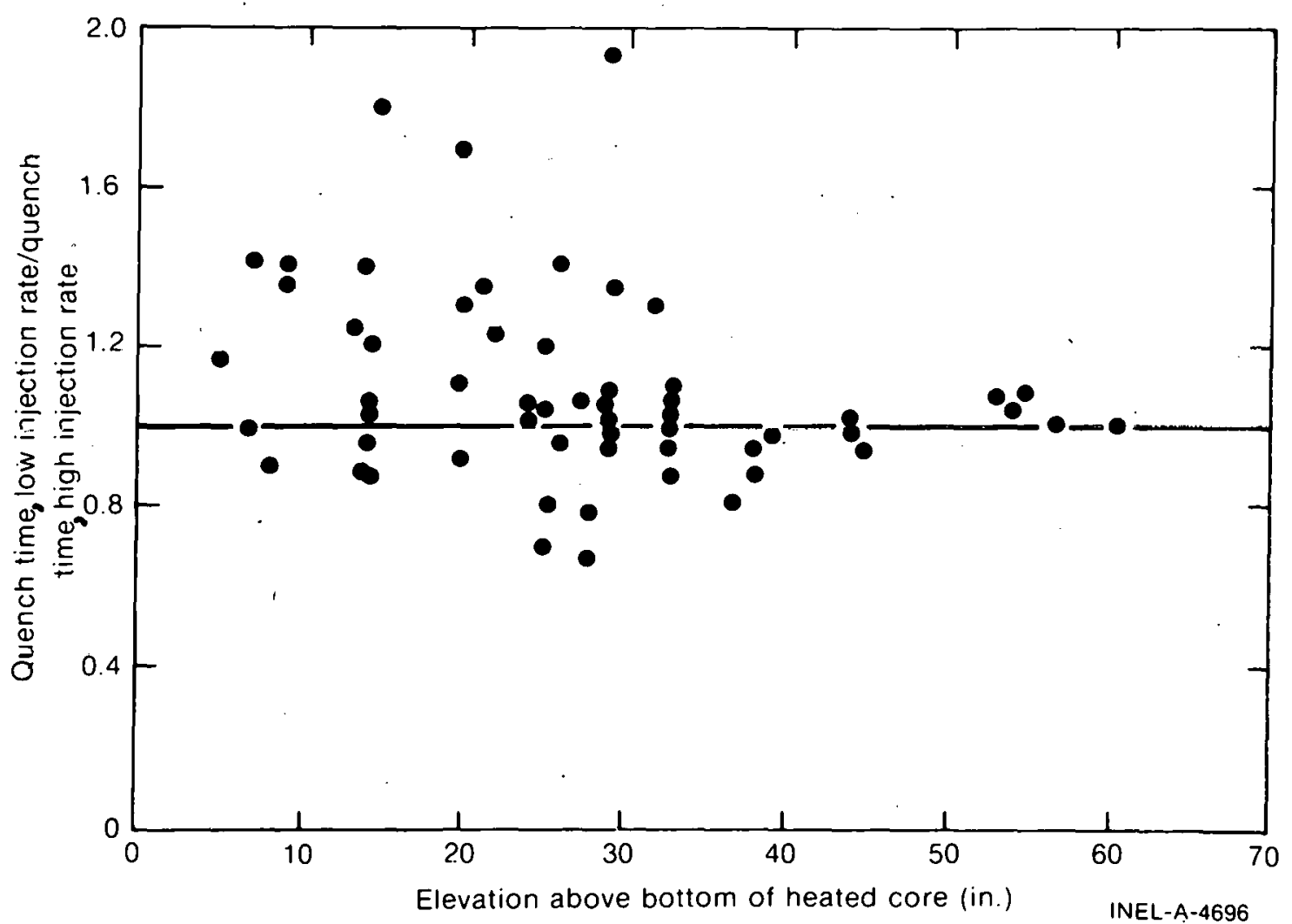

Fig. B-7 Effect of upper plenum injection rate on core quenching. 
injection rate'test essentially encloses the quench time data points from the low injection rate test. Over the same range of elevation Figure B-7 indicates that the quench time ratios for different locations lie predominantly in a band from 9.0 to 1.1. Both of these observations indicate that the quench behavior in the upper portions of the core is not sensitive to the upper plenum injection rate. In the lower half of the core, Figure B-6 indicates that the earliest quenches (about 30 to $45 \mathrm{sec}$ ) occur at about the same time irrespective of injection rate but that later quenches (about 100 to $170 \mathrm{sec}$ ) are delayed with the lower injection rate. Although the earliest quenches occur at about the same time in the two tests, different temperature measurements may have been involved in obtaining the quench time at a given elevation. Consequently, Figure B-7 indicates quench time ratios less than 1.0 as well as greater than 1.0. However, the preponderance of the data is towards ratios greater than 1.0 in the lower part of the core. Both the delayed quench data points in Figure B-6 and the preponderance of quench time ratios greater than 1.0 in Figure B-7 indicate a more rapid quenching of the lower portions of the core with the higher upper plenum injection rate.

The presence of the unpowered rods had a noticeable effect on the quenching behavior of adjacent powered rods. For example, Figure B-4 shows that one thermocouple at the 14-in. elevation which was adjacent to an unpowered rod, quenched at about $45 \mathrm{sec}$ after rupture, whereas another thermocouple at the same elevation that was not adjacent to an unpowered rod did not quench until about $170 \mathrm{sec}$ after rupture. An examination of all the thermocouple quench times indicated that, at a given elevation, most of the thermocouples adjacent to unpowered rods exhibit earlier quenching than those not adjacent to unpowered rods. This quench behavior leads to the conclusion that preferential channeling of the coolant occurred down through regions containing an unheated rod. Since the quench times for locations adjacent to unheated rods were similar in each of the tests, the variation of the upper plenum injection rate did not appear to affect the channeling of the coolant. The quenching of locations not adjacent to unpowered rods was delayed in the test with the lower injection rate, however, possibly indicating that less total coolant was available in the core even though the channelized coolant remained relatively unchanged.

\subsection{Core Heat Transfer}

Knowledge of the heat transfer between the core heater rods and the core fluid contributes to an understanding of the phenomena controlling the core reflood process. Therefore, the heat transfer coefficients prior to, during, and after quenching were examined for different core locations.

The heat transfer coefficients ${ }^{[a]}$ prior to quenching exhibited an oscillatory behavior related to the local flow quality. Figures B-8 and B-9 show heat transfer coefficients from the high injection rate test at the 9-and 29-in. core elevations, respectively. Prior to quench

[a] Heat transfer coefficients were calculated from core rod thermocouple responses using an inverse conduction calculation and are based on the difference between the rod surface temperature and the fluid saturation temperature. 


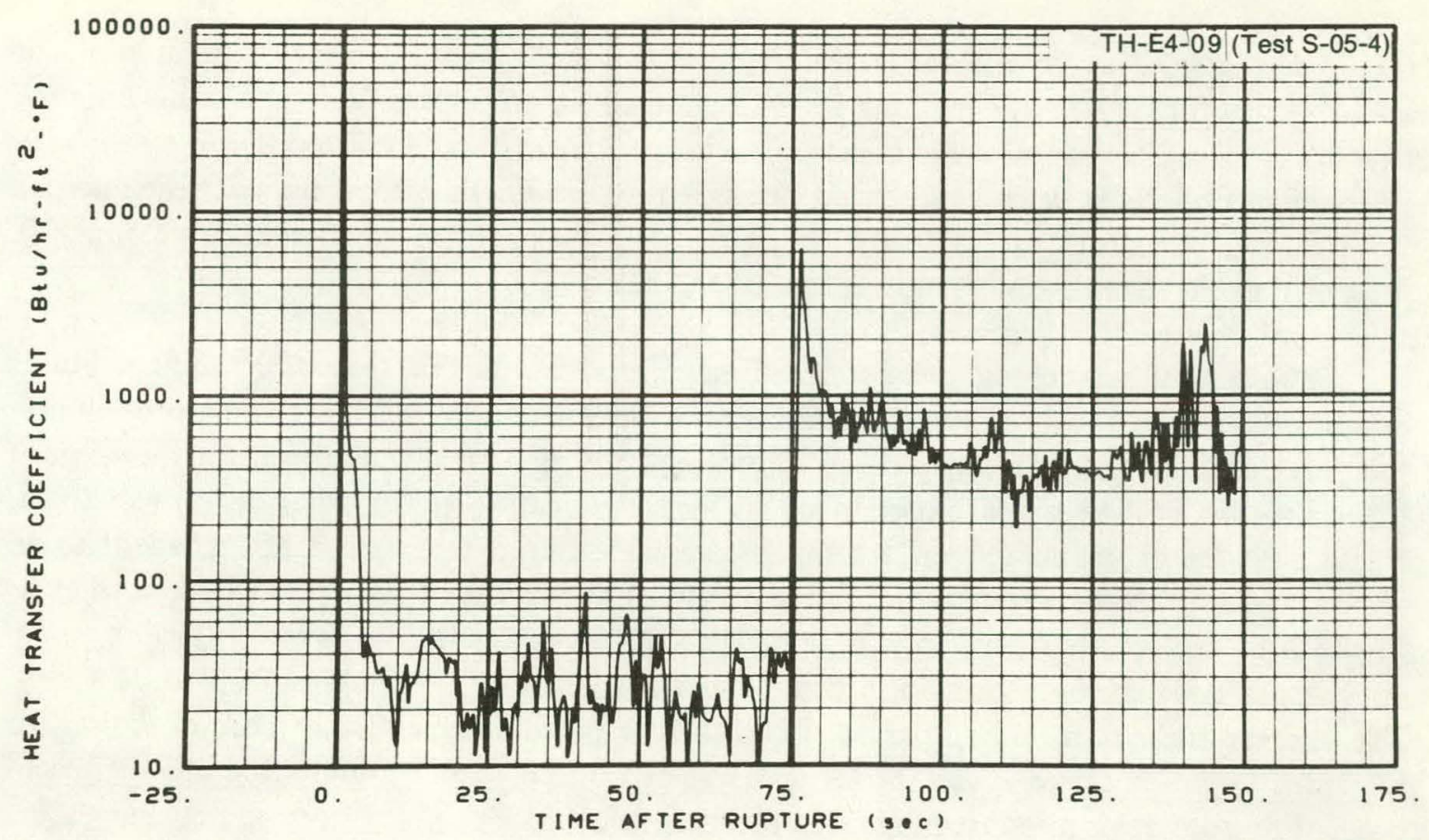

Fig. B-8 Heat transfer coefficient at the 9-in. elevation for the 16-gpm upper plenum injection rate.

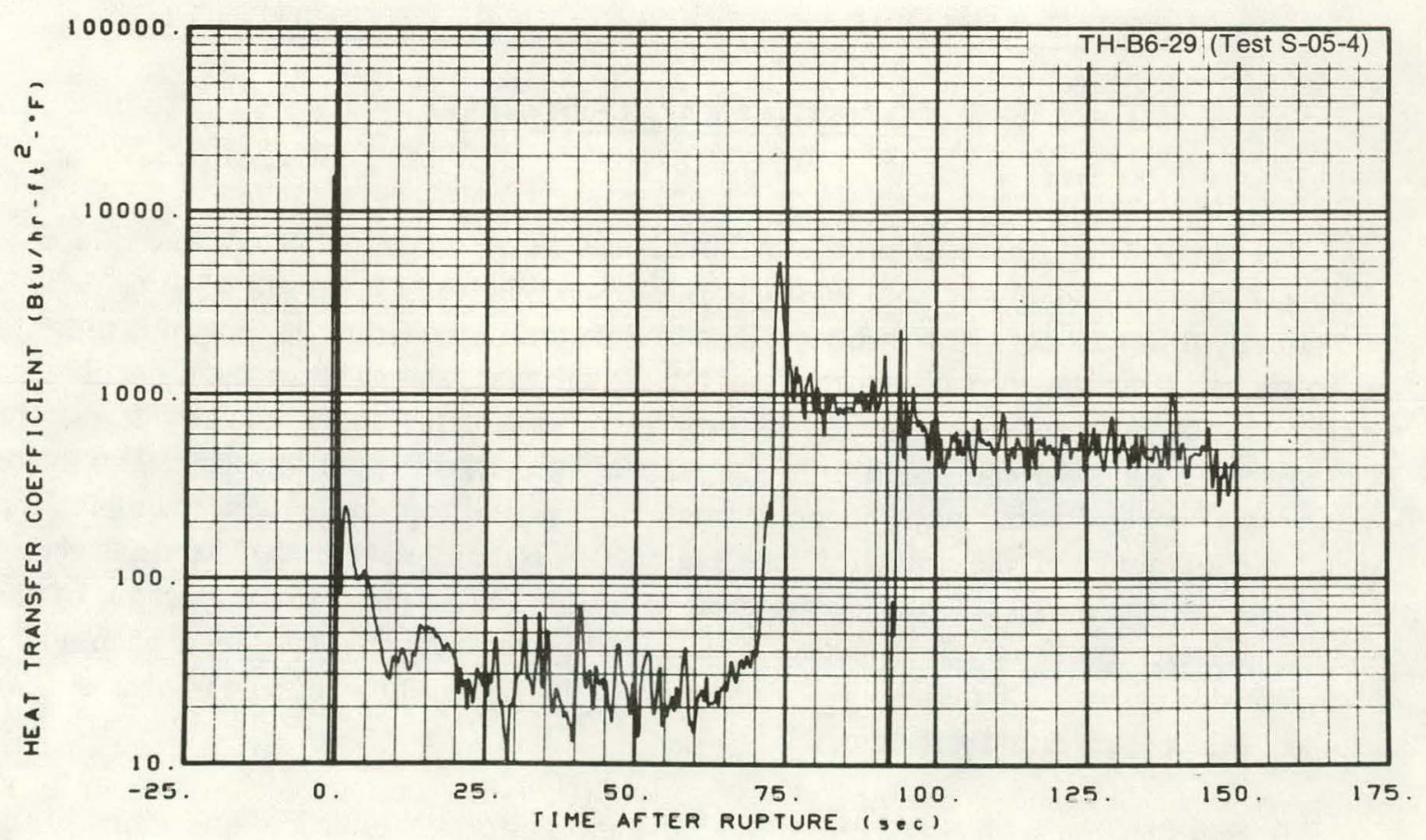

Fig. B-9 Heat transfer coefficient at the 29 -in. elevation for the 16 -gpm upper plenum injection rate. 
(at $75 \mathrm{sec}$ and $70 \mathrm{sec}$ in the respective figures) the coefficients oscillate with minima of about $10 \mathrm{Btu} / \mathrm{hr}-\mathrm{ft}^{2}{ }^{\circ} \mathrm{F}$ and maxima in the region of 50 to $80 \mathrm{Btu} / \mathrm{hr}-\mathrm{ft}^{2}-{ }^{\circ} \mathrm{F}$. This range of heat transfer coefficient values is consistent with periods of forced convection to steam with intervening periods in which the liquid phase is present. Furthermore, the periodic maxima for the two elevations are virtually concurrent, indicating that when the liquid phase is present it exists throughout the lower half of the core.

The actual quenching process involves only a few sec of transition boiling, but is important because much of the thermal energy stored in the rod cladding is removed during this brief period. The proximity of an unpowered rod had an influence on the duration of the transition boiling phase experienced at a given location on an adjacent powered rod. Figure B-9, based on data from a temperature measurement on a rod not adjacent to an unpowered rod, shows a transition boiling period of about $4 \mathrm{sec}$ (from 70 to $74 \mathrm{sec}$ ) whereas Figure B-8, based on data from a temperature measurement on a rod adjacent to an unpowered rod, shows a transition boiling period of about $1.5 \mathrm{sec}$ (from 75 to $76.5 \mathrm{sec}$ ). The shorter transition boiling period was found to occur irrespective of core elevation for locations adjacent to unpowered rods and was attributed to the preferential channeling of coolant through regions containing an unpowered rod.

Following the quench, the heat transfer coefficients indicate the existence of nucleate boiling. This heat transfer regime appears to be maintained, pointing to the continued presence of low quality fluid at a given location following quenching.

\section{SYSTEM THERMAL-HYDRAULIC BEHAVIOR CONTRIBUTING TO}

\section{CORE THERMAL RESPONSE}

The analysis of the system thermal-hydraulic phenomena indicated that the core cooling, demonstrated by the core thermal response, was actually the result of three periods of distinctly different core flow behavior. The first period lasted from the time of rupture to about six sec after the start of upper plenum ECC injection, and the associated phenomena contributed strongly to the rapid and uniform quenching of the upper core elevations. The second period followed and lasted until the start of cold leg nitrogen injection. The major system thermal-hydraulic phenomena during this period controlled the cooling and quenching of much of the core hot spot region (29-in. core elevation). The final period continued during and after cold leg nitrogen injection and covered the quenching of the remaining lower portions of the core. The major system thermal-hydraulic phenomena occurring during each of these periods are discussed in the following paragraphs, and are related to the core thermal response.

During the first core flow period, the rapid and uniform cooling and quenching of the upper core elevation resulted from upper plenum ECC being swept directly into the core by established negative intact loop and core flows. These flows developed prior to any ECC 
injection and were nearly identical to the initial core flow observed in previous experimental investigations. Intact loop cold leg accumulator injection, initiated between 17 and $19 \mathrm{sec}$ after rupture, occurred before the start of upper plenum injection. Subcooled water from the intact loop accumulator entered the cold leg and inlet annulus and provided a condensation sink for the already established negative core steam flow. Therefore, when ECC injection into the upper plenum started, about $22 \mathrm{sec}$ after rupture, the negative intact loop and core flows, apparently aided by condensation in the downcomer inlet annulus, swept upper plenum ECC into the core and resulted in the observed fast and uniform quenching of the upper portions of the core. During this initial core flow period, little evidence existed that significant initial steam generation caused by the cooldown of upper plenum structures occurred in either of the upper plenum accumulator injection tests. Therefore, the effect of the upper plenum structures on overall system behavior and core thermal response appears to be minimal for the injection rates investigated in the Semiscale tests.

During the second core flow period, the continued effectiveness of the upper plenum injection was dependent on a complex oscillatory relationship which developed as a result of phenomena associated with steam generation in the core and condensation in the downcomer inlet annulus. The penetration of the core by ECC injected into the upper plenum resulted in large volumes of steam being generated within the core which in turn caused large negative flows to develop out of the core inlet and up the downcomer. The large negative core flow which developed for the case of an upper plenum ECC injection rate of $16 \mathrm{gpm}$ is shown relative to that for the case with cold leg injection only in Figure B-10.

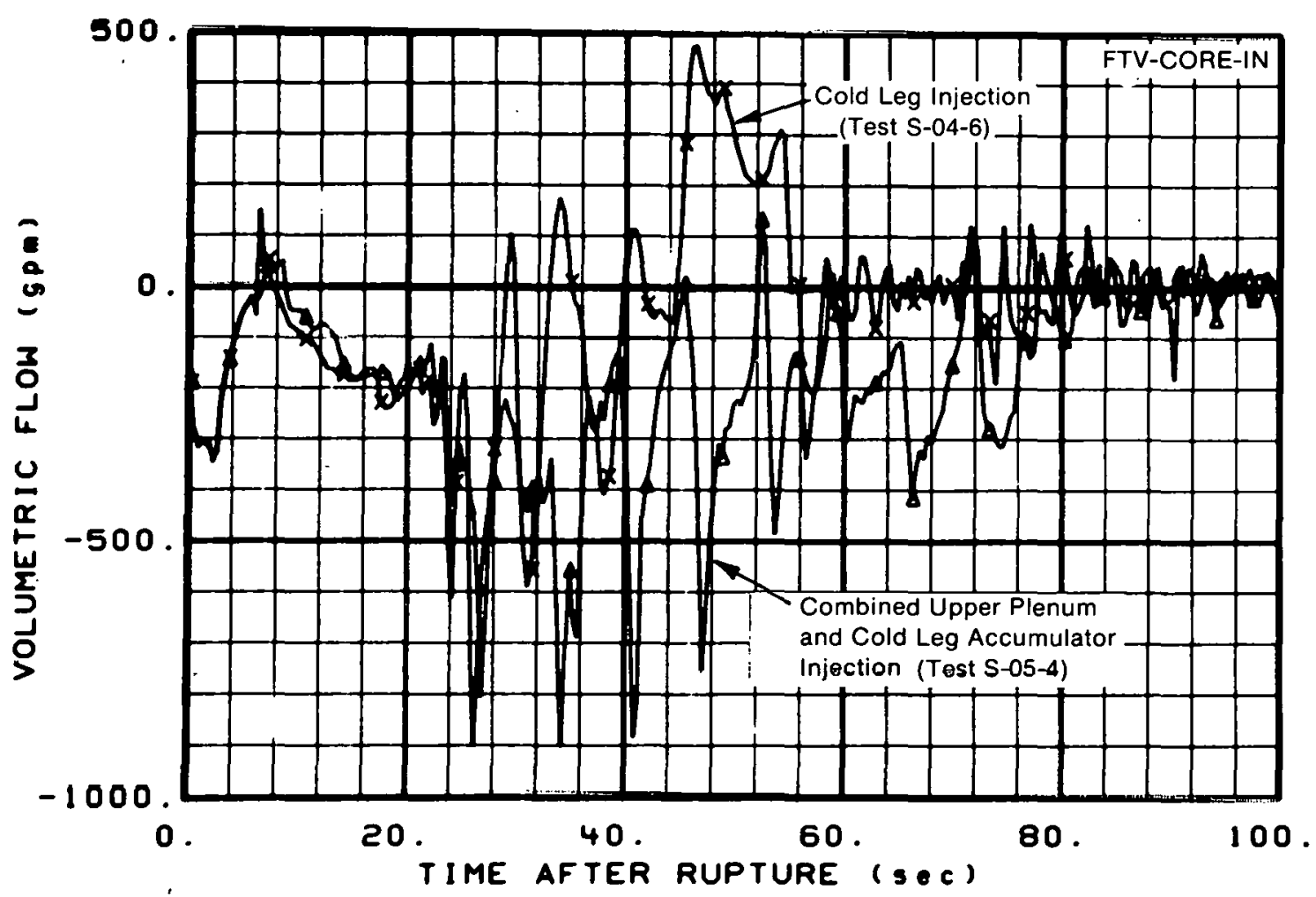

Fig. B-10 Comparison of core inlet volumetric flows for cold leg ECC injection and for upper plenum ECC injection - $16 \mathrm{gpm}$. 
With upper plenum ECC injection, the large negative flows out the bottom of the core and up the downcomer caused significant bypass of the intact loop ECC out of the broken loop cold leg and delayed penetration of the cold leg ECC to the lower plenum.

The mechanism underlying the strong negative core flow which caused bypass and the penetration delay during this period is related to the condensation process which occurred in the downcomer inlet annulus. The process was initiated when subcooled water from the intact loop accumulator entered the downcomer inlet annulus causing condensation of steam in the annulus and inducing a surge of steam flow down through the core and up the downcomer. The relation between the negative surges in steam flow and the subcooled water in the inlet annulus is demonstrated in Figure B-11 which indicates an increase in negative core flow corresponding to and slightly lagging the decrease in annulus fluid temperature from saturated to subcooled. The subcooled liquid causes rapid condensation

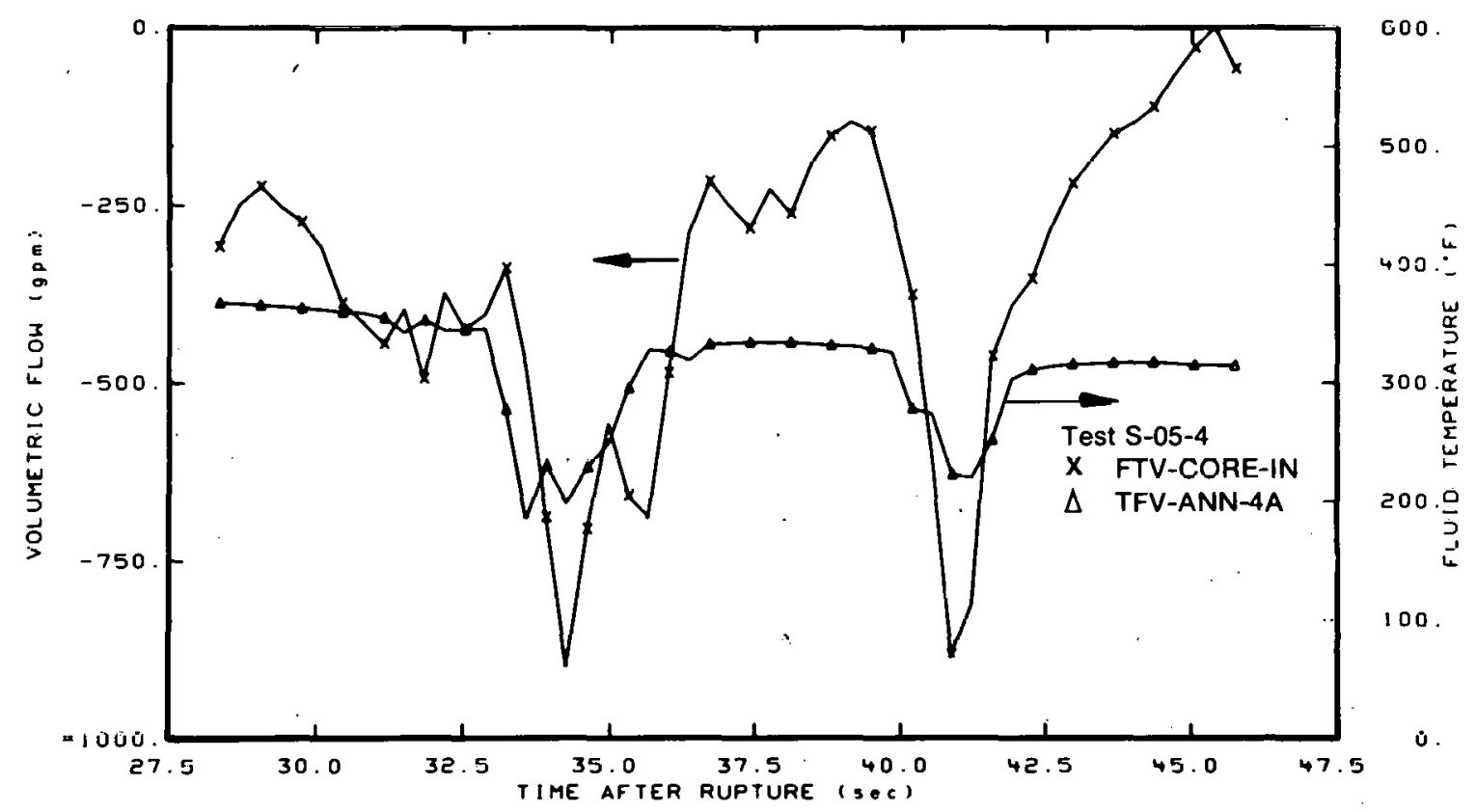

Fig. B-1 1 Relationship between core flow oscillations and condensation in the vessel inlet annulus - 16 gpm upper plenum injection rate.

of the steam flowing up the downcomer from the core and, therefore, the downcomer steam flow rate is increased toward the low pressure region formed by the condensation front. The significant negative steam flow caused the ECC bypass out the cold leg. As the temperature of the water in the inlet annulus changes from a subcooled state toward a saturated state due to the mixing of liquid and steam, the amount of condensation in the inlet annulus region decreases causing a decreased downcomer and core flow. When the temperature of the annulus water reaches the saturation condition, condensation ceases and the reduced but continuing downcomer steam flow pushes the water out of the downcomer and broken loop cold leg. Evidence of the saturated liquid being pushed out the broken loop cold leg is found in Figure B-12 for the high upper plenum injection rate. Figure B-12 shows the fluid density in the broken loop cold leg and the fluid temperature in the inlet annulus. A rapid decrease is 


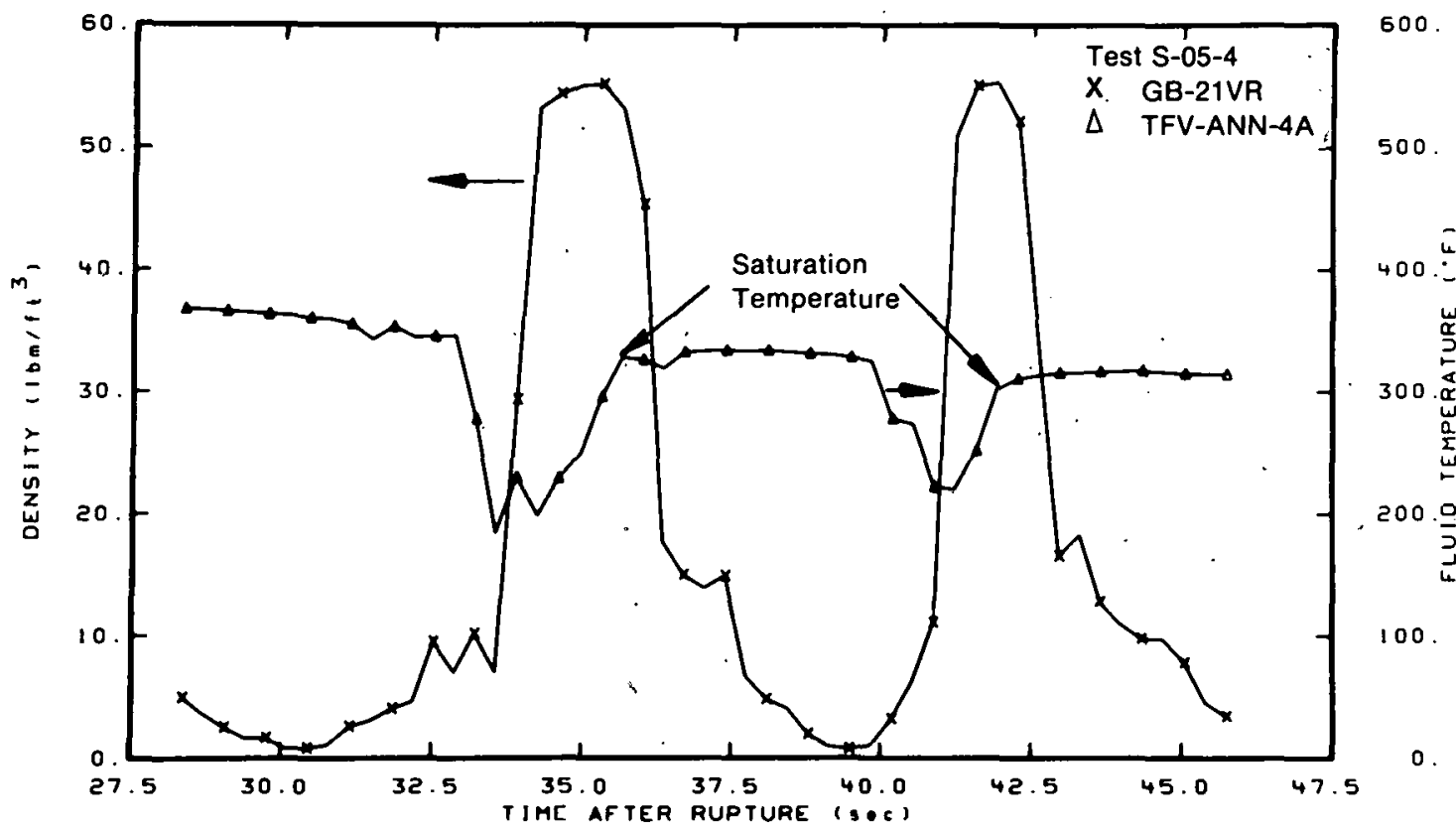

Fig. B-12 Comparison of cold leg broken loop fluid density and the inlet annulus fluid temperature for the 16-gpm upper plenum injection rate.

observed in the broken loop cold leg fluid density, corresponding to the time when the inlet annulus fluid temperature reached the saturation condition. The rapid decrease in the fluid density at the broken loop cold leg indicates a voiding of the piping corresponding to the removal of the water from the annulus and broken loop cold leg. Following the removal of the saturated liquid, fresh subcooled ECC is supplied to the inlet annulus and downcomer, again causing condensation and inducing negative core and downcomer flows. This process is repeated a number of times during the cold leg intact loop injection period causing the series of oscillations observed throughout the system. In addition, this oscillatory system flow phenomenon occurs for both the high and low upper plenum injection rates.

The condensation process described in the preceding paragraph strongly influenced the effectiveness of the upper plenum ECC injection concept through the induced negative surges in core flow. The flow surges controlled the penetration of upper plenum liquid into the core. The core volumetric flow rate is compared in Figure B-13 with the thermal response of the fluid at a location on the grid near the top of the heated core. Periods of high negative core flow correspond to periods during which the fluid temperature is changing from a superheated condition to a subcooled condition. The subcooled condition indicates that water is present, and subcooled liquid at the top of the core indicates a possible penetration of liquid into the core. The decreases in the upper core fluid temperature to subcooled levels lag the negative surges in core flow. The fluid injected into the upper plenum appears to be held up by core steam generation until the high negative core volumetric flow develops. Shortly after the high negative core flow develops, due to condensation in the inlet annulus, the fluid temperature at the top of the core reaches the subcooled state indicating penetration of the core by liquid. Similarly, shortly after the high negative core volumetric flow rate decreases, the fluid temperature at the top of the core 


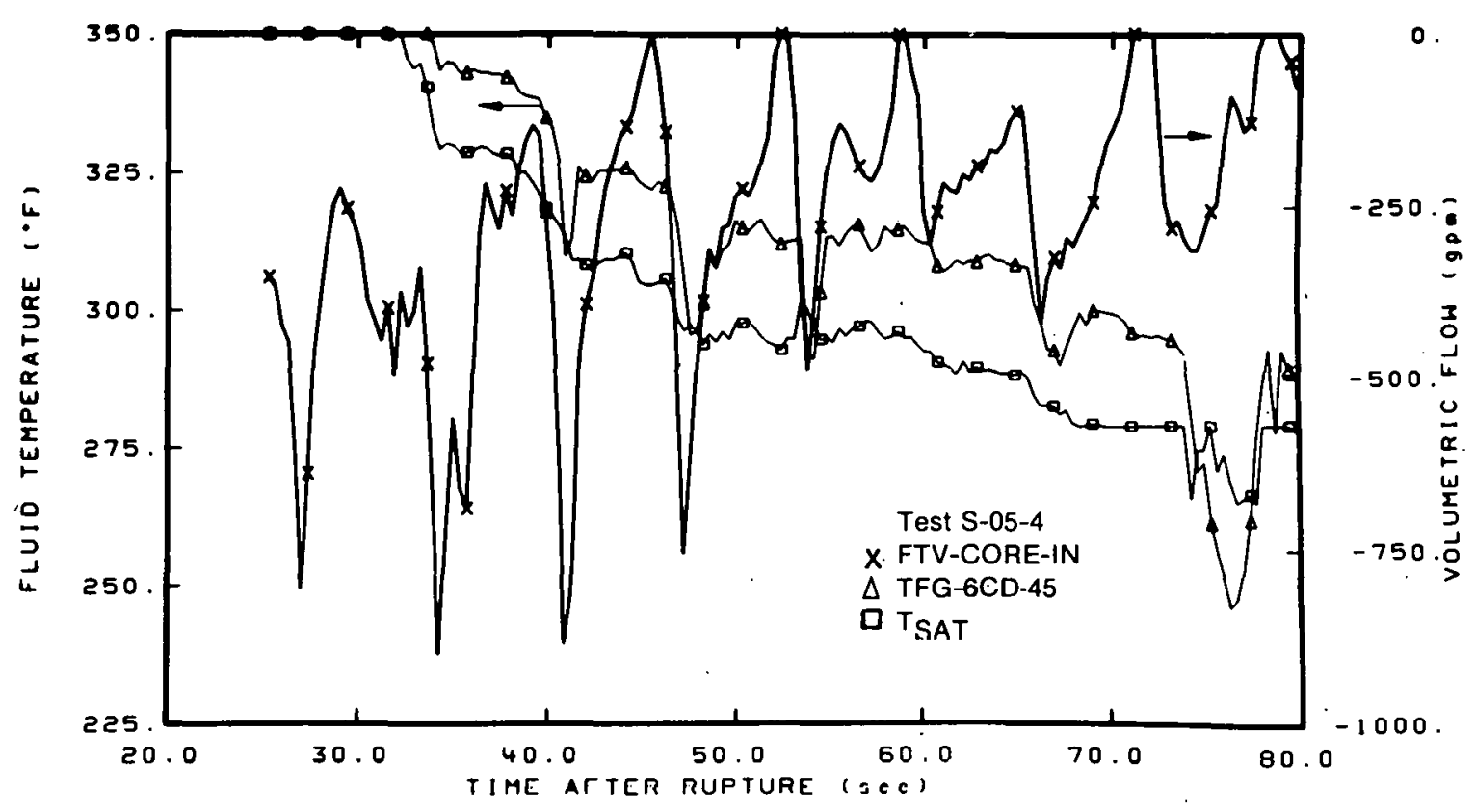

Fig. B-13 Coupling between negative core flow and fluid temperature at the top of the core for the 16-gpm upper plenum injection rate.

increases to a superheated value indicating holdup of the injected liquid. The holdup was important because it not only controlled the penetration of fluid into the core but it also caused bypass of the fluid injected in the upper plenum out of the broken loop hot leg. This bypass of fluid, indicated by the relatively high densities measured in the broken loop hot leg next to the vessel, occurred for both the high and low upper plenum accumulator injection rates. However, a more substantial quantity of ECC bypassed the core for the larger injection rate $(16 \mathrm{gpm})$ than for the lower injection rate $(8.4 \mathrm{gpm})$. Therefore, the full effect of the difference in upper plenum injection rates was not felt by the core, and as a result, the core cooling effectiveness for the two injection rates was very similar.

The periodic penetration of liquid into the core caused by the negative flow surges results in periodic increases in cooling throughout the core. The oscillatory increases in core heat transfer, discussed in Section 2.2, were found to follow the oscillatory increases in negative core flow. The core heat transfer coefficient at the lower part of the core (7-in. elevation) is compared in Figure B-14 with the core volumetric flow rate. Periods of high negative volumetric core flow correspond to periods of high heat transfer coefficient. Higher elevations in the core exhibit the same relationship between core volumetric flow and heat transfer. As noted in Section 2.2, the magnitudes of the maxima of the oscillating heat transfer coefficient suggest that, during periods of high negative volumetric core flow rate, liquid droplets are entrained down through the core. The negative flow surges are, therefore, directly related to the cooling process with the upper plenum accumulator injection concept because they provide the liquid necessary for the cooling during the second core flow period.

The final period of distinctly different core flow behavior occurred after the termination of cold leg accumulator water injection, when nitrogen flow from the 


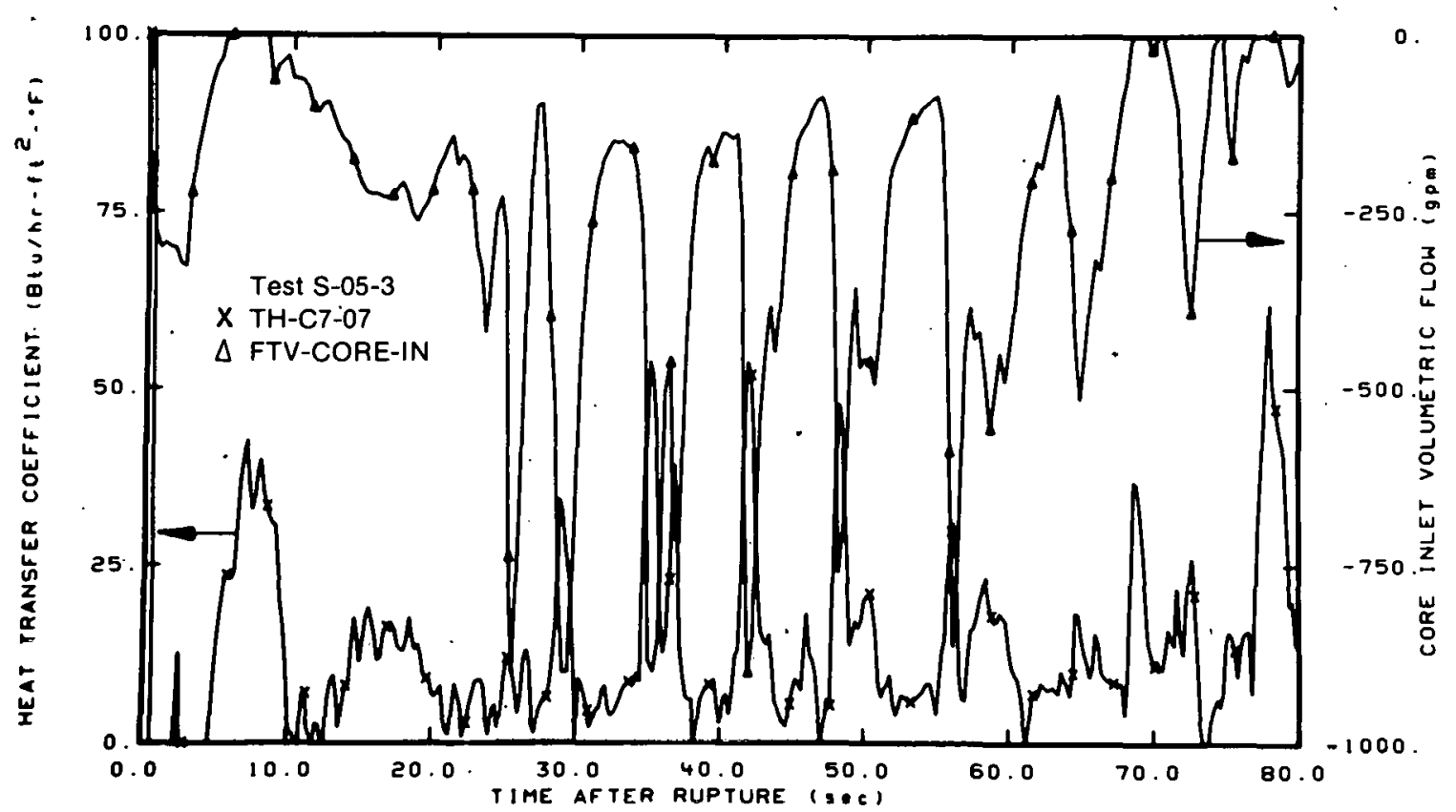

Fig. B-14 Effect of oscillatory core flow on core heat transfer - 7-in. elevation for the 8.4-gpm upper plenum injection rate.

accumulator entered the system. Following the initiation of nitrogen injection, several distinct system hydraulic events occur almost simultaneously. One event is that the intact and broken loop cold legs are cleared of liquid. The densitites in the intact and broken loop cold legs are shown in Figures B-15 and B-16, respectively, for the test with the 8.4-gpm upper plenum injection rate. The rapid decreases in the measured density following the start of nitrogen injection correspond to the loops being cleared of liquid. Another system hydraulic event that occurs when nitrogen injection starts is that liquid is forced into the vessel downcomer and core with the result that the established negative core flow decreases to essentially zero. Figure B-17 shows an increase in density at the core entrance starting with the onset of nitrogen injection for the test with the high upper plenum injection rate, indicating a hydraulically blocked downcomer. The blocking of the downcomer with liquid. effectively creates a more hydraulically resistive path for core steam removal. With the downcomer essentially blocked, a third system hydraulic event occurs. Core steam flow appears to hold up the injected upper plenum fluid to such an extent that liquid flow out the broken loop hot leg is increased. Figure B-18 indicates a general increase in measured density in the broken loop hot leg beginning with the intact loop nitrogen injection for the higher upper plenum injection rate test. The continuously high density indicates that liquid is being bypassed. The same overall hydraulic response occurs following intact loop nitrogen injection for both upper plenum injection rates.

The core thermal response is strongly affected as a result of the system hydraulic behavior following nitrogen injection. Figures B-4 and B-5 show that the quenching rate is considerably reduced after nitrogen injection, compared with the rapid top down quenching which occurred prior to nitrogen injection. The reduced quenching rate occurred because the core cooling mechanism changes with the onset of nitrogen injection. The high negative 


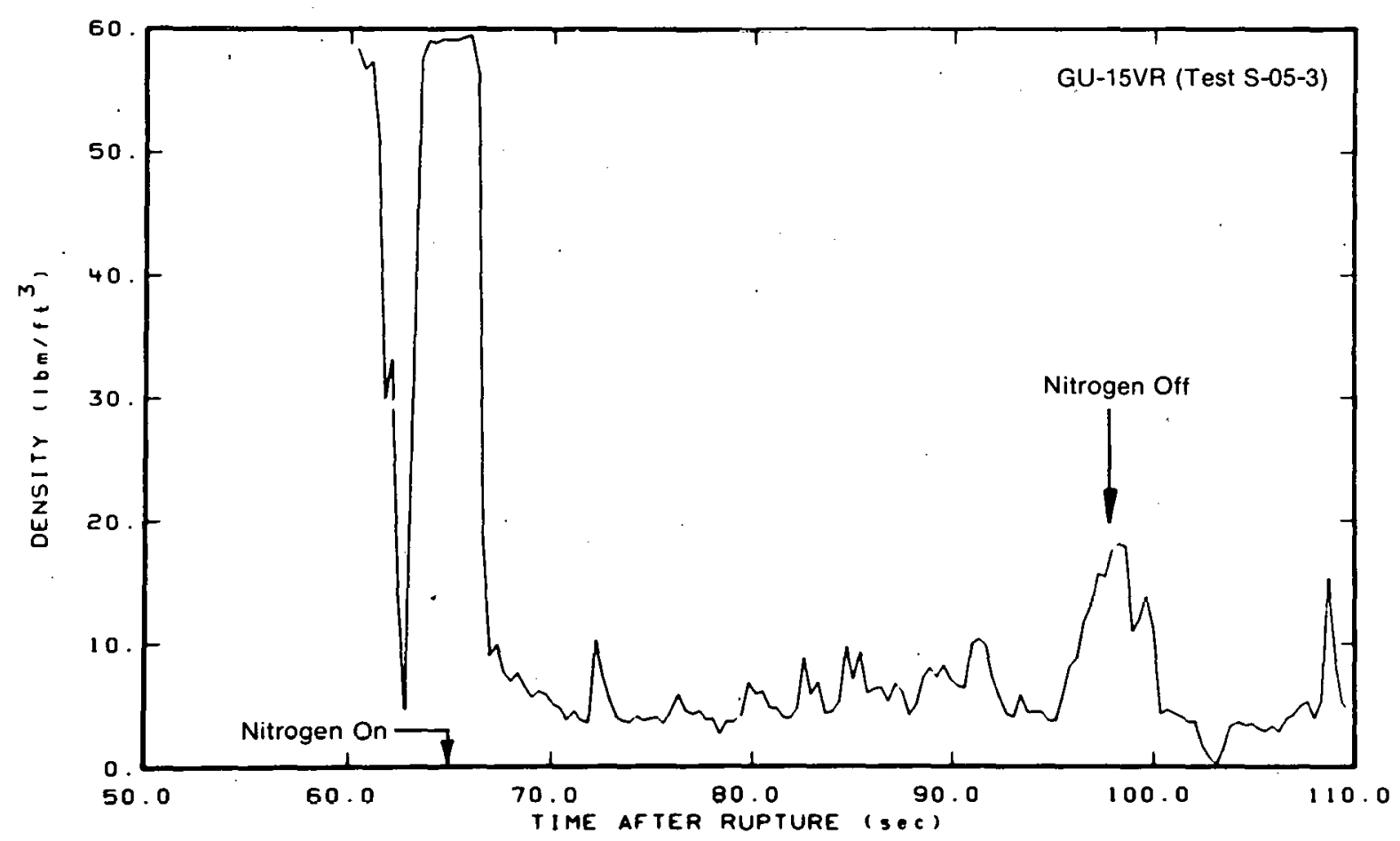

Fig. B-15 Effect of nitrogen injection on intact loop cold leg fluid density - 8.4-gpm upper plenum injection rate.

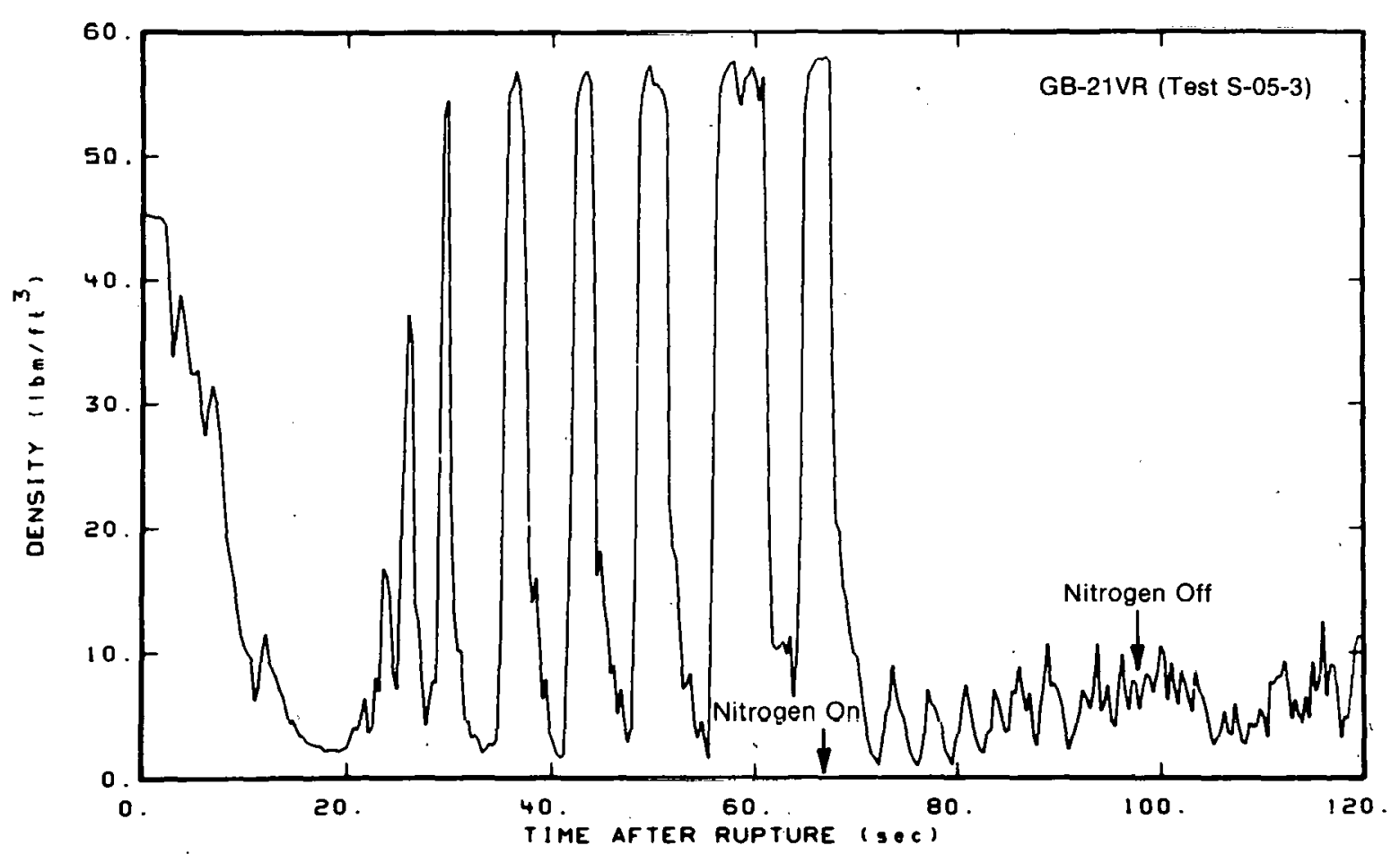

Fig. B-16 Effect of nitrogen injection on cold leg broken loop fluid density - 8.4-gpm upper plenum injection rate. 


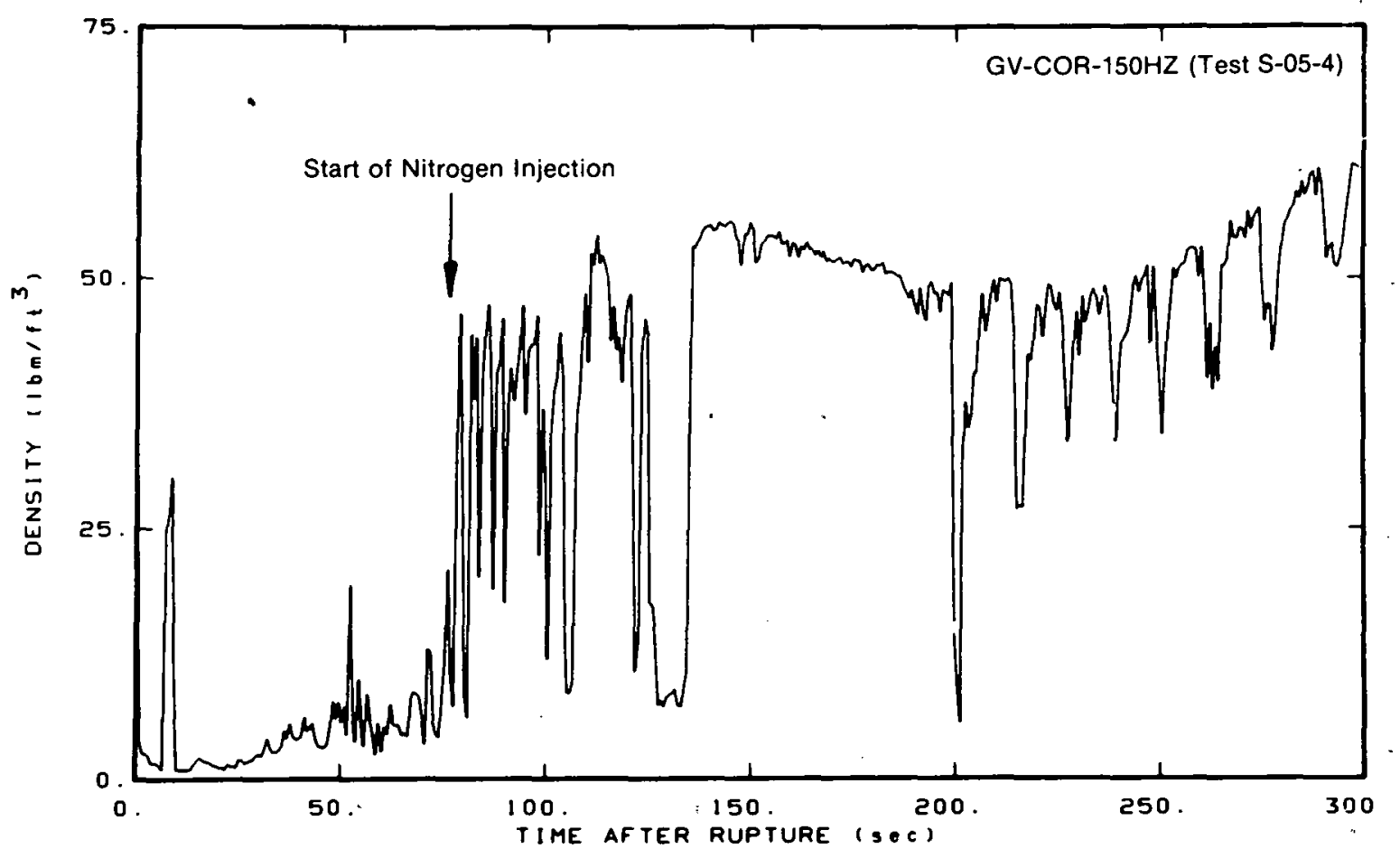

Fig. B-17 Effect of nitrogen injection on core inlet fluid density - 16-gpm upper plenum injection rate. :

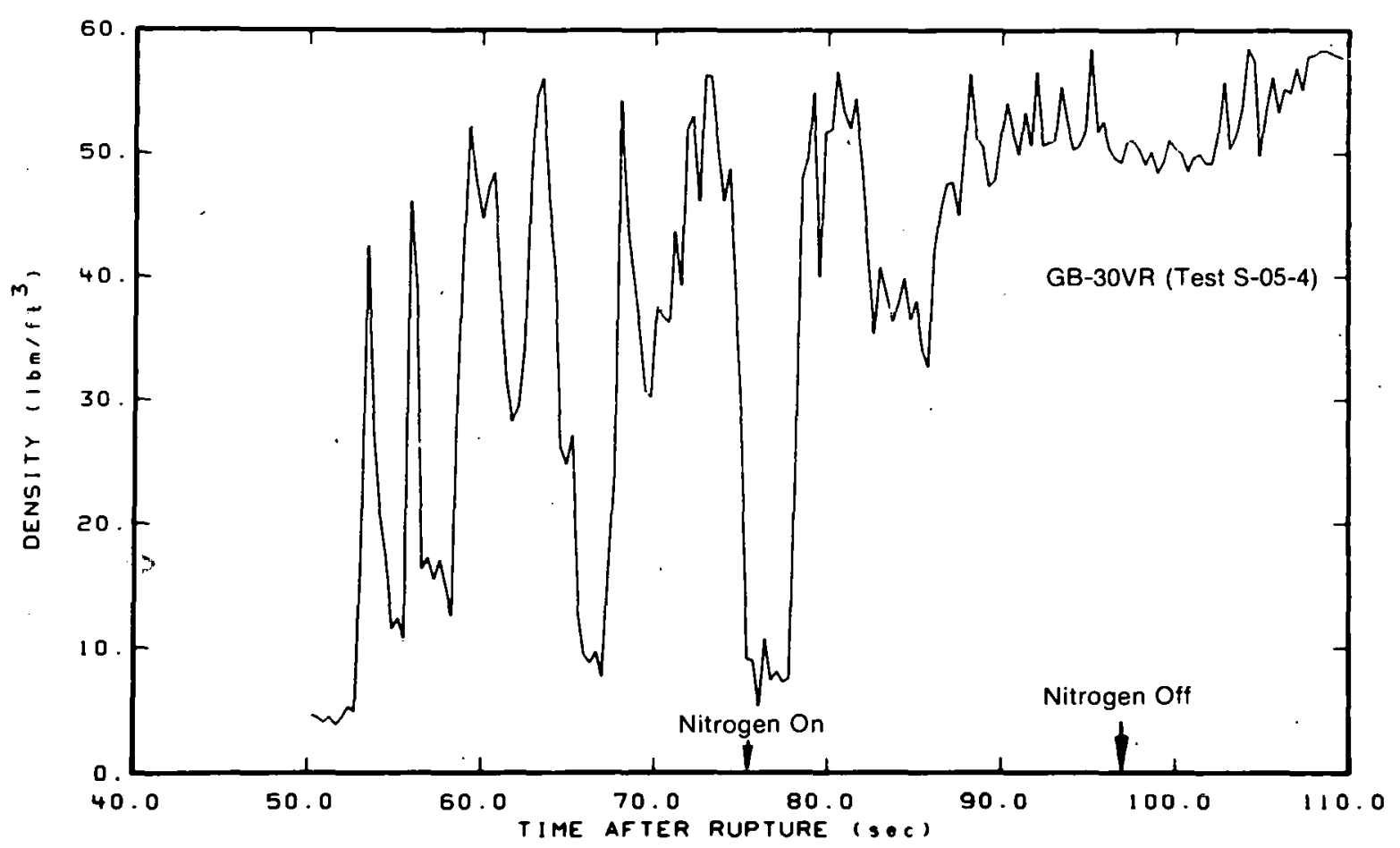

Fig. B-18 Effect of nitrogen injection on broken loop hot leg fluid density for the 16-gpm upper plenum injection rate. 
core flow (which entrained liquid from the upper plenum) is terminated due to the removal of the condensation sink in the downcomer inlet annulus and due to the blocking of the core inlet. Without the entrained liquid, the core cooling is decreased. Figure B-19 shows a typical cladding temperature response for a position that had not quenched prior to nitrogen injection. At the onset of nitrogen injection the slope of the temperature curve decreased, indicating the decreased cooling resulting from the change in the cooling mechanism. The decreased cooling was responsible for the generally slower and more scattered quenching behavior during and following nitrogen injection.

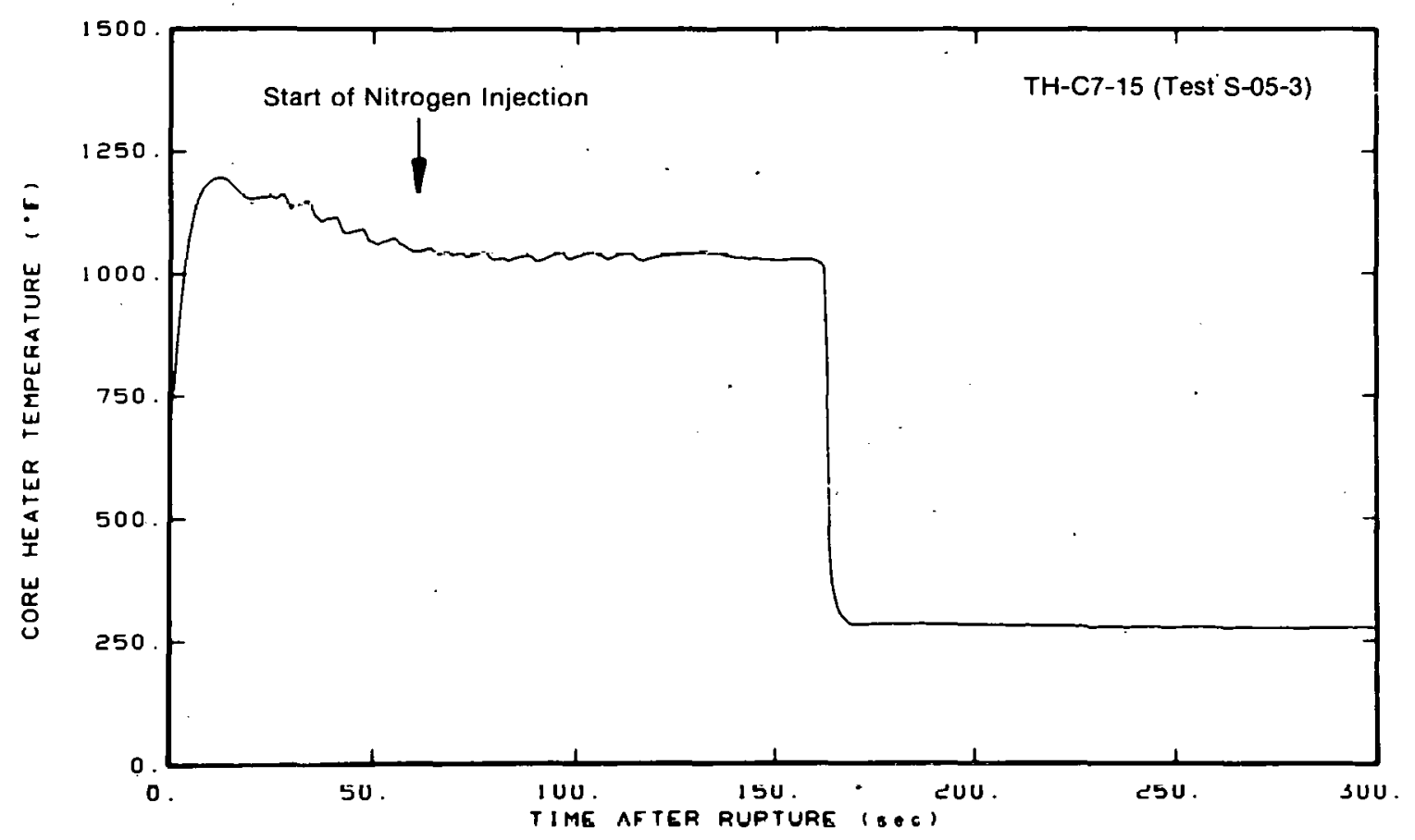

Fig. B-19 Effect of nitrogen injection on cladding temperature for the 8.4-gpm upper plenum injection rate -15 -in. elevation.

Overall, the sequential occurrence of the three different thermal-hydraulic behaviors caused the different thermal responses in the upper and lower portions of the core. The early delivery of ECC to the core, followed by condensation induced oscillating core flow surges, resulted in good core cooling and early quenching of the upper portions of the core which was relatively independent of injection rate. The elimination of the condensation front in the downcomer inlet annulus, caused by the injection of nitrogen into the intact loop cold leg, and the fluid blocking of the core inlet, resulted in a reduction in the negative core flow and a slower, more scattered quenching of the lower core regions.

\section{CONCLUSIONS}

The concept of simultaneous accumulator injection into the upper plenum and into the cold legs, coupled with pumped ECC injection in the cold legs, was investigated in the 
Semiscale Mod-1 system with a simulated 200\% double-ended cold leg break. This concept was found to provide good core cooling rates and early quench times in the Semiscale Mod-1 system.

The good core cooling effectiveness was primarily the result of upper plenum ECC fluid being swept into the core by negative intact loop and core flows. The negative flows were strongly related to condensation in the downcomer inlet annulus due to the presence of subcooled ECC fluid injected into the cold leg. This cooling mechanism caused the core to quench predominantly from the top down, which could represent a disadvantage with strongly bottom skewed axial power profiles. The investigation of upper plenum accumulator injection rate as an operating parameter led to the conclusion that core cooling effectiveness was not strongly related to upper plenum injection rate for the injection rates tested. The absence of a strong relationship between upper plenum accumulator injection rate and core cooling effectiveness occurred because, for the vessel injection rates used, penetration of the core by ECC injected into the upper plenum was largely controlled by the condensation process in the downcomer inlet annulus rather than by a supply mechanism in the upper plenum.

\section{REFERENCE}

B-1. J. M. Cozzuol, Thermal Hydraulic Analysis of Semiscale Mod-1 Integral Blowdown Reflood Tests (Baseline ECC Test Series), TREE-NUREG-1077 (March 1977). 


\section{THIS PAGE}

\section{WAS INTENTIONALLY}

LEFT BLANK 


\section{APPENDIX C \\ LOW PRESSURE INJECTION SYSTEM ECC INJECTION \\ IN THE UPPER PLENUM WITH OTHER ECC \\ INJECTION IN THE COLD LEG}


i

THIS PAGE

\section{WAS INTENTIONALLY LEFT BLANK}




\author{
APPENDIX C \\ LOW PRESSURE INJECTION SYSTEM ECC INJECTION \\ IN THE UPPER PLENUM WITH OTHER ECC \\ INJECTION IN THE COLD LEG
}

\title{
1. INTRÓDUCTION
}

The concept of injecting emergency core coolant (ECC) into the upper plenum by means of the low pressure injection system (LPIS) was investigated with the Semiscale Mod-1 system in a configuration that represented a two-loop pressurized water reactor (PWR) system as nearly as possible. The two-loop representation was used because, although the upper plenum LPIS injection concept could be applied to four-loop PWRs, it has historically been associated with two-loop plants. The evaluation of this concept entailed two separate experimental investigations. In the first, the effects on the system response of the system modifications required for the two-loop representation were evaluated. This evaluation was accomplished by including all the system modifications necessary to represent a two-loop PWR but injecting ECC from the accumulator and LPIS into the intact loop and broken loop cold legs. Since these injection locations were identical to those used in the four-loop baseline test with cold leg injection, an assessment of the effects of the two-loop plant scaling could be made by a direct comparison of test results from the two-loop and four-loop cold leg ECC injection experiments. The second experimental investigation used the same two-loop plant scaling as the first but the LPIS fluid was injected into the upper plenum rather than into the cold legs. Through this single change, the effects of upper plenum LPIS injection on the system thermal-hydraulic response could be isolated by direct comparison of the results from the two-loop plant scaled experiments.

The Semiscale Mod-1 system configuration used in both of the experimental investigations is shown in Figure C- 1 . The system consisted of a pressure vessel with simulated reactor internals; an intact loop with a steam generator, pump, and pressurizer; and a broken loop with a simulated steam generator, simulated pump, and two rupture assemblies. The simulated steam generator and pump contained orifices to provide the appropriate hydraulic resistance. Since the Semiscale Mod-1 system, shown in Figure C-1, is basically modeled after a four-loop PWR system and is primarily scaled from the Loss-of-Fluid Test facility, careful specification of the break area and the system resistances was required to allow the best possible representation of a two-loop system. The details of the break area, system resistances, and other system modifications required for the two-loop Semiscale representation are presented in Table C-I. The Semiscale break area was system volume scaled to a $200 \%$ double-ended cold leg break in a typical two-loop PWR. The volume scaling of the break area is particularly important during the blowdown portion of the transient when the depressurization rate and the system flow magnitudes and directions are directly influenced by the break flow rates. The intact loop hỳdraulic resistance was core 


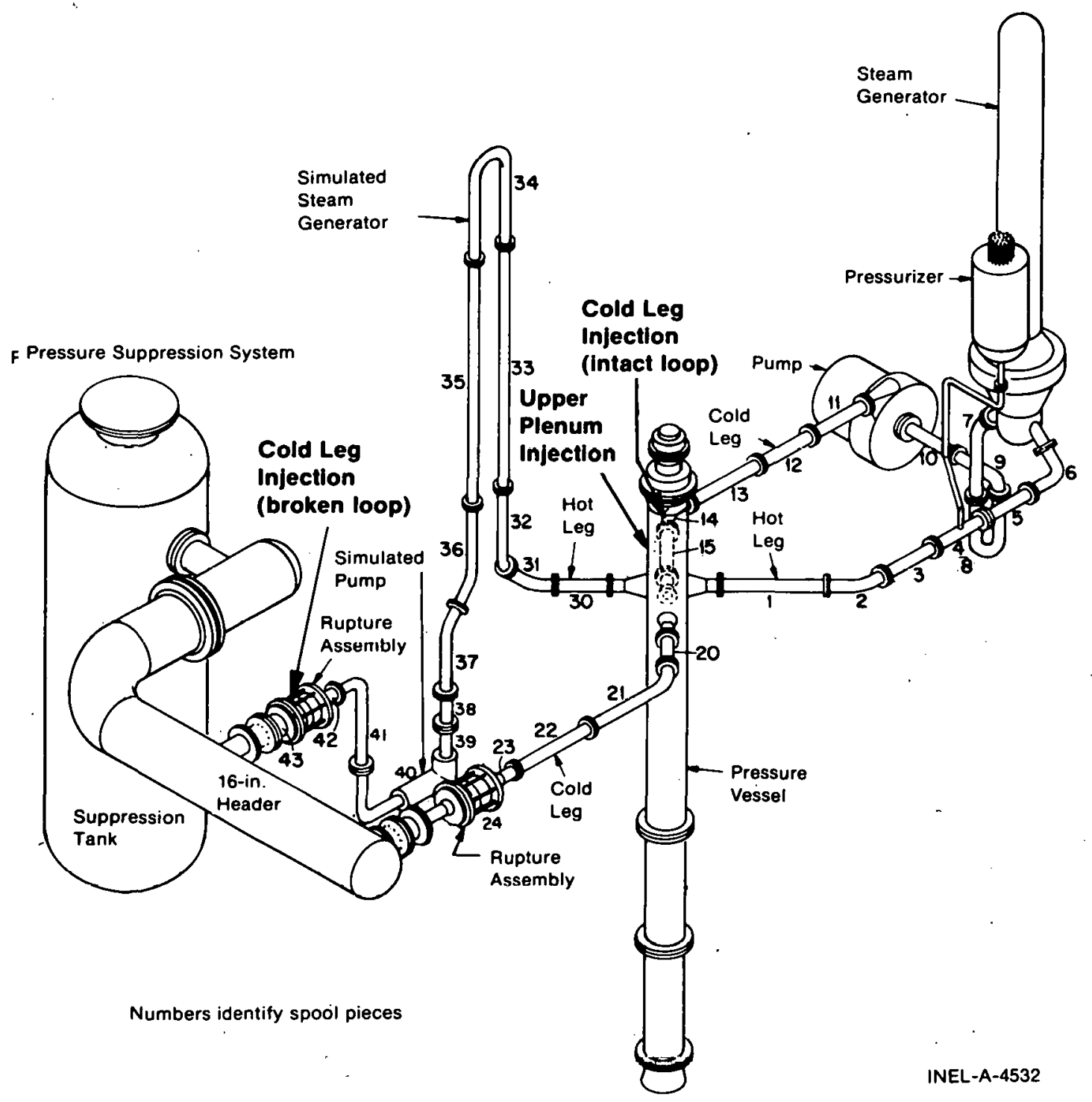

Fig. C-1 Semiscale Mod-1 system.

flow area scaled to a two-loop PWR in order to produce a representative pressure drop during the reflood portion of the transient. The vessel hydraulic resistance was fixed and was about one quarter of that which would have resulted had core area scaling methods been applied. Core area scaling was used in the specification of the ECC system volumes and flow rates, and allowances in the accumulator volumes were made for such factors as the delayed delivery of coolant due to the heat transfer rate associated with the hot Semiscale downcomer walls $[\mathrm{C}-1]$.

The upper plenum LPIS injection location used in the second experimental investigation is shown in Figure C-2. The upper plenum LPIS injected ECC horizontally through a nozzle located 13.5 in. above the elevation of the intact loop cold leg. This location introduced LPIS fluid to the upper plenum about 90 in. above the top of the heated core. Since the heater rod extensions run through the upper plenum and out the top of the vessel, the LPIS fluid injected into the upper plenum impinged directly on the rod extensions. 


\section{TABLE C-I}

MODIFICATIONS TO THE SEMISCALE FOUR-LOOP CONFIGURATION TO ACHIEVE A TWO-LOOP. CONFIGURATION ${ }^{[\mathrm{a}]}$

\begin{tabular}{|c|c|c|}
\hline Parameter Changed & $\begin{array}{c}\text { Four-Loop } \\
\text { Configuration }\end{array}$ & $\begin{array}{l}\text { Two-Loop } \\
\text { Configuration }\end{array}$ \\
\hline $\begin{array}{l}\text { Break nozzle area, both nozzles } \\
\left(\mathrm{ft}^{2}\right)\end{array}$ & 0.00524 & 0.01015 \\
\hline \multicolumn{3}{|l|}{$\begin{array}{l}\text { Hydraulic resistance } \\
\left(\sec ^{2} / \mathrm{ft}^{3}-\mathrm{in}^{2}\right)\end{array}$} \\
\hline Intact loop hot leg & 0.52 & 0.52 \\
\hline Steam generator & 1.96 & 4.45 \\
\hline Pump suction & 0.26 & 0.26 \\
\hline Intact loop cold leg & 0.56 & 0.56 \\
\hline Vessel & 1.21 & 1.21 \\
\hline Intact loop and vessel total & 4.51 & 7.00 \\
\hline Broken loop hot leg total & 262 & 262 \\
\hline Broken loop cold leg total & 0.48 & 0.48 \\
\hline $\begin{array}{l}\text { Pressurizer initial liquid mass } \\
(1 \mathrm{bm})\end{array}$ & 20 & 26 \\
\hline $\begin{array}{l}\text { Intact loop accumulator liquid } \\
\text { volume }\left(\mathrm{ft}^{3}\right)\end{array}$ & 2.83 & 2.92 \\
\hline $\begin{array}{l}\text { Intact loop accumulator average } \\
\text { flow rate }(\mathrm{gpm})\end{array}$ & 23 & .18 \\
\hline $\begin{array}{l}\text { LPIS injection rate and location } \\
(\mathrm{gpm})\end{array}$ & 4.0 cold leg & $\begin{array}{l}3.9 \text { cold leg or } \\
3.9 \text { upper plenum }\end{array}$ \\
\hline \multicolumn{3}{|c|}{$\begin{array}{l}\text { [a] The values in this table reflect scaled parameters for a two-loop } \\
\text { PWR facility. Values achieved during the experimental investiga- } \\
\text { tion were within accepted tolerances of the scaled values. }\end{array}$} \\
\hline
\end{tabular}

Section 2 of this appendix presents the experimental results of the two-part investigation of upper plenum LPIS injection in the Semiscale Mod-1 system. The system hydraulic phenomena and core thermal response associated with the two-loop plant scaling are discussed first, and then the effects of upper plenum LPIS injection on the system thermal-hydraulic behavior are evaluated. The significant conclusions from the two-part investigation are presented in Section 3. 


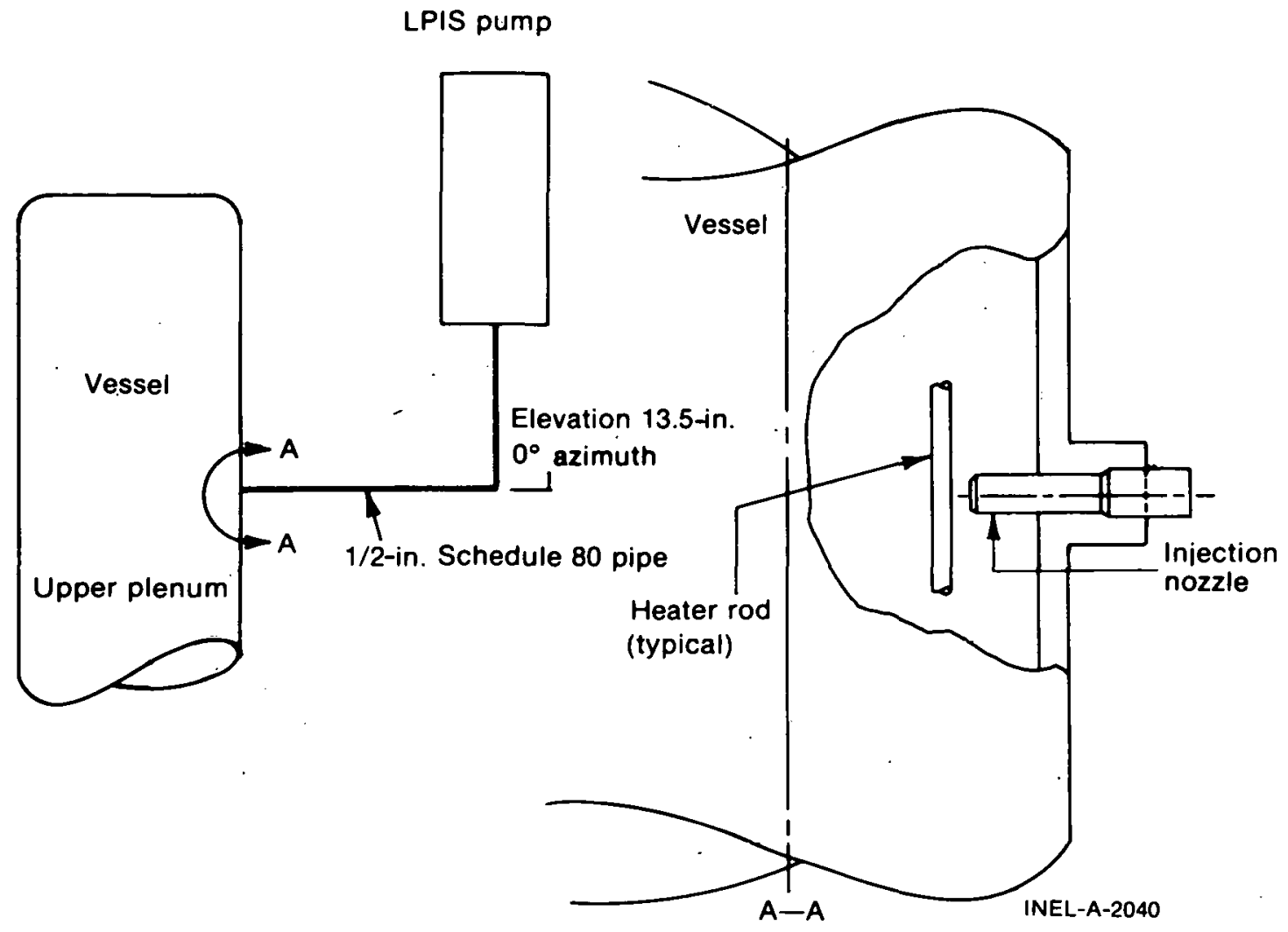

Fig. C-2 Schematic of upper plenum LPIS injection location.

\section{EXPERIMENTAL RESULTS}

The experimental results presented in this section are divided into two parts. First, the system behavior and core thermal response resulting from the two-loop planl scialing are presented. The emphasis of this discussion is on comparison of results from the Semiscale two- and four-loop representations with cold leg ECC injection. The second part of this section discusses the effects of upper plenum LPIS injection on the overall core thermal response. The emphasis of this second part is on comparison of data from the two-loop plant scaling experiments with and without upper plenum LPIS injection.

\subsection{Results from the Semiscale Two-Loop Plant Scaling with Cold Leg ECC Injection}

The first part of the two-part investigation was conducted without upper plenum LPIS injection, but utilized two-loop plant scaling to determine the thermal-hydraulic behavior in the Semiscale Mod-1 system with a $200 \%$ cold leg break scaled to a two-loop plant. In this part of the investigation, two major phenomena were observed. First, a very rapid blowdown occurred as a result of large flow rates at the break, and second, a large and sustained negative core flow occurred. Both of these phenomena affected the core thermal response. In the following paragraphs, the observed system hydraulic phenomena are first discussed in some detail, and then the core thermal response caused by these phenomena is presented and explained. 
The more rapid blowdown process with the two-loop configuration is illustrated by Figure C-3 which shows that the system pressure reached that of the suppression system about $17 \mathrm{sec}$ after rupture, compared with $35 \mathrm{sec}$ for a four-loop configuration. The more rapid blowdown with the two-loop configuration was predominantly the result of the increased flow out of the cold leg side of the break during the first $15 \mathrm{sec}$ of the transient, as shown in Figure C-4. In contrast to the broken loop cold leg flow, the flow through the hot leg toward the break for the two-loop plant scaling was not significantly larger than that for the four-loop plant scaling during the initial blowdown period, indicating that the broken loop hot leg fluid flow rate was not significantly affected by the break size. The small effect of break size on the broken loop hot leg flow was a result of the larger hydraulic resistance of the broken loop hot leg piping (relative to the broken loop cold leg piping). Since the hydraulic resistance of the piping was a major part of the total resistance to the flow out the hot leg break, the change in resistance for the entire broken loop hot leg was small even though the break size for the two-loop configuration was about double that for the four-loop configuration. Consequently, the broken loop hot leg flows were viry similar for the two- and four-loop configurations. The rapid blowdown, combined with the fact that the additional break flow occurs very largely on the cold leg side of the break, indicates a significant redistribution of flows within the system during the blowdown period.

The redistribution of the system blowdown flows resulted in a large negative core flow early in the transient. The negative flow was sustained for some $70 \mathrm{sec}$ after rupture, as shown in Figure C-5. Both density measurements and core heat transfer calculations indicated that the negative flow consisted mostly of high quality steam. Condensation in the

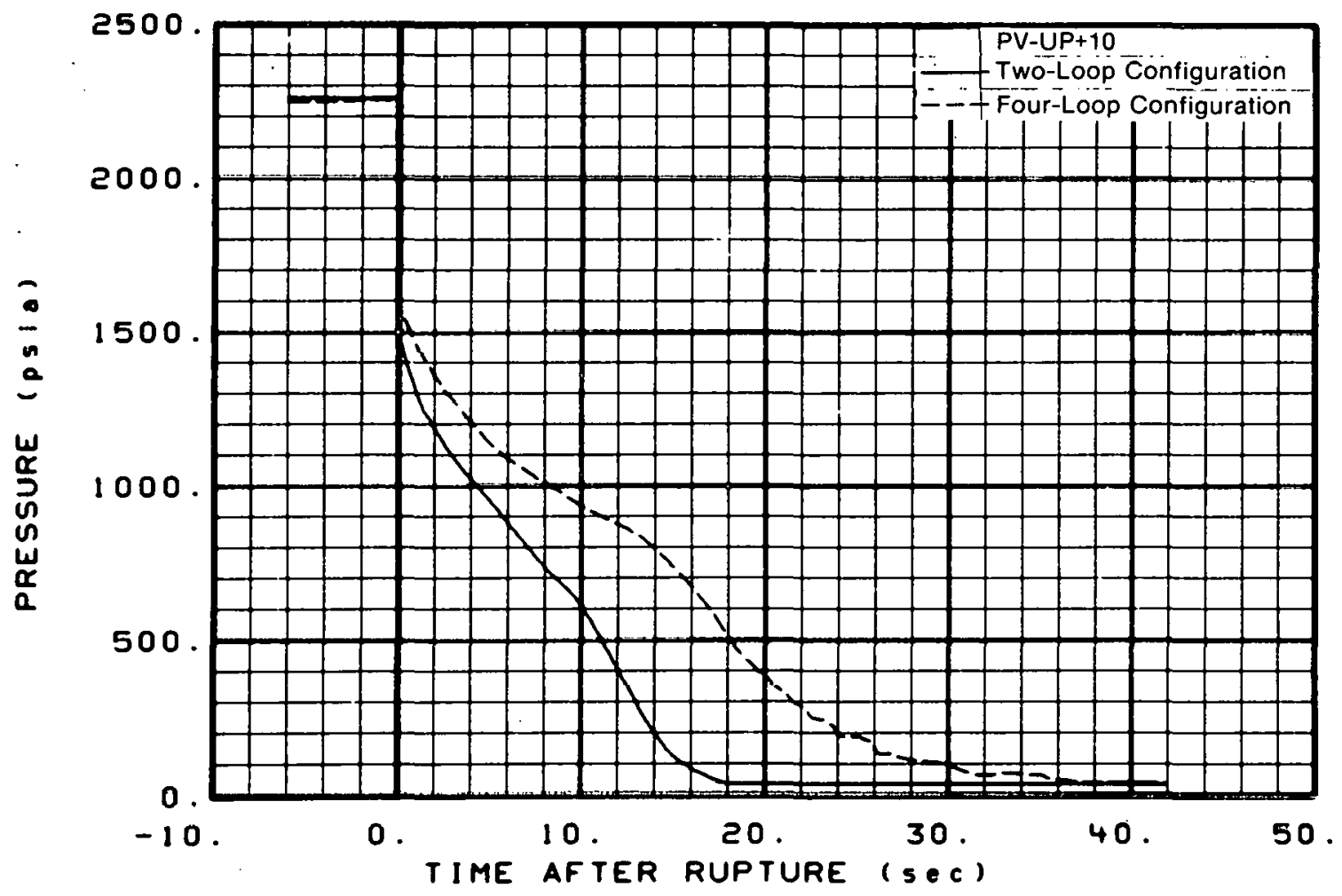

Fig. C-3 Effect of system configuration on depressurization rate. 


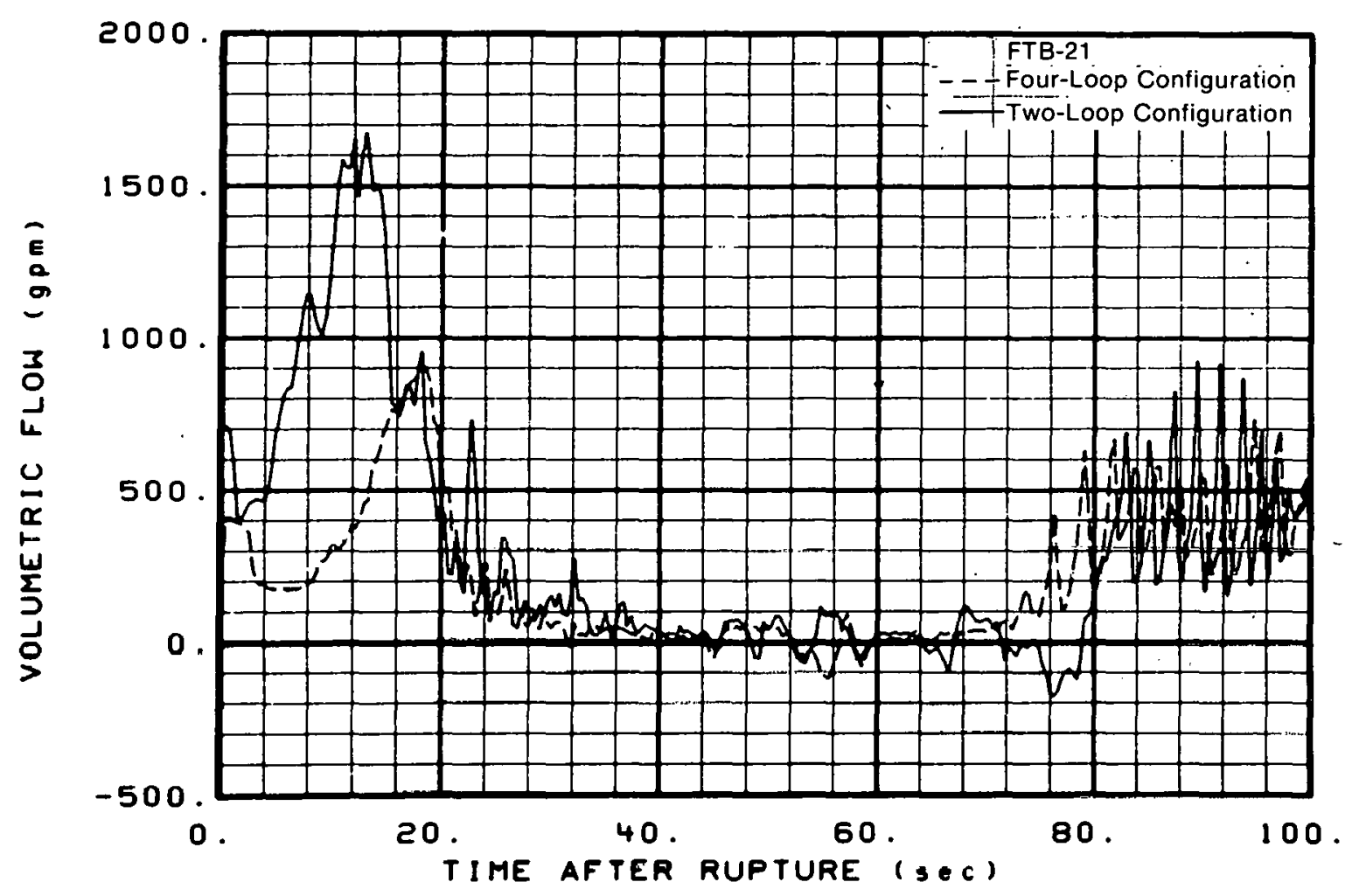

Fig. C-4 Effect of system configuration on broken loop cold leg flow.

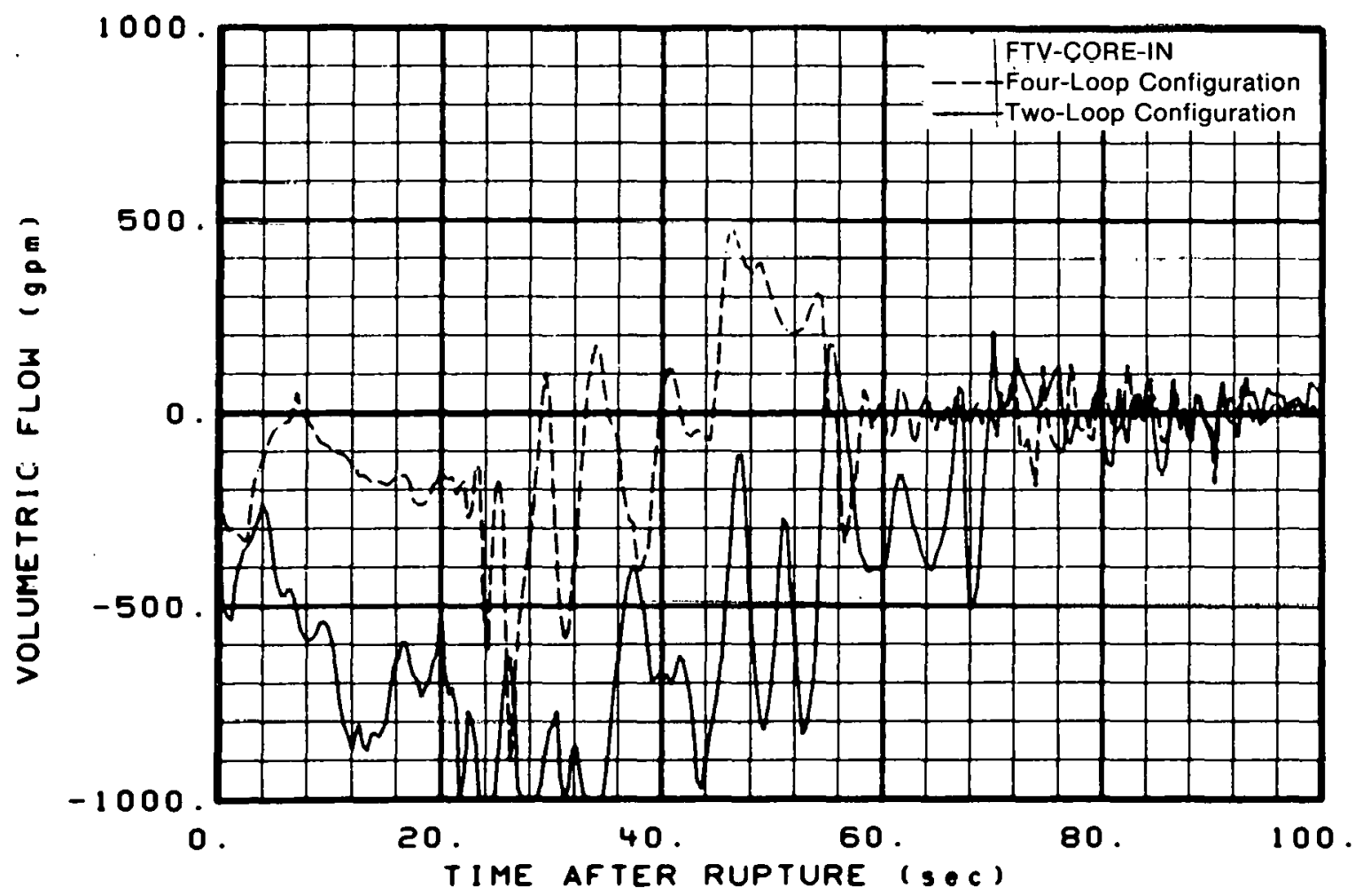

Fig. C-5 Comparison of core inlet volumetric flow rates for two- and four-loop configurations. 
downcomer was the principal driving mechanism by which the negative flow was sustained for the extended period after the end of blowdown. The broken loop hot leg was a contributor to the negative core flow but the major source of fluid was the intact loop hot leg. The intact loop hot leg fluid flow towards the vessel during the first $60 \mathrm{sec}$ of the transient was considerably greater for the two-loop system configuration as shown in Figure C-6. The increased intact loop hot leg flow is attributed partly to the increased initial liquid inventory in the pressurizer and partly to the reduced resistance of the flow path through the core and the broken loop cold leg due to the larger break. For the two-loop configuration, the pressurizer contained about $25 \%$ more liquid prior to blowdown than it did for the four-loop configuration. Consequently, more fluid was available to supply the in tact loop hot leg and core flow. The reduced resistance of the broken loop cold leg due to the larger break in the two-loop configuration promoted intact loop flow toward the vessel and down through the core at an increased rate relative to that in the four-loop configuration. The increase in the intact loop hot leg volumetric flow is equivalent to only a few pounds mass of fluid, however, and any small increase in residual liquid in the steam generator, pressurizer, or intact loop hot leg could also produce the necessary increase in volumetric steam flow due to piping heat transfer.

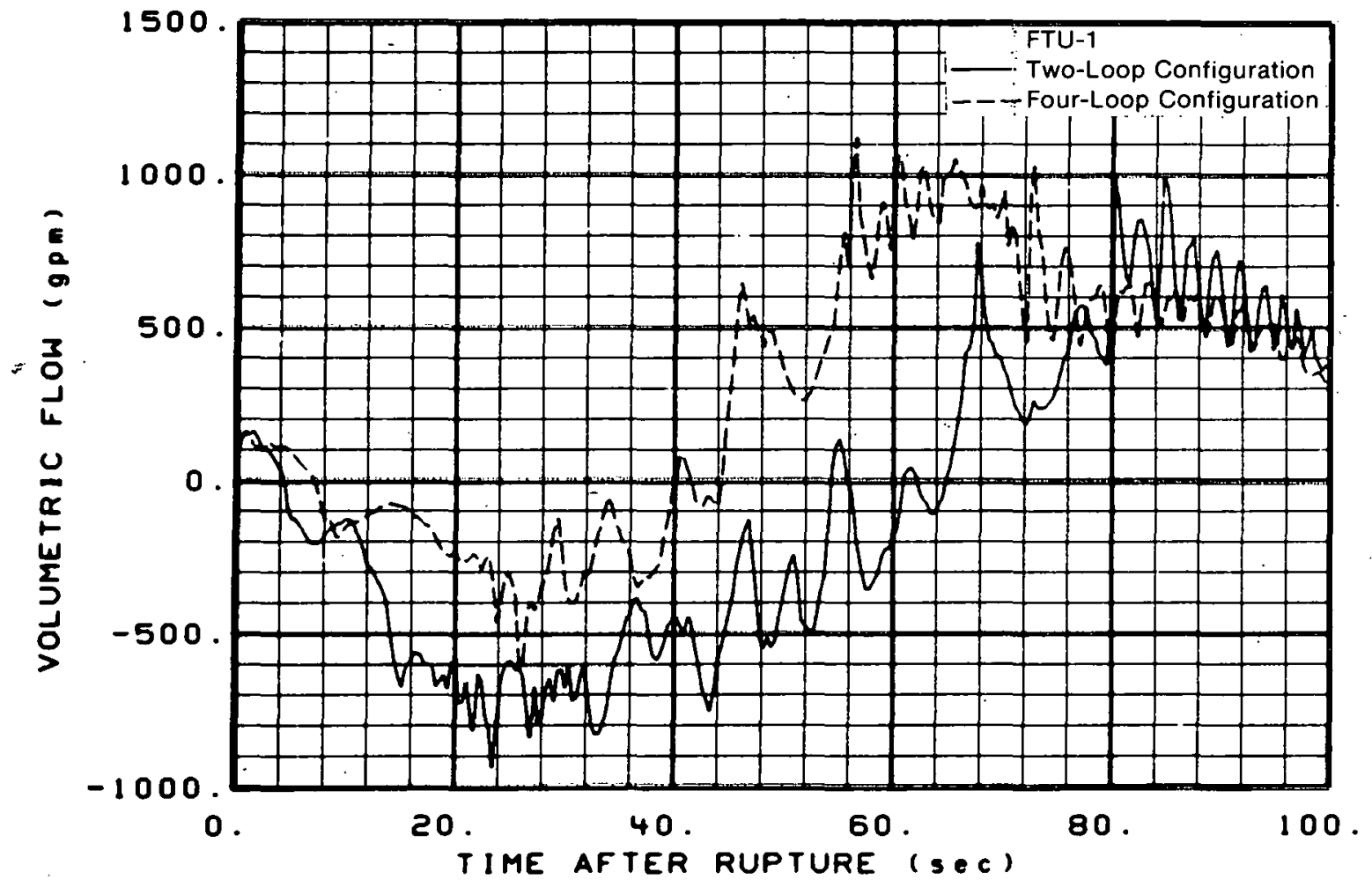

Fig. C-6 Comparison of intact loop hot leg volumetric flows for the two- and four-loop configurations.

Overall, the size of the break area, and the other system changes associated with the two-loop representation, greatly affect the system hydraulic response. Most system fluid flow rates were significantly increased during the early blowdown period for the two-loop configuration compared to those with the four-loop configuration. Following blowdown, the core volumetric flow rate was increased considerably for the two-loop representation, due to a larger incoming intact loop hot leg flow. 
The differences in the system hydraulic behavior between the two- and four-loop configurations resulted in significant differences in the core thermal response. During the blowdown, early and stable departure from nucleate boiling (DNB) was completely absent for the two-loop configuration. The delayed DNB, compared with that obtained with the four-loop configuration, was accompanied by early turnover of the temperatures and by lower peak blowdown temperatures at many locations throughout the core. Figures C-7 and C-8 compare temperature responses for the two- and four-loop representations at the 29and 15-in. elevations, respectively. The two-loop test produced later or delayed DNB for both locations. Also, comparison of maximum rod temperatures in Figure C-7 indicates about a $200^{\circ} \mathrm{F}$ lower peak blowdown temperature for the two-loop experiment relative to that for the four-loop experiment. Both the consistently delayed DNB and the lower peak temperatures were caused by the increased initial negative core flow discussed previously.

Following the turnover in the blowdown temperatures, the changed system hydraulic behavior caused a further change in the core thermal response. A rapid drop in core heater rod temperatures was observed between 10 and $14 \mathrm{sec}$ after rupture. This rapid drop in temperature is shown in Figure C-9 which shows the rod cladding temperature at the 14-in. elevation, together with the hot leg fluid density measured in the intact loop next to the vessel. The turnover and decrease in the rod cladding temperature at the 14-in. elevation correspond to an increase in the intact loop hot leg fluid density, demonstrating that high density fluid from the intact loop was a major contributor to the effective core cooling during this period. The rapid drop in temperature was unique to the two-loop representation

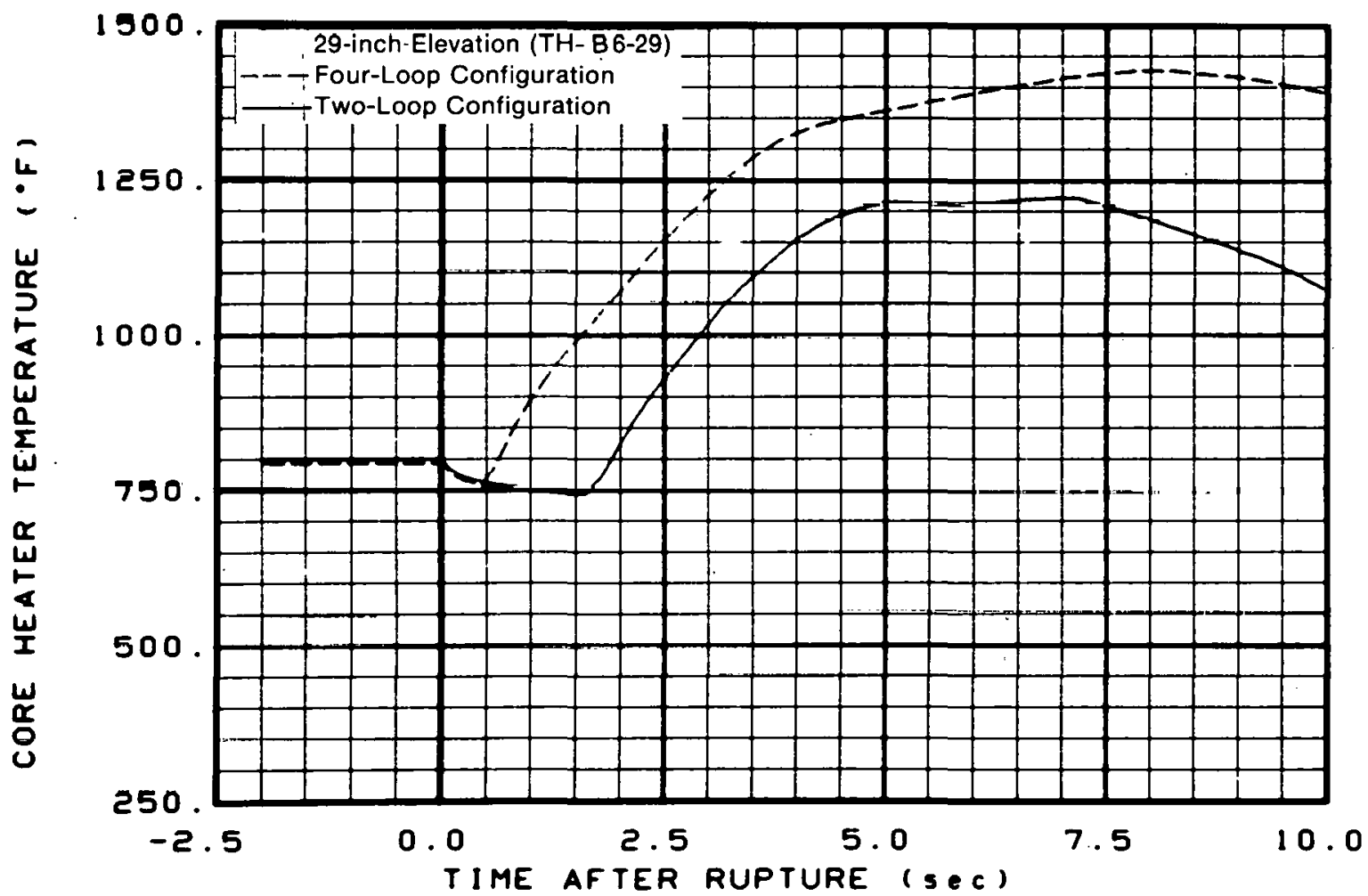

Fig. C-7 Effect of sy stem configuration on core DNB behavior - 29-in. elevation. 


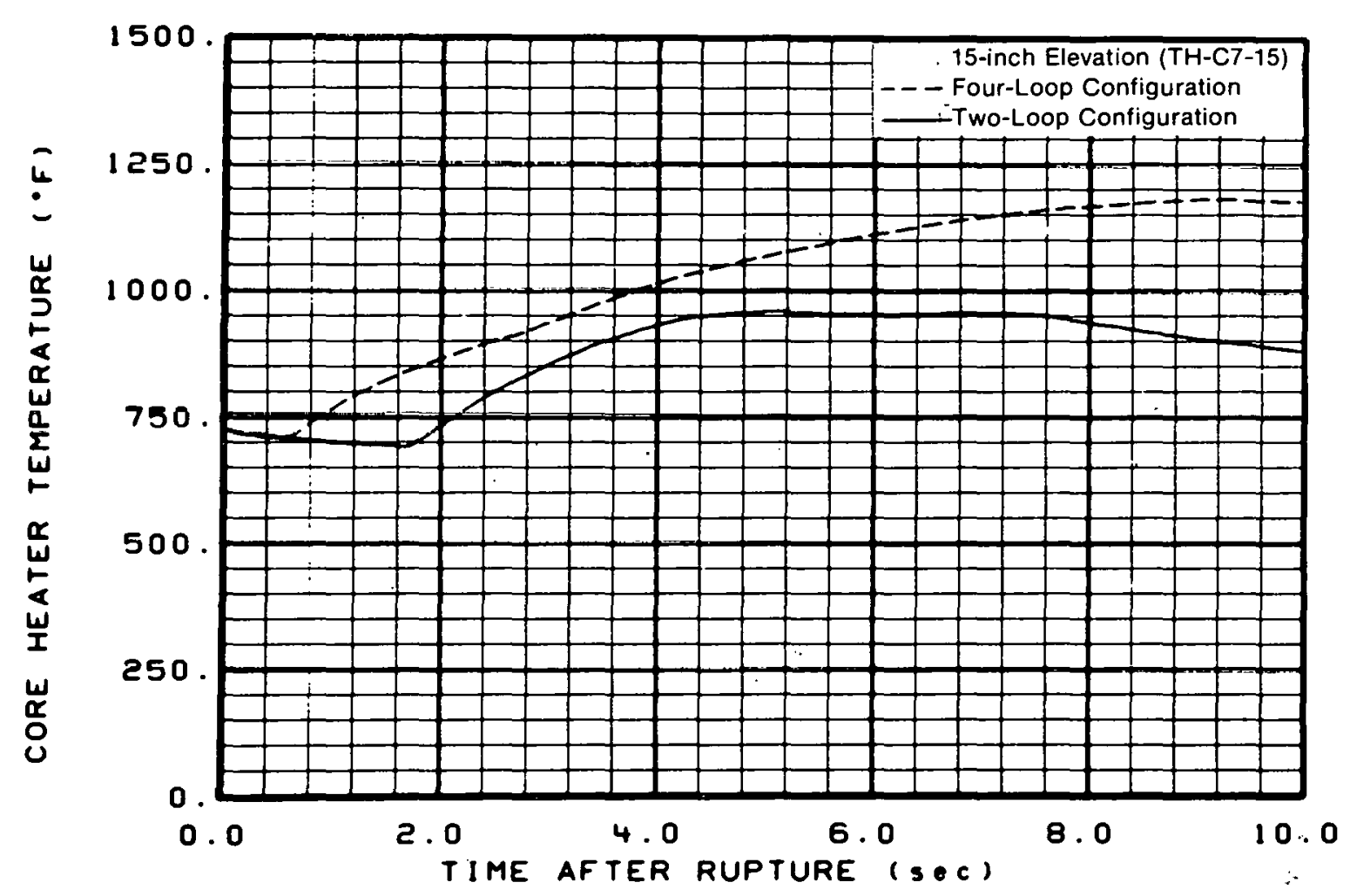

Fig. C-8 Effect of system configuration on core DNB behavior - 15-in. elevation.

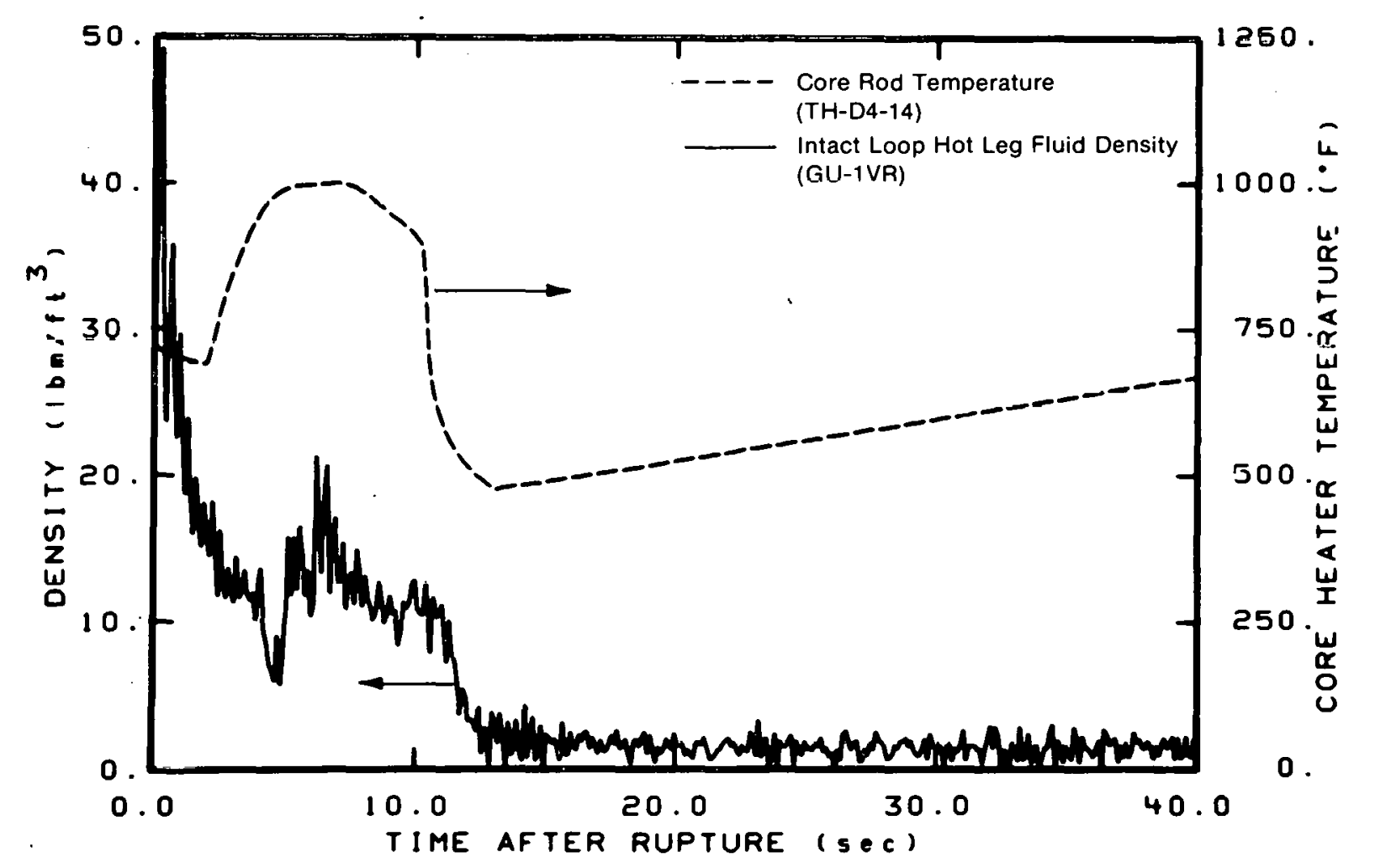

Fig. C-9 Effect of intact loop water on core thermal response for the two-loop configuration. 
only in magnitude. Although liquid also entered the core with the four-loop configuration, the amount of liquid and the resulting core cooling effectiveness were not as great as with the two-loop configuration. The pressurizer appears to have been a significant source for the low quality hot leg fluid which flowed into the core in the two-loop test. The increased volume of liquid in the pressurizer (discussed previously), and the strong negative intact loop and core flows which carried the liquid from the intact loop hot leg and distributed it throughout the core, resulted in the increased extent of the early and effective core cooling during the two-loop investigation with cold leg injection.

After the bulk of the low quality intact loop hot leg fluid was exhausted (about $14 \mathrm{sec}$ after rupture), the negative intact loop and core flows that persisted until about $70 \mathrm{sec}$ after rupture consisted predominantly of steam, but still had signficant effect on the core thermal response. The high quality steam flow through the core during this period provided poor core cooling, and the high volumetric flow caused signficant holdup and bypass of the ECC injected in the intact loop cold leg out of the cold leg break. Therefore, little cold leg ECC penetrated the downcomer during this period, and the calculated downcomer collapsed liquid level, shown in Figure C-10, indicates no significant increase in the downcomer liquid inventory prior to $70 \mathrm{sec}$ after rupture. As a result of the period of poor core cooling, caused by the high quality steam flow through the core and the holdup and bypass of ECC out the cold leg break, a substantial increase in temperature occurred throughout the core starting about $14 \mathrm{sec}$ after rupture. The increase in the core temperatures shown in Figure C-11 for rod temperature measurements at the 14- and 29-in. core elevations are typical of temperature measurements throughout the core. The strong negative core flow

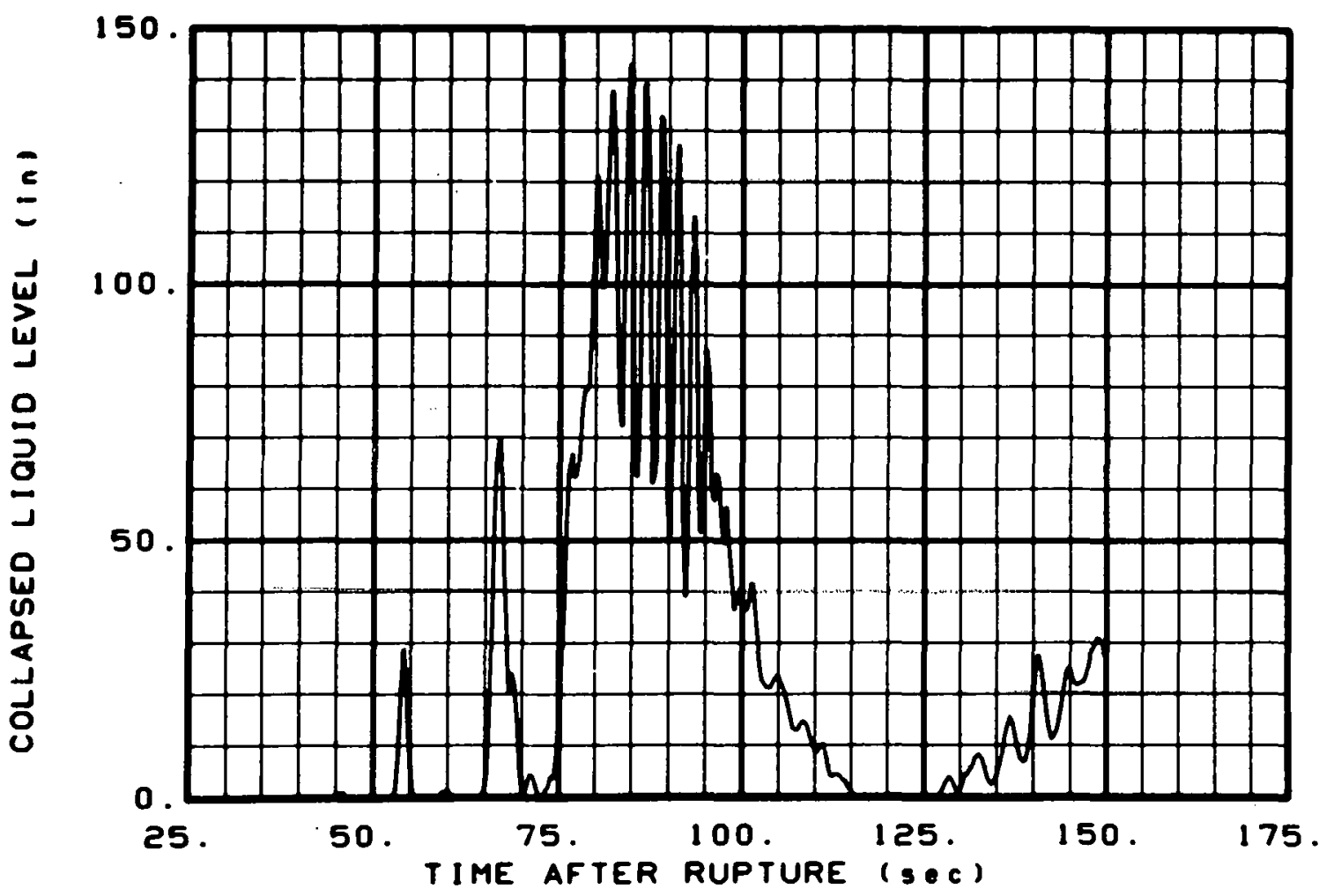

Fig. C-10 Downcomer collapsed liquid level for the two-loop configuration. 


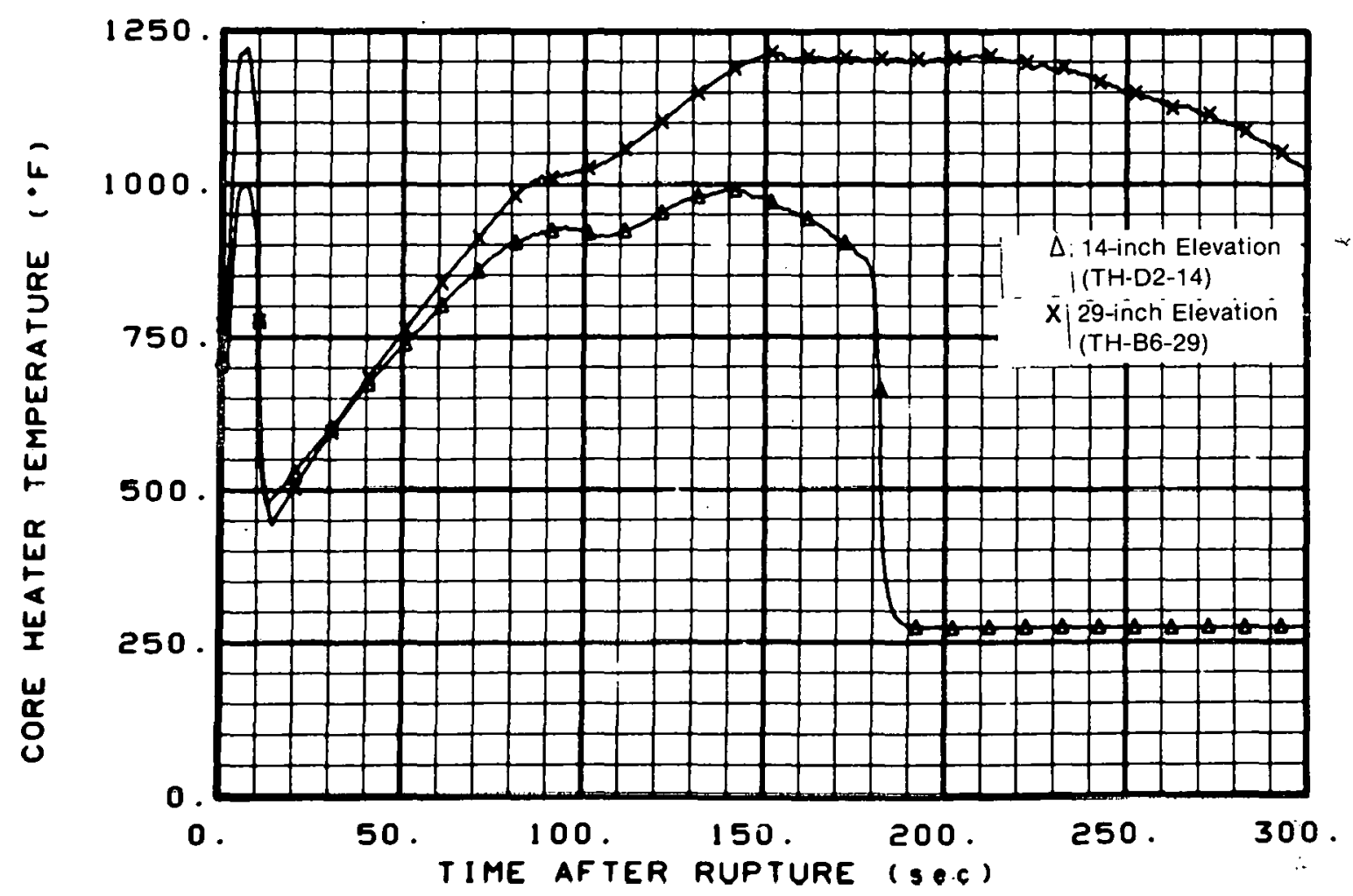

Fig. C-11 Rod cladding temperature at the 14- and 29-in: elevations for the two-loop configuration.

decreased at about $70 \mathrm{sec}$ after rupture, and ECC from the intact loop was finally able to penetrate the downcomer; Figure $\mathrm{C}-10$ shows that an increase in the downcomer liquid inventory occurred at about $75 \mathrm{sec}$ after rupture. However, the major source of the ECC supplied to the downcomer was lost when the intact loop accumulator water was exhausted at about $79 \mathrm{sec}$ after rupture. Although nitrogen flow from the accumulator into the intact loop forced liquid in to the downcomer and core, providing a period of effective core cooling which lasted from 79 to about $104 \mathrm{sec}$ after rupture (Figure C-11), a subsequent core dryout occurred followed by a further rise in core temperatures. The overall effect of the negative core steam flow and the resultant downcomer tilling behavior was that very little of the accumulator ECC fluid injected in the intact loop cold leg was effective in cooling the core.

The hot core was eventually reflooded by the LPIS injection alone, which resulted in very different cooling and quenching behavior than was evident in the four-loop scaled test. The slow downcomer filling process (Figure $\mathrm{C}-10$ ) began at about $130 \mathrm{sec}$ after rupture. As fluid then began to enter the core from the downcomer, Figure C-11 indicates that an improvement in core cooling occurred and rod temperatures began to turn over at about $150 \mathrm{sec}$ after rupture. However, because of the small ECC supply rate provided by the LPIS, the lower plenum filling and core reflood process was very slow, resulting in a slow bottom upward quench progression. The quenching process illustrated in Figure C-12 appeared almost linear, and the lack of significant quenching above the core high power zone (29 in. above the bottom of the core) indicates that relatively little entrainment took place. This 


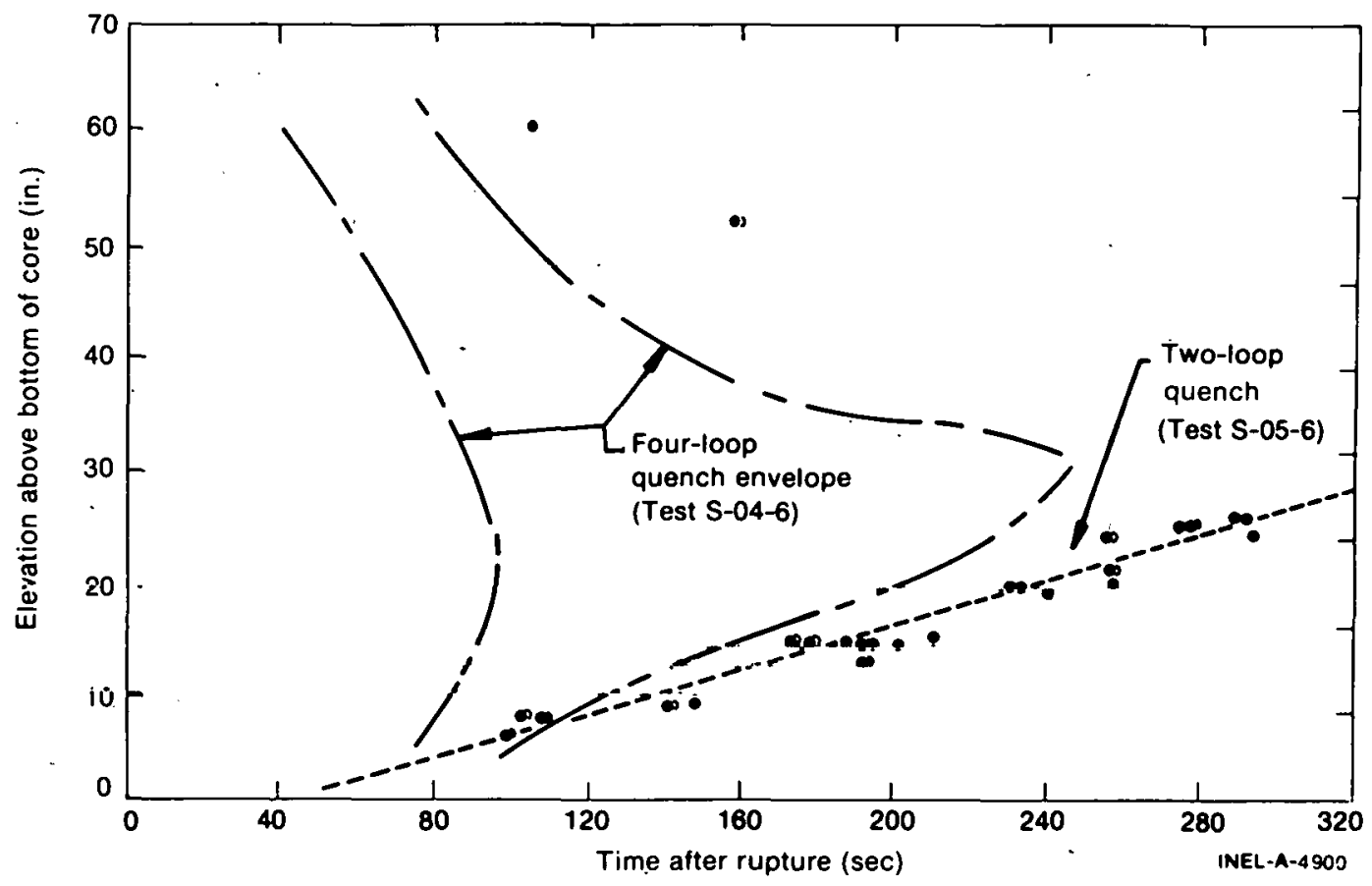

Fig. C-12 Axial quenching pattern for two- and four-loop configurations.

quenching pattern is in contrast to the quench pattern envelope for the four-loop configuration (also shown in Figure C-12), which indicates concurrent quenching at both high and low core elevations, which in turn indicates significant entrainment. Therefore, the two-loop system modifications appear to have had substantial influence on the reflood processes in the Mndil conre.

In summary, comparison of the results from the four- and two-loop scaled tests shows that the system modifications significantly changed the core thermal response. Mostly delayed DNB occurred throughout the core for the two-loop representation and as a result, the peak blowdown rod cladding temperature for the two-loop representation was about $200^{\circ} \mathrm{F}$ lower than with the four-loop representation. Early in blowdown the intact loop hot leg fluid flow influenced the core thermal response for both the two- and four-loop representations, but the effect was stronger for the two-loop representation. Later in the transient the stronger negative core volumetric flow rates for the two-loop representation, compared with those for the four-loop representation, caused increased holdup and bypass of ECC from the intact loop accumulator. Consequently, the quenching of the core was later for the two-loop representation compared with that for the four-loop representation. Ihe differences in the system hydraulic behavior, as a result of the two-loop scaling, significantly influenced the core cooling effectiveness in the subsequent investigation of upper plenum LPIS injection, which is discussed in the following section.

\subsection{Results from the Semiscale Two-Loop Configuration with Upper Plenum LPIS Injection (Test S-05-7)}

The system hydraulic behavior for the two-loop plant scaling tests with and without upper plenum LPIS injection indicates that the system hydraulic response was essentially 
unchanged when the LPIS injection location was moved from the cold leg to the upper plenum. The important negative core flow again developed early and was sustained until about $80 \mathrm{sec}$ after rupture. The magnitude of the negative flow at the core inlet was somewhat larger with the upper plenum LPIS injection, apparently because of additional steam generation in the core due to the presence of LPIS fluid; however, the phenomena driving the flow appeared to be essentially the same for the two tests. Consequently, the following discussion of the results from the two-loop scaled test with upper plenum LPIS injection concentrates on the core thermal response, and the hydraulic response is discussed only in that the thermal response is related to the flow characteristics in and around the upper plenum.

Comparison of temperature data for the two-loop tests with and without upper plenum LPIS injection indicates that the core thermal response was directly affected by the injection of ECC into the upper plenum. After initiation of LPIS injection the negative core flow, originating largely in the intact loop hot leg, swept LPIS fluid directly into the core. Since the LPIS injection velocity was low (about $8 \mathrm{ft} / \mathrm{sec}$ ), the large negative core flow carried the fluid into the region of the core immediately below the injection location. Consequently, very rapid top down quenching of this core region occurred shortly after LPIS injection began. This early. quenching is illustrated in Figures C-13 and C-14 which compare temperature responses for the two-loop representation with and without upper plenum injection at the 14- and 57-in. elevations, respectively. In each case, the temperatures were obtained on the side of the core immediately below the upper plenum

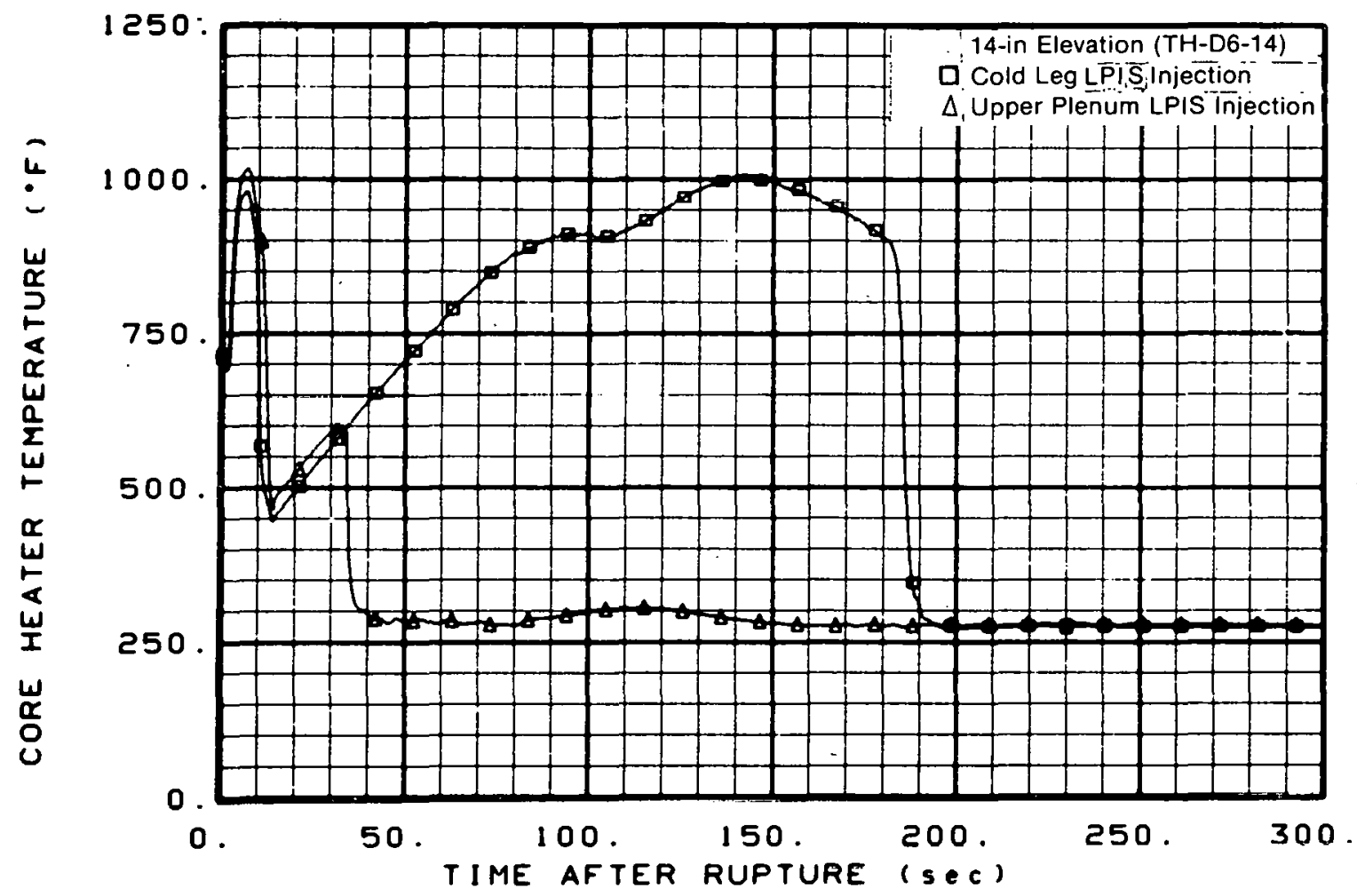

Fig. C-13 Effect of upper plenum LPIS injection on rod cladding temperature at the 14-in. elevation in the core region below the LPIS injection location. 


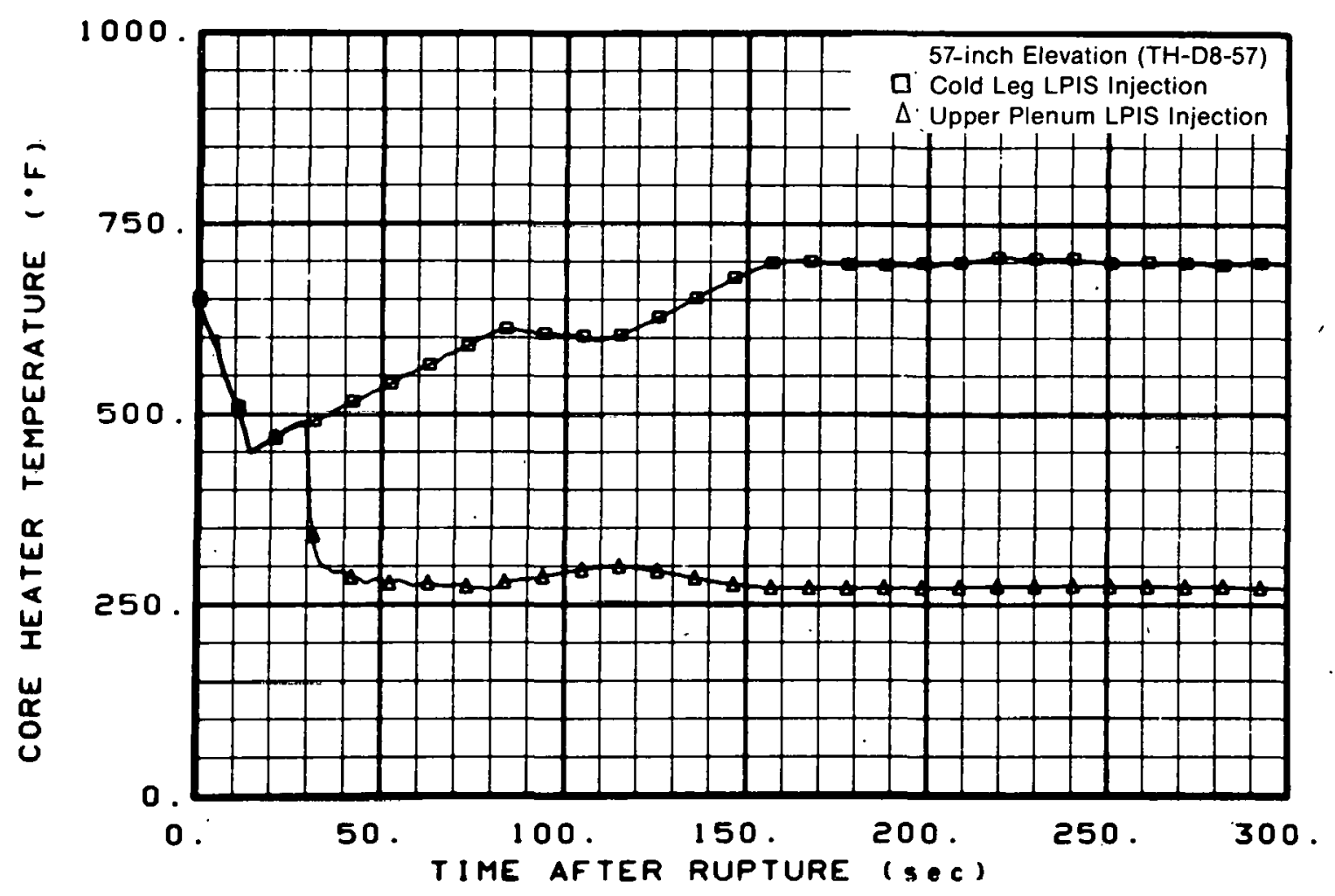

Fig. C-14 Effect of upper plenum LPIS injection on rod cladding temperature at the 57-in. elevation in the core region below the LPIS injection location.

injection location, and both figures indicate earlier quenching with LPIS injection into the upper plenum. In contrast, very little LPIS fluid initially penetrated to the side of the core opposite the upper plenum LPIS injection point. The lack of penetration into this region of the core is demonstrated by Figure C-15 which compares the heat transfer coefficients at two 29-in. core elevations. one on the side of the core below the upper plenum LPIS injection location and the other on the side of the core removed from the injection location. For much of the transient the heat transfer coefficient on the side removed from the injection location indicates forced convection to steam ( $\simeq \simeq 10 \mathrm{Btu} / \mathrm{hr}-\mathrm{ft}^{2}-{ }^{\circ} \mathrm{F}$ ), whereas the coefficient for the point below the injection location is high enough to indicate the presence of significant quantities of liquid. The steam environment on the side of the core removed from the upper plenum injection point indicates that the local conditions were not significantly influenced by the LPIS injection for a substantial portion of the transient. This lack of intluence is confirmed by Figures $\mathrm{C}-16$ and $\mathrm{C}-17$ which compare temperature responses for the two-loop representation with and without LPIS uppei plenum injection at the 21- and 33-in. elevations, respectively. In each case the temperatures were obtained on the side of the core opposite the upper plenum injection location, and both figures show similar temperature response and quenching behavior with and without upper plenum LPIS injection. Clearly, the uppcr plcnum LPIS injection in the Semiscale Mod-1 system results in very different thermal behavior on the side of the core below the injection location than it does on the side removed from the injection location. 


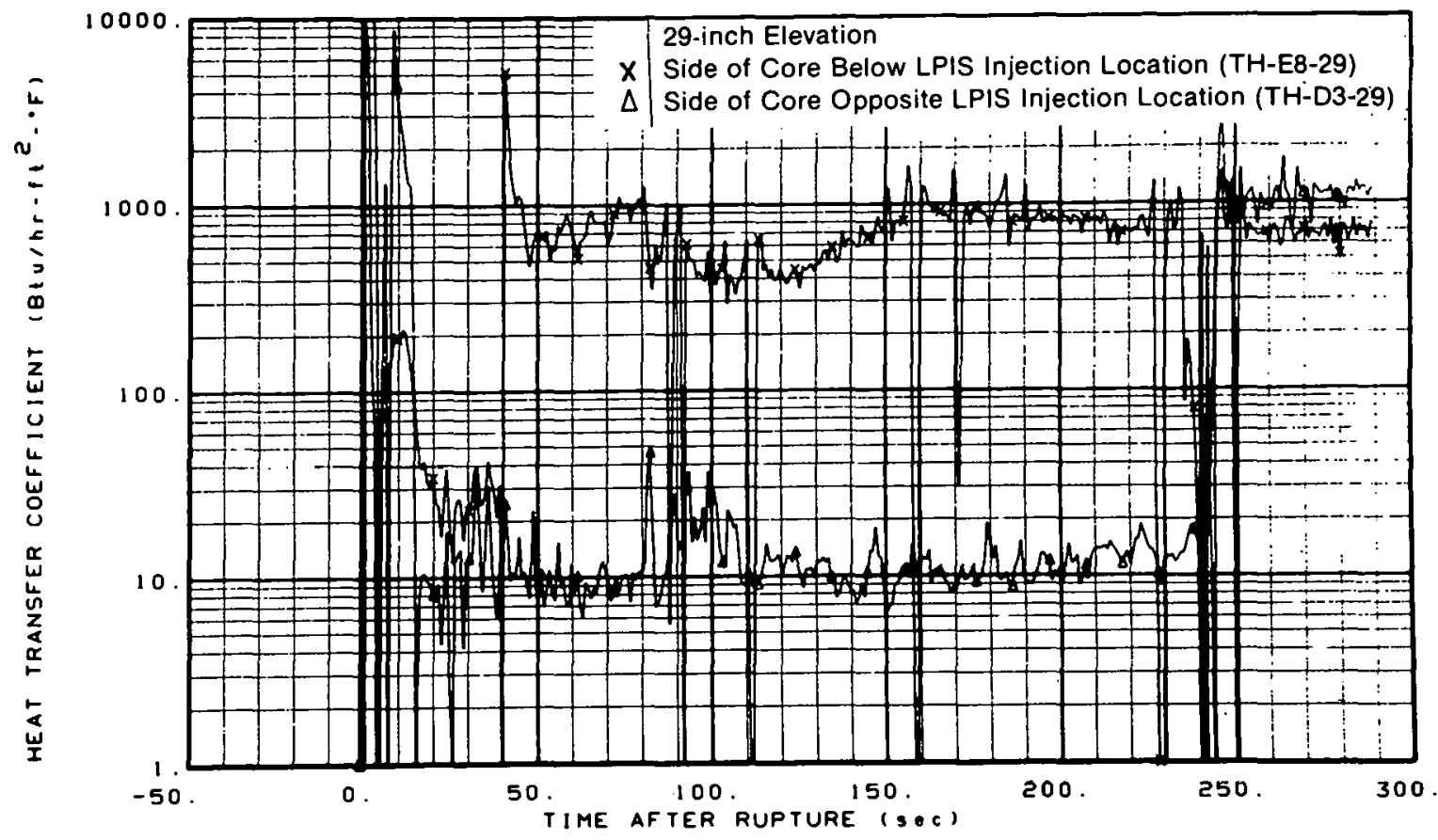

Fig. C-15 Dependence of local heat transfer coefficient on transverse location in the core in the two-loop configuration with upper plenum LPIS injection.

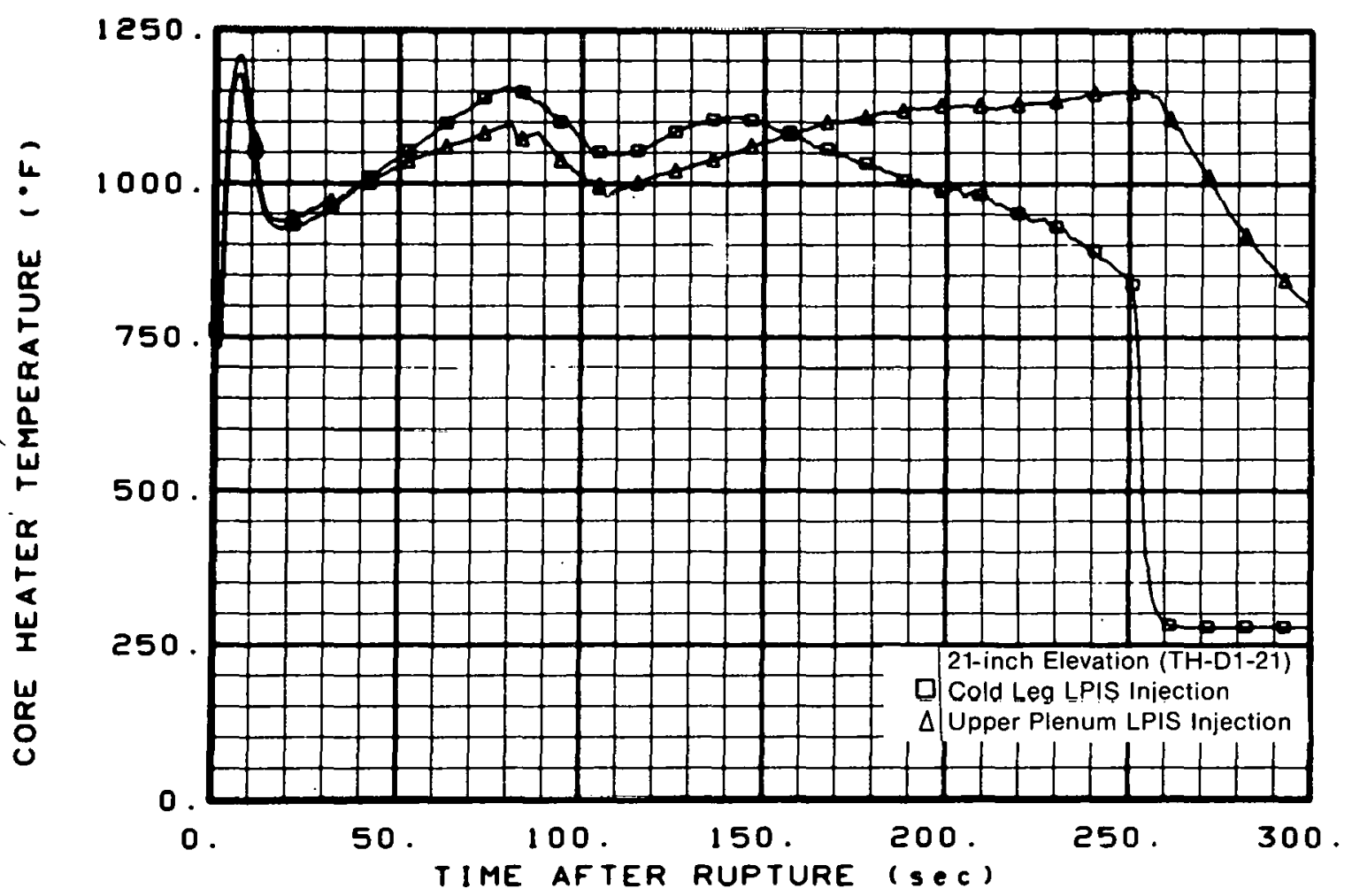

Fig. C-16 Effect of upper plenum LPIS injection on rod cladding temperature ar the 21-in. elevation in the core region opposite the LPIS injection location. 


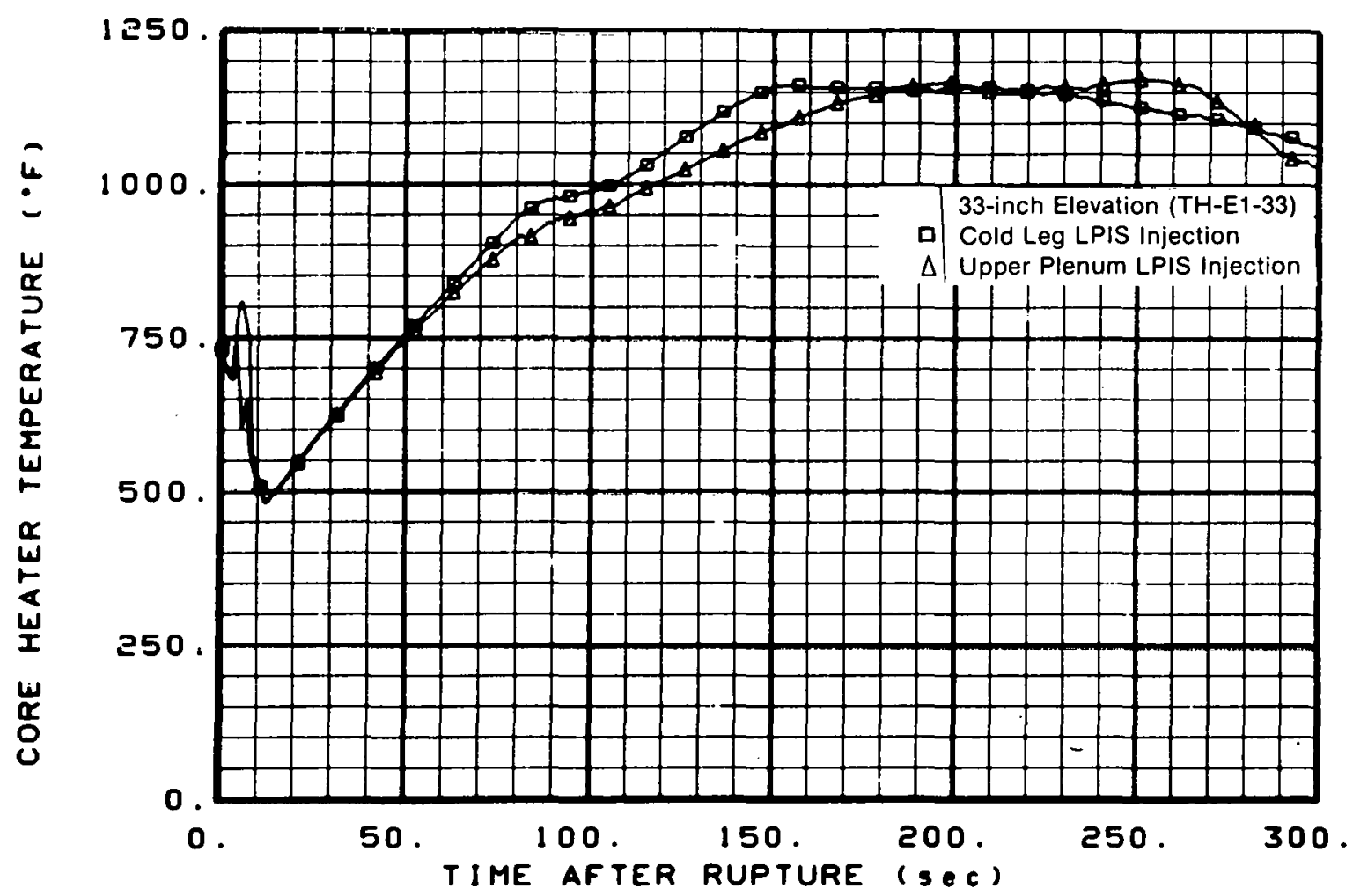

Fig. C-17 Effect of upper plenum LPIS injection on rod cladding temperature at the 33-in. elevation in the core region opposite the LPIS injection location.

An overview of the thermal behavior in the different regions of the core can be seen in the presentation of the axial quenching pattern in Figure C-18. The rapid top down quench in the core region below the LPIS injection location is illustrated by the large number of quenches in this region prior to $80 \mathrm{sec}$ after rupture. The strong negative core flow, vital to this early quenching behavior, ended at $80 \mathrm{sec}$ after rupture when nitrogen injection from the accumulator began in the intact loop cold leg. As a result, a period of sporadic quenching activity followed. Eventually, the continued LPIS injection in the upper plenum caused fluid to penetrate in to the core even in the absence of negative flow and resulted in the second, slower, and more scattered top down quench later in the transient.

As indicated in the preceding paragraphs, the core thermal behavior during the upper plenum LPIS injection period appeared to be closely related to the fluid flow characteristics in and around the upper plenum region. Evidence of the relation between the system flow characteristics and core thermal response is provided by the density measurements near the vessel in the intact and broken loop hot legs as shown in Figures C-19 and C-20, respectively. From $25 \mathrm{sec}$ after rupture when the LPIS injection started, to about $80 \mathrm{sec}$ after rupture when nitrogen injection in the cold leg began, large negative intact loop and core flows existed, and the density measurements indicate that little bypass of LPIS fluid occurred. Most of the LPIS fluid during this period was, therefore, available to the core to provide good cooling and rapid quenching. After the start of nitrogen injection the negative intact loop and core flows terminated, and bypass of the LPIS fluid out the intact and broken loop hot legs occurred as indicated by the rise in measured density in Figures C-19 


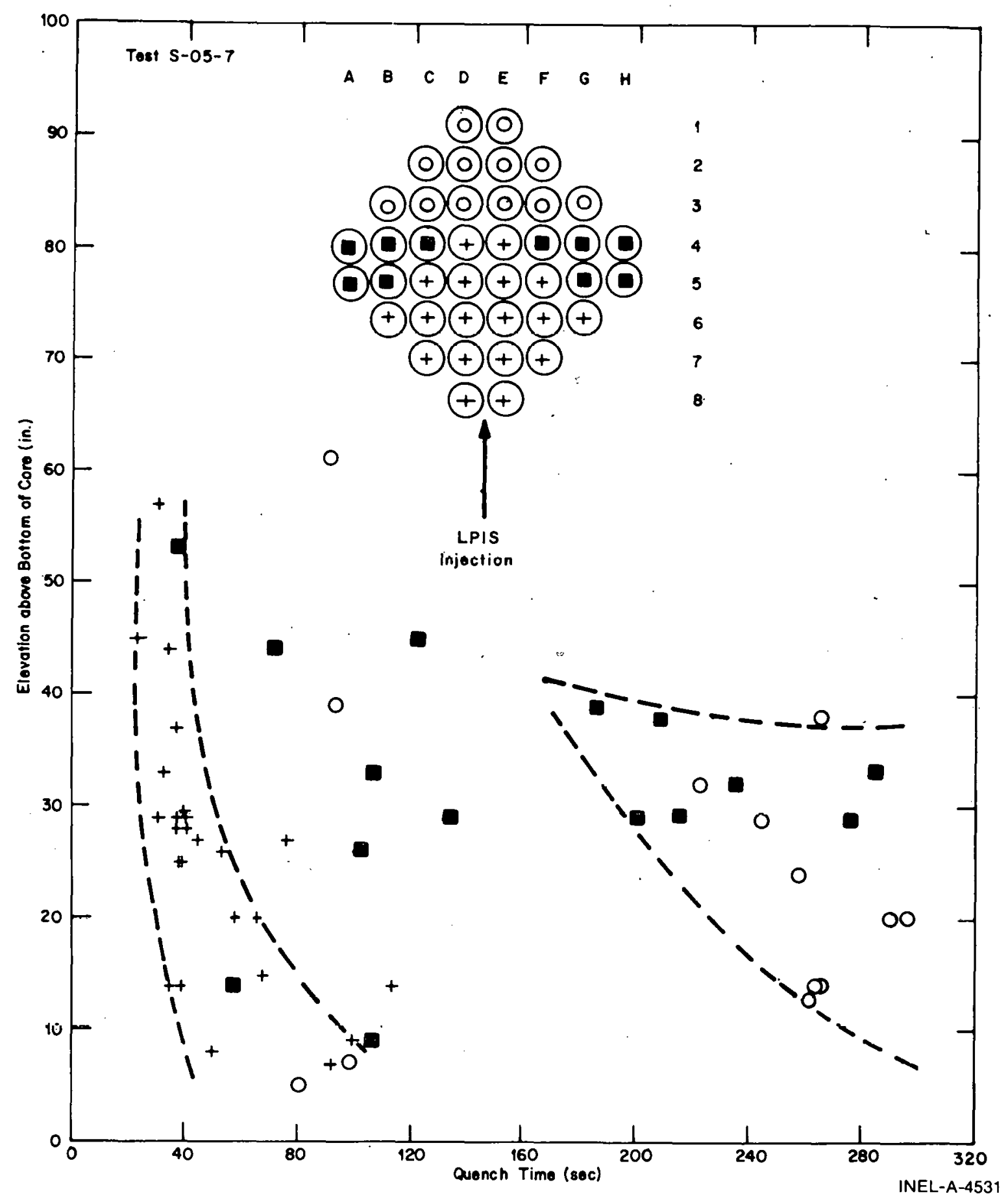

Fig. C-18 Quench time profile for upper plenum LPIS injection.

and C-20. Therefore, a decrease occurred in the supply of LPIS fluid to the core resulting in the less effective cooling. About $170 \mathrm{sec}$ after rupture, the oscillations in the hot leg density measurements indicate periods of reduced bypass flow which correspond to the start of the second top down quenching process. Eventually, as more of the core was quenched the countercurrent flow caused by steam generation in the core was reduced, resulting in reduced LPIS bypass, as indicated by the decreasing measured hot leg densities. The decreased bypass resulted in an increased supply of LPIS fluid to the core which again aided the cooling and quenching process. 


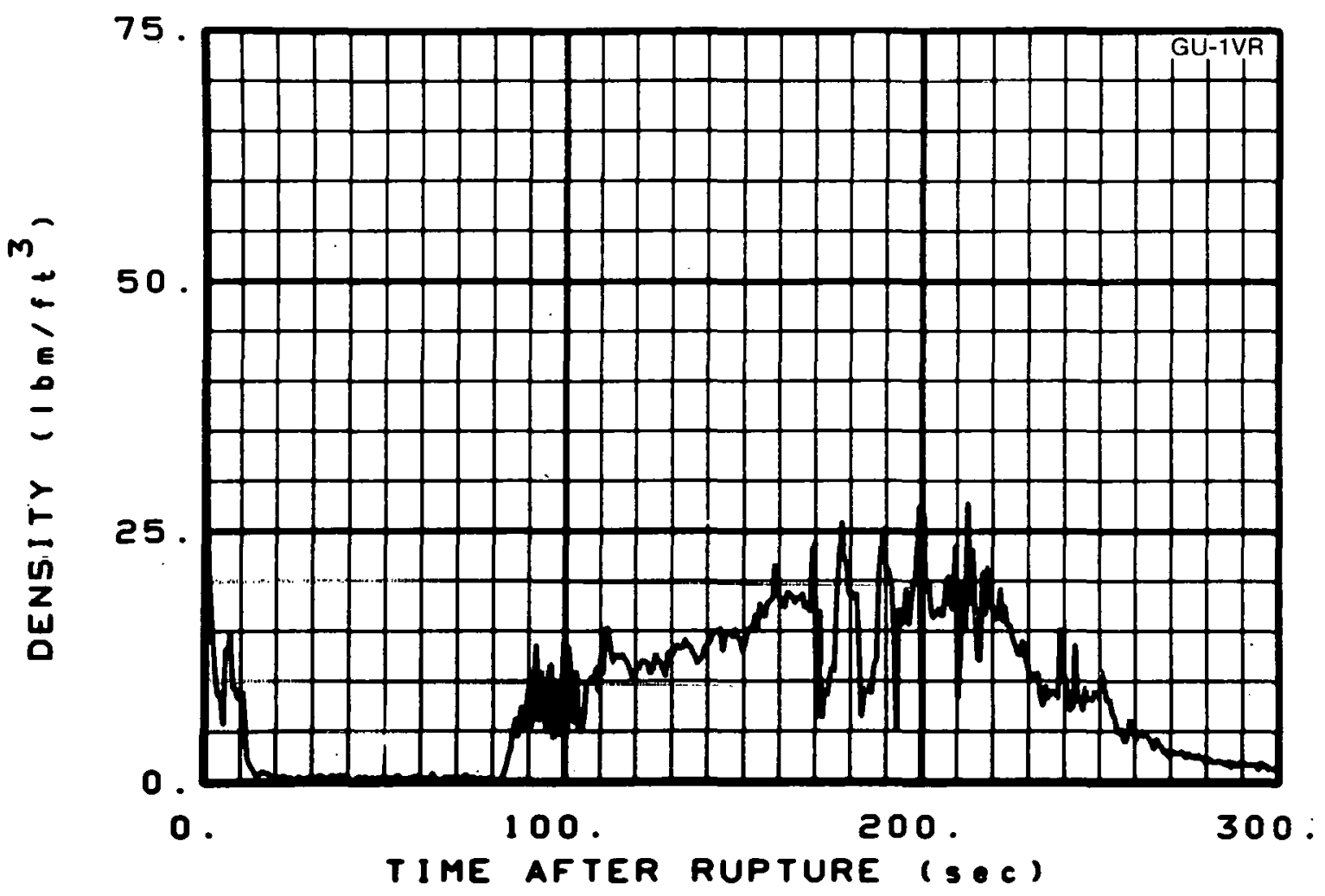

Fig. C-19 Intact loop hot leg fluid density for the two-loop configuration with upper plenum LPIS injection.

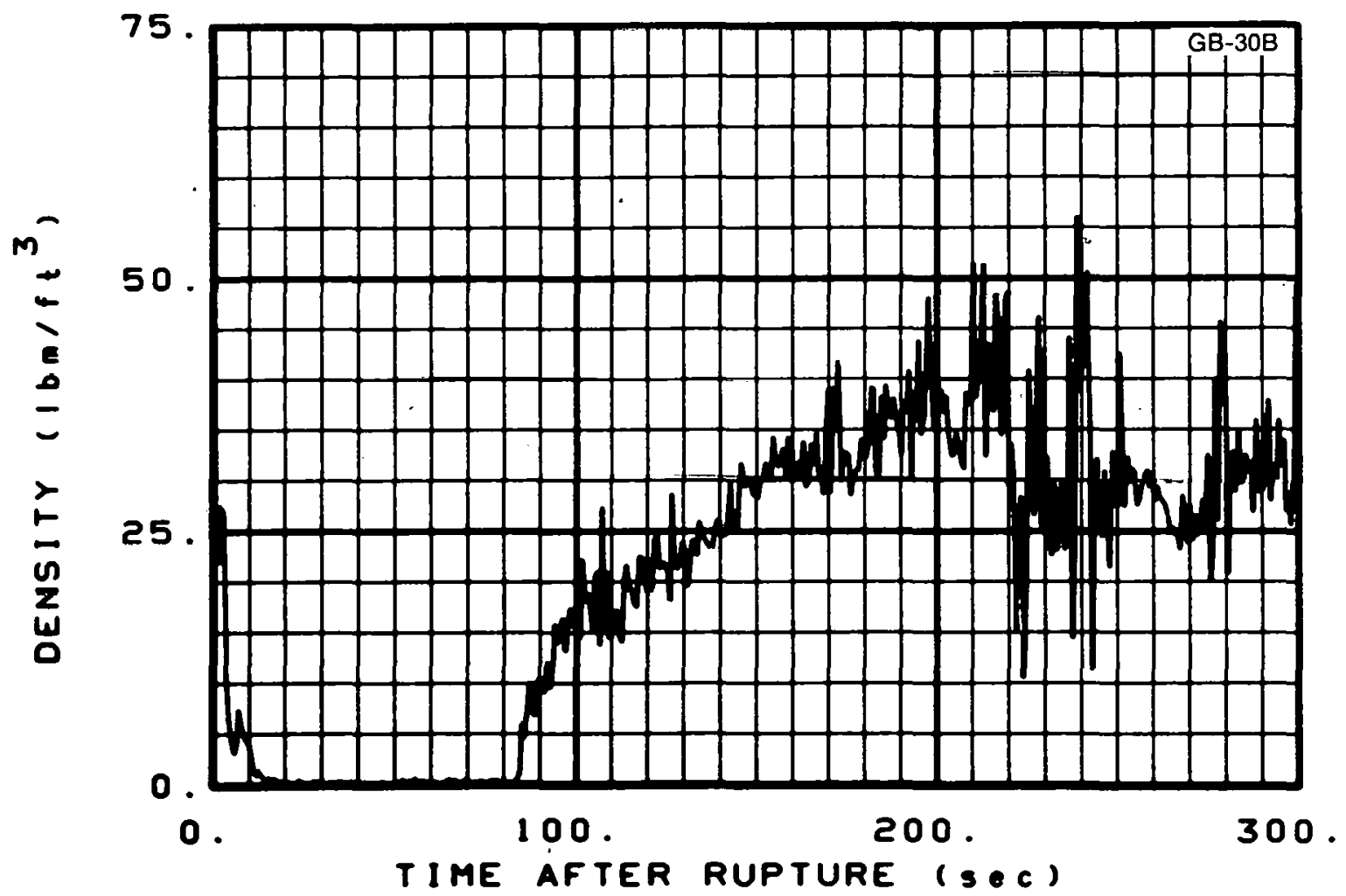

Fig. C-20 Broken loop hot leg fluid density for the two-loop configuration with upper plenum LPIS injection. 
In summary, injecting the LPIS fluid into the upper plenum, rather than into the cold leg, caused little change in the overall system hydraulic response but resulted in significant changes in the core thermal response. The localized penetration of LPIS fluid into the core resulted in good cooling in the region below the LPIS injection location and less effective cooling elsewhere in the core. The significant conclusions with regard to the two-loop scaling and the core cooling phenomena resulting from LPIS injection into the upper plenum are presented in the following section.

\section{CONC.LUSIONS}

The concept of using the LPIS to inject ECC into the Semiscale Mod-1 upper plenum following a $200 \%$ double-ended cold leg break was evaluated in a two-part experimental investigation. Since upper plenum LPIS injection has been historically associated with two-loop plants, operating modifications were made to the Semiscale Mod-1 system to allow the best possible representation of a two-loop system. The objective of the first part of the investigation was. to determine the effects of these operating modifications on the system thermal-hydraulic response. A test was conducted using the system modifications and employing cold leg ECC injection. The effects of the modifications were then isolated through comparative analysis with the results from a previously conducted test using cold leg injection in the absence of any system modifications, the system being operated in the four-loop configuration.

The objective of the second part of the investigation was to determine the effects of locating the LPIS injection in the upper plenum. A second test employing the two-loop operating modifications was conducted, identical in every way to the first test, with the single exception that the LPIS injection location was changed from the cold leg to the upper plenum. The effects of the change in LPIS injection location were then isolated through comparative analysis of the results from the two tests using the two-loop operating modifications.

The following sections present the major conclusions from the two analyses. The first section presents conclusions relating to the effects of the system modifications, and the second section presents conclusions relating to the effects of the LPIS injection location.

\subsection{Conclusions from Two-Loop Plant Scaling with Cold Leg ECC Injection}

Overall, the system hydraulic behavior and core thermal response for the two-loop Semiscale test configuration without upper plenum LPIS injection were significantly different than those observed in the previous experiment with the Semiscale Mod-1 system in a four-loop configuration. For the two-loop test configuration, a very rapid blowdown occurred as a result of the large broken loop cold leg flow rate. Large negative intact loop and core flows also developed, which resulted in good initial cooling due to delayed DNB and intact loop water being swept well into the core. Following the initial blowdown, 
substantial bypass of the cold leg accumulator fluid occurred due to strong negative intact loop and core' steam flows. Reflood was eventually initiated and sustained by the intact loop LPIS flow which produced a very slow bottom up quenching with little evidence of entrainment. The slow bottom up quenching process quenched only the lower half of the core during the $300-\mathrm{sec}$ duration of the experiment.

\subsection{Conclusions from Two-Loop Plant Scaling with Upper Plenum LPIS Injection}

The upper plenum LPIS injection had little effect on the general system hydraulic response, but the core thermal response was substantially affected. LPIS water, swept into the core by the prevailing negative intact loop and core flows, resulted in a rapid quenching of that part of the core immediately below the injection location. The cooling on the opposite side of the core was not as good, however, and periods of significant LPIS bypass occurred before this side of the core was quenched. The regional core cooling caused by the preferential channeling of ECC fluid through the section of the core below the LPIS injection location was significant in that it indicated that long-term upper plenum LPIS injection (longer than $300 \mathrm{sec}$ ), as would be practical in a PWR, has the potential for providing fluid through the core to the lower plenum, which could contribute to a bottom up core reflood.

\section{REFERENCE}

C-1. D. J. Hanson et al, ECC Performance in the Semiscale Geometry, ANCR-1161 (June 1974). 
APPENDIX D

COLD LEG ECC INJECTION WITH A VENT LINE 
THIS PAGE

\section{WAS INTENTIONALLY LEFT BLANK}




\section{APPENDIX D \\ COLD LEG ECC INJECTION WITH A VENT LINE}

\section{INTRODUCTION}

The potential benefits of using emergency core coolant (ECC) injection in the cold legs in conjunction with a vent line connecting the broken loop hot and cold legs were examined in the investigation of alternate ECC concepts conducted in the Semiscale Mod-1 system. The vent line offered the advantage of improved steam flow out of the upper plenum region, thereby increasing the rate of core cooling by reducing the resistance to bottom flooding. The vent line connections on the broken loop hot and cold legs were close to the vessel. The vent flow path was, therefore, similar to those used in pressurized water reactors (PWR) that include a vent system from the upper plenum to the downcomer inlet annulus.

The effectiveness of the vent line concept was investigated primarily through comparative analysis of experiments. Two tests were employed in the analysis, each using the same initial and boundary conditions and each using cold leg injection, but with one test (Test S-05-5) ${ }^{[D-1]}$ with the vent line and the other without (Test S-04-6) ${ }^{[D-2]}$. The effects of the vent line could, therefore, be isolated by direct comparison between the two tests. The vent line resistance $R$ ' was an important parameter in the investigation and was core area scaled to a PWR vent valve. The effect on the core thermal response of varying the vent line resistance was investigated analytically to determine the dependence of the experimental results on the particular vent line resistance employed in the test.

The experimental investigation was carried out using the Semiscale Mod-1 system configuration shown in Figure D-1. The system consisted of a pressure vessel with simulated reactor internals; an intact loop with a steam generator, active pump and pressurizer, and a broken loop with a simulated steam generator, simulated pump, and two rupture assemblies. The simulated steam generator and pump contained orifices to provide the appropriate hydraulic resistance. The intact loop accumulator and low pressure injection system (LPIS) injected into the cold leg. The broken loop accumulator and LPIS injected into the broken loop cold leg. A 3-in. (Schedule 160 Grade 316 stainless steel) reflood bypass vent line with a control valve and a check valve (allowing flow from the hot leg to the cold leg only) was installed to connect the hot and cold legs of the broken loop. Additional details of the system instrumentation are identified in Reference D-1. The initial conditions and ECC flow rates investigated are tabulated in Table D-I.

The analytical study was performed using the RELAP4 computer code to investigate the sensitivity of the core and system thermal-hydraulic response to the resistance of the vent line. Two calculations were performed using vent line resistances, based on core area scaling and volume scaling of a PWR vent valve, respectively, so that the sensitivity to the scaling approach could be determined. A third calculation was performed to determine the effects of using a very low vent line resistance. 


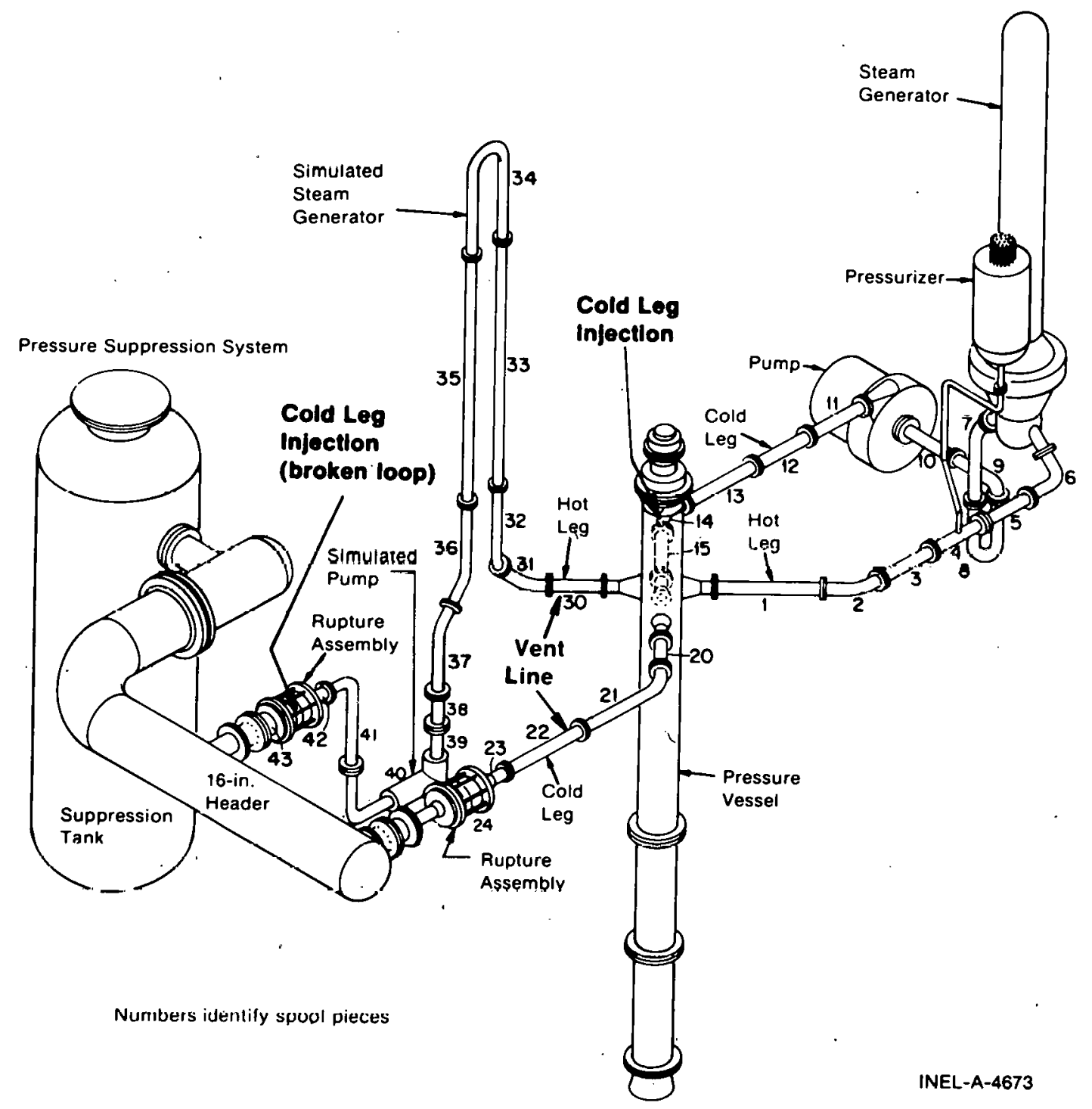

Fig. D-1 Semiscale Mod-1 system configuration for cold leg ECC injection with a vent line.

A discussion of the influence of the vent line on the measured core and system thermal-hydraulic response during cold leg ECC injection is contained in Section 2 of this appendix. The thermal-hydraulic response calculated by RELAP4 using selected vent line resistances is documented and discussed in Section 3. Section 4 prësents the signiffcant conclusions from the experimental investigation and the analytical study of the effect of using a vent line between the broken loop hot and cold legs along with cold leg ECC injection. 
Core power (MW) ${ }^{[\mathrm{a}]}$

Test $\mathrm{S}-05-5$

Intact loop cold leg fluid temperature $\left({ }^{\circ} \mathrm{F}\right)^{[\mathrm{a}]}$

Hot leg to cold leg temperature differential $\left({ }^{\circ} \mathrm{F}\right)^{[\mathrm{a}]}$

Steam generator feedwater temperature $\left({ }^{\circ} \mathrm{F}\right)^{[\mathrm{a}]}$

Steam generator liquid level (in.) ${ }^{[a, b]}$

Pressurizer pressure (psia) ${ }^{[a]}$

Pressurizer liquid volume $\left(\mathrm{ft}^{3}\right)^{[a, c]}$

Core flow rate $(\mathrm{gpm})^{[\mathrm{a}]}$

0.60

Pressure suppression system pressure (psia) ${ }^{[a]}$

Intact/broken loop accumulator injection location

$$
\begin{aligned}
& \text { Liquid volume }\left(\mathrm{ft}^{3}\right) \\
& \text { Injection rate }(\mathrm{gpm}) \text { [d] } \\
& \text { Actuation pressure (psia) }
\end{aligned}
$$

Intact/broken loop LPIS injection location

Injection rate $(\mathrm{gpm})^{[\mathrm{d}]}$

Actuation pressure (psia)
$2.8 / 0.5$

$24.0 / 6.0$ $600 / 600$

Cold leg/ Spool 42

$4.7 / 1.16$

$170 / 110$

[a] Prior to rupture.

[b] Above bottom of tube sheet.

[c] Based on average fluid density of $37.41 \mathrm{bm} / \mathrm{ft}^{3}$.

[d] Average attained during test.

\section{EXPERIMENIAL THERMAL-HYDRAULIC RESPONSE}

The results of the experimental investigation of the alternate ECC injection concept which used a vent line together with cold leg ECC injection were evaluated to determine whether this injection concept provides improved core cooling relative to that resulting from 
cold leg injection alone. The examination of the core thermal response was, therefore, of major importance and the results are discussed in the first of the following sections. The system behavior related to the core thermal response is important to a complete understanding of the injection concept and to a meaningful evaluation of the effectiveness of the concept relative to core cooling. Consequently, the second section discusses the system behavior and the major controlling phenomena leading to the core thermal response.

\subsection{Core Thermal Response}

The vent line between the broken loop hot and cold legs had the potential for affecting the system response whenever the pressure in the hot leg became greater than that in the cold leg. A greater hot leg pressure would result in coolant flow from the broken loop hot leg to the cold leg which would alter the flow distribution throughout the system. Periods existed in which the hot leg pressure was greater than the cold leg pressure during blowdown and refill as. well as during reflood, so the vent line influenced the mass flow distribution throughout the transient. Consequently, the vent line affected the rod thermal response during the blowdown and refill periods in addition to the expected effect during the reflood period.

An indication of the effect of the vent line on the core thermal response during blowdown was obtained by examining the core thermal response for cold leg ECC injection with and without the vent line. The effect of the vent line on the critical heat flux (CHF) behavior during blowdown is illustrated in Figure D-2 by a temperature measurement at the

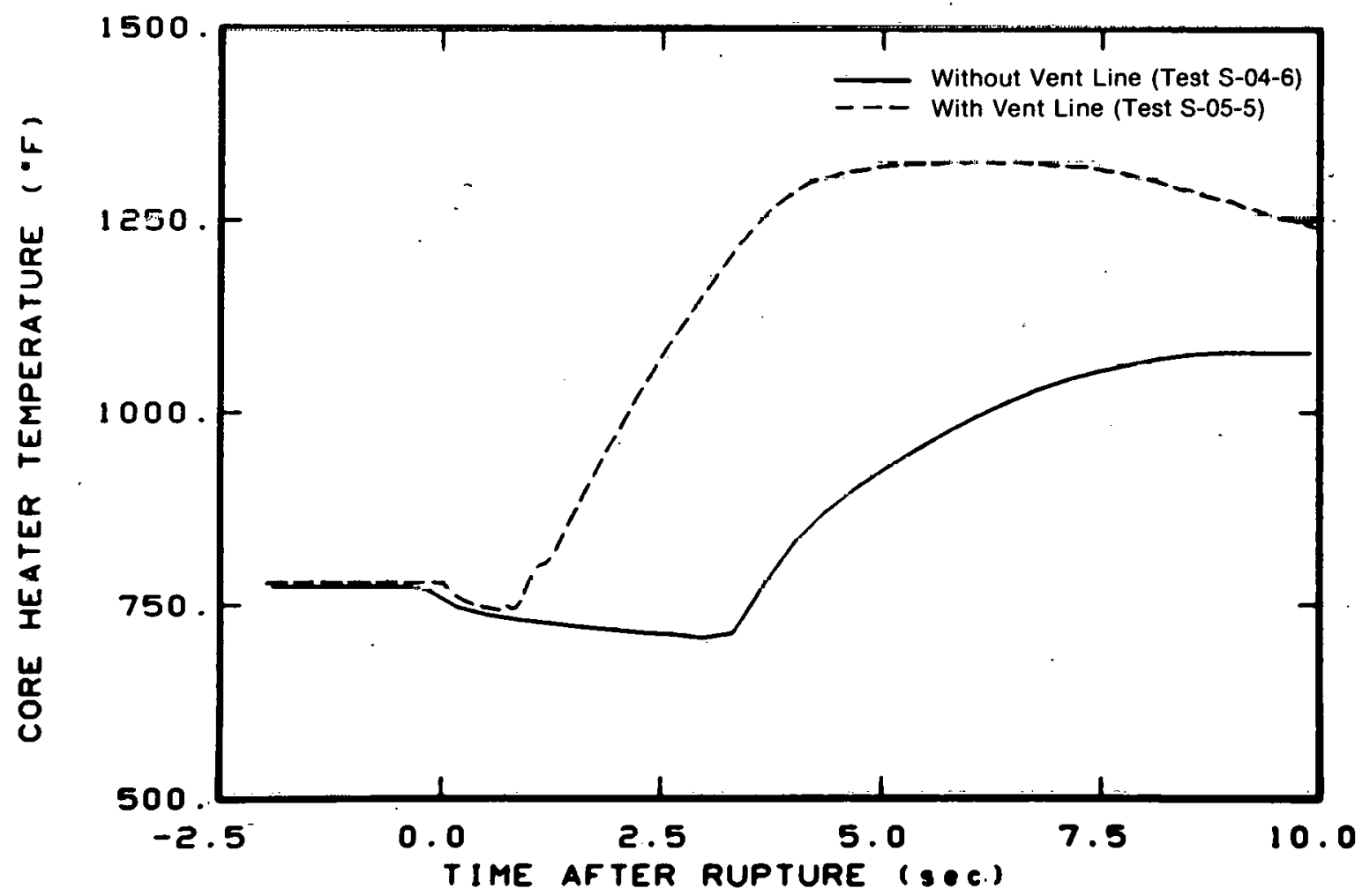

Fig. D-2 Short-term rod cladding temperature response at the core peak power elevation with and without a vent line - Tests $S-05-5$ and $S-04-6$. 
peak power elevation of the core (29-in. elevation). The temperature measurements at this elevation indicate that $\mathrm{CHF}$ occurred at about $0.5 \mathrm{sec}$ when the vent line was installed, whereas CHF was delayed until about $3.4 \mathrm{sec}$ without the vent line. (Reference D-3 discusses the causes of the CHF phenomenon in the Semiscale Mod-1 core in detail including the causes of delayed CHF.) The early CHF which occurred at the 29-in. elevation when the vent line was installed is typical of the effects on the entire core. The early CHF caused by the vent line resulted in significantly higher peak rod cladding temperatures at some positions in the core. The rod cladding temperature responses presented in Figure D-3 show that locations that experienced delayed CHF without the vent line (such as the location of thermocouple TH-D3-29) reached significantly higher peak temperatures with the vent line, whereas locations that had early CHF without the vent line (such as the location of thermocouple TH-B6-29) had similar peak temperatures (within the usual experimental repeatability). Since the peak rod cladding temperature for cold leg ECC injection without the vent line occurred at a location that experienced an early CHF, the maximum rod cladding temperature in the core was essentially unchanged by the vent line. However, the overall temperature level of the core was higher for the test with the vent line because of the widespread early CHF.

An earlier turnaround of the rod cladding temperature and effective cooling from the turnaround until about $20 \mathrm{sec}$ after rupture occurred when the vent line was installed. The temperature turnaround and, therefore, peak temperature occurred at about $6 \mathrm{sec}$ after rupture using cold leg ECC injection with a vent line, whereas the temperature turnaround

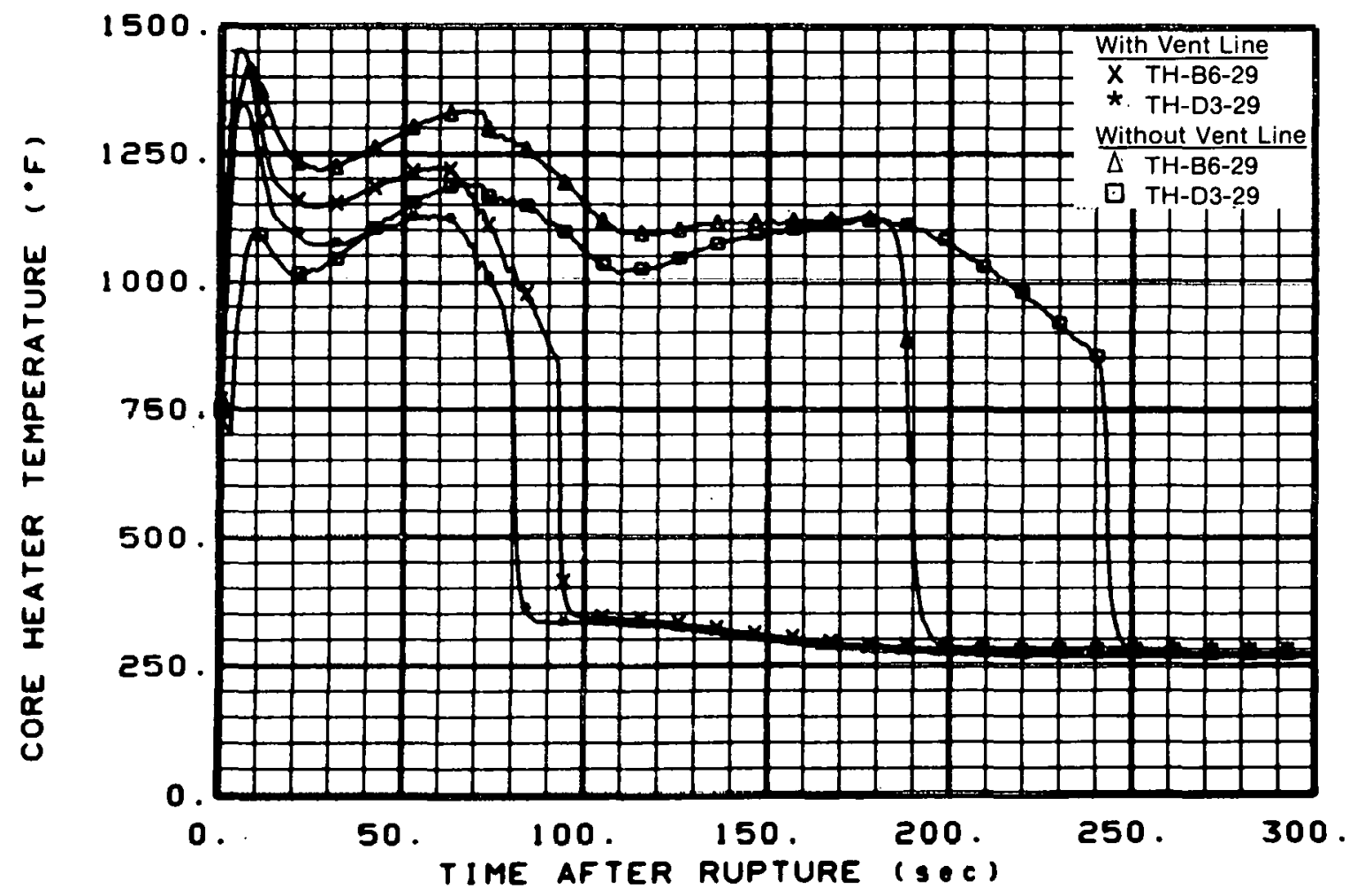

Fig. D-3 Comparison of rod cladding temperature responses at the 29 -in. elevation with and without a vent line - Tests S-05-5 and S-04-6. 
occurred from about 8 to $10 \mathrm{sec}$ after rupture without the vent line. Following the temperature turnaround, the rod cladding temperatures decreased rapidly for the test with the vent line, as indicated by the rod cladding temperature responses shown in Figure D-3. The rapid rod cladding temperature decrease indicates that extremely good core cooling was occurring until about $20 \mathrm{sec}$ after rupture. The good core cooling is reflected in the heat transfer coefficient shown in Figure D-4 which was calculated from the rod cladding temperature response using an inverse heat conduction technique and which is based on the system saturation temperature. As shown in Figure D-4, for the core high power elevation (29 in.) during the period from about 4 to $14 \mathrm{sec}$ after rupture, heat transfer coefficients up

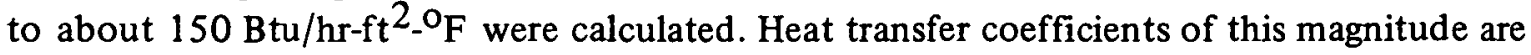
typical of dispersed flow or dispersed flow film boiling as discussed in Reference D-4. These high heat transfer coefficients indicate the presence of low quality fluid in the core during this period.

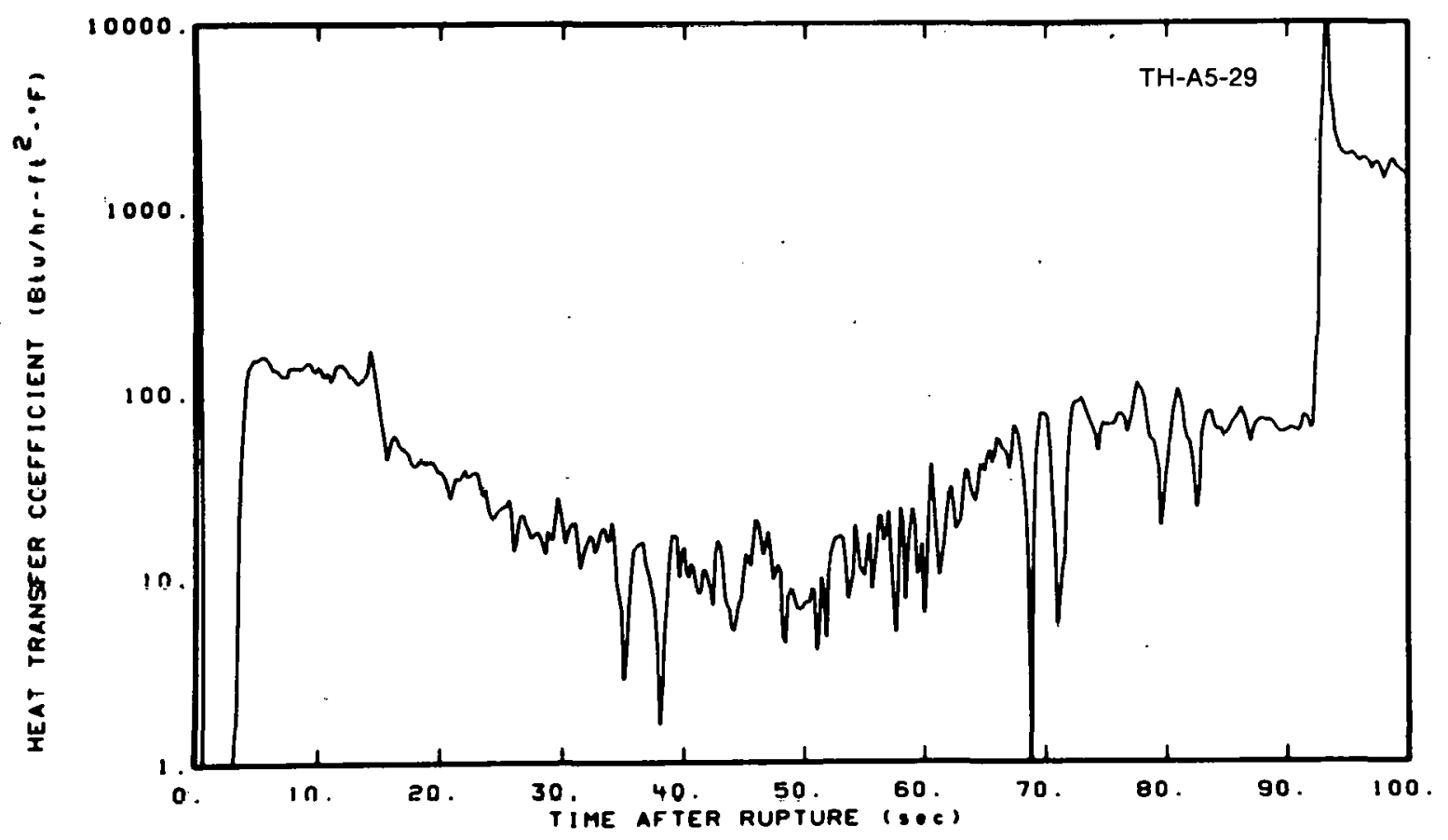

Fig. D-4 Response of the heat transfer coefficient at the core peak power elevation with vent line - Test S-05-5.

The effect of the cooling in the initial blowdown period (from about 4 to $20 \mathrm{sec}$ after rupture) was more apparent for about the lower 22 in. of the core. The temperature response at the 9- and 22-in. elevations with and without the vent line are compared in Figure D-5. This figure illustrates that, for the test with the vent line, following the temperature turnaround the rods were cooled very effectively compared with the cooling for cold leg ECC injection alone, and were apparently quenched at about 20 to $25 \mathrm{sec}$ after rupture. This quench resulted in the bottom $22 \mathrm{in}$. of the core being as much as $6000^{\circ} \mathrm{F}$ cooler with the vent line than without it at $20 \mathrm{sec}$ after rupture. Even though the rod cladding temperature increased from about $20 \mathrm{sec}$ after rupture until reflood was initiated at $60 \mathrm{sec}$ after rupture for the vent line test, the temperatures for the lower half of the core 


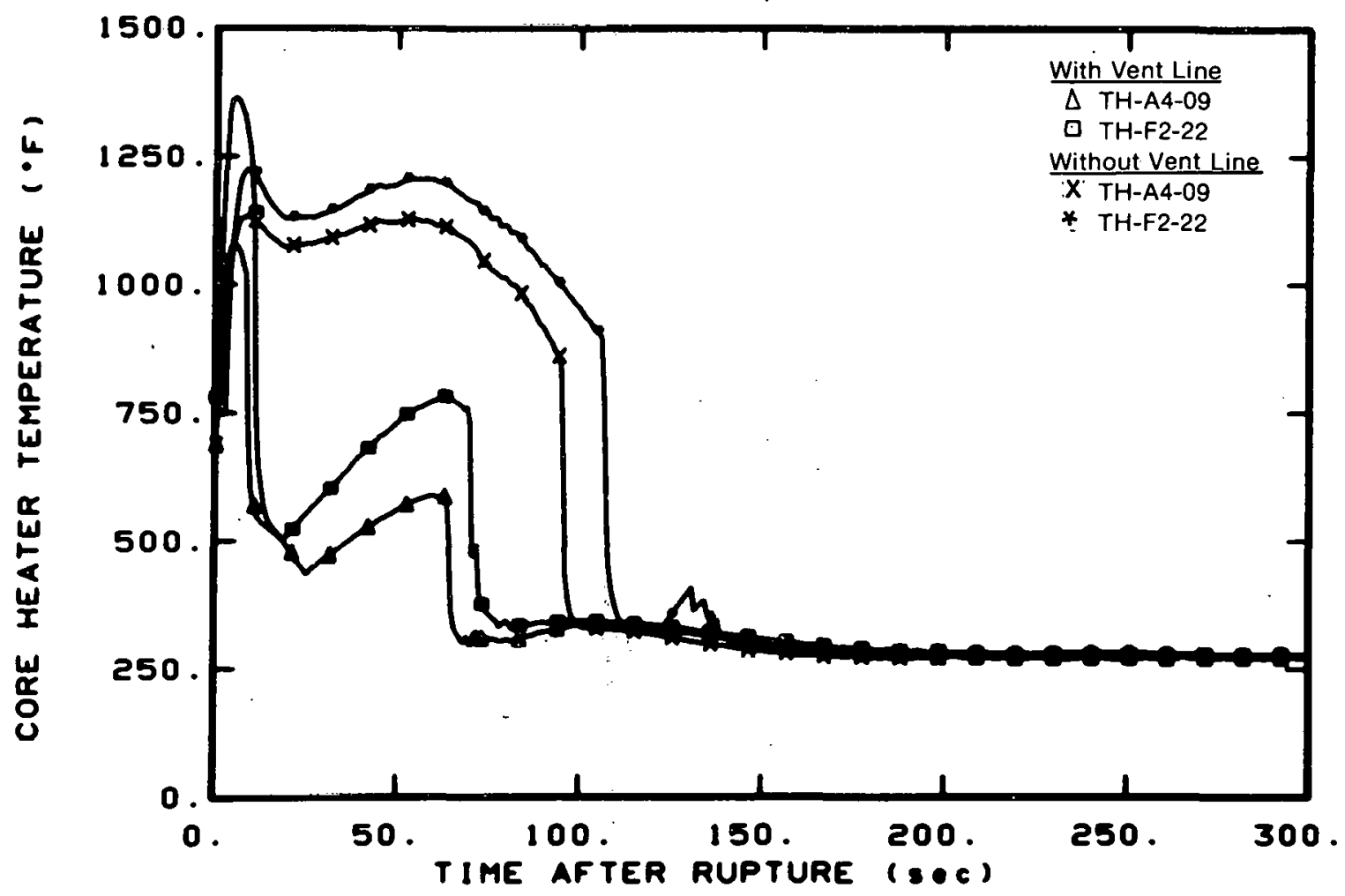

Fig. D-5 Comparison of rod cladding temperatures at the 9-and 22-in. elevations with and without vent line - Tests S-05-5 and $\mathrm{S}-046$.

were significantly lower at the initiation of reflood with a vent line as shown in Figure D-6. The lower initial temperature is significant because it indicates that less stored energy has to be removed from the core during reflood.

Overall, the vent line produced relatively early and uniform quenching of the core. Figure D-7 shows that little scatter existed in the quench times, that the core hot spot (29-in. elevation) was completely quenched by $94 \mathrm{sec}$ after rupture, and that the last quench occurred at $106 \mathrm{sec}$ after rupture. By comparison, without the vent line the core hot spot was not completely quenched until $242 \mathrm{sec}$ after rupture and one core location was not quenched by 300 sec after rupture when the test ended.

In summary, cold leg ECC injection in conjunction with the vent line resulted in an early CHF at some core locations in the blowdown. However, effective core cooling during the latter stages of blowdown and during reflood resulted in a relatively early core quench. The complex interrelationship between the vent line flow and the core and system behavior that resulted in the thermal response associated with this concept is discussed in more detail in the following section.

\subsection{Major System Behavior Contributing to the Core Thermal Response}

A detailed investigation of the system behavior was performed to investigate the reasons for the early CHF and for the improved core cooling with the vent line. This investigation concentrates on the influence of the vent line on the core hydraulic behavior. 


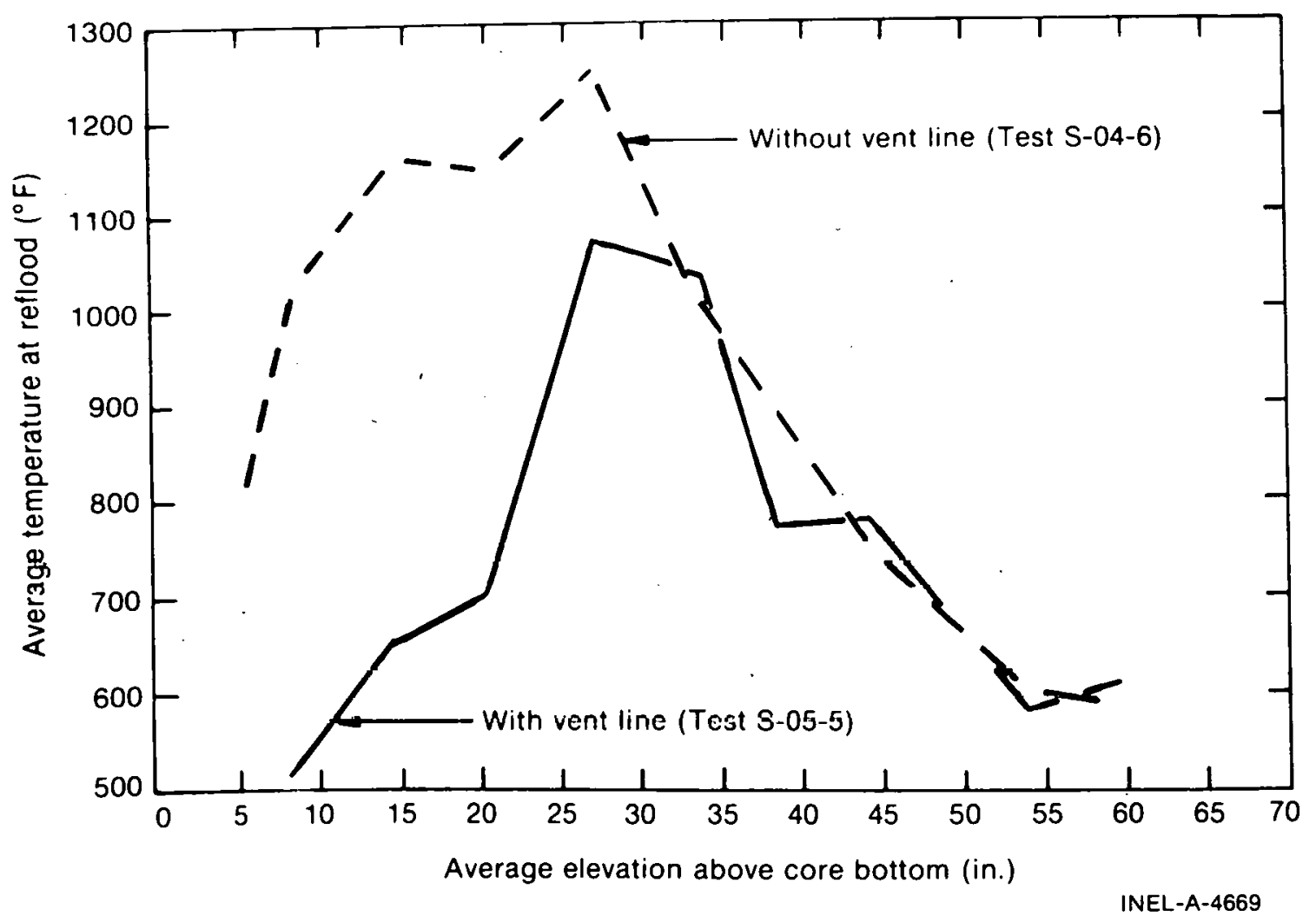

Fig. D-6 Comparison of rod cladding temperatures at the initiation of reflood with and without vent line.

The flow in the vent line caused changes in the core inlet flow that resulted in the observed differences in the CHF behavior obtained during blowdown. Flow in the vent line began at the time of rupture as shown in Figure D-8. At this time the vent line flow was drawn from the intact loop hot leg and the upper plenum, which resulted in a lower magnitude and duration of reverse core inlet flow with the vent line compared with the results without the vent line. After an immediate reversal upon rupture, the core inlet flow again reversed and eventually became positive during the first four sec of the transient with the vent line; a peak magnitude of about $120 \mathrm{gpm}$ occurred in the negative direction, as shown in Figure D-9. In contrast, without the vent line the core inlet flow remained negative during this period and had a peak magnitude of about $350 \mathrm{gpm}$. The decreased negative core flow with the vent line appears to have caused the change in the CHF behavior. This conclusion is supported by the comparison of CHF behavior obtained both with and without the vent line with that obtained in a subsequent test which resulted in an intermediate negative flow peak. Reference D-5 points out that for these three tests, peak negative flows of $350 \mathrm{gpm}$ and $270 \mathrm{gpm}$ (without the vent line), and $120 \mathrm{gpm}$ (with the vent line) occurred in conjunction with $31 \%, 75 \%$, and $92 \%$ of the core thermocouples indicating early $\mathrm{CHF}$, respectively. The relationship between decreasing peak negative flow and the increasing incidence of early DNB is clear.

The reduction in the negative core flow during blowdown caused by the vent line was also important in the effective cooling that occurred from about 4 to $20 \mathrm{sec}$ after rupture. As a result of the reduced negative core flow, the core inlet was not completely voided of 


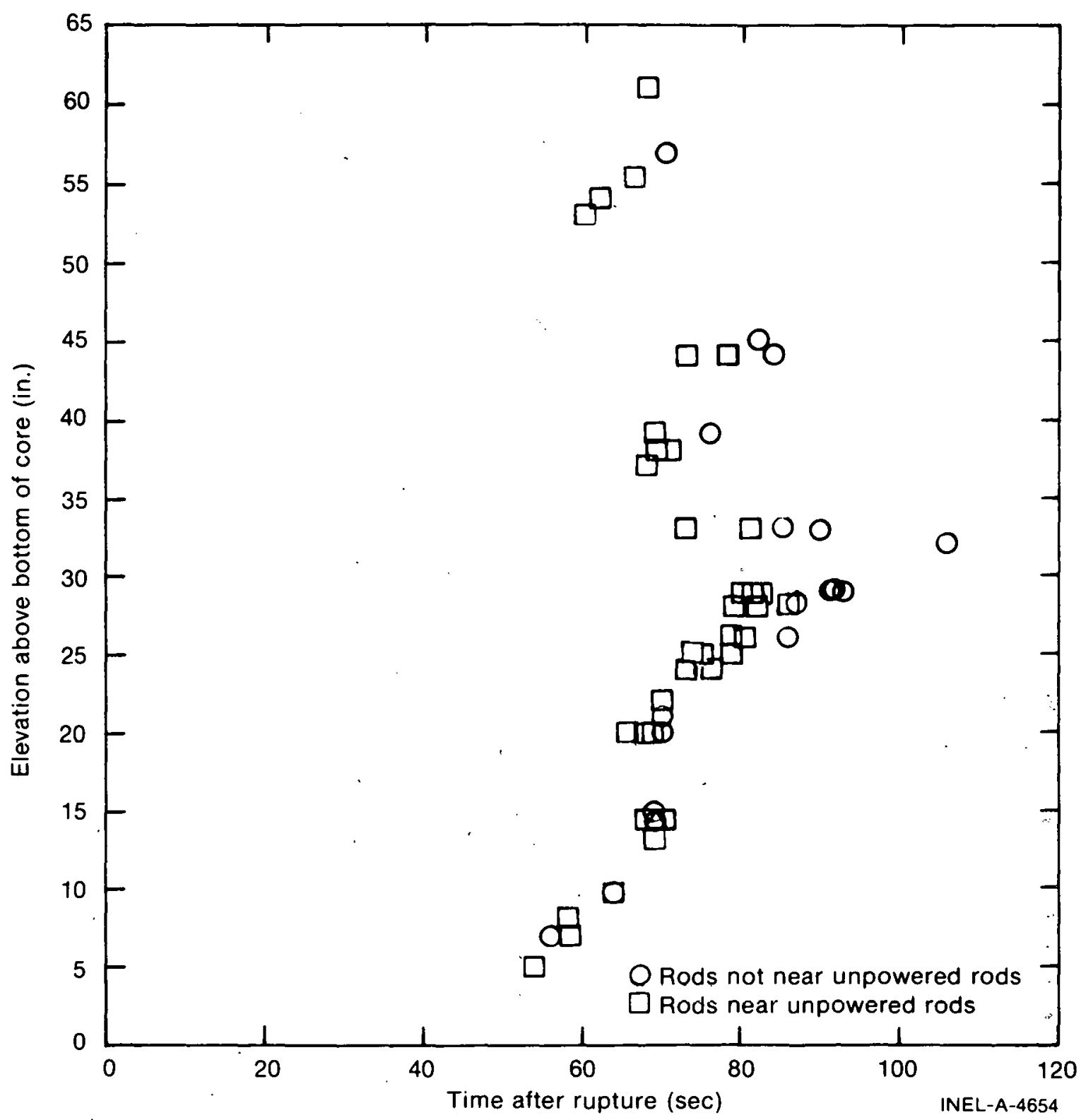

Fig. D-7 Quenching at various elevations as a function of the time after rupture for the test with vent line - Test S-05-5.

coolant during the initial depressurization period as indicated by the core inlet density measurement presented in Figure D-10. The high density at the core inlet from about 3 to $35 \mathrm{sec}$ indicates that water could enter the core during the periods of positive core inlet flow which occurred over this same time (Figure D-9). Therefore, the effective cooling at about four sec after rupture probably resulted from the positive core flow carrying liquid into the core. The continued effective core cooling until about $20 \mathrm{sec}$ after rupture appears to result from the continued positive core inlet flow. The density of the coolant at the core inlet continues to decrease as boiloff of coolant in the lower plenum continues, and at about $20 \mathrm{sec}$ after rupture decreases to about $10 \mathrm{lbm} / \mathrm{ft}^{3}$. The increase in the core inlet quality that results from voiding of lower plenum fluid results in a decrease in the overall core cooling rate. Figure D-4 shows that at the 29-in. elevation at about $35 \mathrm{sec}$ after rupture, the heat transfer coefficient becomes about $10 \mathrm{Btu} / \mathrm{hr}-\mathrm{ft}^{2}-{ }^{\circ} \mathrm{F}$ (indicative of a low liquid fraction 


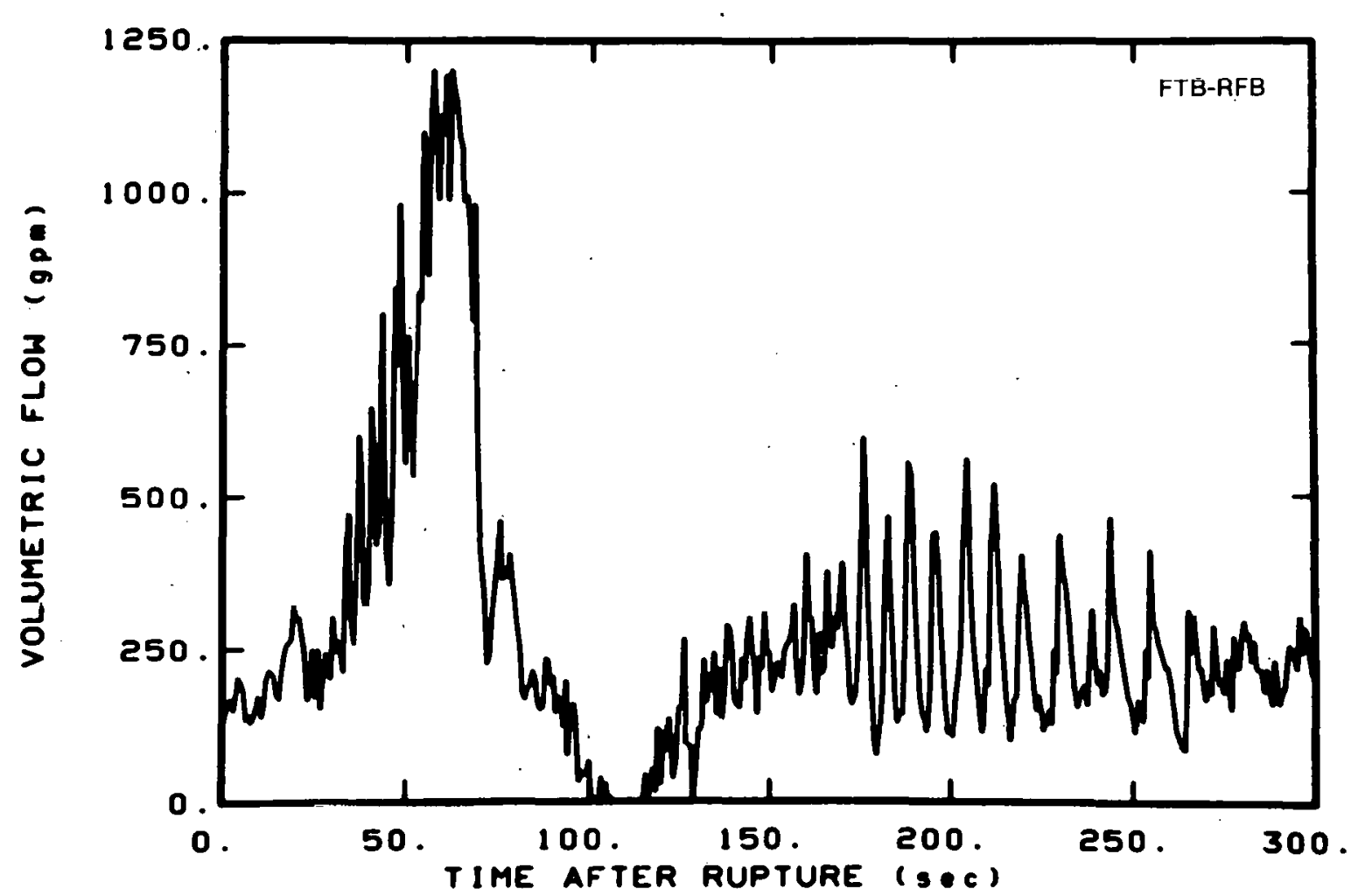

Fig. D-8 Volumetric flow in vent line - Test S-05-5.

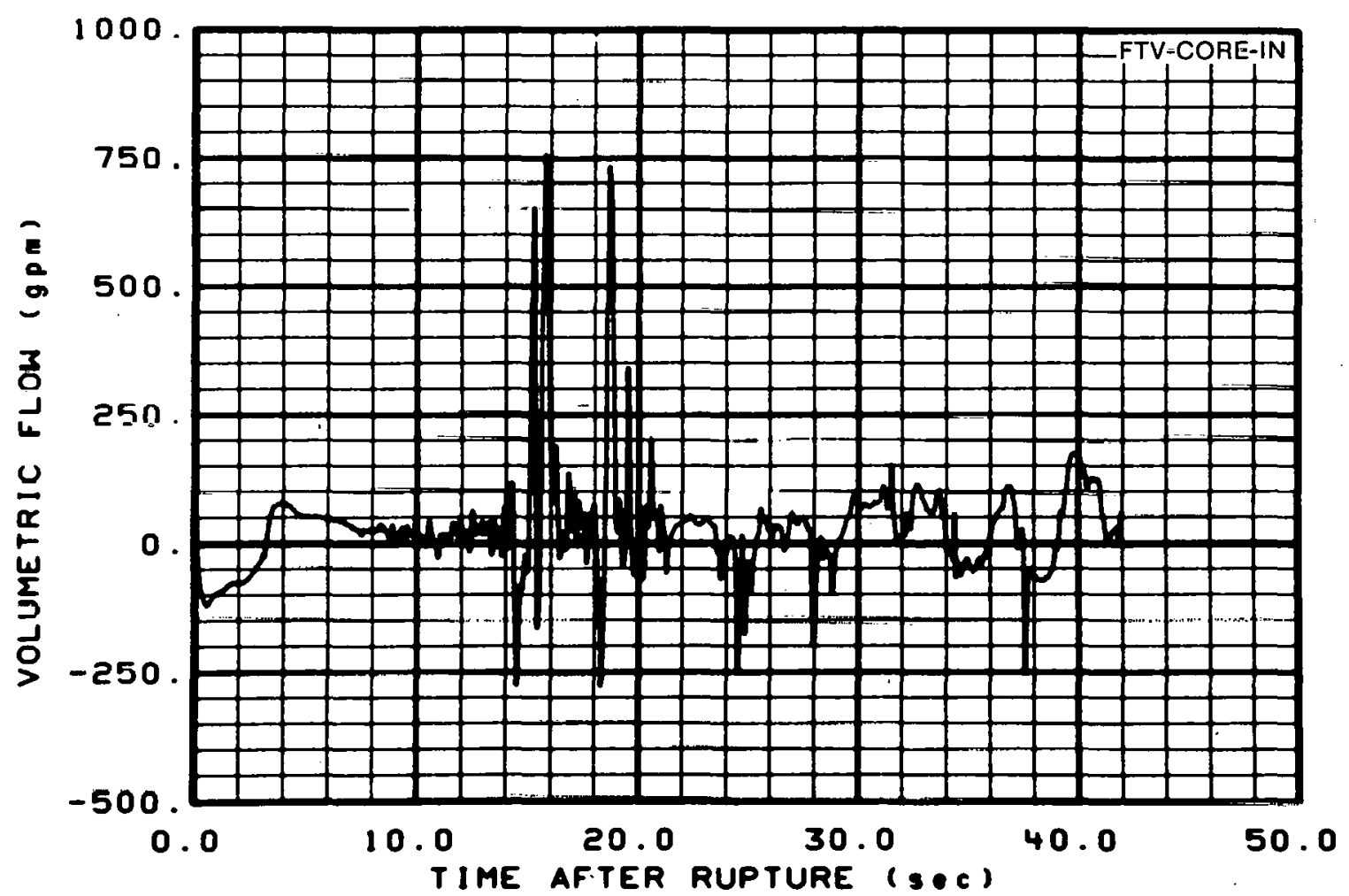

Fig. D-9 Short-term core inlet volumetric flow with vent line - Test S-05-5. 


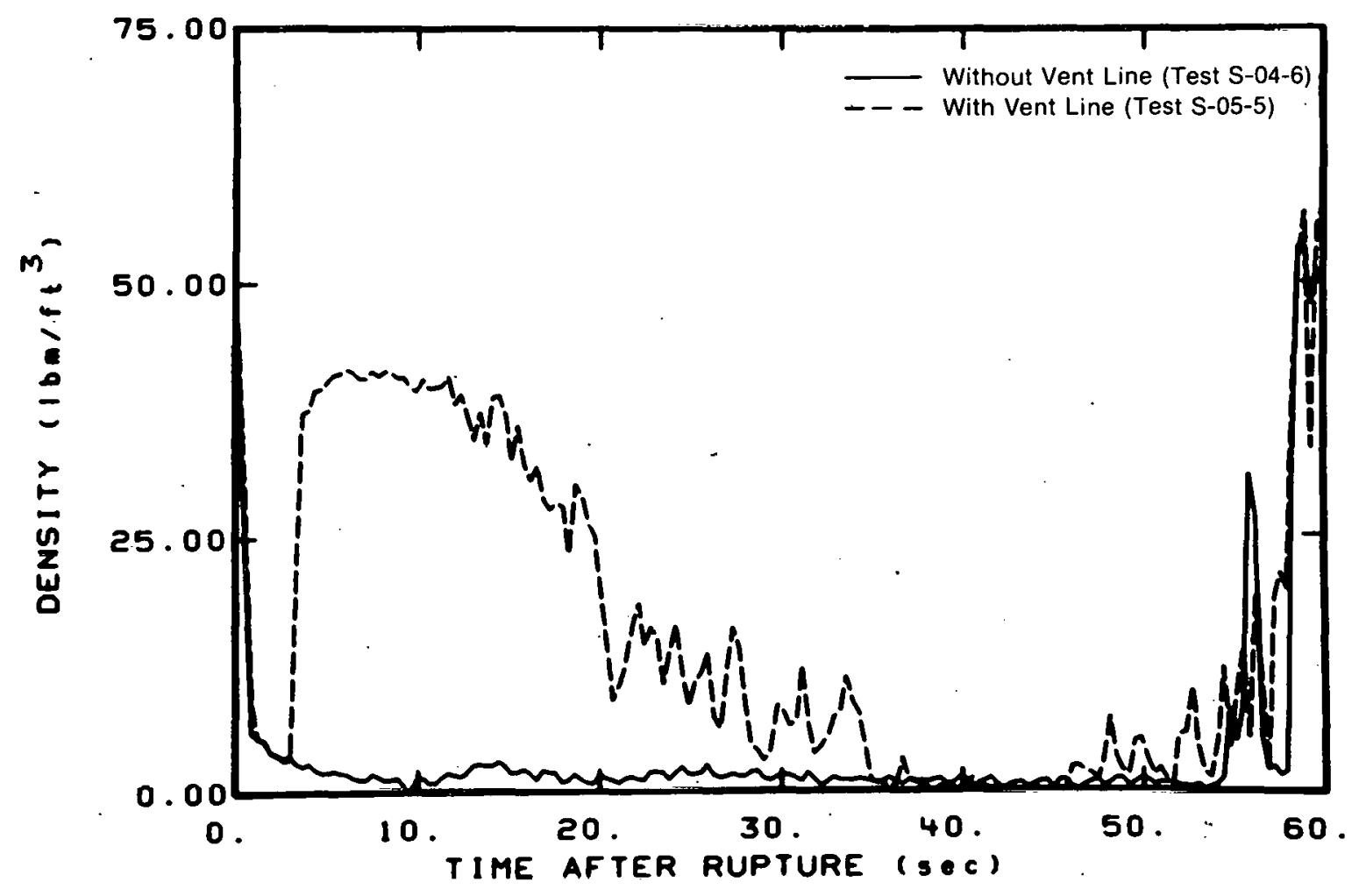

Fig. D-10 Comparison of core inlet density with and without vent line - Tests S-05-5 and S-04-6.

in the coolant). In summary, the effective core cooling during the period from 4 to $20 \mathrm{sec}$ after rupture is a result of positive flow sweeping coolant into the core from the lower plenum; the presence of the coolant in the lower plenum being the result of the reduced initial negative flow.

The vent line did not have a significant effect on the behavior of the fluid in the downcomer either during the initial blowdown period or during the refill period that followed it. During the initial blowdown, even though the core flow became positive at about three sec after rupture, the flow direction in the downcomer was not affected. However, the magnitude of the reverse downcomer flow (flow up the downcomer) was less for cold leg ECC injection with the vent line than without the vent line. The reduction in the magnitude of the negative downcomer flow persisted during the refill period, but did not appear to affect the amount of ECC bypass or downcomer penetration. The downcomer collapsed liquid levels for cold leg ECC injection with and without a vent line, compared in Figure D-11, show that the downcomer initially filled at the same rate in each case. This similarity indicates that the vent line did not significantly affect the countercurrent flow or hot wall phenomena in the Semiscale Mod-1 system.

During the reflood period the vent line appeared to decrease the resistance to steam flow out of the upper plenum. As a result, the reflood of the core proceeded more rapidly with the vent line than without it. The similarity in the filling of the downcomer, with and without the vent line, led to reflood being initiated at about the same time in each case 


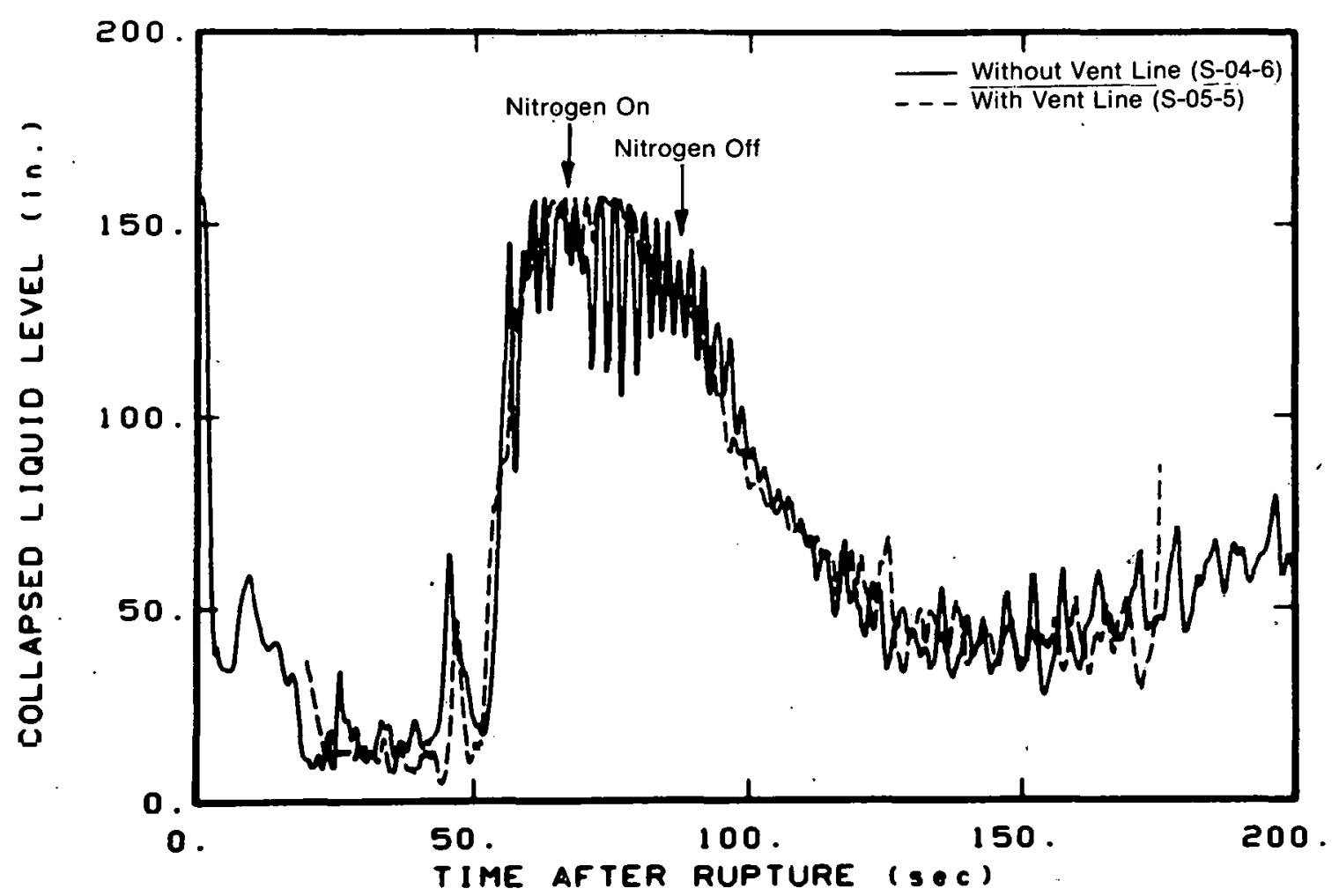

Fig. D-11 Comparison of downcomer collapsed liquid level with and without vent line - Tests S-0S-5 and S-04-6.

(about $55 \mathrm{sec}$ after rupture). However, the reduced resistance to steam flow out of the upper plenum, provided by the vent line, resulted in the core being entirely quenclied by about $50 \mathrm{sec}$ after reflood was initiated. In the absence of the vent line the core hot spot was not completely quenched until $187 \mathrm{sec}$ after the start of reflood and one core location was not quenched at the termination of the test $245 \mathrm{sec}$ after the start of reflood.

Neither the rapid core reflooding and quenching obtained with the vent line nor the system behavior responsible for this thermal response was adversely affected by accumulator nitrogen injection in the cold leg. In fact much of the core quenching occurred during the nitrogen injection period. Intact loop and broken loup culd leg density measurements indicate that when nitrogen began to flow from the accumulator, the cold legs were substantially cleared of water. At the same time, the collapsed liquid level in the downcomer began to decrease and continued to decrease throughout the nitrogen injection period. Substantially similar downcomer behavior was also observed in the cold leg injection test without the vent line.

After nitrogen injection terminated, the mass depletion in the core and downcomer was very similar both with and without the vent line. The effects of the mass depletion on the rod temperatures differed, however, because the bulk of the core had quenched before significant depletion took place in the vent line test. As a result, no dryout of rods occurred in the upper portions of the core in the presence of the vent line, whereas dryout did occur on some rods without it. 
Overall, using a vent line between the broken loop hot and cold legs with cold leg ECC injection resulted in substantially improved core cooling when compared with the results obtained without the vent line.

\section{RESULTS OF THE ANALYTICAL STUDY}

The vent line resistance $R^{\prime}$ was an important parameter in the investigation of the effectiveness of the ECC injection concept using cold leg injection with the vent line between the broken loop hot and cold legs. The vent line resistance employed in the experimental investigation was core area scaled to the resistance of a PWR vent valve. This scaling is appropriate during the reflood portion of the test, but volume scaling is more appropriate during the blowdown period. An analytical study was performed, using the RELAP4 computer code, to determine the effects of volume scaling the vent line resistance during blowdown. An additional calculation was made to determine the effects of using a very low vent line resistance. A description of the RELAP4 model used in this study and a discussion of the results of the analysis are presented in the following sections.

The RELAP4 computer code (Mod-E Version 72) ${ }^{[D-6]}$ was used to predict the system response ${ }^{[a]}$. The nodalization used in the RELAP4 representation of the Semiscale Mod-1 system is shown in Figure D-12. The Henry-Fauske and homogeneous equilibrium critical flow models were used for the subcooled and saturated break flow regimes, respectively. A break flow multiplier of 1.0 was used during the subcooled regime and a flow multiplier of 0.84 was used during the saturated regime. Vertical slip was used at all junctions in the core. RELAP4 calculations were performed up to $20 \mathrm{sec}$ after rupture with vent line resistances of $10.7 \mathrm{sec}^{2} /$ in. ${ }^{2}-\mathrm{ft}^{3}$ (to represent volume scaling), $5.5 \mathrm{sec}^{2} / \mathrm{in}^{2}{ }^{2} \mathrm{ft}^{3}$ (to represent core area scaling), and $1.0 \sec ^{2} /$ in. $^{2}-\mathrm{ft}^{3}$ (to determine the effects of a low resistance vent line).

The effects of using a system volume scaled vent line resistance on the blowdown behavior may be gauged by comparing the analytical results for the $10.7 \mathrm{sec}^{2} / \mathrm{in}^{2}-\mathrm{ft}^{3}$ and the $5.5 \mathrm{sec}^{2} / \mathrm{in}^{2}-\mathrm{ft}^{3}$ resistances. The temperature plots in Figure D-13 indicate that very little temperature difference developed between these two cases during the first $20 \mathrm{sec}$ of the blowdown. The sensitivity of the calculated temperature at $20 \mathrm{sec}$ after rupture to the vent line resistance is shown in Figure D-14. The indicated interpolation between the vent line resistances of 5.5 and $10.7 \mathrm{sec}^{2} / \mathrm{in}^{2}-\mathrm{ft}^{3}$ may not be exactly correct; however, this figure illustrates that changing the resistance scaling to a system volume basis would not have much influence on the blowdown thermal response.

The effects of using a very low vent line resistance may be determined by comparing the results of the calculation using a vent line resistance of $1.0 \mathrm{sec}^{2} / \mathrm{in}^{2}-\mathrm{ft}^{3}$ with the results obtained using the higher resistances. Figure D-13 shows that after $10.5 \mathrm{sec}$ after rupture the

[a] Configuration Control Number H00006IB. 


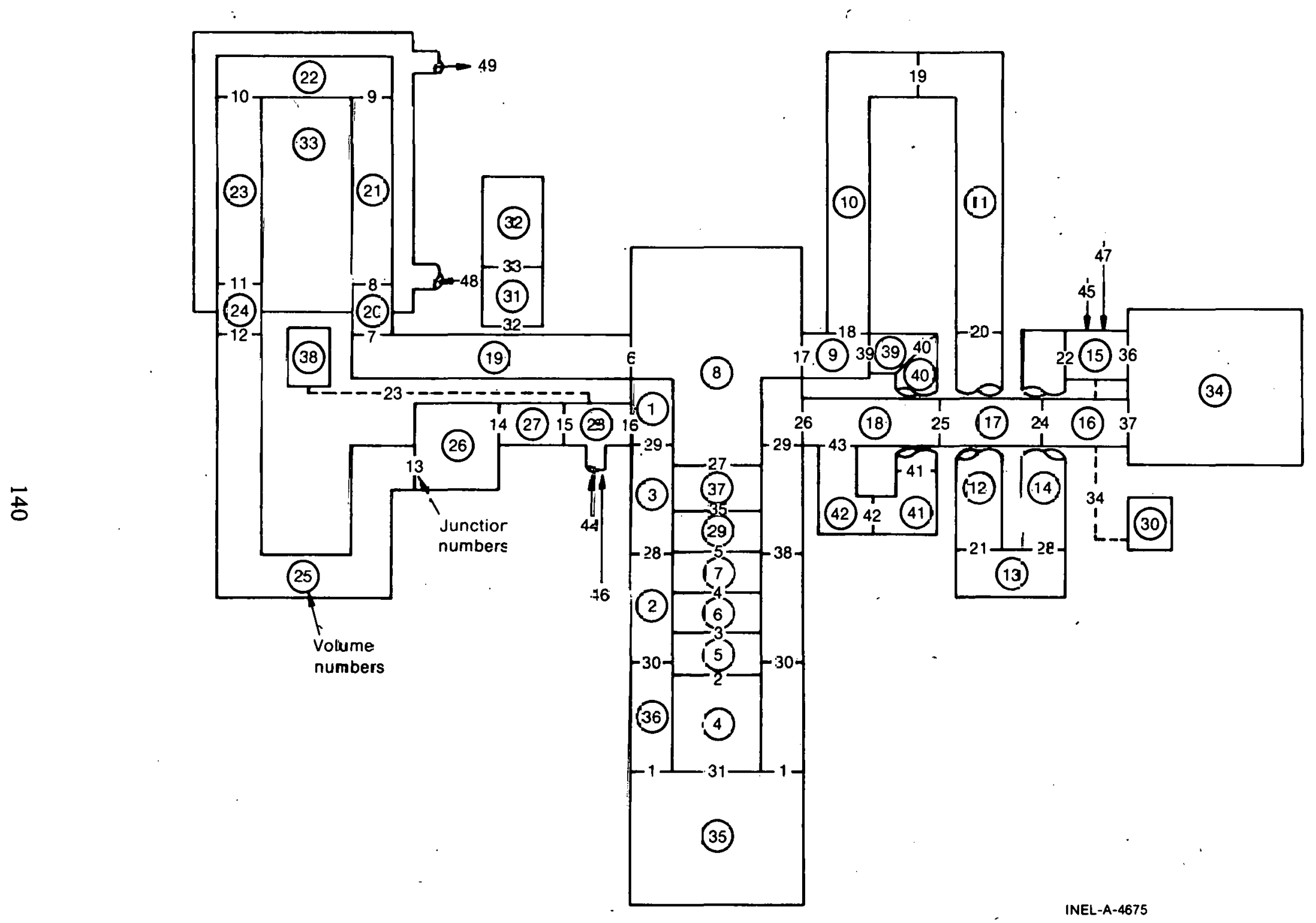

Fig. D-12 RELAP4 model cf Serniscale Mod-1 system using cold leg ECC injection with a vent line. 


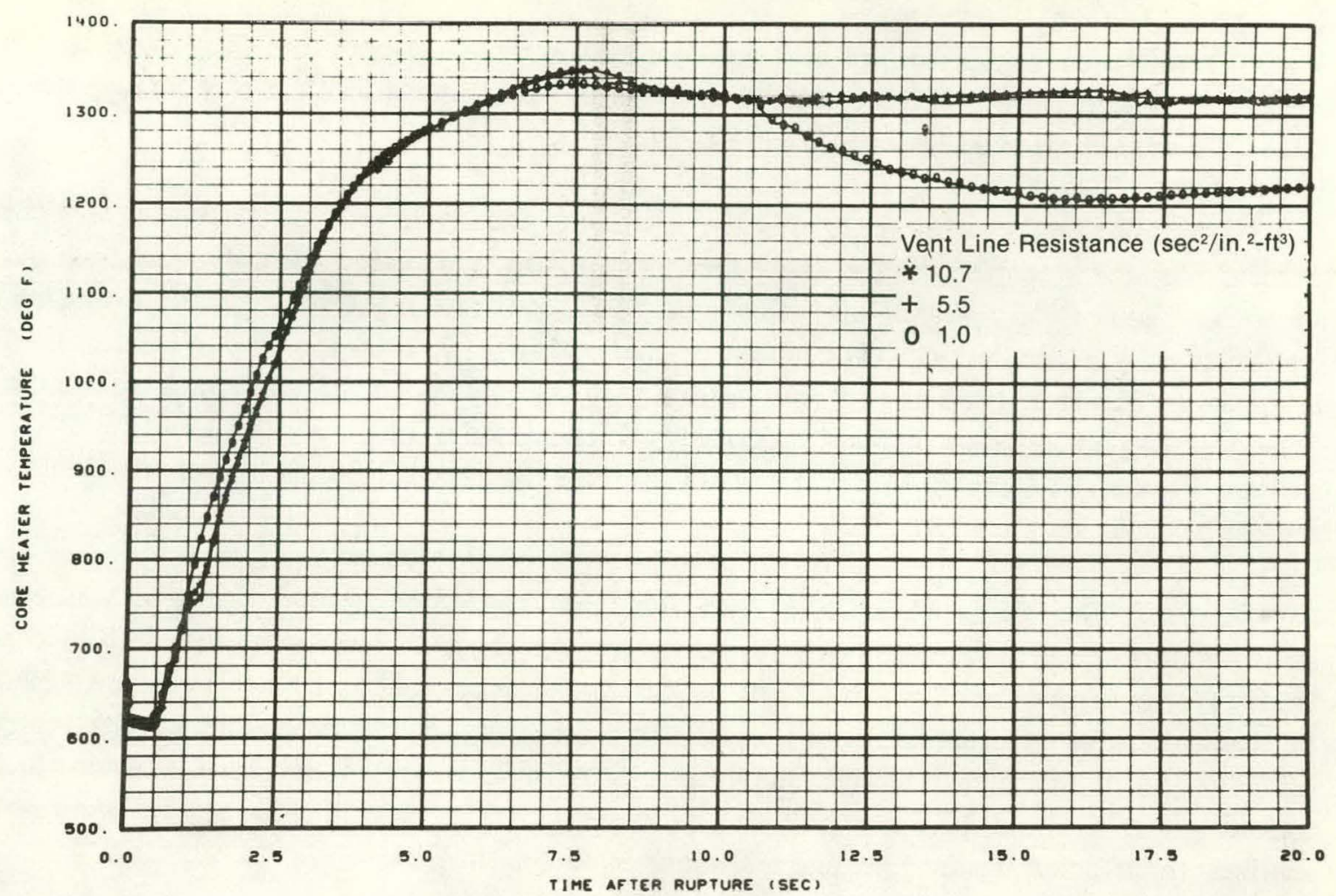

Fig. D-13 Effect of vent line resistance on the RELAP4 calculated rod surface temperature at rod high power elevation.

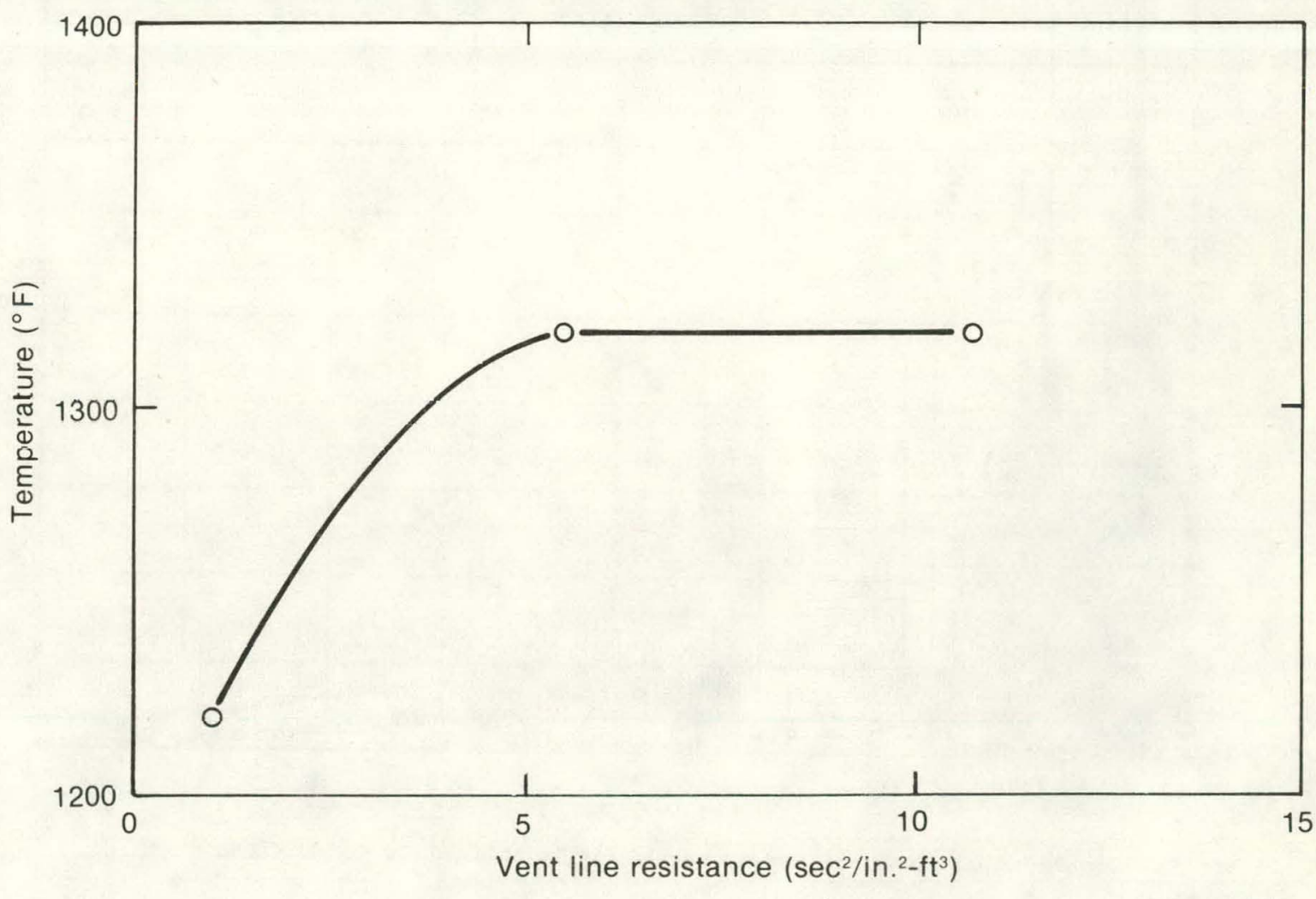

INEL-A-4677

Fig. D-14 Effect of vent line resistance on the RELAP4 calculated surface temperature at 20 sec after rupture at the core high power elevation. 
lower vent line resistance results in a reduced rod surface temperature. The trend in the calculated temperature at $20 \mathrm{sec}$ after rupture as the vent line resistance is increased from 1.0 to $5.5 \mathrm{sec}^{2} /$ in. $^{2}-\mathrm{ft}^{3}$ is shown in Figure D-14.

The major factor in the more effective cooling at the lower vent line resistance was the reduction in the steam binding in the upper plenum which increased the core mass flow. As shown in Figure D-15 a higher mass flow rate was calculated in the vent line for a vent line resistance of $1.0 \mathrm{sec}^{2} / \mathrm{in}^{2}-\mathrm{ft}^{3}$. The effect of the vent resistance on the core inlet mass flow is shown in Figure D-16. The higher core flow with the lower vent line resistance resulted in better cooling and increased steam generation which caused a slower depressurization of the system. Figure D-17 shows that the system pressure was about $100 \mathrm{psi}$ higher for the low resistance at $20 \mathrm{sec}$ after rupture.

Overall, the RELAP4 analysis indicated that the core thermal response was not strongly dependent on the vent line resistance for the range of resistances included in this study. However, the use of relatively low vent line resistances (about $10 \%$ of a volume scaled PWR vent valve resistance) could result in some improvement in the core cooling effectiveness of this concept. The relative insensitivity of the calculated results to vent line resistances of 5.5 and $10.7 \mathrm{sec}^{2} / \mathrm{in}^{2}-\mathrm{ft}^{3}$ indicates that the experimental results were not signficantly affected by the vent line resistance scaling technique.

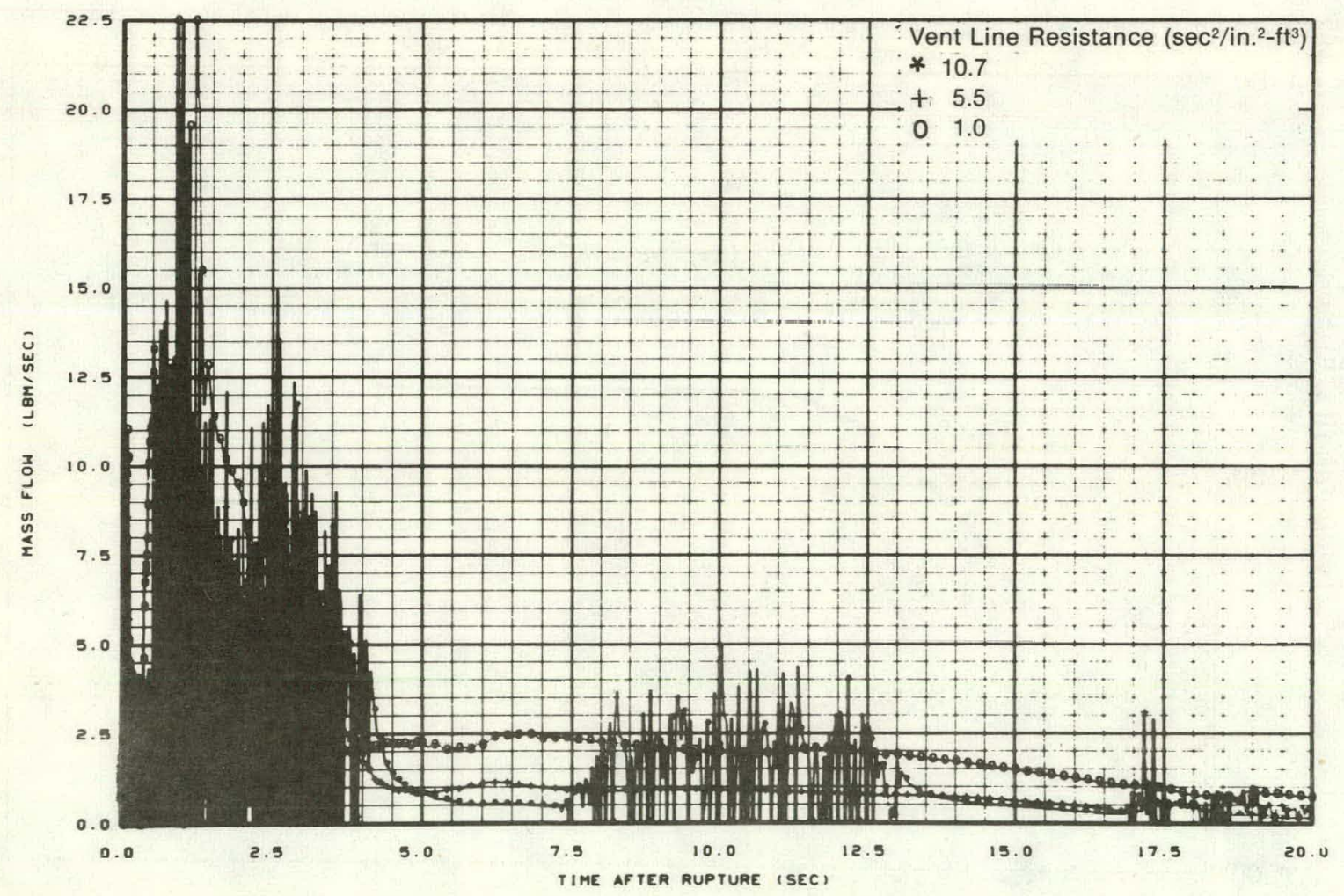

Fig. D-15 Effect of vent line resistance on the RELAP4 calculated vent line mass flow. 


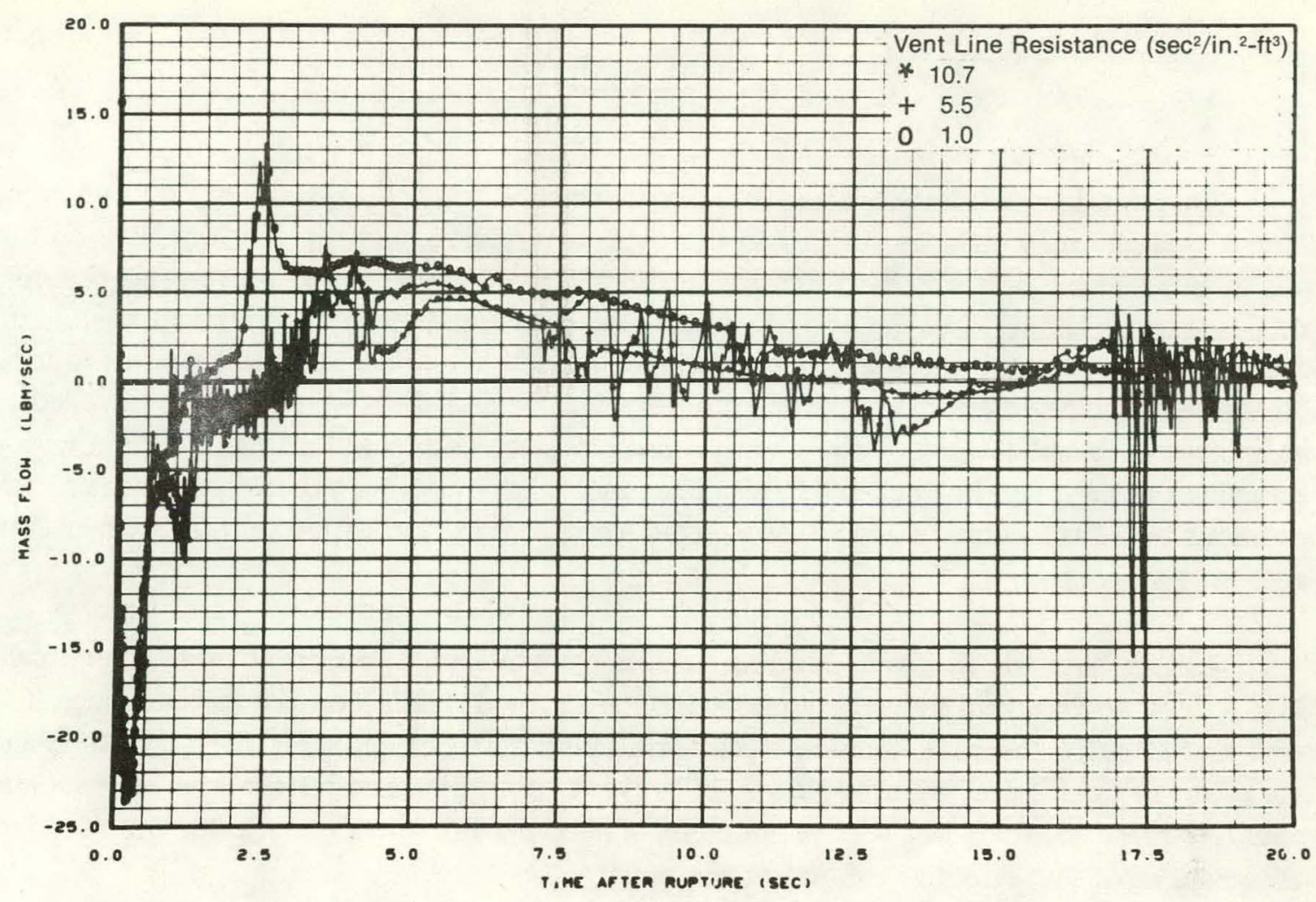

Fig. D-16 Effect of vent line resistance on the RELAP4 calculated core inlet flow.

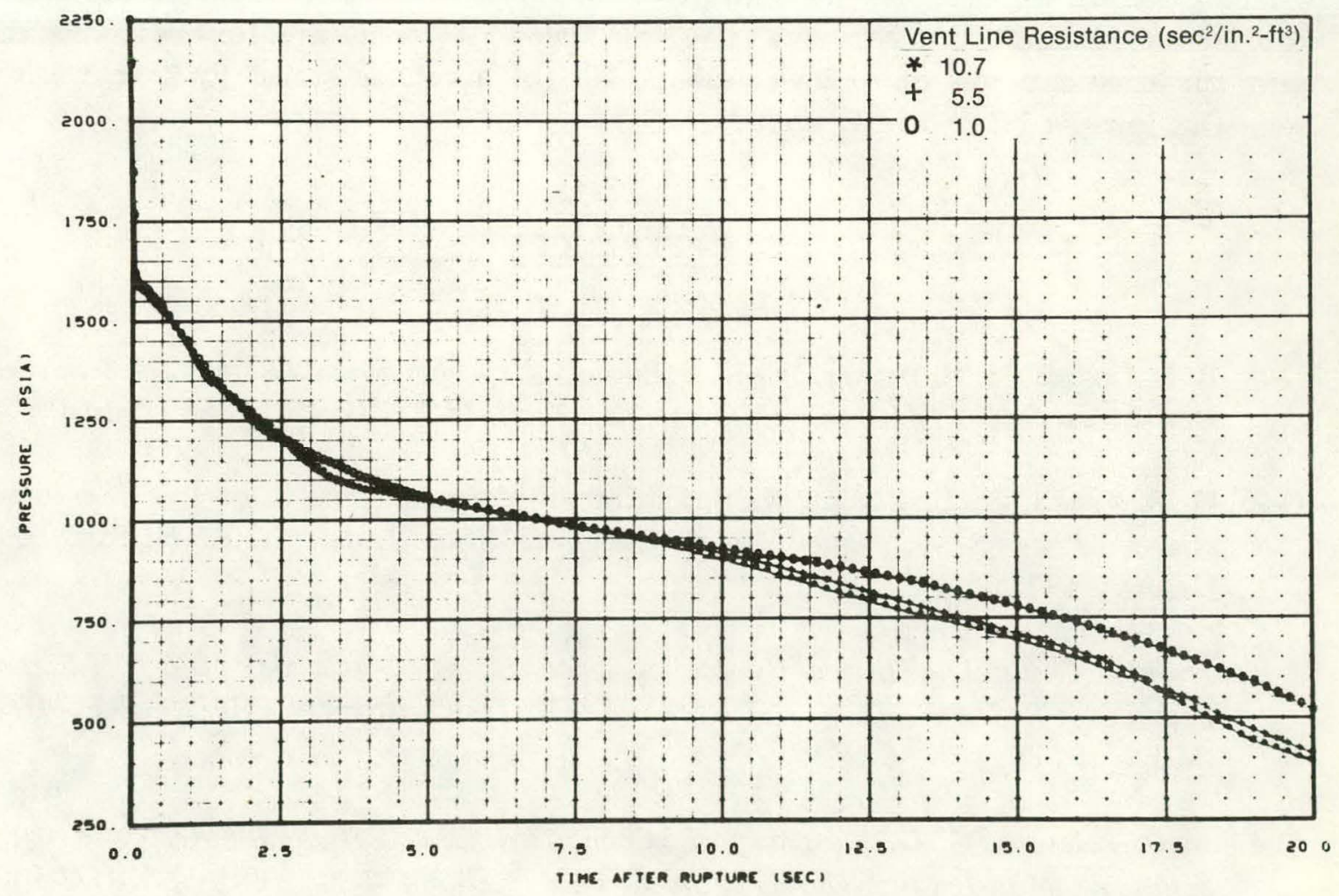

Fig. D-17 Effect of vent line resistance on the RELAP4 calculated upper plenum pressure. 


\section{CONCLUSIONS}

An experimental investigation of the thermal-hydraulic response of the Semiscale Mod-1 system using cold leg ECC injection with a vent line between the broken loop hot and cold legs was performed to determine the effect of the vent line on the rod cladding temperature response. An analytical study was performed using the RELAP4 code to evaluate the effect of the vent line resistance on the system and core response during blowdown. The results of the experimental investigation and the analytical study have led to an increased understanding of the phenomena associated with cold leg ECC injection with a vent line between the hot and cold legs. The results have also been useful in evaluating the potential benefits to core cooling of using cold leg ECC injection with a vent line rather than willıuul a vent linc.

A difference in the rod cladding temperature response occurred in the Semiscale Mod-1 core when a vent line was connected between the broken loop hot and cold legs. The vent line affected the peak temperatures during blowdown by reducing the magnitude and duration of the core negative flow. The vent line did not affect the downcomer countercurrent flow or hot wall phenomena. Following initiation of reflood, the vent line allowed a rapid and effective reflood of the core.

The RELAP4 analy sis of cold leg ECC injection with a vent line indicated that the rod cladding thermal response was not sensitive to the resistance of the vent line for resistances that are representative of a core area or volume scaled PWR vent valve. However, when the vent line resistance was much lower (about $10 \%$ of a volume scaled PWR vent valve) somewhat improved core cooling resulted.

\section{REFERENCLS}

D-1. B. L. Collins, M. L. Patton, Jr., K. E. Sackett, Experiment Data Report for Semiscale Mod-1 Test S-05-5 (Alternate ECC Injection Test), TREE-NUREG-1054 (April 1977).

D-2. H. S. Crapo, B. L. Collins, K. E. Sackett, Experiment Data Report for Semiscale Mod-1 Tests S-04-5 and S-04-6 (Baseline ECC Tests), TREE-NUREG-1045 (January 1977).

D-3. J. M. Cozzuol, Thermal-Hydraulic Analysis of Semiscale Mod-1 Intergral Blowdown-Reflood Tests (Baseline ECC Test Series), TREE-NUREG-1077 (March 1977).

D-4. A. C. Peterson, G. G. Loomis, L. L. Chen, Thermal and Hydraulic Response of the Semiscale Mod-1 Core During Forced Feed Reflood Tests, TREE-NUREG-1001 (October 1976). 
D-5. R. G. Hanson, Evaluation of the Effects of Break Nozzle Configuration in the Semiscale Mod-1 System, TREE-NUREG-1118 (August 1977).

D-6. C. G. Bruch (ed.), RELAP4/MOD5, A Computer Program for the Transient Thermal-Hydraulic Analysis of Nuclear Reactors and Related Systems, ANCR-NUREG-1335 (September 1976). 
THIS PAGE

\section{WAS INTENTIONALLY LEFT BLANK}


APPENDIX E

PUMP SUCTION LEG ECC INJECTION 
THIS PAGE

\section{WAS INTENTIONALLY}

LEFT BLANK 


\section{APPENDIX E \\ PUMP SUCTION LEG ECC INJECTION}

\section{INTRODUCTION}

Following a postulated loss-of-coolant accident (LOCA), the emergency core cooling system (ECCS) provides coolant to the core. Injection of the ECC into the pump suction leg could result in rapid and effective core cooling as a result of the pump aiding the delivery of the ECC to the core. The injection of subcooled ECC into the pump suction leg could reduce steam binding and result in effective core cooling by condensing the high velocity steam flow in the intact loops before that steam reached the pumps, which is the potential largest hydraulic resistance in the system. The relative effectiveness, with respect to core cooling, of using pump suction leg ECC injection (as compared to cold leg ECC injection) was investigated in the Semiscale Mod-1 system as part of the alternate ECC injection investigations.

The core cooling effectiveness of using pump suction leg ECC injection and the major system response that resulted in the observed core cooling were evaluated both experimentally and analytically. The pump speed was expected to have significant effect on the delivery of coolant into the core and was the major parameter investigated in the experimental study. The rate of ECC injection into the pump suction leg and the characteristics of the pump were also expected to affect the overall core cooling due to their effect on the delivery of ECC into the core. These latter two effects were investigated in the analytical study. The interpretation of the experimental and analytical results provided an assessment of the overall effects of using ECC injection in the pump suction leg.

To investigate, experimentally, the effect of the pump speed profile on the core thermal response during pump suction leg ECC injection, tests using three different pump speed controls were conducted. Included in this investigation was a test using a constant pump speed of $100 \%$ of the prerupture speed and a test using a pump speed control that simulated the calculated response of a pressurized water reactor (PWR) pump that lost power at the time of rupture during pump suction leg injection resulting in the pump coasting to a stop. These two pump speed controls provide the limiting cases of pump operation that might be expected in a PWR system. An additional speed control was investigated in which the pump speed coasted down to $64 \%$ of the prerupture value and then remained constant at this speed. This pump speed control was the same as that used during the investigation of other ECC injection concepts and is the same as was used for cold leg ECC injection. The ECC accumulator injection rate remained nominally constant at about $23 \mathrm{gpm}$ for each of the tests conducted in this investigation.

The Semiscale Mod-1 system configuration shown in Figure E-1 was used for the experimental investigation. The system consisted of a pressure vessel with simulated reactor internals; an intact loop with a steam generator, pump, and pressurizer; and a broken loop 


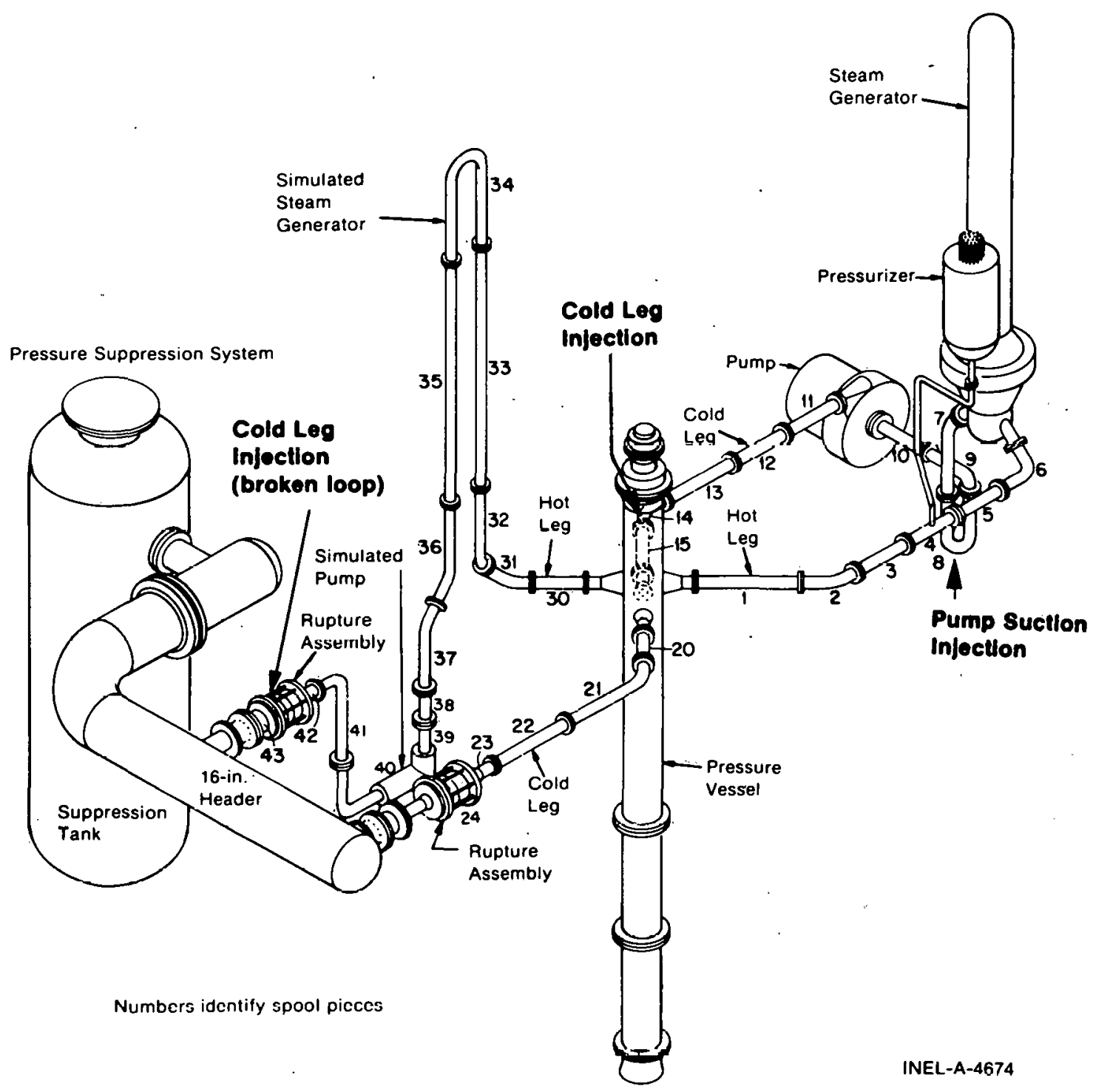

Fig. E-1 Semiscale Mod-1 system configuration for pump suction leg ECC injection.

with a simulated steam generator, simulated pump, and two rupture assemblies. The simulated steam generator and pump contained orifices to provide the appropriate hydraulic resistance. The ECC was injected into the system from two sources: an accumulator pressurized by nitrogen and a low pressure injection pump. To achieve the pump suction leg ECC injection, the intact loop accumulator was connected to the bottom of the ' $U$ ' shaped pump suction leg for each test. The ECC from the low pressure injection system (LPIS) was injected into the bottom of the pump suction leg for the test at $64 \%$ pump speed and into the cold leg for the other two tests. The broken loop accumulator and LPIS was injected into the broken loop cold leg downstream of the simulated pump discharge. The ECC was not injected into the broken loop pump suction because it was judged that the broken loop pump simulator would behave differently than an active pump and, therefore, would produce hydraulic behavior that would be atypical of that expected to occur in a PWR. The initial conditions and ECC flow rates for each test are tabulated in Table E-I and the pump speed controls investigated are shown in Figure E-2. 
TABLE E-I

TEST CONDITIONS FOR PUMP SUCTION INJECTION TESTS

Core power $(\mathrm{MW})^{[\mathrm{a}]}$

Intact loop cold leg fluid temperature $\left({ }^{\circ} \mathrm{F}\right)^{[\mathrm{a}]}$

Hot leg to cold leg temperature differential $\left({ }^{\circ} \mathrm{F}\right)^{[\mathrm{a}]}$

Steam generator feedwater temperature $\left({ }^{\circ} \mathrm{F}\right)^{[\mathrm{a}]}$

Steam generator liquid level (in.) ${ }^{[a, b]}$

Pressurizer pressure (psia) [a]

Pressurizer liquid volume $\left(\mathrm{ft}^{3}\right)^{[\mathrm{a}, \mathrm{c}]}$

Core flow rate $(\mathrm{gpm})^{[\mathrm{a}]}$

Pressure suppression system pressure (psia) [a]

Intact/broken loop accumulator injection location

Liquid volume $\left(\mathrm{ft}^{3}\right)$

Injection rate $(\mathrm{gpm})$ [d]

Actuation pressure (psia)

Intact/broken loop LPIS injection location

Injection rate $(\mathrm{gpm})^{[\mathrm{d}]}$

Actuation pressure (psia)

Intact/broken locp HPIS injection location

Injection rate (gpm) ${ }^{[\mathrm{d}]}$

Actuation pressure (psia)

[a] Prior to rupture.

[b] Above bottom of tube sheet.

\begin{tabular}{|c|c|c|}
\hline Test S-05-2 & Test $\mathrm{S}-05-2 \mathrm{~A}$ & Test $\mathrm{S}-05-2 \mathrm{~B}$ \\
\hline 1.456 & 1.453 & 1.454 \\
\hline 545 & 543 & 542 \\
\hline 65 & 68 & 68 \\
\hline 440 & 437 & 445 \\
\hline 116 & 115 & 115 \\
\hline 2263 & 2263 & 2272 \\
\hline 0.54 & 0.66 & 0.67 \\
\hline 146 & 146 & 144 \\
\hline 35 & 35 & 35 \\
\hline $\begin{array}{l}\text { Pump suction/ } \\
\text { Spool } 42\end{array}$ & $\begin{array}{l}\text { Pump suction/ } \\
\text { Spool } 42\end{array}$ & $\begin{array}{l}\text { Pump suction/ } \\
\text { Spool } 42\end{array}$ \\
\hline $\begin{array}{r}2.9 / 1.0 \\
18.8 / 8.0 \\
597 / 600\end{array}$ & $\begin{array}{r}2.6 / 1.1 \\
24.0 / 8.0 \\
597 / 602\end{array}$ & $\begin{array}{r}2.9 / 0.9 \\
25.0 / 7.0 \\
596 / 600\end{array}$ \\
\hline $\begin{array}{l}\text { Pump suction/ } \\
\text { Spool } 42\end{array}$ & $\begin{array}{l}\text { Cold leg/ } \\
\text { Spool } 42\end{array}$ & $\begin{array}{l}\text { Cold leg/ } \\
\text { Spool } 42\end{array}$ \\
\hline $\begin{array}{l}4.7 / 1.18 \\
165 / 130\end{array}$ & $\begin{array}{l}4.7 / 1.16 \\
170 / 130\end{array}$ & $\begin{array}{l}4.7 / 1.17 \\
160 / 170\end{array}$ \\
\hline $\begin{array}{l}\text { Pump suction/ } \\
\text { Spool } 42\end{array}$ & $\begin{array}{l}\text { Not used/ } \\
\text { not used }\end{array}$ & $\begin{array}{l}\text { Not used/ } \\
\text { not used }\end{array}$ \\
\hline \multicolumn{3}{|l|}{$\begin{array}{l}0.6 / 0.6 \\
1800 / 1800\end{array}$} \\
\hline $\begin{array}{l}\text { Based on avera } \\
\text { Average attain }\end{array}$ & $\begin{array}{l}\text { did density } \\
\text { ring test. }\end{array}$ & $4 \mathrm{lbm} / \mathrm{ft}^{3}$. \\
\hline
\end{tabular}




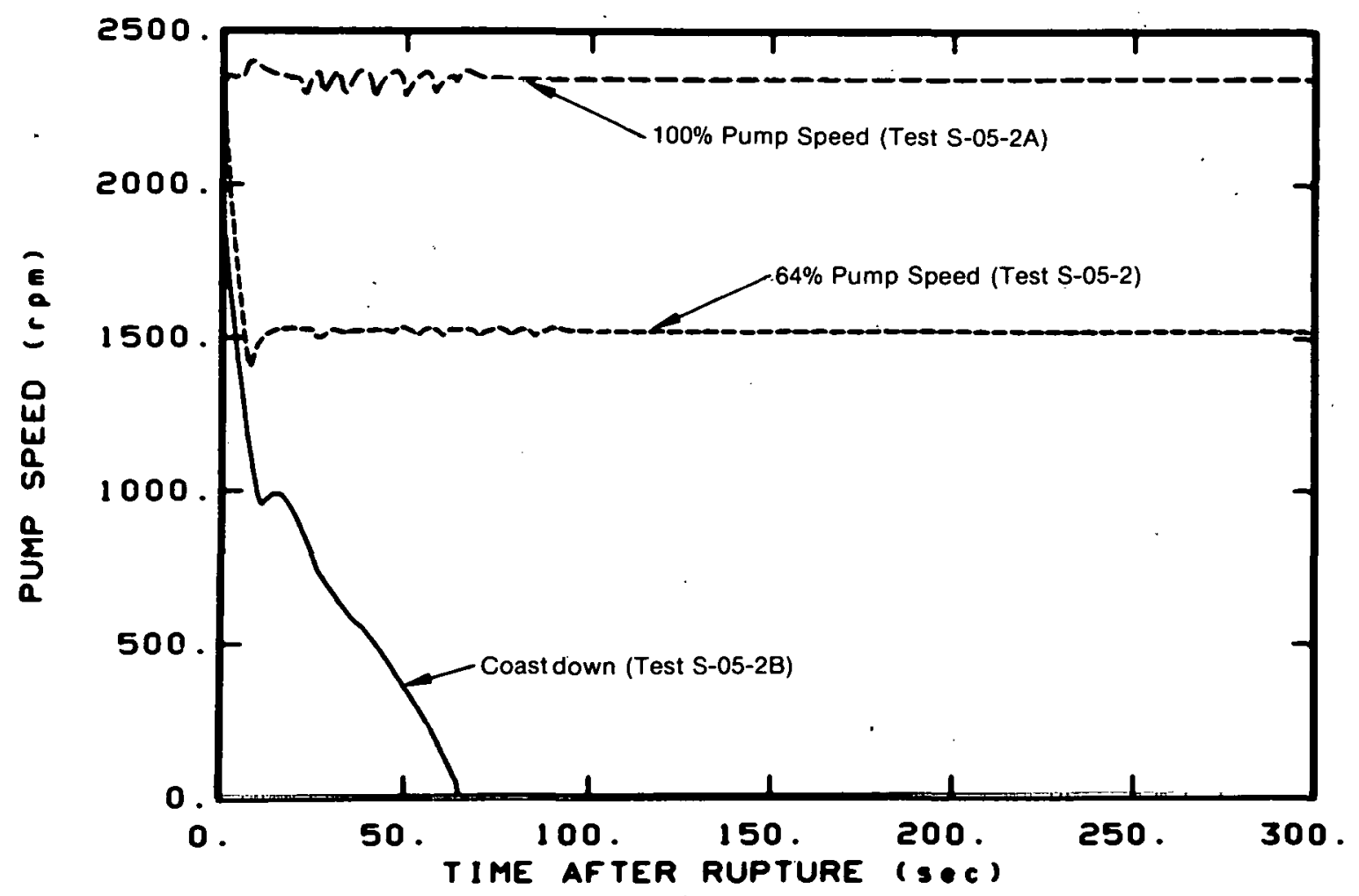

Fig. E-2 Pump speed control profiles investigated during pump suction leg ECC injection.

To extend the investigation of the concept of using pump suction leg ECC injection, a two-part analytical study using RELAP4 ${ }^{[\mathrm{E}-1]}$ was performed ${ }^{[a]}$. The first part of the analytical study consisted of the investigation of the effect of the ECC injection rate during pump suction injection, at a constant pump speed, on the core and system response. The analytical study of the effect of the variation of injection rate complimented the experimental investigation which evaluated the effect of the pump speed control on the core thermal response at a constant ECC injection rate. Calculations were performed at ECC injection rates of $23,46,74$, and $101 \mathrm{gpm}$ with a constant pump speed of $2350 \mathrm{rpm}$. The second part of the analytical study consisted of an investigation of the effect of the pump characteristics on the core and system thermal response during pump suction leg ECC injection at a constant pump speed. Calculations were performed using models of Westinghouse Electric Corporation and Bingham-Willamette Company pumps as well as a model of the Semiscale Mod-1 pump. Therefore, the combination of the experimental investigation and the analytical study covered the effects of pump speed profile, ECC injection rate, and pump characteristics during ECC injection in the pump suction leg.

Section 2 of this appendix contains an assessment of the influence of pump speed control on the core thermal response during pump suction leg ECC injection and discusses the effectiveness of the core cooling relative to cold leg ECC injection for each pump speed control investigated. The measured system thermal and hydraulic results of using different pump speed controls are also documented in Section 2 along with a discussion of the major

[a] Configuration Control Number H000061B. 
system behavior resulting in the observed core thermal response. The thermal-hydraulic response calculated by RELAP4 using a range of ECC injection rates and using pumps with different characteristics during pump suction leg ECC injection is documented and discussed in Section 3. The significant conclusions from the experimental investigation of the effect of pump speed control at a constant ECC accumulator injection rate on the core and system response and from the analytical study of the effect of the ECC injection rate and pump characteristics at a constant pump speed on the core and system response are presented in Section 4.

\section{RESULTS OF THE EXPERIMENTAL INVESTIGATION}

In the experimental investigation of the alternate ECC injection concept which used pump suction leg ECC injection, the pump speed control was the major parameter investigated. Pump speed controls of $100 \%$ of the prerupture value, coastdown to $64 \%$ of the prerupture value, and coastdown in a similar manner to that calculated for a PWR pump with pump suction leg. ECC injection were employed in a series of integral blowdown-reflood tests. The thermal-hydraulic response of the Semiscale Mod-1 system was then evaluated with each pump speed control. The results of the evaluations are discussed in the following sections by relating the pump performance to the system thermal and hydraulic responses. The effect of the pump speed control on the core thermal response is evaluated in the first section, along with a comparison of the pump suction leg ECC injection results for each pump speed control with the cold leg injection results. The second, third, and fourth sections discuss the system thermal-hydraulic response obtained with the pump speed coasting down to $64 \%$ of the prerupture value, remaining constant at $100 \%$ of the prerupture value, and coasting down similar to a PWR pump, respectively.

\subsection{Influence of Pump Speed Control on the Core Thermal Response}

An indication of the dependence of the core thermal response on the pump performance was obtained by examining the rod cladding temperature response with each pump speed control investigated. The temperature responses at the 29 -in. elevation for the three tests using pump suction ECC injection and the baseline test using cold leg injection are compared in Figure E-3. This comparison shows that significantly different results were obtained for each pump speed profile. The temperature traces at the 29-in. elevation shown in Figure E-3 are typical of those obtained at most other elevations in the core.

The most effective initial core conling and earliest rod quenching for the series of tests using pump suction leg ECC injection occurred when the pump coasted down to $64 \%$ of the prerupture pump speed. The relatively rapid decrease in the rod cladding temperature from about 10 to $75 \mathrm{sec}$ after rupture shown in Figure E-3 for a pump speed of $64 \%$ indicates that effective core cooling was occurring during this period. The core hot spot (29 in.) elevation quenched about $75 \mathrm{sec}$ after rupture and the entire core was quenched about $78 \mathrm{sec}$ after rupture. However, a second heatup of the rod cladding surfaces occurred 


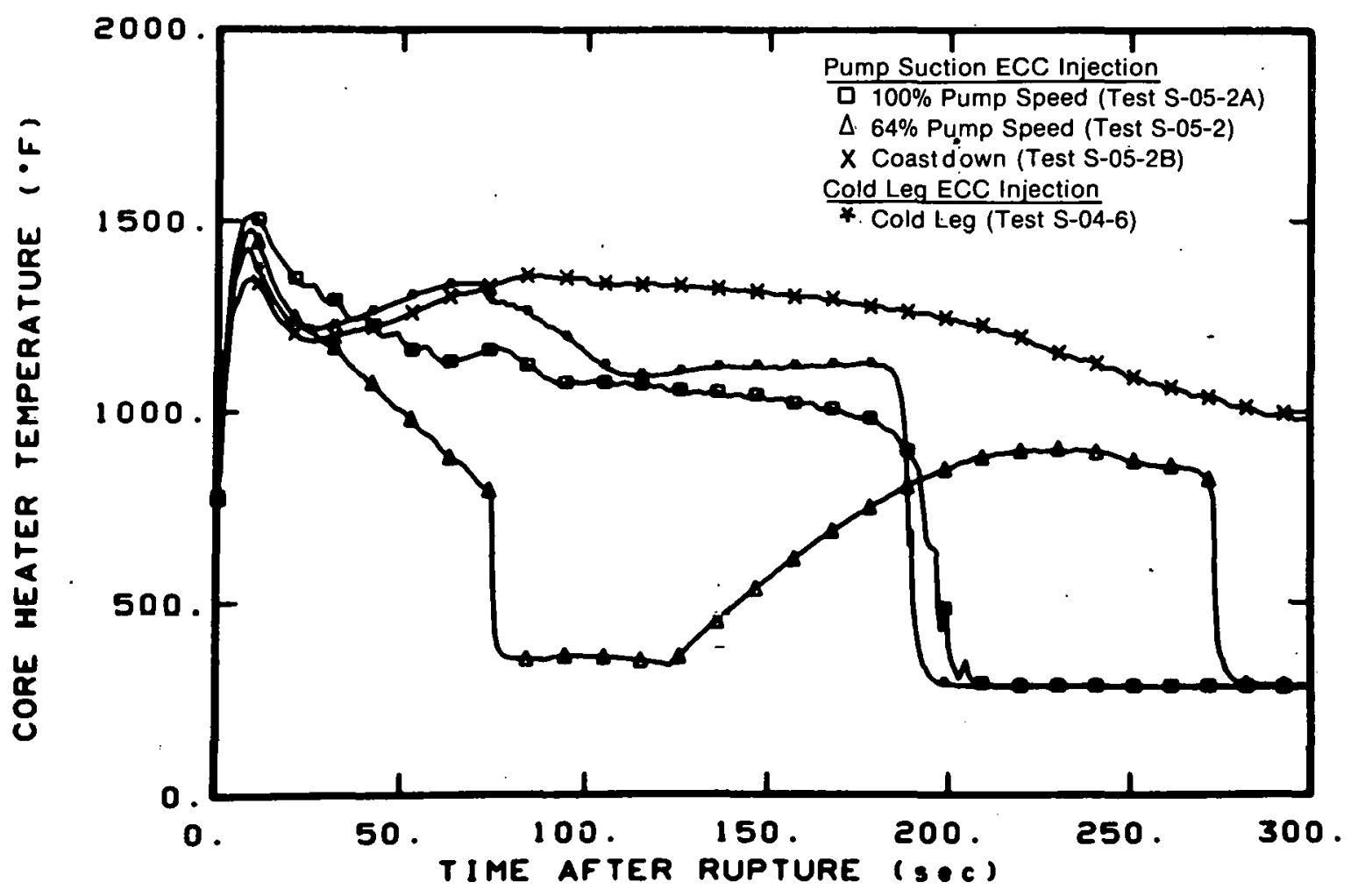

Fig. E-3 Comparison of rod cladding temperature response at the 29-in. elevation showing the effect of pump speed.

following the initial core quench. The second heatup of the core, which was a result of the location of the LPIS injection, did not result in high temperatures. This second heatup is discussed in more detail in Section 2.2.

The second most effective core cooling indicated in Figure E-3 occurred when the pump speed was maintained at $100 \%$ of the prerupture value. The overall core cooling was less effective than when the pump speed was at $64 \%$ of the initial value, but was more effective than that obtained with cold leg ECC injection or when the pump coasted down to a stop. The decrease in the rod cladding temperature shown in Figure E-3 for a $100 \%$ pump speed indicates that more effective (compared to cold leg ECC injection) core cooling occurred from about 10 to $70 \mathrm{sec}$ after rupture resulting in lower rod cladding temperatures than occurred with cold leg ECC injection. The quench time at most elevations was earlier with pump suction leg ECC injection and $100 \%$ pump speed than with cold leg ECC injection. However, the last measured rod quench at the core hot spot occurred at about $250 \mathrm{sec}$ after rupture using $100 \%$ pump speed, whereas for cold leg ECC' injection the last measured rod quench at this elevation occurred at about $242 \mathrm{sec}$ after rupture. The entire core quenched about $280 \mathrm{sec}$ after rupture for this pump suction leg ECC injection test, whereas one thermocouple at the 45 -in. elevation had not quenched by $300 \mathrm{sec}$ after rupturc with cold lcg ECC injcction.

The least effective core cooling for the three pump speed profiles investigated occurred for the test in which the pump speed coasted down to a stop. The temperature traces shown in Figure E-3 illustrate the higher temperature for this test, from about 72 to 
$300 \mathrm{sec}$ after rupture, than for the other tests compared in Figure E-3 including the baseline test. The 29-in. elevation had not quenched in the 300-sec duration of the test using a pump speed coastdown to a stop.

The rod thermal response that occurred during the blowdown for the test with the pump coasting down to a stop differed from that obtained with the other pump speed controls. An early quenching of upper portions of the core down to the 25 -in. elevation was measured. The other tests exhibited early quenching of the core down to the 33-in. elevation. The early quench of the upper portion of the core from the top down is associated with the emptying of the pressurizer coolant. (The details of this phenomenon are discussed in Reference E-2.) The early quenching to the lower elevation was a result of an interaction between the effect of the lower pump speed on the intact loop flow and the effect of the pressurizer flow behavior on the intact loop hot leg flow.

In summary, effective core cooling and early rod quench can be achieved with ECC injection in the pump suction leg. However, conditions may occur during pump suction leg ECC injection that result in poorer core cooling relative to cold leg ECC injection. The complex interrelationship between the core and system behavior that influenced the effectiveness of the core cooling is discussed in greater detail in the following three sections.

\subsection{System Thermal-Hydraulic Response with the Pump at $64 \%$ ( $\simeq 1530 \mathrm{rpm}$ ) of the Prerupture Speed}

Effective initial core cooling and an early quench of the core resulted from pump suction leg ECC injection with the pump coasting down to $64 \%$ of the prerupture speed. A detailed investigation of the core and system response that resulted in this effective core cooling was performed to understand the complex phenomena that occurred. The results of this investigation indicated that the effective core cooling for this pump speed control primarily resulted from the thermal-hydraulic conditions at the core inlet and within the core. The magnitude of the pressure difference developed by the pump was a principal factor in establishing and maintaining the required thermal-hydraulic conditions at the core inlet and the pump pressure differential was in turn critically dependent on the fluid density in the pump suction leg. The density of the fluid in the pump suction leg shown in Figure E-4 indicates that the pump suction leg was voided of hot water (density about $47 \mathrm{lb} / \mathrm{ft}^{3}$ ) at about $7 \mathrm{sec}$ after rupture and was filled with cold water (density about $62 \mathrm{lb} / \mathrm{ft}^{3}$ ) at about $25 \mathrm{sec}$ after rupture, which was about $8 \mathrm{sec}$ after accumulator ECC injection was initiated. As shown in Figure E-5, the pump developed a relatively large pressure difference about $27 \mathrm{sec}$ after rupture which was about $2 \mathrm{sec}$ after the density measurement in the pump suction leg indicated that region was filled with coolant. Oscillations in the pressure difference across the pump occurred at about $40 \mathrm{sec}$ after rupture. Figure E-5 shows the magnitude and duration of these oscillations. Comparison of pump inlet density with the pump differential pressure (Figures E-4 and E-5) shows that oscillations in the density at the pump inlet occur which are similar to the oscillations in the pressure differences across the pump, and indicate that the oscillations in the pump pressure difference are due to the filling and partial emptying of the pump suction leg. Figure E-5 


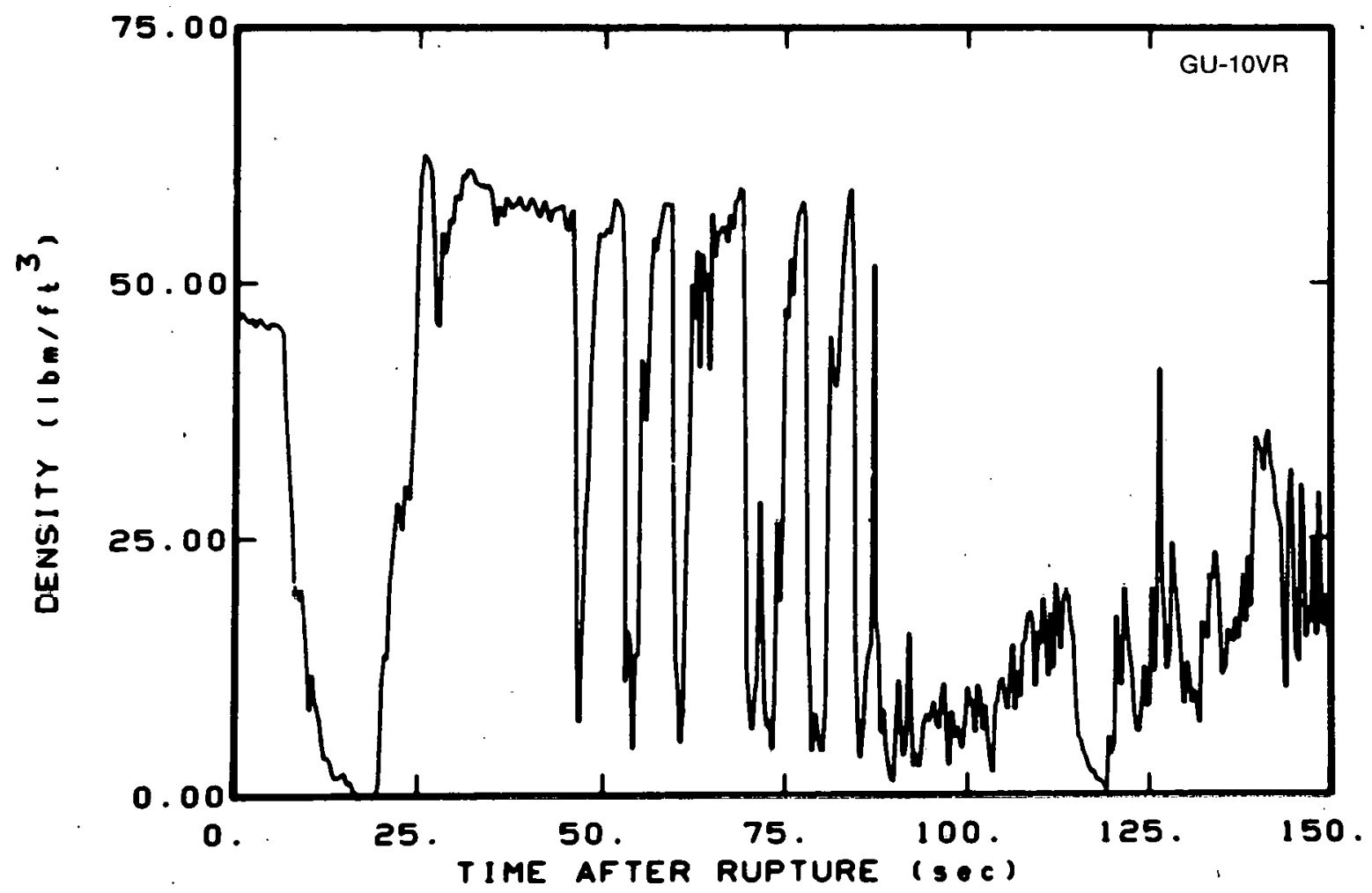

Fig. E-4 Density response in the pump suction leg during pump suction leg ECC injection with a pump speed of $64 \%$ of initial speed - Test S-0S-2.

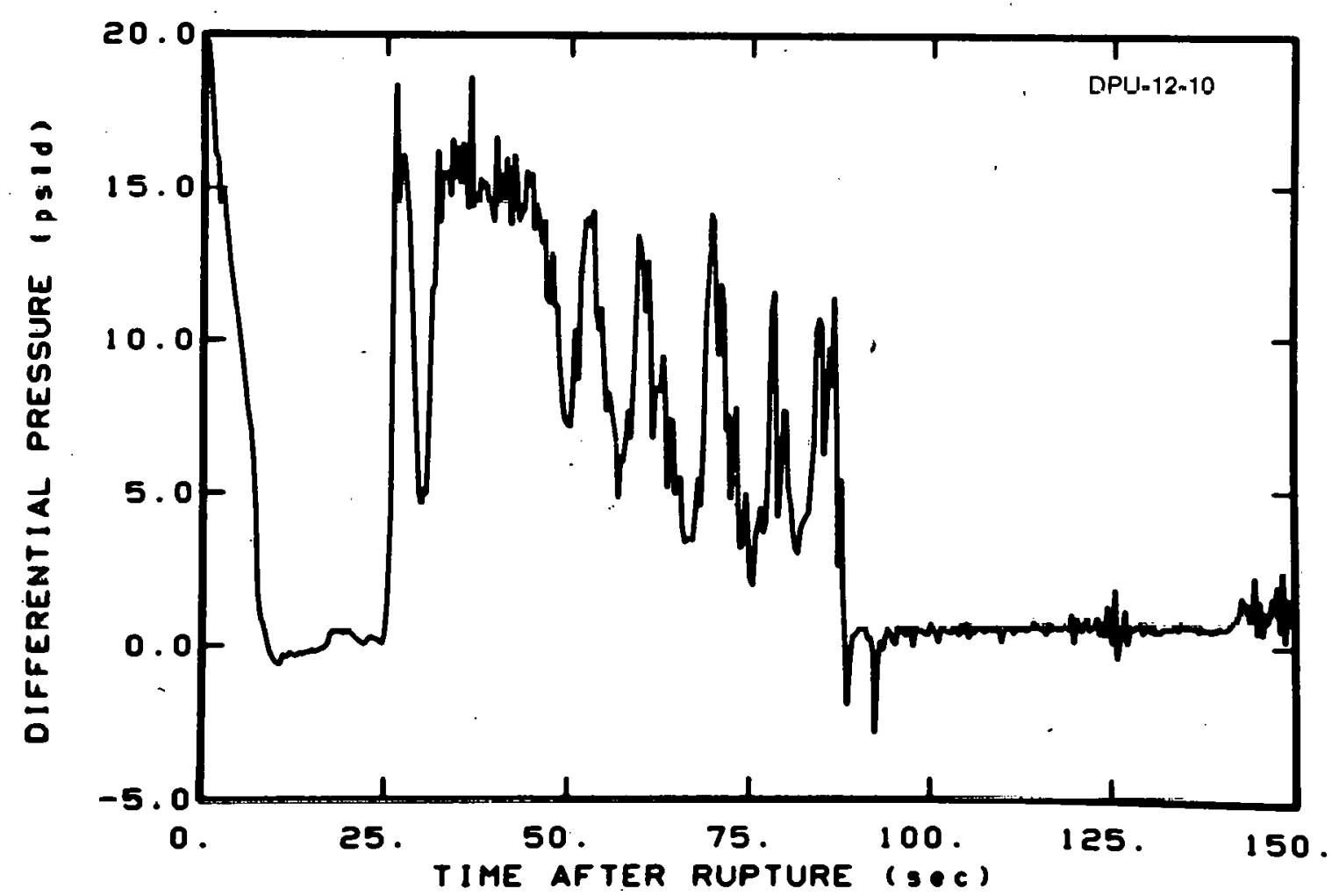

Fig. E-5 Differential pressure response across the pump during pump suction leg ECC injection with a pump speed of $64 \%$ of initial speed - Test S-05-2. 
shows that even though the pump pressure difference oscillated for the system conditions of this test, it was always positive. This positive pressure difference was a major factor in the effectiveness of this ECC concept because it established and maintained a predominantly positive core inlet flow from 26 to about $49 \mathrm{sec}$ after rupture as shown in Figure E-6. In addition to maintaining this positive core flow, the pump also forced liquid down the downcomer, which resulted in the core inlet flow being a mix ture of liquid and steam. The measurement of the core inlet density shown in Figure E-7 illustrates the two-phase mix ture at the core inlet, especially after about $32 \mathrm{sec}$. The liquid, entering the core as a result of the pump pressure differential, was entrained and flowed up through the core. The increase in the density measurement in the broken loop hot leg, shown in Figure E-8, at about 45 sec after rupture illustrates that the entrained fluid had penetrated the entire length of the core. Improved reflood heat transfer has been observed in other reflood tests when entrainment occurred $^{[\mathrm{E}-3]}$.

A second important factor in the effective core cooling for this pump speed control was the thermodynamic condition of the ECC entering the downcomer. The development of a consistently positive pump differential pressure resulted in a positive intact loop flow as indicated by the large increase in the intact loop flow as shown in Figure E-9 at about 27 sec after rupture. This positive intact loop flow in conjunction with the rotating pump appeared to result in good mixing in the pump suction leg of the cold ECC injected in the pump suction leg and the steam flowing in the intact loop, which resulted in appreciable steam condensation. The condensation raised the temperature of the injected coolant to near the saturation temperature as is indicated by the comparison of the temperature of the coolant

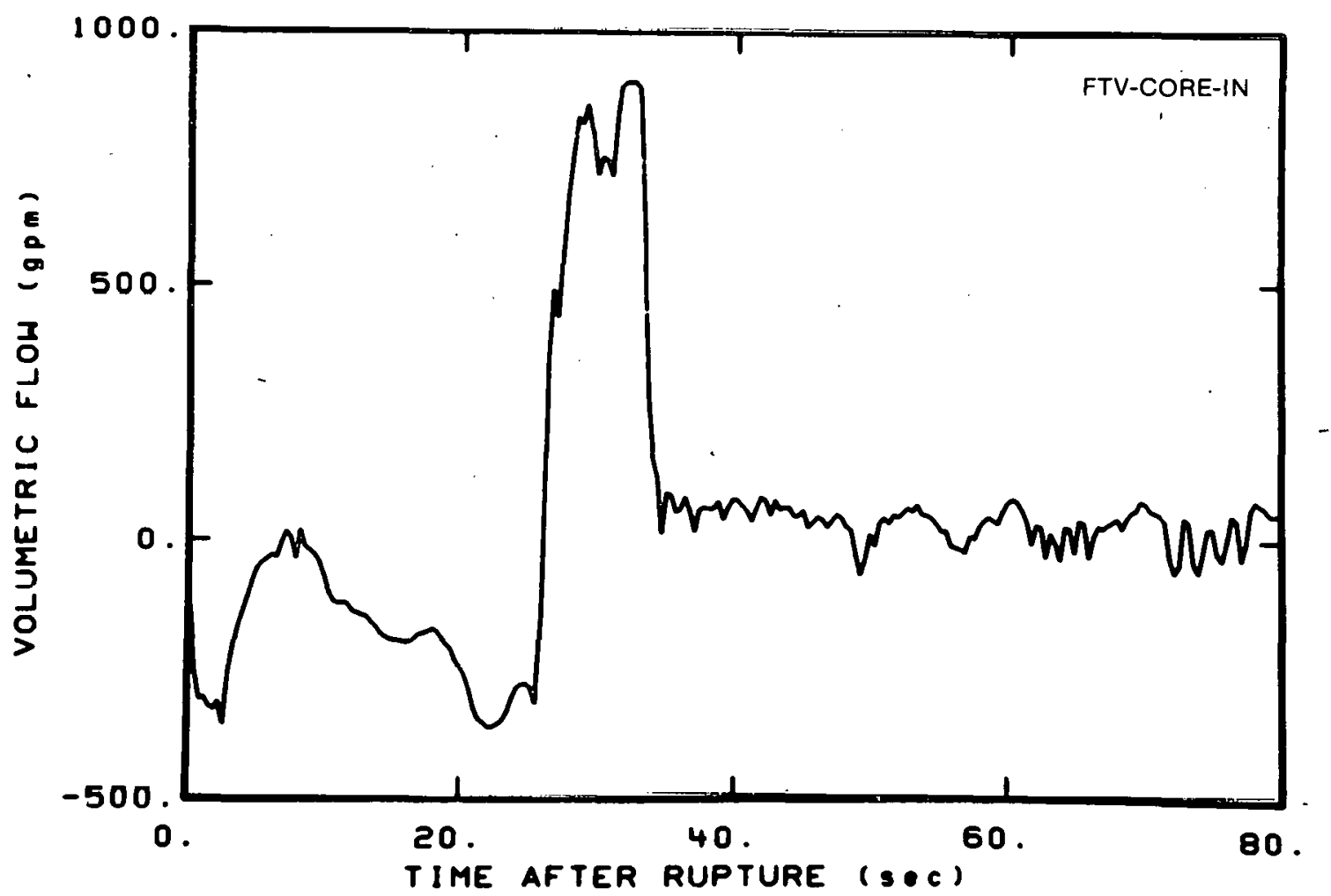

Fig. E-6 Short-term core inlet flow during pump suction leg ECC injection with a pump speed of $64 \%$ of initial speed - Test S-05-2. 


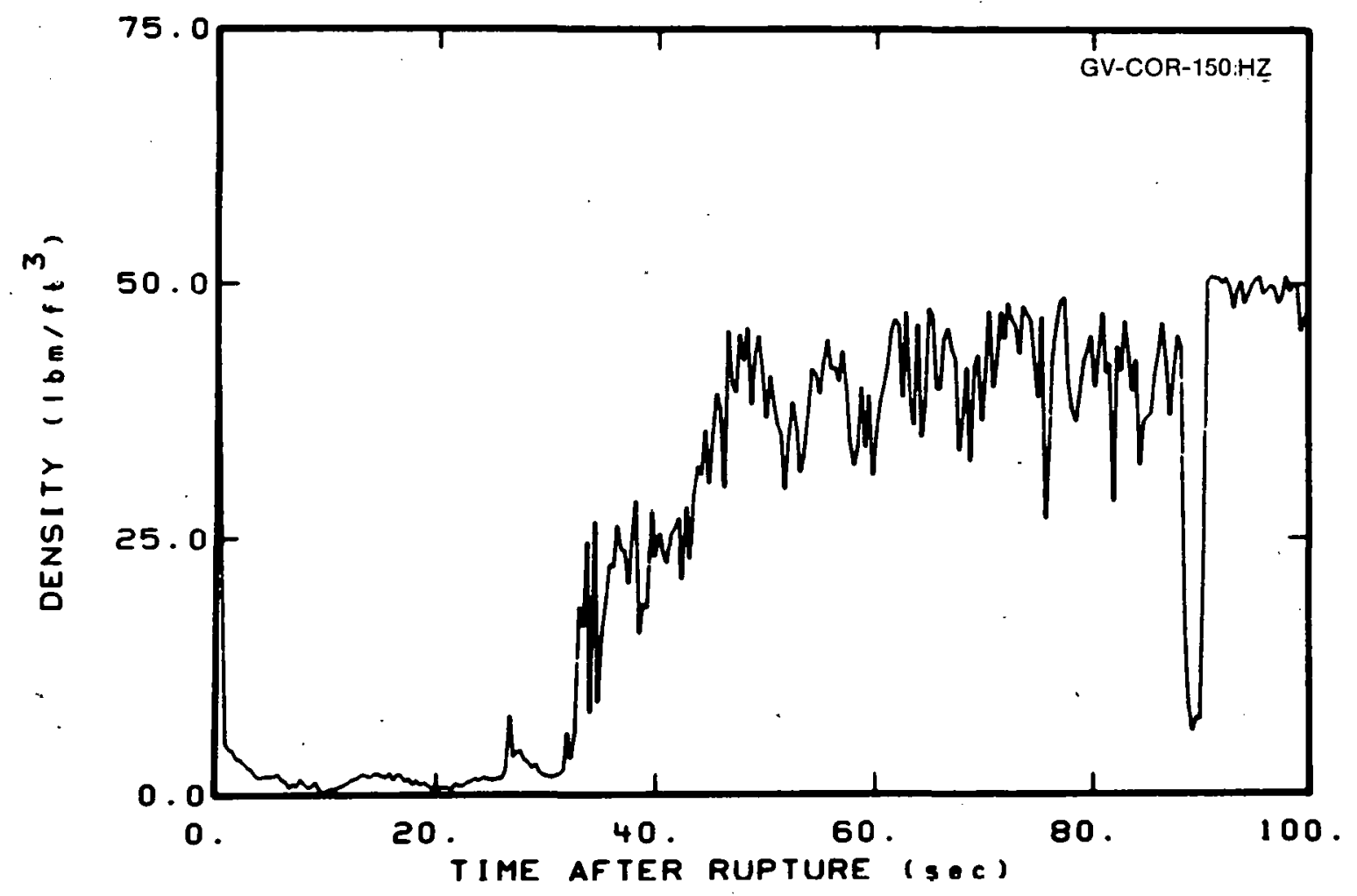

Fig. E-7 Short-term core inlet density response during pump suction leg ECC injection with a pump speed of $64 \%$ of initial speed - Test S-05-2.

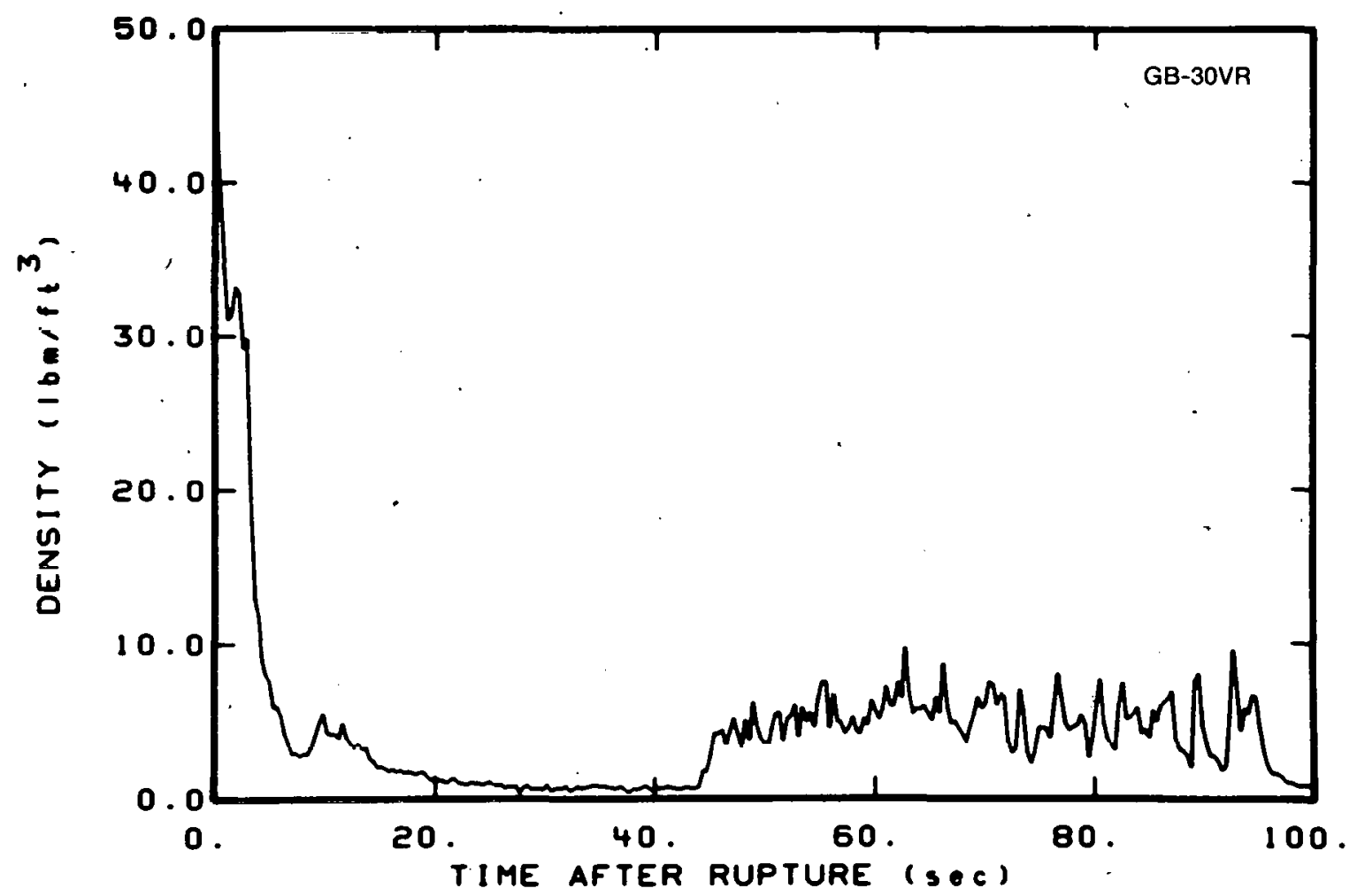

Fig. E-8 Density response in broken loop hot leg during pump suction leg ECC injection with a pump speed of $64 \%$ of initial speed - Test S-05-2. 


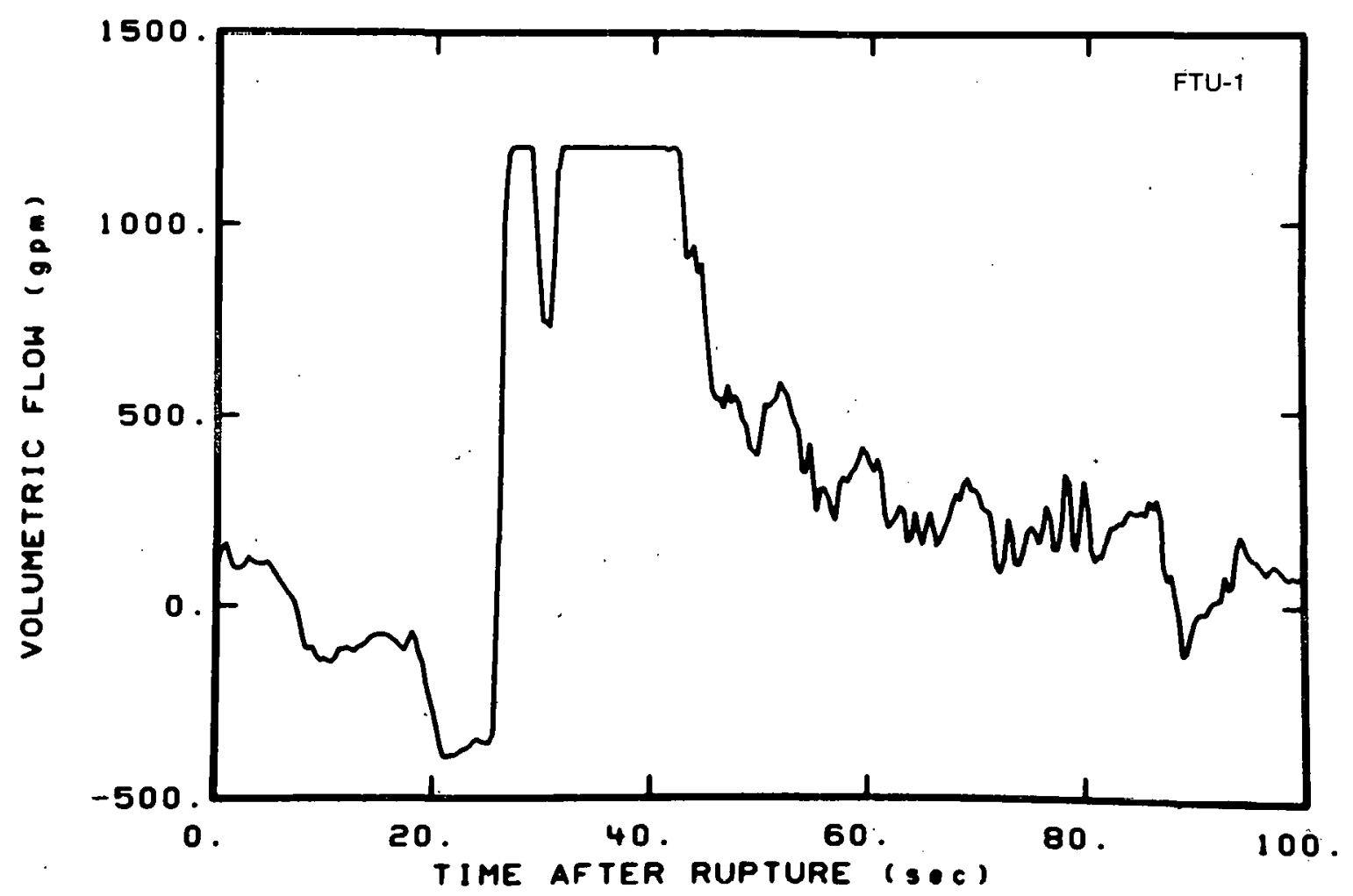

Fig. E-9 Intact loop hot leg volumetric flow during pump suction leg ECC injection with a pump speed of $64 \%$ of initial speed - Test S-05-2.

entering the downcomer and the system saturation temperature shown in Figure E-10. The injection into the downcomer of coolant that was near the saturation temperature decreased the potential for condensation of steam in the annulus. Coolant that is near the saturation temperature when entering the downcomer decreases the potential for countercurrent flow, and in this case, allowed the maintenance of positive downcomer and core flows even during periods of low pump differential pressure. The positive flows increased the coolant penetration of the downcomer and the core inlet. Therefore, the combination of the pump performance and the increase in the temperature of the coolant entering the downcomer to near saturation, resulted in a two-phase mixture entering the core and producing the effective core cooling. The overall effective cooling is shown by the quench of the entire core in about $78 \mathrm{sec}$ after rupture.

The period of nitrogen flow from the accumulator did not have an initial effect on the core thermal response. Following the exhaustion of coolant flow from the accumulator, nitrogen flow occurred from about 86 to $114 \mathrm{sec}$ after rupture. The system pressure increased about 15 psia at the initiation of nitrogen flow. Since the entire core was quenched at the initiation of nitrogen injection, the only noticeable initial thermal effect on the core due to the nitrogen flow was a slight increase in the rod cladding temperature which is due to the increase in the system saturation temperature.

However, following termination of nitrogen flow, the core thermal response was affected. The initial surge of nitrogen flow emptied the pump suction leg, intact loop cold 


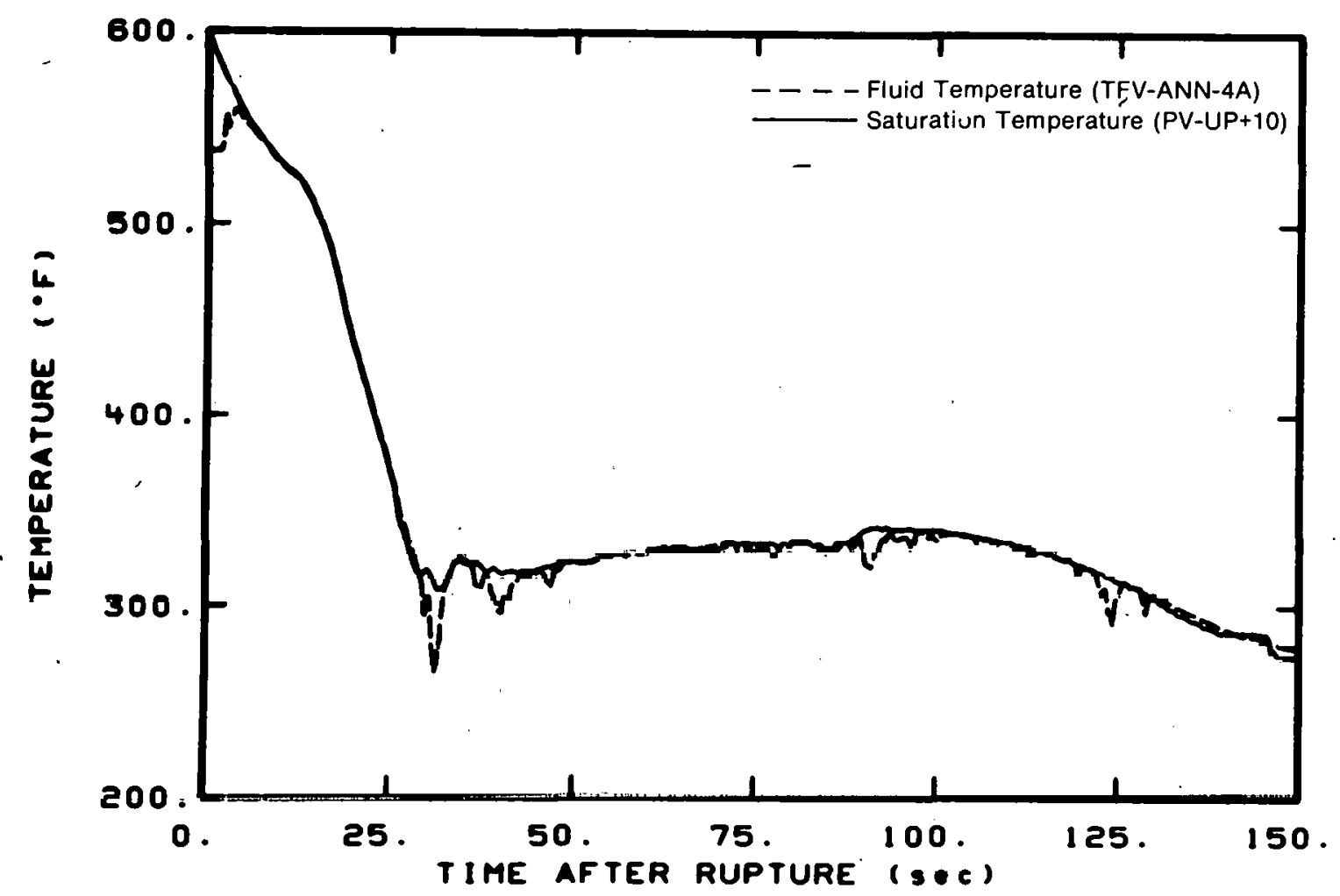

Fig. E-10 Comparison of downcomer annulus fluid temperature and saturation temperature during pump suction leg ECC injection with a pump speed of $64 \%$ of initial speed - Test S-05-2.

leg, and core of coolant. The core was emptied of liquid by a short period of negative core flow at the initiation of nitrogen injection. Much of this coolant entered the downcomer as indicated in Figure E-11 by the increase in the downcomer collapsed liquid level shortly after initiation of nitrogen flow. The effect of the increase in the downcomer collapsed liquid level was to increase the collapsed liquid level of the core that was netarly empty of liquid which resulted in good core cooling. Figure E-11 shows that the core collapsed liquid level decreased, following the intial surge of coolant during the period of nitrogen injection, but overall was maintained high enough to result in good core cooling. Following the termination of nitrogen flow, the pump suction leg and cold leg were nearly voided of liquid and LPIS flow alone was required to refill the pump suction leg before coolant would flow into the downcomer. During this period when no liquid was being delivered to the downcomer, the downcomer and core collapsed liquid level continued to decrease. At about $118 \mathrm{sec}$ after rupture which was about $4 \mathrm{sec}$ after the termination of nitrogen injection, the core collapsed liquid level, as shown in Figure E-11, decreased to about the bottom of the core. Figure E-3 shows that at about $125 \mathrm{sec}$ after rupture a second heatup of the core began. The difference in time between the indication that the core collapsed liquid level decreased to below the bottom of the heated length and the second heatup of the core is believed to be due to the time required to dry out the surface of the rods. This heatup continues, until the LPIS flow alone can supply sufficient fluid to reflood the core. If the LPIS injection location had been in the cold leg rather than at the pump suction, an extended period of no ECC flow in to the downcomer would not have occurred and the large second heatup would have been prevented. 


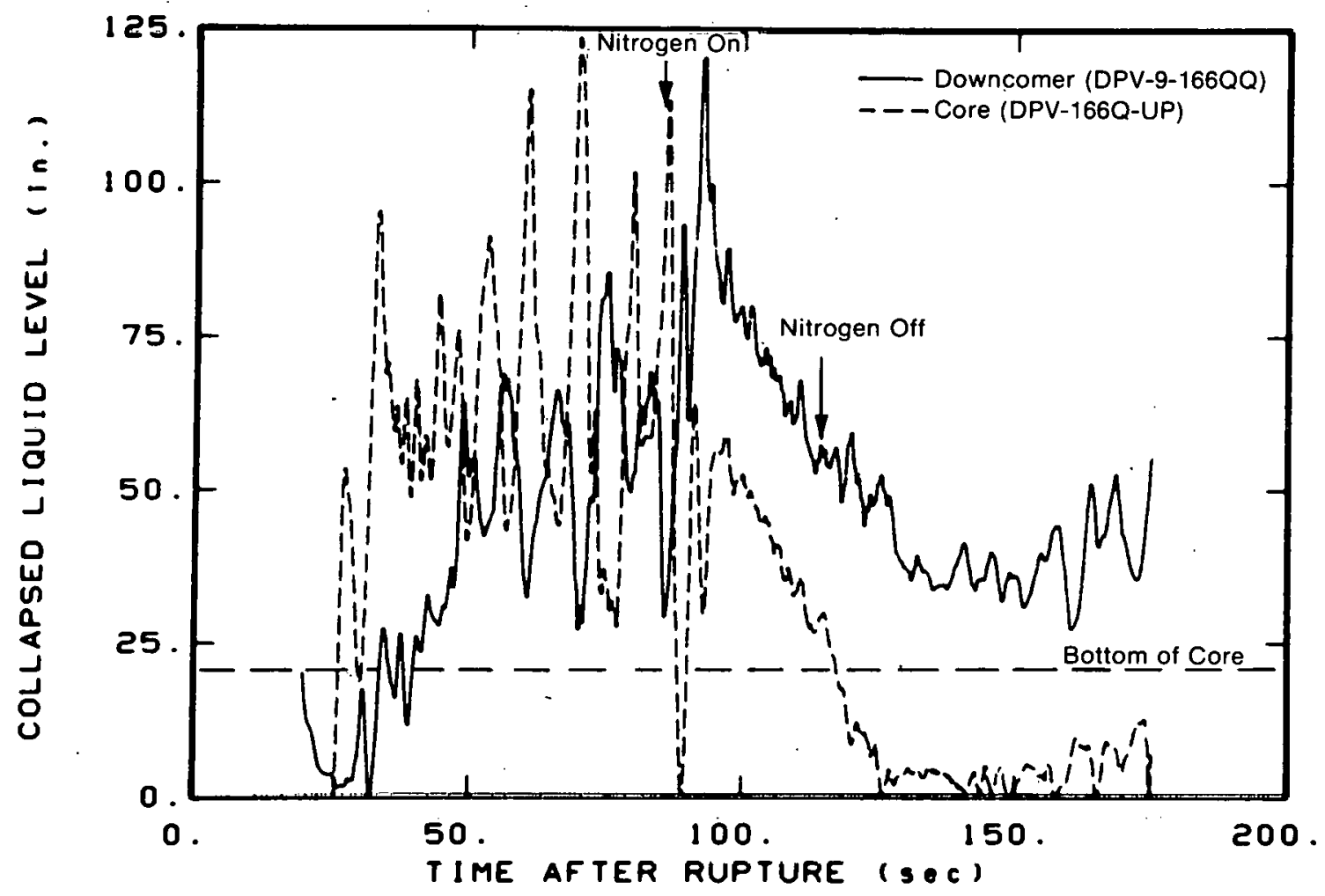

Fig. E-11 Comparison of downcomer and core collapsed liquid levels during pump suction leg ECC injection with a pump speed of $64 \%$ of initial speed - Test S-05-2.

Another indication of the importance of the pump performance on the core thermal response is obtained from comparing the downcomer and core collapsed liquid level shown in Figure E-11. During the period of accumulator coolant injection (23 to $86 \mathrm{sec}$ after rupture) the collapsed. liquid level in the core was larger than in the downcomer. The larger collapsed liquid level in the core than in the downcomer indicates that the pressure head in the downcomer, which was the main force in injecting coolant into the core during cold leg ECC injection, was not the only pressure force during pump suction leg ECC injection. The pressure head developed by the pump was also significant in forcing coolant into the core.

\subsection{System Thermal-Hydraulic Response with the Pump at $100 \%$ (2345 rpm) of the Prerupture Speed}

The core cooling which occurred with the pump operating at $100 \%$ of the prerupture speed was not as effective as the core cooling with the pump operating at $64 \%$ of the prerupture speed. A detailed investigation of the system behavior was performed to investigate the major reasons for the difference in the core thermal response for these different pump speeds. The results of this investigation indicate that the reduced core cooling effectiveness that occurred when the pump speed was maintained at $100 \%$ of the prerupture speed primarily resulted from a difference in the magnitude and direction of the core inlet flow from that which occurred when the pump was operating at $64 \%$ of the prerupture speed. The difference in the core inlet flow was related to a difference in the pump differential pressure history. For the test with the pump operating at $100 \%$ of the 
prerupture pump speed, the pump developed an oscillatory pressure difference throughout the accumulator ECC injection period with the differential pressure maxima being on the order of 30 psid but with the minima being essentially zero, as shown in Figure E-12. A comparison of the pump pressure difference shown in Figure E-12 and the density at the pump suction shown in Figure E-13 shows that the pump head degrades due to nearly complete emptying of the pump suction leg and increases due to filling of the pump suction leg. Therefore, the oscillations in the pump differential pressure result from emptying and filling of the pump suction leg. The degrading of the pump differential pressure to less than about 1 psi, resulted in negative oscillations in the core and intact loop flow. Figures E-14 and E-15 show the core inlet and intact loop volumetric flows, respectively, and illustrate these oscillations with periods of negative core flow. The negative core flow reduced the core cooling effectiveness compared with the results obtained with the pump operating at $64 \%$ of initial speed.

An indication of the effect of the periods of negative core flow on the core cooling is obtained by examining the heat transfer coefficient. The heat transfer coefficient calculated from a thermocouple measurement at the 29 -in. elevation and the core inlet flow are overlayed in Figure E-16. The reduction in the heat transfer coefficients during the periods of negative core flow are typical of heat transfer to superheated steam. These periods of decreased heat transfer to superheated steam did not occur when the pump was operating at $64 \%$ of the prerupture speed and, therefore, better core cooling was achieved at the lower speed.

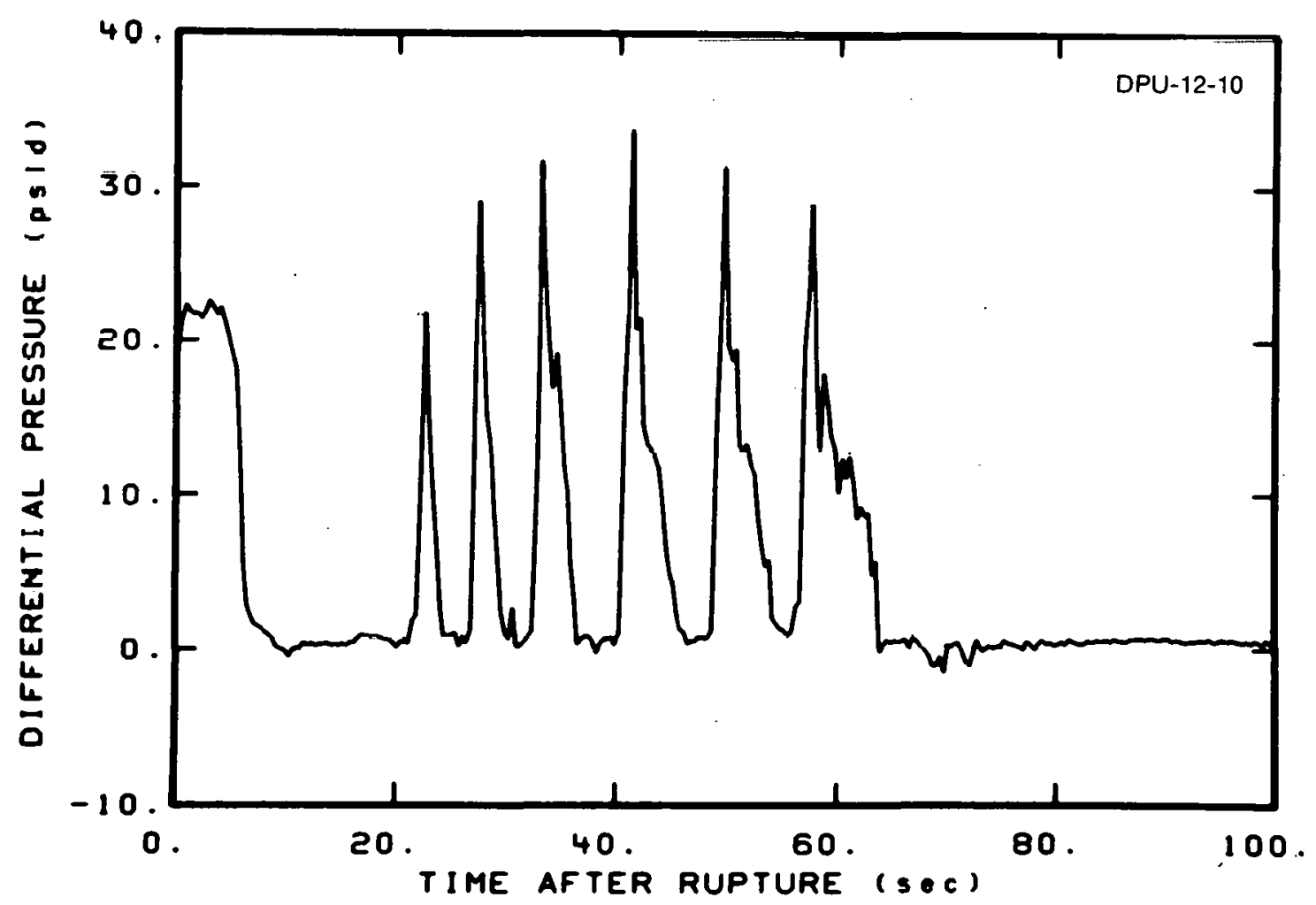

Fig. E-12 Differential pressure response across the pump during pump suction leg ECC injection with a pump speed of $100 \%$ of initial speed - Test S-05-2A. 


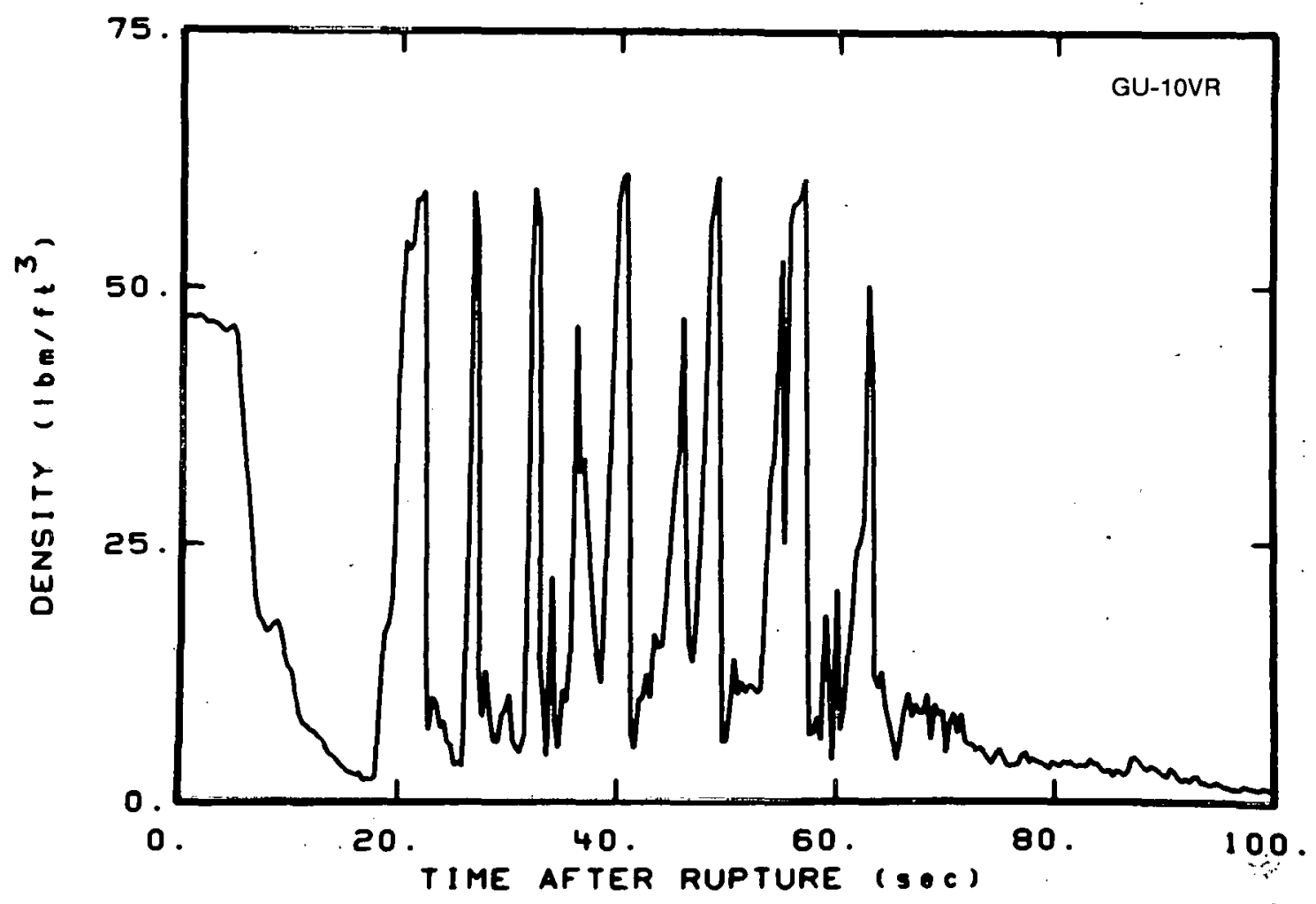

Fig. E-13 Density response in the pump suction leg during pump suction leg ECC injection with a pump speed of $100 \%$ of initial speed - Test S-05-2A.

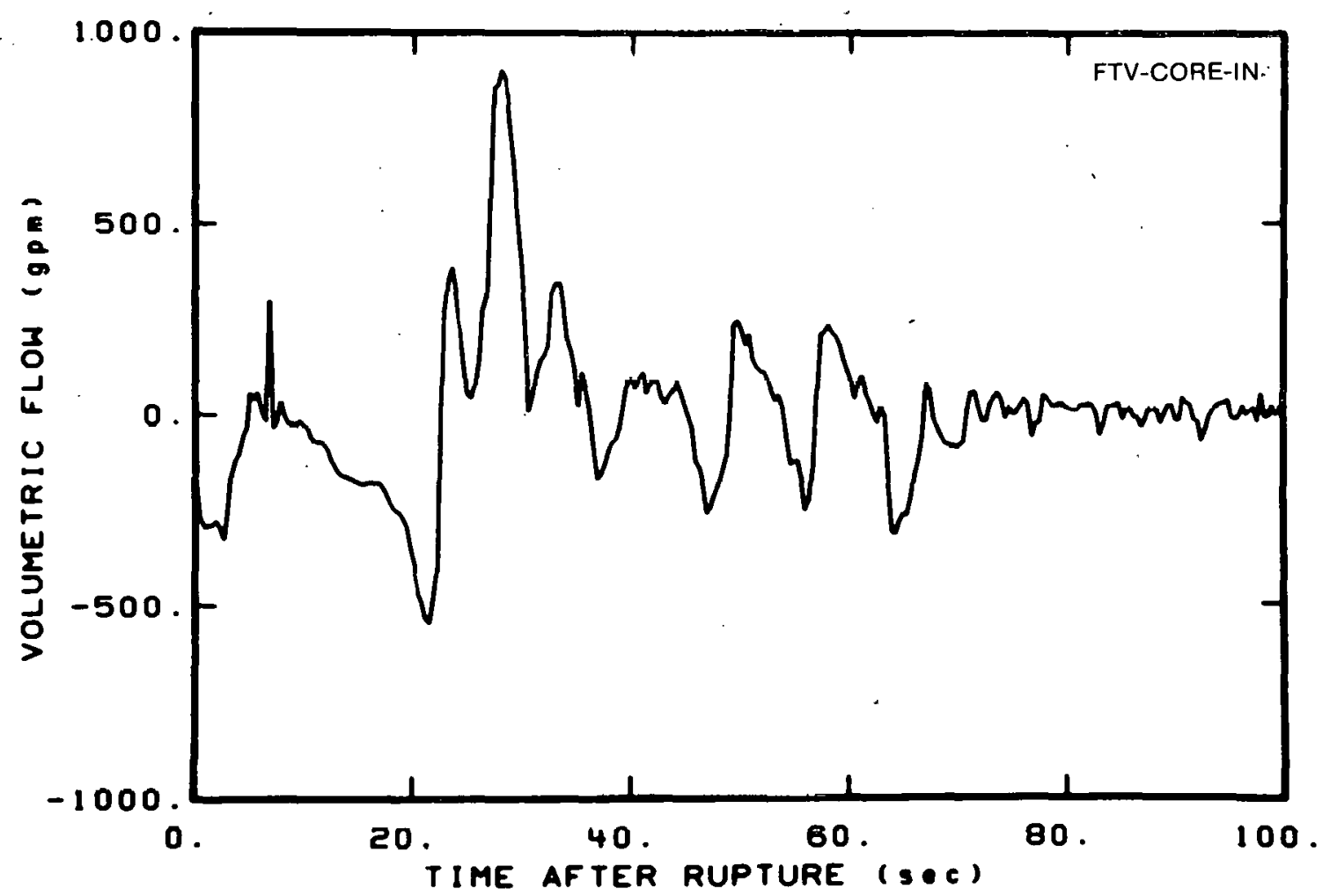

Fig. E-14 Core inlet volumetric flow during pump suction leg ECC injection with a pump speed of $100 \%$ of initial speed - Test S-05-2A. 


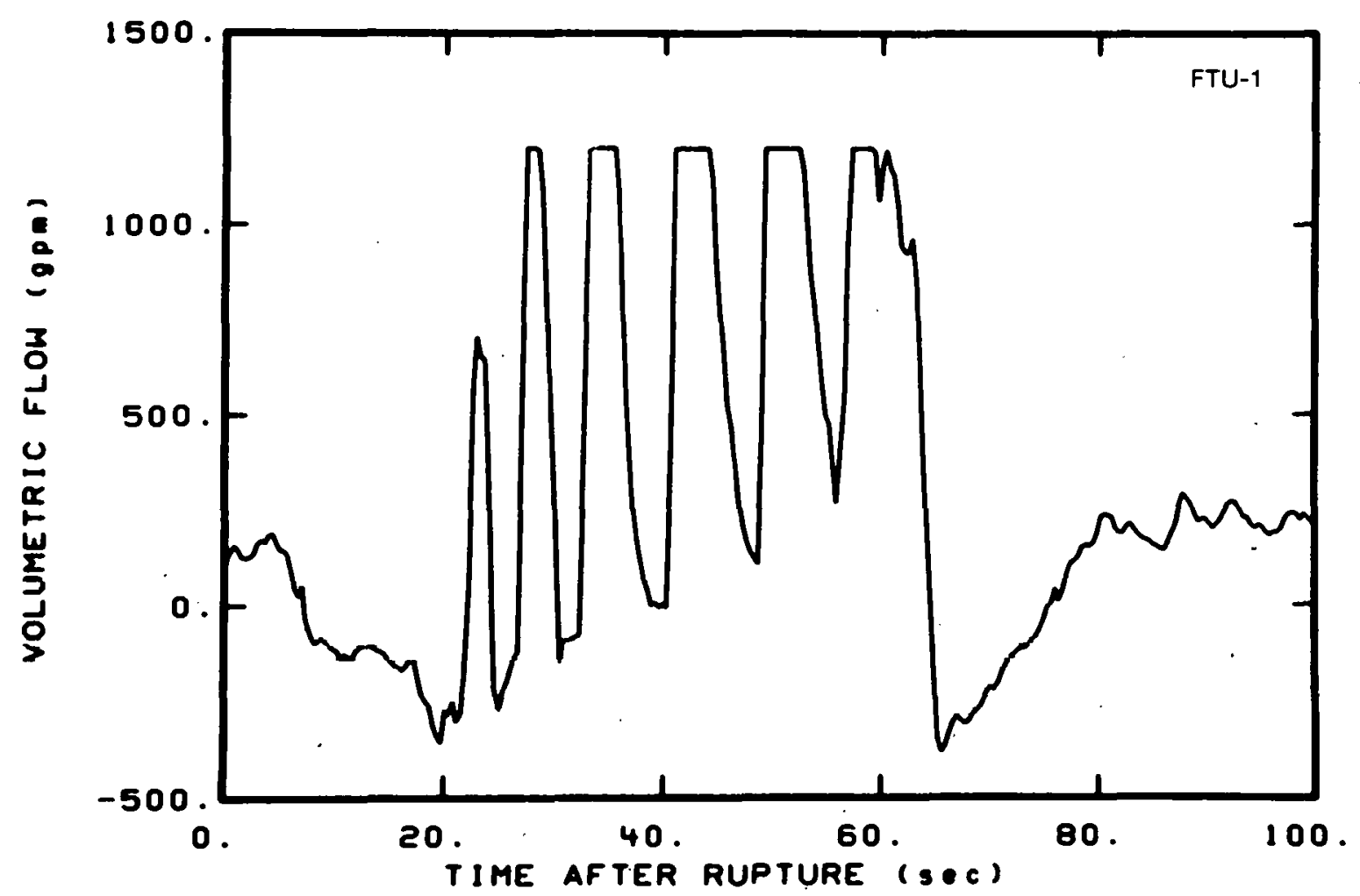

Fig. E-15 Volumetric flow in the intact loop hot leg during pump suction leg ECC injection with a pump speed of $100 \%$ of initial speed - Test S-05-2A.

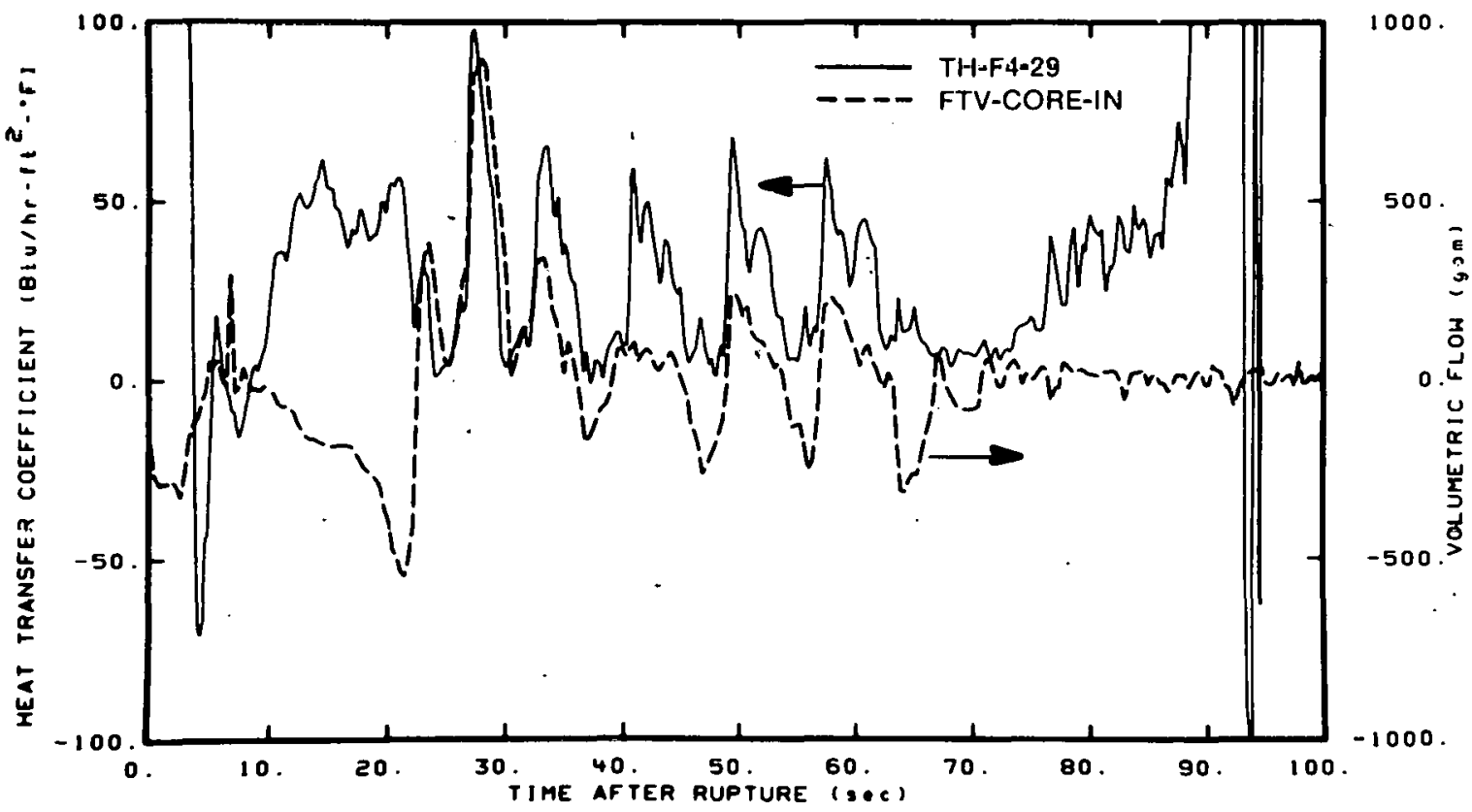

Fig. E-16 Effect of the core inlet volumetric flow on the heat transfer coefficent during pump suction leg ECC injection with a pump speed of $100 \%$ of initial speed - Test S-05-2A. 
The temperature of the ECC delivered to the downcomer inlet annulus also affected the direction of core flow. Contact in the pump suction leg between the steam in the intact loop and the ECC from the pump suction was apparently not sufficient at a pump speed of $100 \%$ of the inital value to remove the subcooling from the ECC due to the reduced intact loop steam flow. The temperature of the ECC entering the downcomer and the system saturation temperature are compared in Figure E-17, which illustrates that ECC entering the downcomer was subcooled by up to $90^{\circ} \mathrm{F}$. This large subcooling provided a potential for significant condensation in the upper inlet annulus. During the periods when the pump head degraded, the subcooled coolant in the upper inlet annulus condensed the steam in the downcomer and induced negative downcomer and core flows. The upflow in the downcomer increased the bypass of coolant out the vessel side of the break (relative to the results at a $64 \%$ pump speed). An indication of the increased bypass is obtained by examining the density in the vessel side of the break which is shown in Figure E-18. The increases in the density shown in Figure E-18 during the period from about 25 to $70 \mathrm{sec}$ after rupture correspond to the degrading of the pump differential pressure shown in Figure E-12. The increased loss-of-coolant out the break reduced the amount of coolant available to the core.

After the accumulators were emptied of water, a period of nitrogen injection occurred. This period of accumulator nitrogen flow affected the system behavior and the core thermal response. One effect of the nitrogen flow resulted in a decrease in the core cooling, whereas another effect of the nitrogen increased the core cooling. The intact loop and core inlet flow reversed at about $64 \mathrm{sec}$ after rupture which was about $2 \mathrm{sec}$ after the

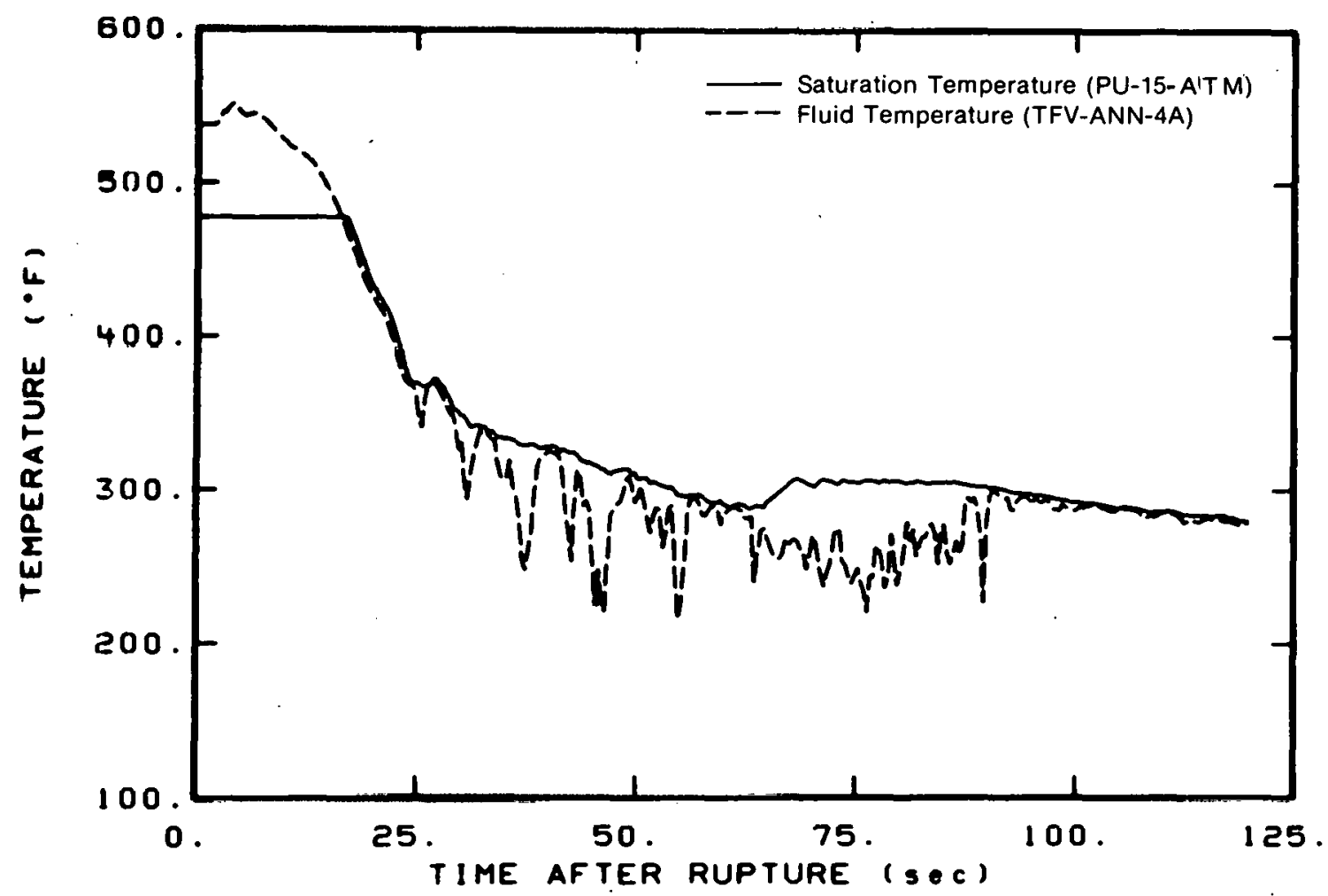

Fig: E-17 Comparison of downcomer inlet annulus fluid temperature and saturation temperature during pump suction leg ECC injection with a pump speed of $100 \%$ of initial speed - Test S-05-2A. 


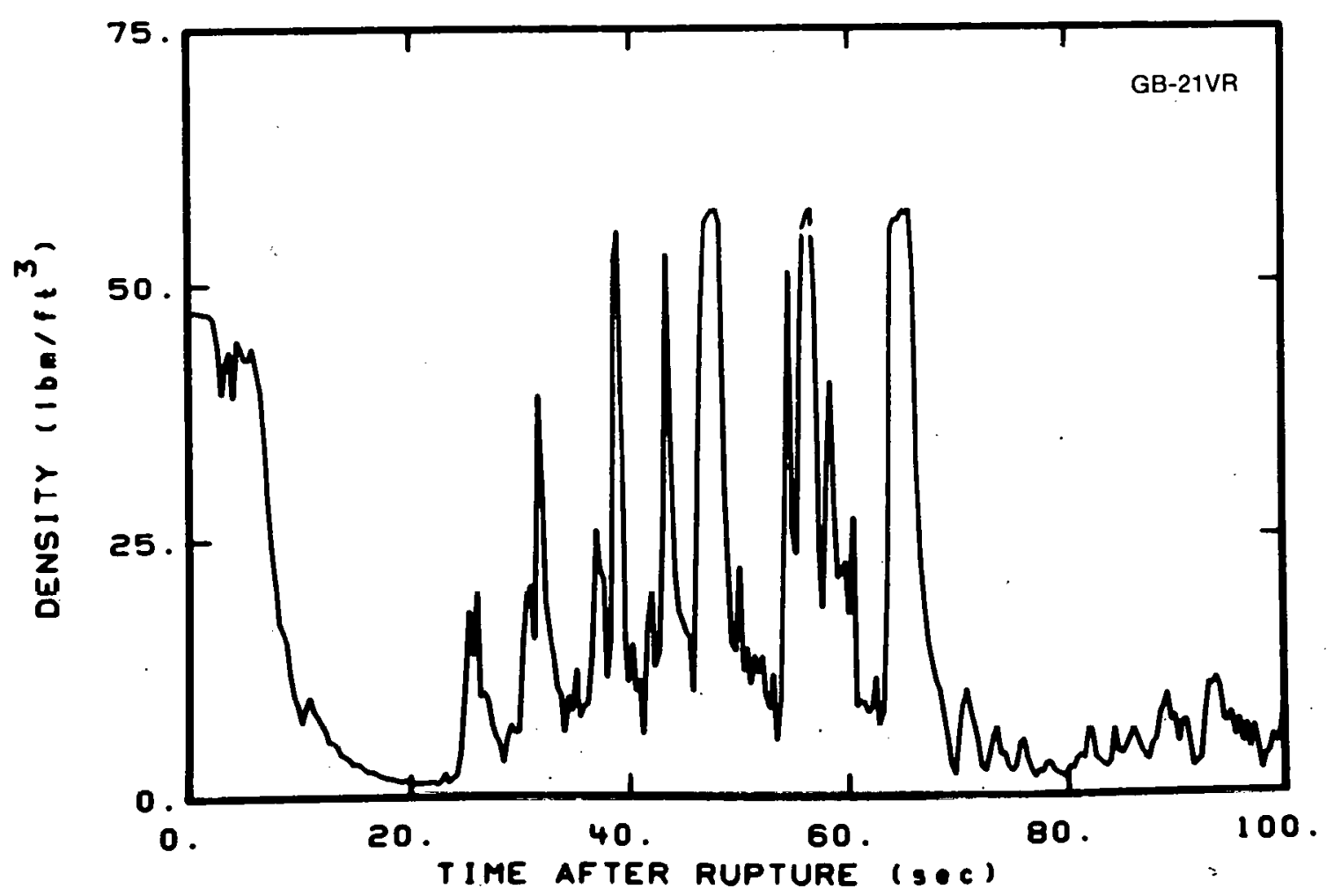

Fig. E-18 Density response in vessel side of broken loop during pump suction leg ECC injection with a pump speed of $100 \%$ of initial speed - Test S-05-2A.

initiation of nitrogen injection. The reversal of these flows, shown in Figures E-14 and E-15, resulted in a decrease in the core heat transfer. Figure E-16 shows that the heat transfer coefficient at the 29 -in. elevation was less than $10 \mathrm{Btu} / \mathrm{hr}-\mathrm{ft}^{2}-{ }^{\circ} \mathrm{F}$ from about 66 to $74 \mathrm{sec}$ after rupture. The nitrogen flow also swept coolant from the pump suction leg and cold leg piping into the downcomer and, as indicated in Figure E-19, resulted in a signficant increase in the downcomer collapsed liquid level. The increase in the downcomer collapsed liquid level resulted in an increase in the core collapsed liquid level beginning about $70 \mathrm{sec}$ after rupture which was $6 \mathrm{sec}$ after the beginning of nitrogen injection. An increase in the core collapsed liquid level indicates fluid would be available, which would cause an improvement in the core heat transfer. This improvement in heat transfer is shown in Figure E-16 by the general increase in the heat transfer coefficient at about $74 \mathrm{sec}$ after rupture. Overall, the decreased heat transfer during the initial period of nitrogen flow is considered to have had a larger effect on the core thermal response than the increased heat transfer later in the period of nitrugen injection.

\subsection{System Thermal-Hydraulic Response with a Pump Coastdown to a Stop}

The core cooling effectiveness obtained with pump suction leg ECC injection, with the pump coastdown speed profile similar to the calculated coastdown of a PWR pump with pump suction leg ECC injection, was not as good as that obtained when the pump was at $100 \%$ or $64 \%$ of the initial speed, or that obtained with cold leg ECC injection. A detailed analysis of the system behavior that resulted in the observed response was performed to 


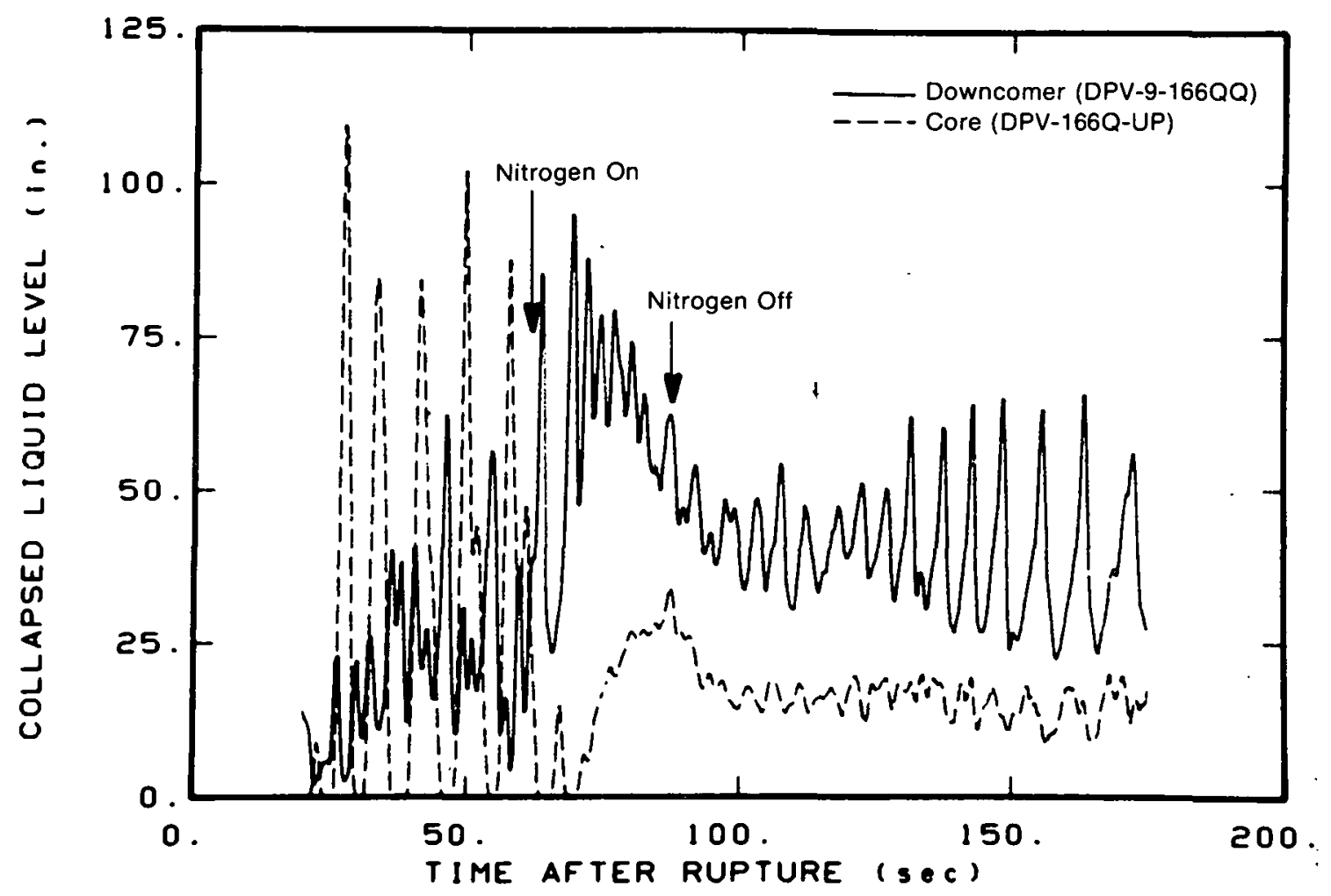

Fig. E-19 Comparison of downcomer and core collapsed liquid levels during pump suction leg ECC injection with a pump speed of $100 \%$ of initial sped - Test S-05-2A.

understand the processes that occurred. The results of this investigation indicate that the lower pump speed for this test had some effect on the core thermal response during blowdown and that, similar to the other pump speeds investigated; the effect of the pump performance on the core inlet flow was the major factor in determining the core thermal response.

The effect of the pump coastdown on the core thermal response during blowdown was evaluated by examining the rod cladding temperature response of the core heater rods. The thermal response in the midsection of the core indicated that a lower pump speed (coastdown to a stop) affected the core thermal response during blowdown. For most of the other tests in this series, coolant from the intact loop penetrated down the core and resulted in an early quench of the core down to about the 32-in. elevation, whereas, early rod quenches were observed down to the 25 -in. elevation with a pump coastdown to a stop. The temperature response of two thermocouples at the 26-in. elevation are compared in Figure E-20 to illustrate the difference in the quench phenomena with a pump coastdown to a stop. The penetration of coolant from the intact loop is indicated by the decrease observed in the temperature measurement obtained from Thermocouple TH-C4-26, to about the system saturation temperature (indicating a rod quench) at about $20 \mathrm{sec}$ after rupture, whereas the temperature response at the other 26-in. location shown in Figure E-20 does not indicate a rod quench. This later response is typical of that obtained throughout the 26-in. elevation region during other tests. The deeper penetration of the quench for the upper portions of the core was related to the effect of the lower pump speed on the intact 


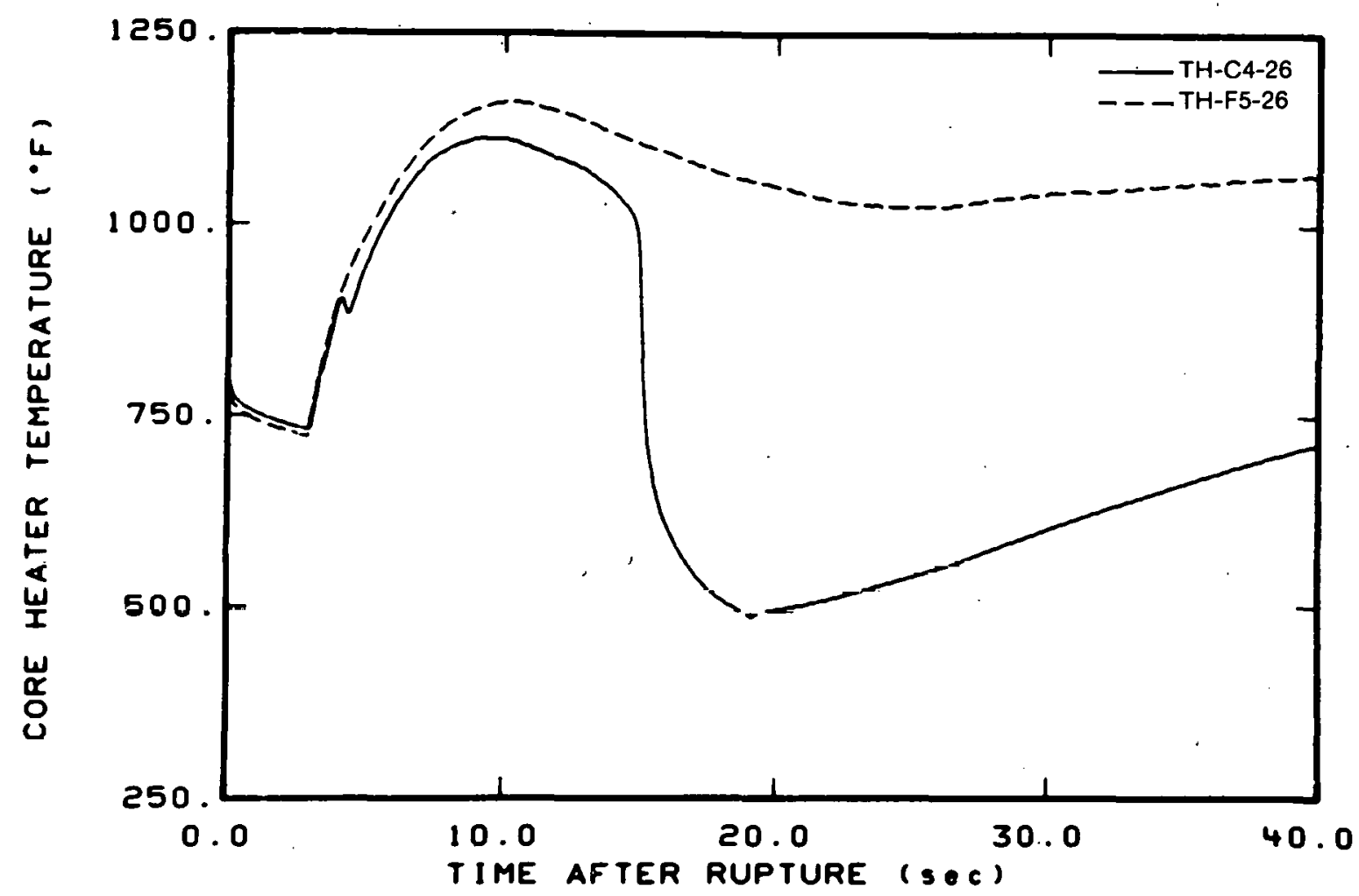

Fig. E-20 Short-term comparison of rod cladding temperature response at the 26-in. elevation during pump suction leg ECC injection with a pump coastdown to a stop - Test S-05-2B.

loop flow and is not considered to be a major result of this concept, but does indicate that the pump performance can affect the core thermal response during blowdown.

The reduced effectiveness of the core cooling during pump suction leg ELC injection when the pump coasted down to a stop resulted primarily from the effect of the pump on the core flow. As a result of the pump speed coastdown profile, the pump was at about $40 \%$ of the prerupture speed at the initiation of accumulator injection. Due to the low pump speed, the differential pressure developed by the pump was relatively low (less than 4 psid) and did not oscillate during the period of accumulator injection (from 25 to $64 \mathrm{sec}$ after rupture), as shown in Figure E-21. The fact that the differential pressure did not uscillate, indicates that the pump suction leg did not undergo repeated cycles of filling and emptying at this low pump speed. The low differential pressure developed by the pump initially established a positive intact loop and core flow. Figure E-22 shows that volumetric flowrates up to about $500 \mathrm{gpm}$ occurred from about 30 to $40 \mathrm{sec}$ after rupture. The fluid entering the core during this initial period was mostly steam so the heat transfer was relatively low and the rod cladding temperature increased. As a result of the continued decrease in the pump speed, the differential pressure developed by the pump decreased. At about $41 \mathrm{sec}$ after rupture, the core volumetric flow decreased to near zero, and the pump differential pressure dropped to about $1.5 \mathrm{psid}$. The low core flow at this time also resulted in poor heat transfer and the rod cladding temperatures continued to increase. At the termination of accumulator coolant injection the flow into the core was nearly stagnant and the rod cladding temperatures were increasing. 


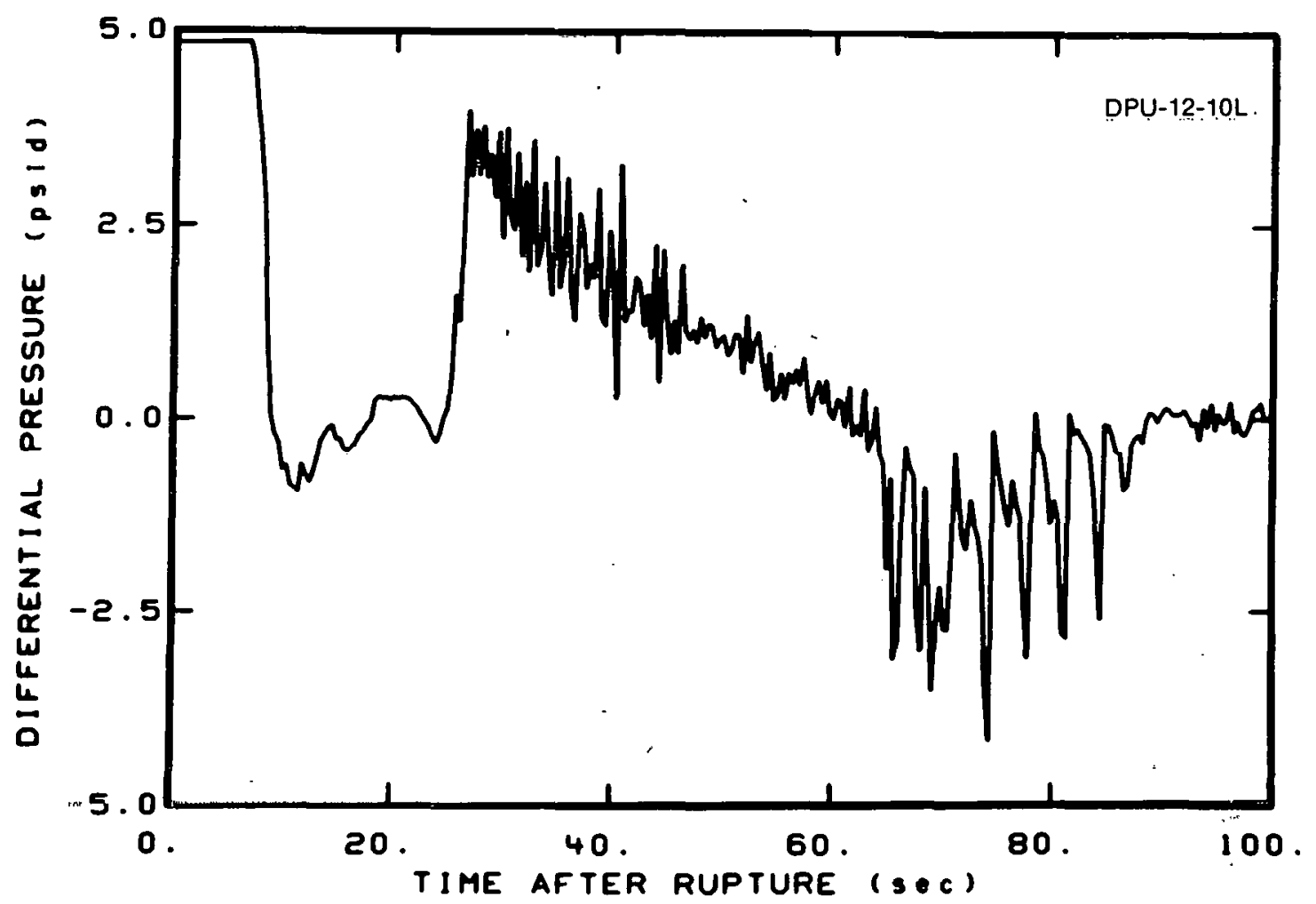

Fig. E-21 Response of the differential pressure across the pump during pump suction leg ECC injection with pump coastdown to a stop - Test S-05-2B.

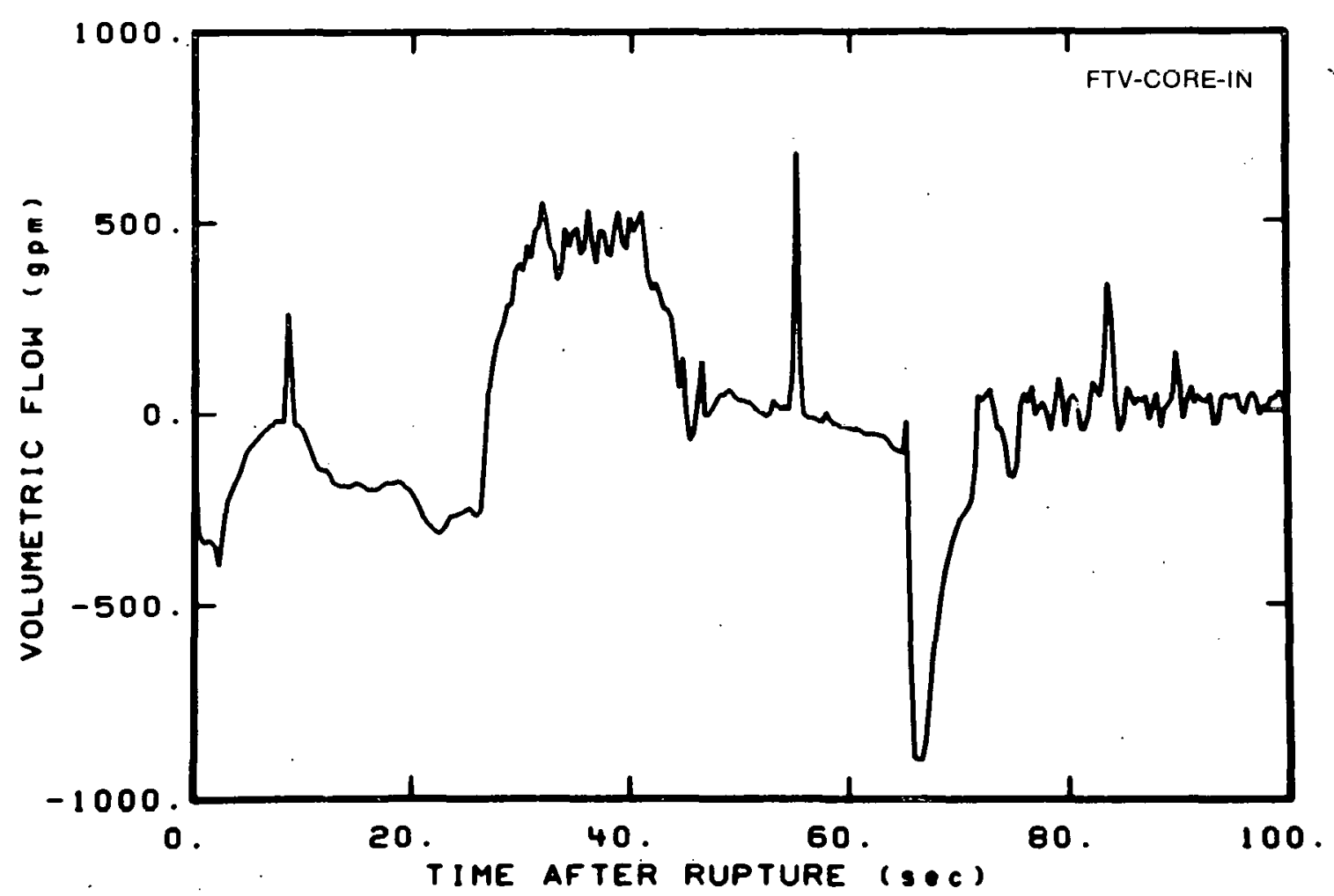

Fig. E-22 Core inlet volumetric flow during pump suction leg ECC injection with a pump coastdown to a stop - Test S-05-2B. 
The flow of nitrogen from the accumulator following the depletion of accumulator water had a major effect on the system behavior and the resulting core thermal response. The nitrogen flow intially resulted in a large reverse core flow, however, later it forced the coolant from the pump suction and intact loop cold leg into the downcomer, and partially filled the downcomer as shown in Figure E-23.

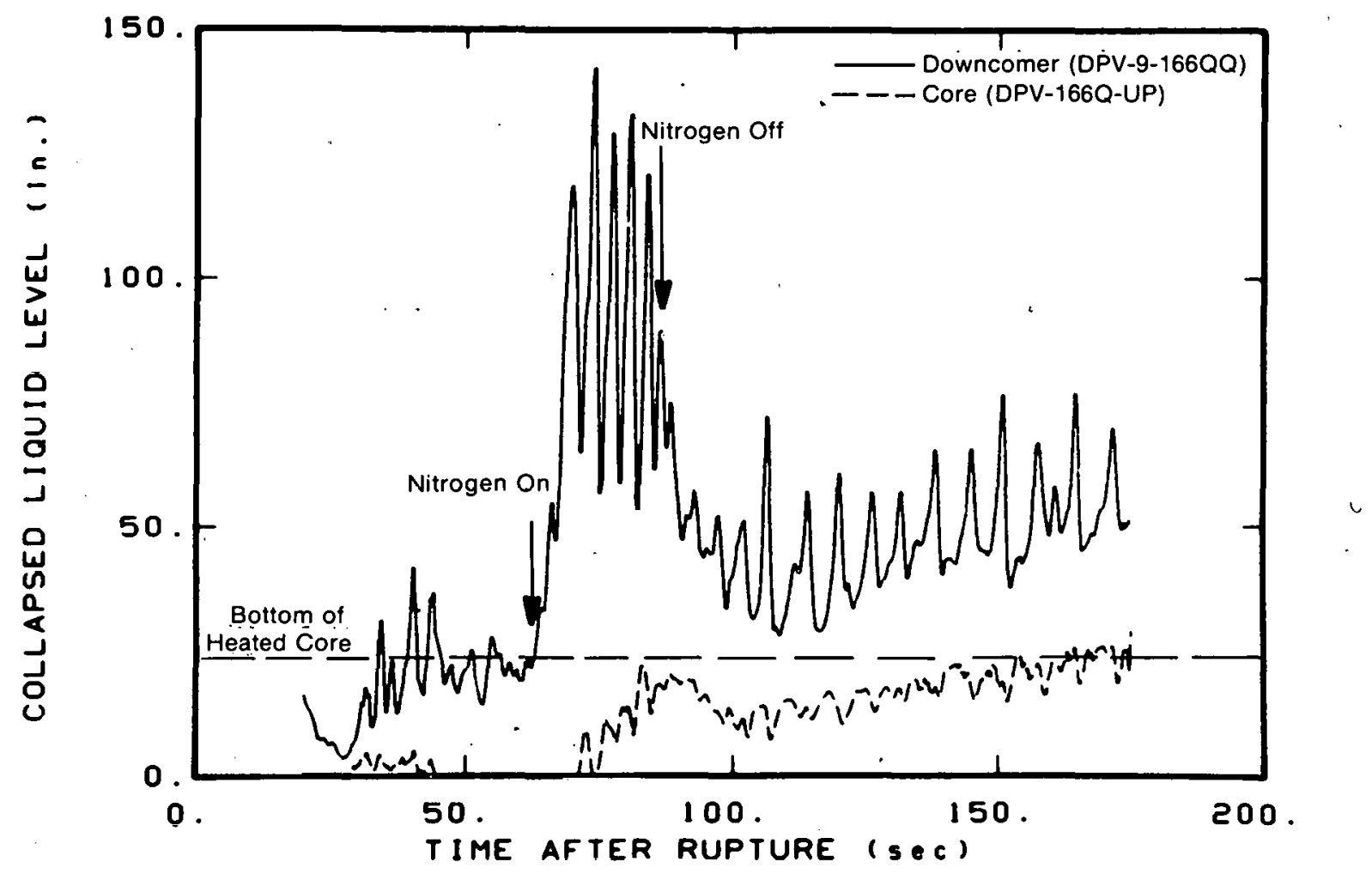

Fig. E-23 Comparison of downcomer and core collapsed liquid levels during pump suction leg ECC injectlon with a pump coastdown to a stop Test S-05-2B.

The increase in the downcomer collapsed liquid level, as a result of the nitrogen flow, caused the hydraulic pressure head in the downcomer to increase. However, the calculation of the core collapsed liquid level did not indicate that coolant entered the core and the temperature trace shown in Figure E-3 for this pump speed indicate relatively poor core cooling occurred. Following the termination of nitrogen flow al aboul 88 séc after rupture, the downcomer level initially decreased and then increased as the LPIS flow reflooded the core. The core collapsed liquid level indicated that coolant entered the core at about $155 \mathrm{sec}$ after rupture and the temperature trace shown in Figure E-3 at this pump speed indicates improved core cooling. Howcver, the majority of the core above the 29-in. elevation was not quenched at the termination of the test ( $300 \mathrm{sec}$ after rupture).

A systcm behavior which was generally different than observed on the other two pump suction injection tests occurred when the calculated PWR pump coastdown profile was used with pump suction leg ECC injection. Due to the low pump speed, the pump developed a low differential pressure. The low pressure differential was not capable of forcing liquid down the downcomer and into the core which resulted in more ECC bypass and less effective core cooling. 


\section{RESULTS OF THE ANALYTICAL INVESTIGATION}

The analytical investigation of the alternate ECC injection concept which utilized pump suction leg ECC injection consisted of two parts: an investigation of the effect of the rate of ECC injection and an investigation of the effect of the pump characteristics. This analysis was performed with the RELAP4 computer code. The RELAP4 calculations of the thermal-hydraulic response of the Semiscale Mod-1 system during blowdown and refill have been evaluated to determine the effects of changing the ECC injection rate or the pump characteristics on the system behavior and the core thermal response. The results of this evaluation are discussed in the following sections. The effect of the ECC injection rate is presented initially and is followed by a discussion of the effect of the pump characteristics.

\subsection{Effect of ECC Injection Rate on the System and Core Response}

An analytical analysis of the effect of the ECC injection rate on the core and system response was performed by parametrically increasing the ECC injection rate while holding all other initial system conditions the same. Injection rates of $23,46,74$, and $101 \mathrm{gpm}$. were investigated with the pump operating at $100 \%$ of the prerupture speed. This section primarily discusses the effect of the ECC injection rate on the pump performance, ECC bypass, and the core thermal response.

The RELAP4 (Mod-E Version 72) ${ }^{[E-1]}$ computer code was used in this investigation to calculate the core and system response. The nodalization used in RELAP4 to represent the Semiscale Mod-1 system is shown in Figure E-24. The Henry-Fauske and homogeneous equilibrium critical flow models were used for the subcooled and saturated break flow regimes, respectively. A break flow multiplier of 1.0 was used during the subcooled regime and a flow multiplier of 0.84 was used during the saturated regime. Vertical slip was used at all junctions in the core.

Since the RELAP4 code calculated the system response reasonably accurately during pump suction leg ECC injection with the pump operating at $100 \%$ of the prerupture speed and an ECC injection rate of $23 \mathrm{gpm}$, additional RELAP4 calculations were used to extend the understanding of the results of using pump suction leg ECC injection. The measured rod cladding temperature response at the core hot spot with the pump operating at $100 \%$ of the prerupture speed is compared with the corresponding RELAP4 calculated temperature response in Figure E-25. The peak temperature was underestimated by the RELAP4 code, however; during the period of ECC injection (from about 20 to $60 \mathrm{sec}$ after rupture) the temperature response was calculated quite accurately by RELAP4. (The agreement shown in Figure E-25 is not typical of that obtained at locations in the core where delayed DNBs or rewets occurred.) The calculated pump inlet fluid density is shown in Figure E-26, and illustrates that oscillations in the density were calculated that were similar to the experimental results discussed in Section 2.3. The similarity between the calculated and experimental results indicates that calculations of the RELAP4 computer code with pump suction leg ECC injection using other operating conditions would indicate the correct trends. 


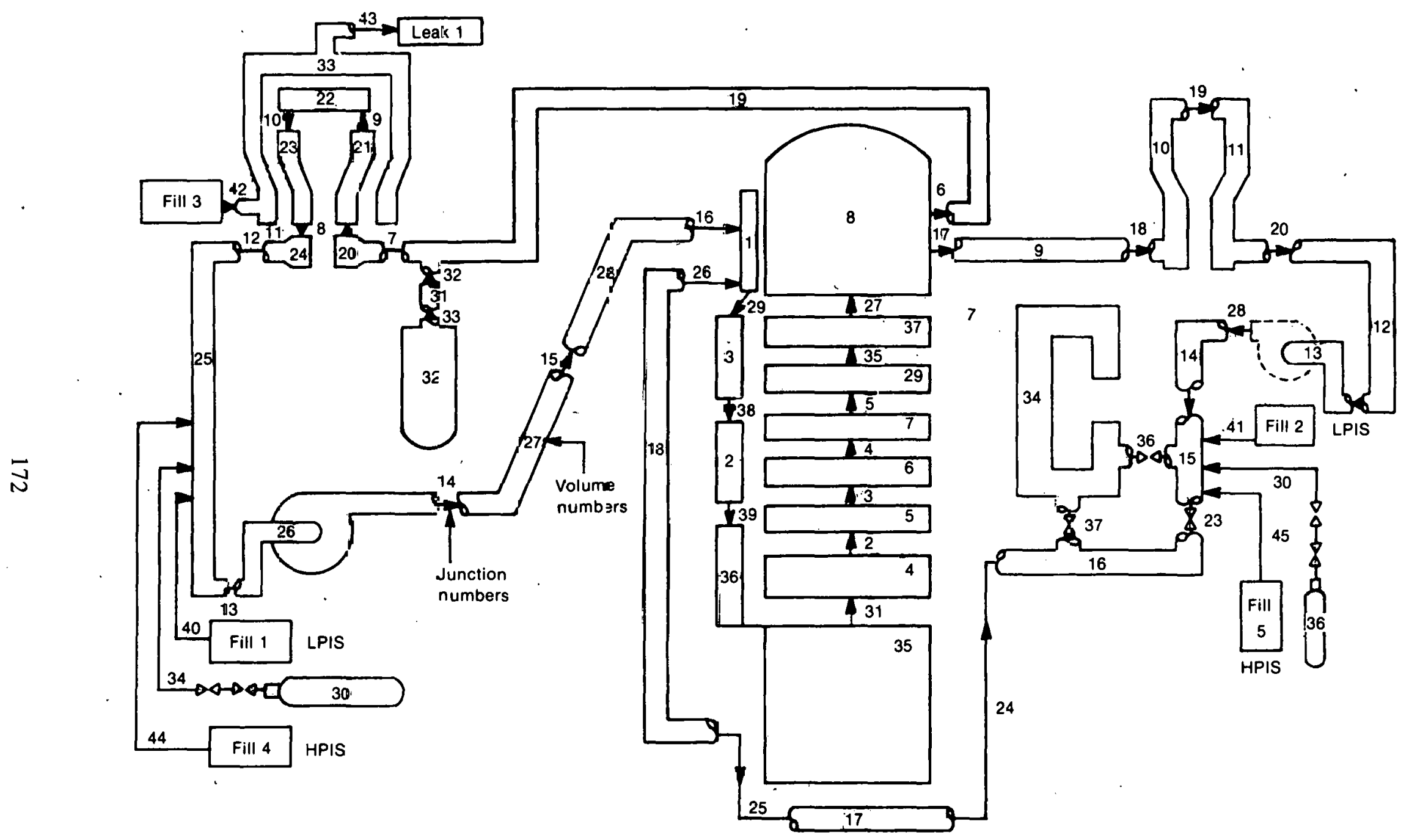

INEL-A-4676

Fi.. E-24 RELAP4 mode of Semiscale Mod-1 system using pump suction leg ECC injection.

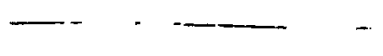




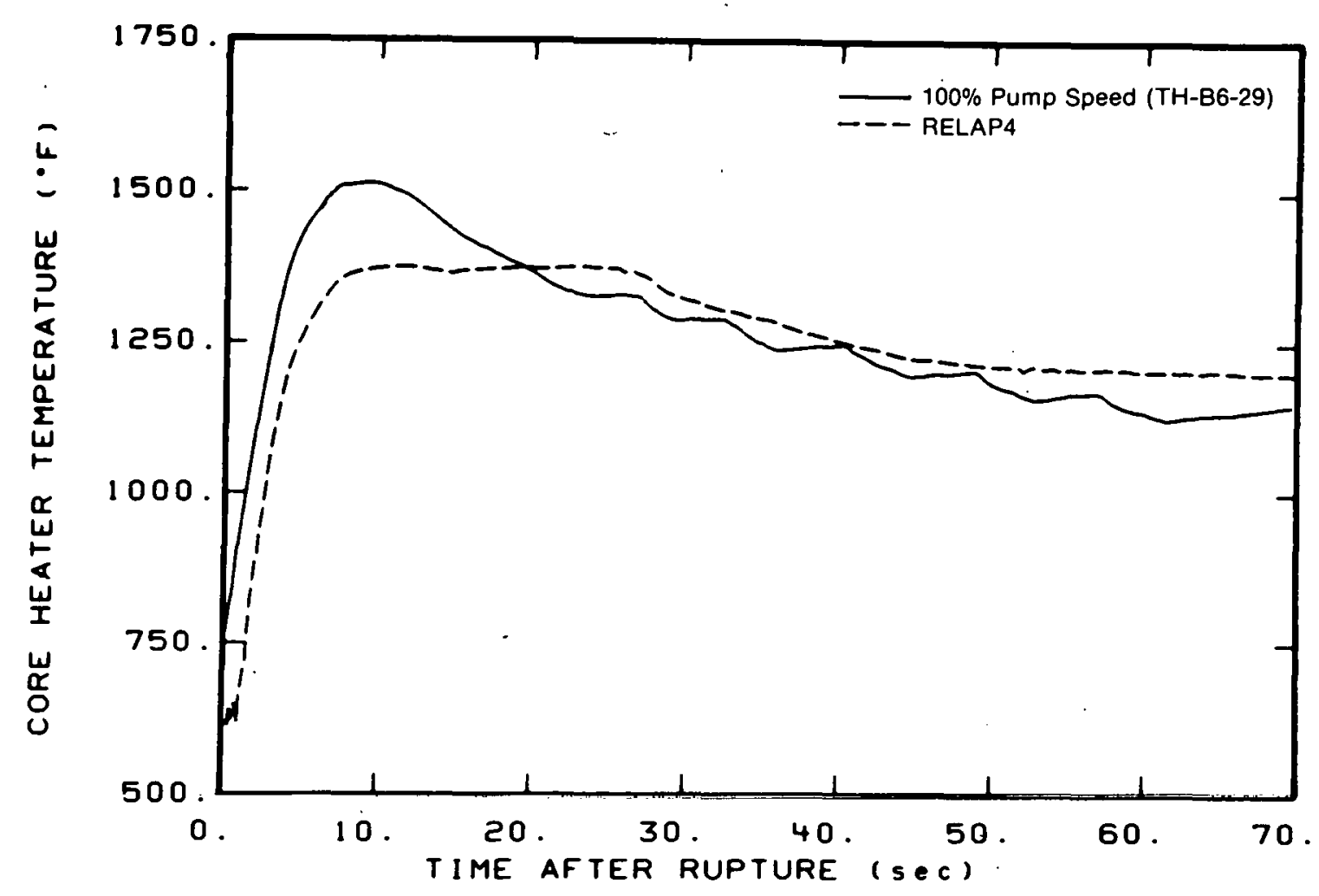

Fig. E-25 Comparison of measured (Test S-05-2A) and calculated (RELAP4) rod cladding temperature responses at the core peak power elevation.

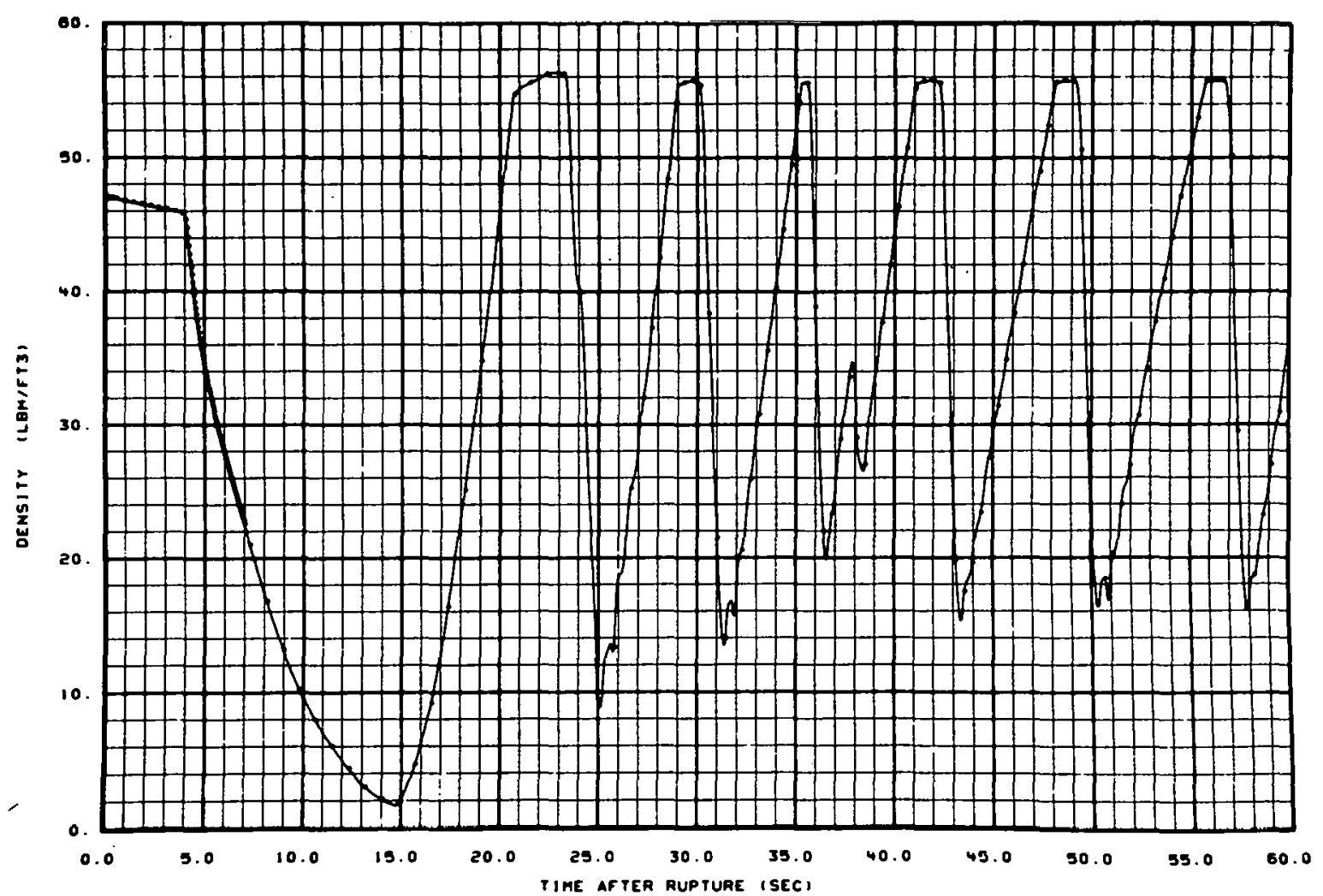

Fig. E-26 Pump suction leg fluid density response calculated by RELAP4 during pump suction leg ECC injection with a pump speed of $100 \%$ of initial speed. 
The calculations indicate that the rate of ECC injection has a significant effect on the calculated rod cladding temperature response during pump suction leg ECC injection. Temperature responses for the four injection rates analyzed are shown in Figure E-27. As expected, the temperature response for each injection rate was identical during the blowdown until ECC injection was initiated at about $14.5 \mathrm{sec}$ after rupture. However, after the initiation of ECC injection the calculated temperatures for the four cases began to deviate. The calculated rod surface temperature at an ECC injection rate of $23 \mathrm{gpm}$ was consistently higher than for the other injection rates investigated from $14.5 \mathrm{sec}$ after rupture until termination of the calculations. The calculated temperature response at ECC injection rates of 46,74 , and $101 \mathrm{gpm}$ continued to be similar until about $23 \mathrm{sec}$ after rupture when the calculated rod cladding temperature decreased in a manner which was related to the ECC injection rate. For these three injection rates, the lowest rod temperatures occurred for an ECC injection rate of $46 \mathrm{gpm}$ and the highest rod temperatures occurred for an ECC injection rate of $101 \mathrm{gpm}$.

The more effective heat transfer and, therefore, the lower rod cladding temperatures which occurred with an injection rate of $46 \mathrm{gpm}$ are primarily related to the magnitude and direction of the core inlet flow. Figure E-28 shows that the calculated core inlet mass flow rate was positive and largest after about $22 \mathrm{sec}$ for an injection rate of $46 \mathrm{gpm}$. The core inlet flow was positive for ECC injection rates of 74 and $101 \mathrm{gpm}$, whereas the core inlet flow oscillated to negative values for the 23-gpm injection rate. The lower core inlet mass flow rates resulted in higher rod cladding temperatures.

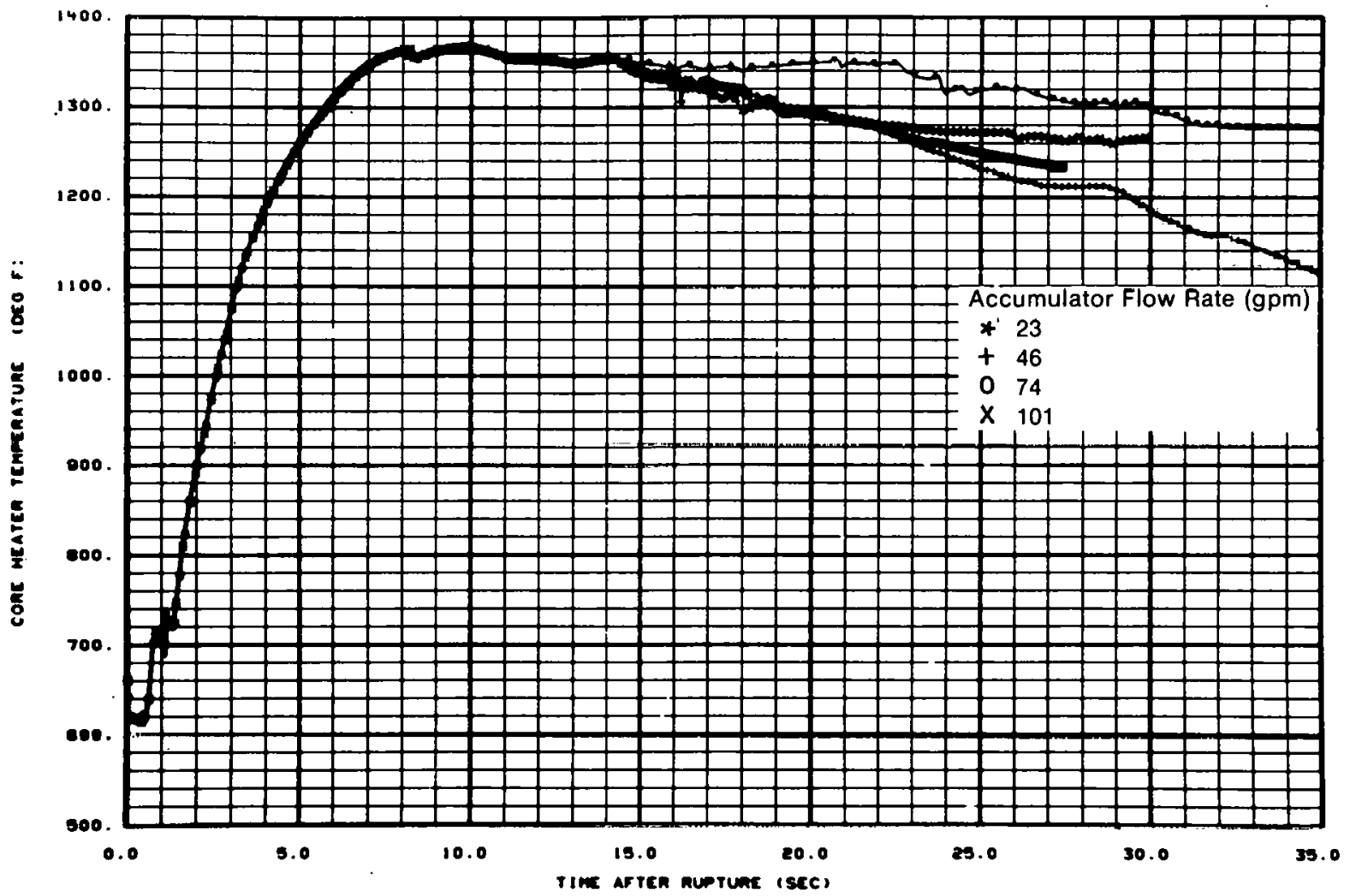

Fig. E-27 Effect of accumulator flow rate on the surface temperature response at the core peak power elevations calculated by RELAP4 during pump suction leg ECC injection with a pump speed of $100 \%$ of initial speed. 


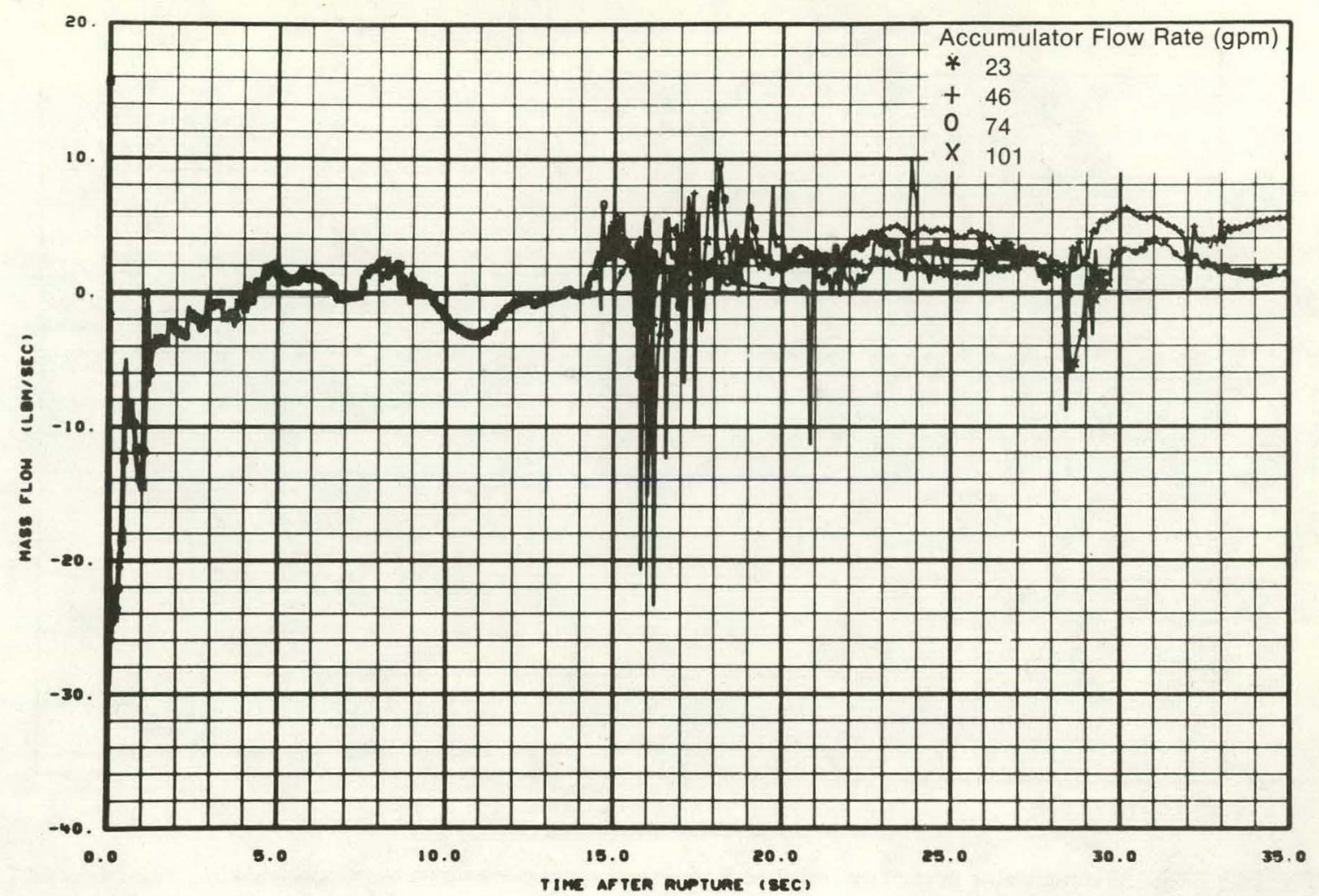

Fig. E-28 Effect of accumulator flow rate on the core inlet mass flowrate calculated by RELAP4 during pump suction leg ECC injection with a pump speed of $100 \%$ of initial speed.

The response of the core inlet mass flow was affected by the amount of ECC bypass and pump performance. The amount of ECC bypass for these calculations was found to be affected by the temperature of the ECC entering the downcomer. When the ECC was near the saturation temperature, as it entered the downcomer, the downcomer countercurrent flow decreased and the ECC bypass decreased. Figure E-29 shows that the temperature of the ECC entering the downcomer was the highest at an ECC injection rate of $46 \mathrm{gpm}$ and was lowest at an ECC injection rate of $101 \mathrm{gpm}$. Therefore, less bypass occurred at $46 \mathrm{gpm}$ and a larger amount of coolant was available to enter and cool the core. The effect of the ECC injection rate on the pump performance is shown in Figure E-30. The pump differential pressure generally increased with an increase in the ECC injection rate up to an ECC injection rate of $74 \mathrm{gpm}$. However, the pump differential pressure for the 74 -gpm ECC injection rate was slightly higher than that for the 101-gpm injection rate. The pump differential pressure for ECC injection rates of $23 \mathrm{gpm}$ oscillated and had negative minima which correspond to the negative core inlet flow shown on Figure E-28. The pump differential pressure was positive for the 46, 74, and $101 \mathrm{gpm}$ ECC injection rates after $18 \mathrm{sec}$ after rupture. Even though the pump differential pressure was larger for the $74 \mathrm{gpm}$ ECC injection rate, the fact that the pump differential pressure was positive for the 46-gpm ECC injection rate combined with the lower amount of ECC bypass resulted in the more effective core cooling. 


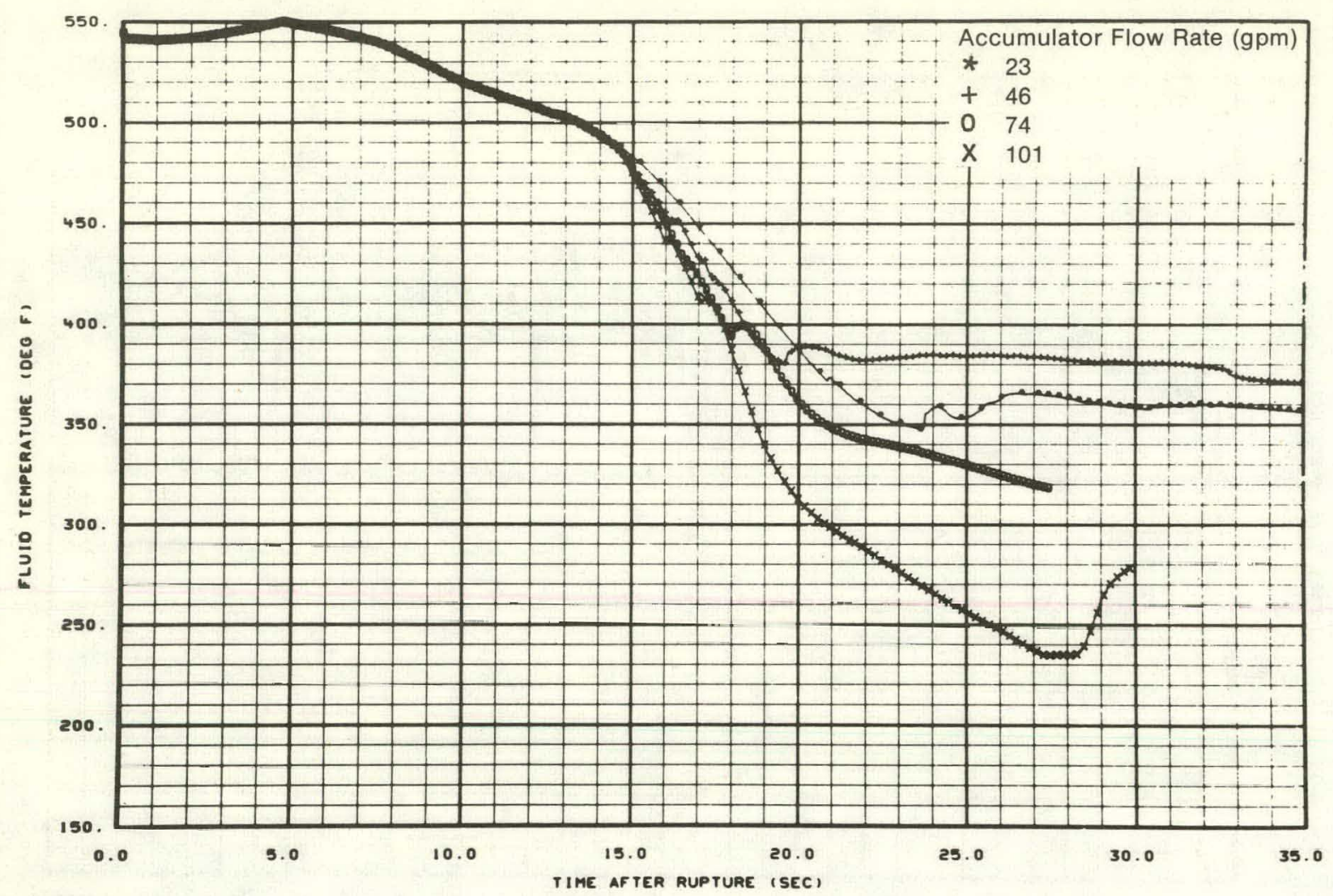

Fig. E-29 Effect of accumulator flow rate on the fluid temperature entering the downcomer calculated by RELAP4 during pump suction leg ECC injection with a pump speed of $100 \%$ of initial speed.

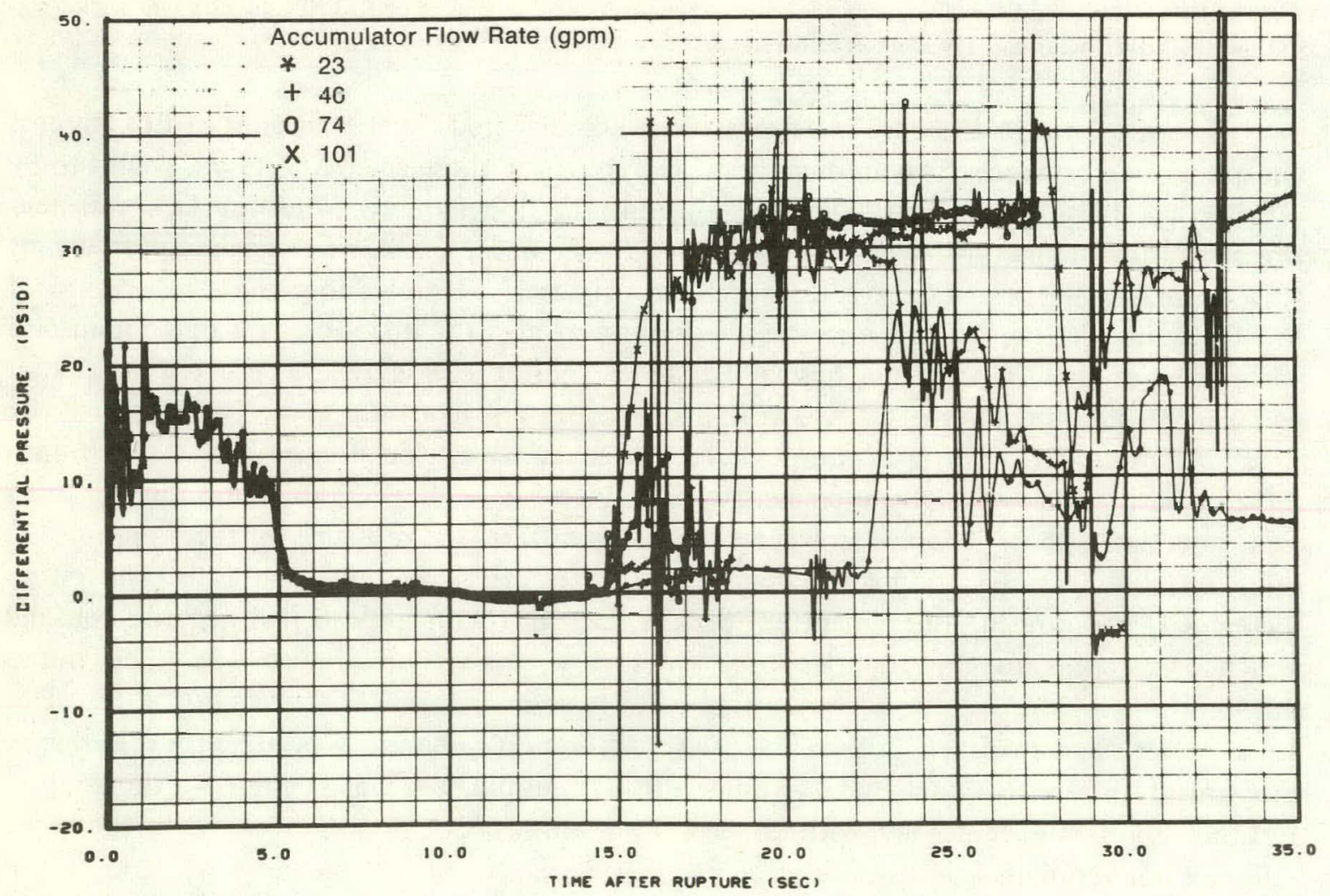

Fig. E-30 Effect of accumulator flow rate on the differential pressure across the pump calculated by RELAP4 during pump suction leg ECC injection with a pump speed of $100 \%$ of initial speed. 


\subsection{Effect of the Pump Characteristics on the System and Core Response}

The analytical investigation of the effect of the pump characteristics on the core and system response evaluated the effects of using the Bingham-Willamette Company, Westinghouse Electric Corporation, or Semiscale Mod-1 pump models in the Semiscale Mod-1 system RELAP4 model. The pump was operating at $100 \%$ of the prerupture speed with an injection rate of $23 \mathrm{gpm}$ for this analysis. The same version of RELAP4, nodalization, and pertinent input discussed in Section 3.1 were used in this study.

Overall, the pump characteristics had a slight effect on the calculated rod temperature response. The temperature response for the three pump models analyzed are compared in Figure E-31. The rod temperature response using the Bingham-Willamette Company pump model was higher than was obtained with Westinghouse Electric Corporation, or Semiscale Mod-1 models. However, the range in rod temperature between the models at $60 \mathrm{sec}$ after rupture was only about $40^{\circ} \mathrm{F}$, which is not considered to be a significant difference.

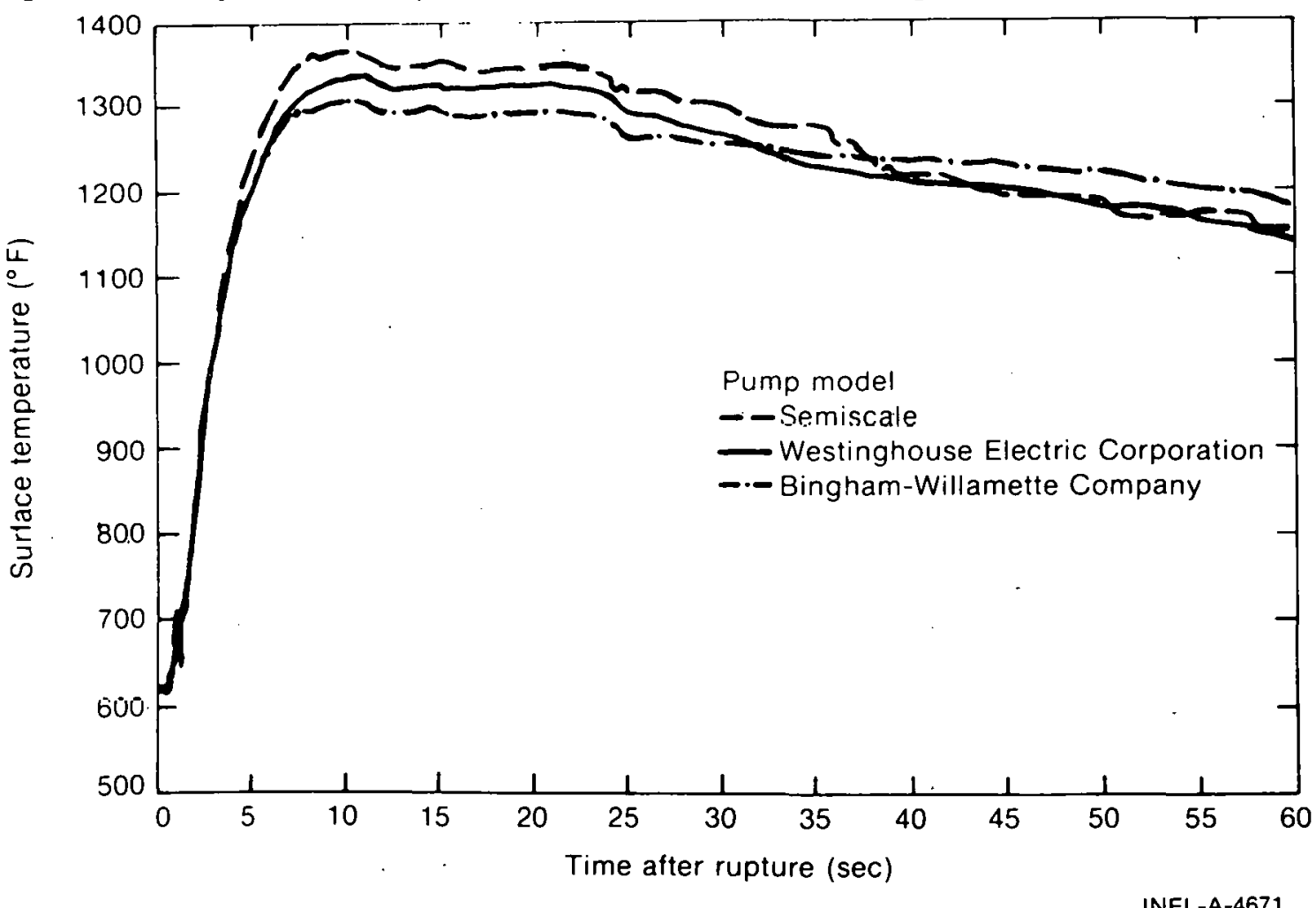

Fig. E 31 Effect of pump model nn the rod cladding surface temperature calculated by RELAP4 during pump suction leg ECC injection with a pump speed of $100 \%$ of initial speed.

\section{CONCLUSIONS}

An experimental investigation of the thermal-hydraulic response of the Semiscale Mod-1 core using ECC injection in the pump suction leg was performed to determine the effect of the pump speed profile on the rod cladding temperature response. An analytical 
study using the RELAP4 code was performed to evaluate the effect of the ECC injection rate and the pump characteristics on the system and core response using pump suction leg ECC injection. The results of the experimental investigation and the analytical study have led to an increased understanding of the phenomena associated with ECC injection in the pump suction leg. The results have also been valuable in evaluating the potential benefits to core cooling of using pump suction leg rather than cold leg ECC injection.

\subsection{Effect of Pump Speed on the Core Thermal Response}

A difference in the rod cladding temperature response occurred in the Semiscale Mod-1 core when the pump speed control was changed. A pump speed coastdown to $64 \%$ of the initial speed resulted in more effective cooling than a pump speed of $100 \%$ of the initial speed. With pump suction ECC injection, a pump speed profile that coasted down to a stop provided less effective cooling than a profile of $100 \%$ of the initial pump speed. Complete coastdown of the pump with pump suction injection also was less effective than for the case of cold leg ECC injection. The difference in the rod cladding temperature response was the result of complex interactions between the pump speed, ECC injection rate, pump suction leg geometry, and the temperature of the ECC delivered to the downcomer.

\subsection{RELAP4 Analysis of Pump Suction Leg ECC Injection}

The rate of ECC injection affected the calculated rod temperatures. More effective core cooling resulted from an ECC injection rate of $46 \mathrm{gpm}$ than for 23,74 , and $101 \mathrm{gpm}$ at a pump speed of $2350 \mathrm{rpm}$. The difference in the rod temperature response was related to the temperature of the ECC. delivered to the downcomer and the differential pressure response of the pump.

The pump characteristics did not have a significant effect on the rod temperature rosponsc. The calculated lod ternperature response for the Semiscale Mod-1, Bingham-Willamette Company, and Westinghouse Electric Corporation pump models were quite similar.

\section{REFERENCES}

E-1. J. G. Bruch (ed.), RELAP4/MOD5, A Computer Prngram for the Transient Thermal-Hydraulic Analysis of Nuclear Reactors and Related Systems, Vol. I. II. III. ANCR-NUREG-1335 (September 1976).

E-2. J. M. Cozzuol, Thermal-Hydraulic Analysis of Semiscale Mod-1 Integral Blowdown-Reflood Tests (Baseline ECC Tests Series), TREE-NUREG-1077 (March 1977).

E-3. A. C. Peterson, G. G. Loomis, L. L. Chen, Thermal and Hydraulic Response of the Semiscale Mod-1 Core During Forced Feed Reflood Tests, TREE-NUREG-1001 (October 1976). 


\section{Internal Distribution}

$$
\begin{aligned}
& 1 \text { - } \text { Chicago Patent Group - ERDA } \\
& 9800 \text { South Cass Avenue } \\
& \text { Argonne, Illinois } 60439 \\
& 2 \text { - C. A. Benson } \text { Idaho Operations Office - ERDA } \\
& \text { Idaho Fal1s, ID } 83401 \\
& 3 \text { - R. J. Beers, ID } \\
& 4 \text { - P. E. Litteneker, ID } \\
& 5 \text { - R. E. Tiller, ID } \\
& 6 \text { - R. E. Wood, ID } \\
& 7 \text { - H. P. Pearson, Supervisor } \\
& \text { Technical Information } \\
& 8-17 \text { - INEL Technical Library } \\
& \text { 18-37 - Authors } \\
& 38-96 \text { - Special Internal }
\end{aligned}
$$

\section{External Distrihution}

$$
\begin{aligned}
& \text { 97-98 - Saul Levine, Director } \\
& \text { Office of Nuclear Regulatory Research, NRC } \\
& \text { Washington, DC } 20555 \\
& \text { 99-403 - Distribution under NRC-2, Water Reactor Safety Research } \\
& \text { Systems Engineering }
\end{aligned}
$$

